Guilherme Leibsohn Martins

\begin{abstract}
Desempenho de expansor axial de estágio único e admissão parcial aplicado a ciclo rankine orgânico para recuperação de calor
\end{abstract}

Tese de Doutorado

Tese apresentada como requisito parcial para obtenção do título de Doutor pelo Programa de PósGraduação em Engenharia Mecânica da PUC-Rio.

Orientador: Prof. Sergio Leal Braga Co-orientador: Dr. Sandro Barros Ferreira 
Guilherme Leibsohn Martins

\section{Desempenho de expansor axial de estágio único e admissão parcial aplicado a ciclo Rankine orgânico para recuperação de calor}

Tese apresentada como requisito parcial para obtenção do título de Doutor pelo Programa de Pós-Graduação em Engenharia Mecânica da PUC-Rio. Aprovada pela Comissão Examinadora abaixo assinada.

Prof. Sergio Leal Braga

Orientador

Departamento de Engenharia Mecânica - PUC-Rio

Dr. Sandro Barros Ferreira

Co-orientador

GT2 Energia

Prof. José Alberto Reis Parise

Departamento de Engenharia Mecânica - PUC-Rio

Prof. Carlos Valois Maciel Braga

Departamento de Engenharia Mecânica - PUC-Rio

Prof. Washington Orlando Irrazabal Bohorquez

Departamento de Engenharia de Produção e Mecânica - UFJF

Prof. Marco Aurélio da Cunha Alves

Departamento de Engenharia de Produção e Mecânica - UFJF

Dr. Marcelo José Colaço

Departamento de Engenharia Mecânica, Escola Politécnica - UFRJ

Prof. José Eugenio Leal

Coordenador Setorial do Centro Técnico Científico - PUC-Rio

Rio de Janeiro, 29 de Maio de 2015 
Todos os direitos reservados. É proibida a reprodução total ou parcial do trabalho sem autorização da universidade, do autor e do orientador.

\section{Guilherme Leibsohn Martins}

Graduado em engenharia mecânica e de automóveis pelo IME em 1984 e M.Sc. pela COPPE/UFRJ em 1991. Trabalha na Petrobras desde 1985 como engenheiro de equipamentos, tendo se especializado em equipamentos rotativos.

Ficha Catalográfica

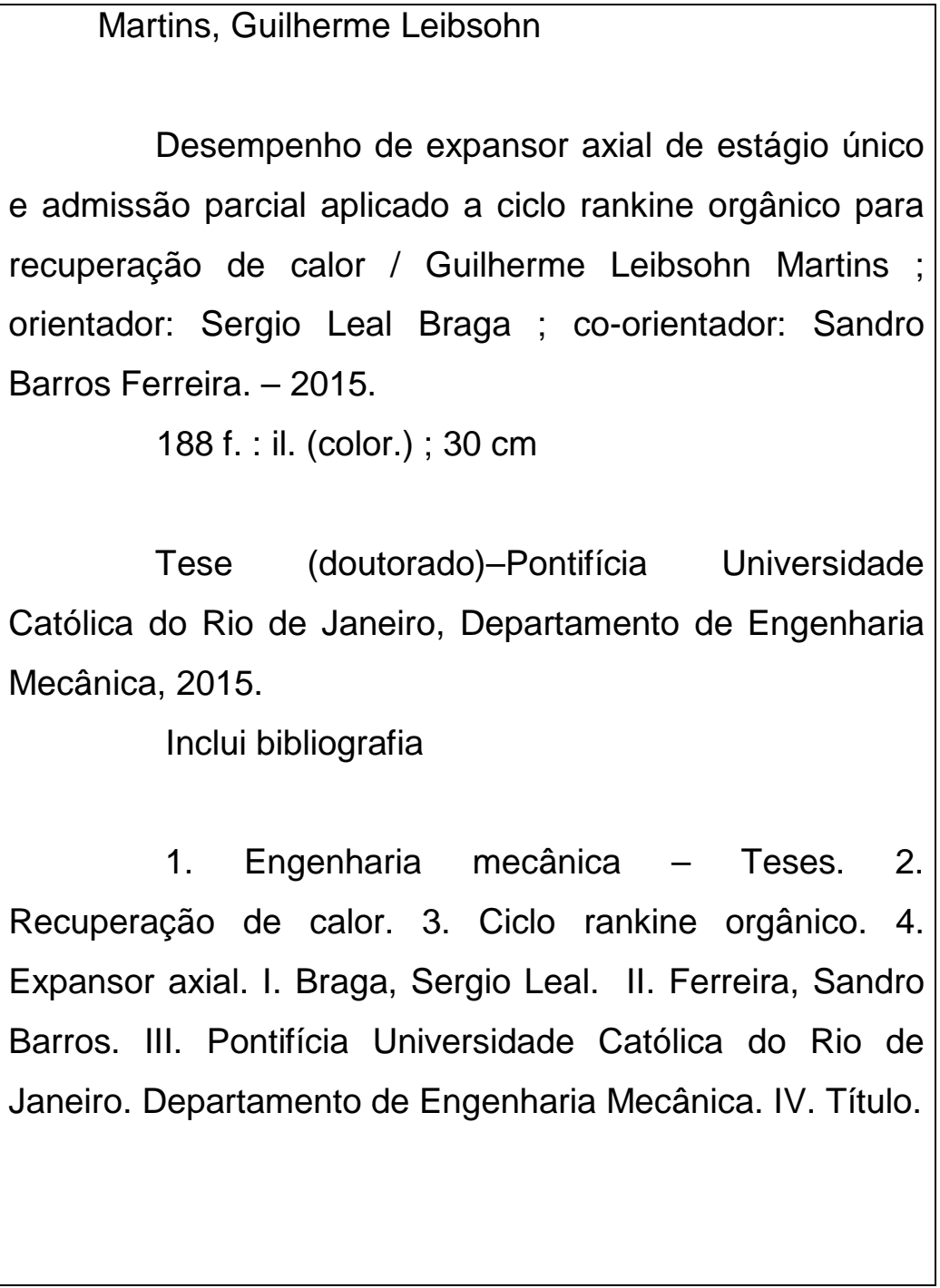

CDD: 621 
Aos meus pais, pela educação recebida que me permitiu chegar a este objetivo. À minha esposa e crianças, pelo tempo que lhes deixei de dedicar. 


\section{Agradecimentos}

Ao meu orientador, Prof. Sergio Leal Braga, e ao meu co-orientador, Dr. Sandro Barros Ferreira, pela sugestão do tema, orientação e ideias imprescindíveis para este estudo.

Aos professores da área de Termociências do Departamento de Engenharia Mecânica da PUC-Rio, pelas aulas memoráveis que tive oportunidade de assistir.

À Petrobras, pelo custeio do programa, em particular aos gerentes José Francisco Oliveira, Grey de Campos Zonzini, Hamilton Romanato Ribeiro e Joemir Avancini Rocha, pelo apoio e o encorajamento que viabilizaram este trabalho. 


\section{Resumo}

Martins, Guilherme Leibsohn; Braga, Sergio Leal. Desempenho de expansor axial de estágio único e admissão parcial aplicado a ciclo rankine orgânico para recuperação de calor. Rio de Janeiro, 2015. 188p. Tese de Doutorado - Departamento de Engenharia Mecânica, Pontifícia Universidade Católica do Rio de Janeiro.

O presente trabalho aborda a análise da aplicação do expansor axial de estágio único e admissão parcial em ciclo Rankine orgânico para recuperação do calor rejeitado por um motor de combustão interna. O fluido adotado é o R245fa, cujos efeitos de gás real são relevantes nas condições estudadas, sendo representados pela equação Redlich-Kwong-Soave. Um modelo de perdas para o escoamento através das palhetas é proposto, tendo como base a teoria da camada limite, o conceito do fator de difusão, experimentos de grades em túnel de vento obtidos na literatura e as equações de conservação para escoamento compressível. O fator de difusão é o parâmetro responsável por quantificar o gradiente de pressão adverso na superfície do perfil das palhetas. A geometria e dimensões básicas para a máxima eficiência do expansor são determinadas para diversas condições subcríticas e supercríticas do ciclo a partir de um algoritmo de otimização com restrições. O valor ótimo da temperatura do evaporador em condições subcríticas é estabelecido de modo a obter a potência máxima do ciclo de recuperação, conforme as alternativas construtivas consideradas. $\mathrm{O}$ projeto do expansor de estágio único mostra ser grandemente influenciado pela compressibilidade do meio e a utilização de bocais com perfil convergentedivergente é promissora para alcançar o maior potencial de desempenho, principalmente nas condições de alta pressão do evaporador.

\section{Palavras-chave}

ciclo Rankine orgânico; gases densos; expansor axial; fator de difusão; perda no perfil; otimização de projeto. 


\section{Abstract}

Martins, Guilherme Leibsohn; Braga, Sergio Leal (Advisor). Performance of Single Stage Partial Admission Axial Expander Applied to a Waste Heat Recovery Rankine Organic Cycle. Rio de Janeiro, 2015. 188p. Doctoral Thesis - Departamento de Engenharia Mecânica, Pontifícia Universidade Católica do Rio de Janeiro.

The present work deals with the analysis of the application of a single stage partial admission axial expander in organic Rankine cycle, in order to recover the heat rejected by an internal combustion engine. The selected fluid is R245fa, whose real gas behavior is relevant under the studied conditions, as modeled by the Redlich-Kwong-Soave equation of state. A loss model for the flow through the axial blades is proposed in this work, based on the boundary layer theory, the concept of diffusion factor, wind tunnel cascade tests available in literature and the conservation equations for compressible flow. The diffusion factor is the parameter responsible to quantify the adverse pressure gradient on the blade profile surfaces. The basic geometry and dimensions needed to achieve maximum expander efficiency are determined under several subcritical and supercritical cycle conditions by means of a restrained design optimization algorithm. The optimum value for the evaporator temperature under subcritical cycle is stablished so as to obtain the maximum power from the recovery cycle, according the constructive alternatives considered. The single stage expander design is shown to be greatly influenced by media compressibility and the use of convergentdivergent profiled nozzles is promising to achieve the highest performance potential, especially at high evaporator pressure conditions.

\section{Keywords}

organic Rankine cycle; dense gases; axial expander; diffusion factor; profile loss; design optimization. 


\section{Sumário}

1 Introdução 23

1.1. Recuperação de Calor Através do Ciclo Rankine Orgânico 23

1.2. Histórico 25

1.3. Revisão Bibliográfica 27

1.4. Descrição da Aplicação Proposta 31

2 Desempenho de Turbinas Axiais 35

2.1. Introdução 35

2.1.1. Geometria e Configurações 36

2.1.2. Definições 39

2.1.3. Conceito de Similaridade 41

2.2. Diagrama de Velocidades 43

2.2.1. Relações Cinemáticas e Eficiência 44

2.2.2. Variação Radial 48

2.3. Evolução Aero-Termodinâmicas 51

2.4. Estimativa de Perdas em Turbinas Axiais 53

2.4.1. Campo de Escoamento e Mecanismos de Perda 55

2.4.1.1. Perdas no Perfil 56

2.4.1.2. Perdas Secundárias 62

2.4.1.3. Demais Fontes de Perdas 63

2.4.1.4. Deflexão do Escoamento na Saída da Grade 69

2.4.2. Revisão de Alguns Métodos de Previsão de Perdas 72

2.4.2.1. Soderberg 72

2.4.2.2. Ainley \& Mathieson $\quad 74$

2.4.2.3. Stewart et Al. 77

2.4.2.4. Baljé 82

2.4.2.5. Craig \& Cox 91 
3. Proposição de Modelo de Perda em Grades de Turbinas 94

3.1. Análise de Teste de Grade Disponível na Literatura 96

3.2. Perda por Sobre-Expansão 108

3.3. Geometria da Grade 109

3.4. Comparação com os Demais Métodos 112

3.5. Validação com Resultados Experimentais Publicados $\quad 115$

3.5.1 Turbinas de Impulso de Ohlsson 115

3.5.2 Turbinas Experimentais da KTH 117

3.5.3 Palhetas Estacionárias da NASA 122

3.5.4 Deflexão do Jato 124

3.5.5. Grades de Turbinas em Regime Transônico 126

3.5.6 Turbinas a Vapor de Admissão Parcial Testadas em Fábrica 128

4 Estudo de Otimização de Eficiência em Ciclo Rankine Orgânico 132

4.1. O Expansor de Fluido Orgânico 132

4.1.1. Considerações Sobre Gases Reais 133

4.1.2. Propriedades do R245fa 140

4.1.3. Relações Aero-Termodinâmicas 144

4.1.4. Coeficiente de Perda da Grade 147

4.1.5. Considerações Sobre os Bocais Supersônicos 148

4.2. Otimização Integrada do Ciclo Termodinâmico e o Expansor 151

4.2.1. Operação do Sistema de Troca Térmica 153

4.2.2. Otimização do Expansor 156

4.2.3. Resultados das Simulações 162

5 Conclusões e Recomendações para Trabalhos Futuros 176

6 Referências Bibliográficas 180 


\section{Lista de figuras}

Figura 1 - Planta de geração baseada no ciclo Rankine orgânico.

Figura 2 - Crescimento das usinas de geração instaladas utilizando o ciclo Rankine orgânico.

Figura 3 - Esquema de recuperação de calor do exausto de um motor de combustão interna .

Figura 4 - Evolução das temperaturas do gás exausto do motor, do óleo térmico e do fluido orgânico em ciclo subcrítico.

Figura 5 - Roda da turbina de impulso e bocal (De Laval). 35

Figura 6 - Vista longitudinal do estágio axial.

Figura 7 - Vista transversal de uma fileira de palhetas componente de um estágio de turbina axial.

Figura 8 - Nomenclatura da fileira de palhetas do estágio axial.

Figura 9 - Arranjo com altura da palheta gradualmente aumentada através do ângulo $F L$ e arranjo com palheta sobreposta.

Figura 10 - Diagrama de velocidades do estágio de turbina axial. $\quad 43$

Figura 11 - Distribuição radial da velocidade e do ângulo de fluxo. $\quad 50$

Figura 12 - Diagrama entalpia - entropia para um estágio axial. 51

Figura 13 - Escoamento através da passagem entre palhetas. 55

Figura 14 - Vetores velocidade e notações da grade.

Figura 15 - Distribuição de pressão típica nas faces de pressão e de sucção da palheta.

Figura 16 - Bocal e rotor em arranjo de admissão parcial. 65

Figura 17 - Nomenclatura da incidência na palheta. 67

Figura 18 - Característica da perda por incidência. 68

Figura 19 - Sobre-expansão na saída da grade conforme avaliação do método das características.

Figura 20 - Correlação perda versus deflexão de Soderberg. 72

Figura 21 - Coeficiente de perda de pressão total no perfil $y_{p}$ de palhetas de bocais (a) e de palhetas de impulso (b) em função do ângulo de saída de fluxo e da razão espaçamento corda $t / C$. 
Figura 22 - Efeito da razão espessura do bordo de fuga -

espaçamento $\left(t_{b} / t\right)$ sobre as perdas no perfil.

Figura 23 - Correlação espessura de quantidade de movimento versus fator de difusão total proposta por Stewart et al.

Figura 24 - Seção entre os bordos de fuga.

Figura 25 - Vetores velocidade em escoamento compressível através da grade.

Figura 26 - Modelo de escoamento através da grade resultante da superposição de um fluxo circulatório ao fluxo uniforme.

Figura 27 - Coeficiente de perda secundária referido à componente axial da velocidade de saída da grade.

Figura 28 - Parâmetro de sustentação (esquerda) e parâmetro básico de perda no perfil (direita) segundo Craig \& Cox.

Figura 29 - Razão de contração (esquerda) e acréscimo na perda de perfil com o número de Mach na saída da grade (direita).

Figura 30 - Coeficiente básico de perda secundária (esquerda) e fator de correção para a razão de aspecto (direita).

Figura 31 - Resultados dos testes de Dunavant e Erwin confrontados com a previsão pelo método de Baljé.

Figura 32 - Distribuição de pressão dinâmica ao redor da palheta: padrões normal (esquerda) e alterado (direita).

Figura 33 - Correlação entre $\vartheta / /$ e o fator de difusão na superfície de sucção, obtidos nos testes de Dunavant e Erwin.

Figura 34 - Correlação entre $V_{s, \max } / V_{1}$ e o parâmetro de circulação $C_{f a x}$ utilizado por Baljé para os testes de Dunavant e Erwin.

Figura 35 - Correlação entre $৩ / /$ e o fator de difusão calculado com base no parâmetro de circulação $C_{\text {fax }}$ utilizado por Baljé para aos testes de Dunavant e Erwin.

Figura 36 - Correlação entre $V_{s, \max } / V_{1}$ e o parâmetro de circulação de Lieblein para os testes de Dunavant e Erwin.

Figura 37 - Correlação entre $ง / /$ e o fator de difusão equivalente calculado com base no parâmetro de circulação $\Delta V_{u} /\left(\sigma V_{1}\right)$ para os testes de Dunavant e Erwin. 
Figura 38 - Correlação entre $V_{s, \max } V_{1}$ e o parâmetro de circulação $\Delta V_{u} /\left(\sigma V_{1} / / C\right)$ com base no comprimento da linha média de curvatura da palheta para os testes de Dunavant e Erwin. 104

Figura 39 - Correlação entre $७ / /$ e o fator de difusão equivalente calculado com base no parâmetro de circulação $\Delta V_{\psi} /\left(\sigma V_{1} l / C\right)$ para os testes de Dunavant e Erwin.

Figura 40 - Comparação dos resultados obtidos no presente trabalho com o modelo de Baljé.

Figura 41 - Perda total em palheta de reação com baixo coeficiente de fluxo $\left(\lambda_{1}=90^{\circ}\right.$ e $\left.\lambda_{2}=15^{\circ}\right)$.

Figura 42 - Perda total em palheta de reação com alto coeficiente de fluxo $\left(\lambda_{1}=90^{\circ}\right.$ e $\lambda_{2}=30^{\circ}$ ).

Figura 43 - Perda total em palheta de impulso $\left(\lambda_{1}=150^{\circ}\right.$ e $\left.\lambda_{2}=30^{\circ}\right)$.

Figura 44 - Fotografia dos componentes das turbinas testadas por Ohlsson (rotores e bocais convergentes).

Figura 45 - Desenho e diagrama de velocidades das turbinas testadas na KTH.

Figura 46 - Simulação do efeito da variação na solidez sobre as perdas no perfil do bocal da turbina "stage 1" da KTH.

Figura 47 - Simulação do efeito da variação na solidez sobre as perdas secundárias do bocal da turbina "stage 1" da KTH.

Figura 48 - Simulação do efeito da variação na solidez sobre as perdas de perfil do rotor da turbina "stage 1" da KTH.

Figura 49 - Simulação do efeito da variação na solidez sobre as perdas secundárias do rotor da turbina "stage 1" da KTH.

Figura 50 - Coeficientes de perda de pressão para o rotor da turbina da KTH sob incidência variável.

Figura 51 - Seção média da palheta estacionária da NASA.

Figura 52 - Resultados experimentais e teóricos de Whitney et al. mostrando a variação de $\vartheta / C \operatorname{com} V / V_{c r}$ para a palheta estacionária de ângulo de giro $62^{\circ}$, confrontados com os do modelo proposto no presente trabalho.

Figura 53 - Resultado do método de avaliação da deflexão angular 
do presente trabalho superposto aos resultados experimentais.

Figura 54 - Variação do coeficiente de perda no perfil com o número de Laval para a grade 10.1.2.

Figura 55 - Fotografia da turbina a vapor instalada na bancada de testes na fábrica.

Figura 56 - Fotografias dos rotores da turbina \#1 e da turbina \#2 testadas na fábrica.

Figura 57 - Detalhe do desenho mostrando a folga entre as palhetas estacionárias e rotativas para a turbina \#1 e turbina \#2.

Figura 58 - Diagrama temperatura - entropia do fluido orgânico.

Figura 59 - Cálculo de diferença de entropia ou entalpia para um gás real, através de duas trajetórias isotérmicas e uma trajetória isobárica na condição de gás ideal.

Figura 60 - Correlação do calor específico a pressão constante no estado de gás ideal com a temperatura reduzida para o R245fa.

Figura 61- Variação do expoente isentrópico do R245fa na condição de gás ideal $k^{*}$ com a temperatura relativa.

Figura 62 - Comparação das funções de desvio isotérmico de entalpia e entropia obtidas a partir da equação RKS com os dados da NIST $\left(T_{\text {red }}=1,014\right)$.

Figura 63 - Comparação do fator de compressibilidade e da velocidade do som obtidos a partir da equação RKS com a NIST ( $\left.T_{\text {red }}=1,014\right)$. Figura 64 - (a) Bocal com a seção supersônica simétrica mais curta possível capaz de produzir um escoamento uniforme, livre de choque e paralelo. (b) Região de expansão e de retificação em bocal com garganta em canto vivo.

Figura 65 - Evolução dos parâmetros aerodinâmicos $M, \Gamma \mathrm{e} \Gamma+M^{-2}$ ao longo de uma expansão isentrópica do R245fa a partir das condições de estagnação $p_{0}=36$ bar e $T_{0}=433,2 \mathrm{~K}$.

Figura 66 - Variação da entalpia do gás exausto com a temperatura. 152 Figura 67 - Evolução das temperaturas no sistema de troca térmica com o calor transferido para o ciclo subcrítico $\left(\mathrm{T}_{\text {evap }}=80^{\circ} \mathrm{C}\right)$. 153

Figura 68 - Evolução das temperaturas no sistema de troca térmica 
com o calor transferido para o ciclo subcrítico $\left(T_{\text {evap }}=140^{\circ} \mathrm{C}\right)$.

Figura 69 - Evolução das temperaturas no sistema de troca térmica com o calor transferido para o ciclo supercrítico (pressão 4,0 MPa).

Figura 70 - Eficiência ótima do expansor de estágio único operando em ciclo subcrítico como função da temperatura do evaporador.

Figura 71 - Potência gerada pelo expansor e potência líquida gerada no ciclo subcrítico como função da temperatura do evaporador.

Figura 72 - Eficiência ótima do expansor de estágio único operando em ciclo subcrítico e supercrítico como função da pressão do gerador de vapor.

Figura 73 - Eficiencia térmica do ciclo de recuperação de calor para o expansor de estágio único em função da pressão do evaporador.

Figura 74 - Diagrama de velocidades adimensionalizado para o expansor com bocal convergente operando em ciclo subcrítico e supercrítico em função da pressão do evaporador.

Figura 75 - Diagrama de velocidades adimensionalizado para o expansor com bocal convergente-divergente operando em ciclo subcrítico e supercrítico em função da pressão do gerador de vapor.

Figura 76 - Grau de reação e números de Mach do escoamento absoluto e relativo para o expansor com bocal convergente operando em ciclo subcrítico e supercrítico em função da pressão do evaporador.

Figura 77 - Grau de reação, fator de aceleração axial e números de Mach para o expansor com bocal convergente-divergente operando em ciclo subcrítico e supercrítico em função da pressão do gerador de vapor.

Figura 78 - Relação entre diâmetro específico e velocidade específica para o expansor em ciclo subcrítico e supercrítico.

Figura 79 - Geometria do estágio com bocal convergente em ciclo subcrítico.

Figura 80 - Geometria do estágio com bocal convergente-divergente 


\section{Lista de tabelas}

Tabela 1 - Informações técnicas do motor EHR CAT G3520C-DM5854. 33

Tabela 2 - Compilação dos resultados dos testes para $\sigma=1,5$. 96

Tabela 3 - Compilação dos resultados dos testes para $\sigma=1,8$. 98

Tabela 4 - Características dos rotores de impulso de Ohlsson. 116

Tabela 5 - Resultados do coeficiente de perda de energia cinética total no rotor $\xi_{\text {tot }}$ para os rotores de impulso testados de Ohlsson. 116

Tabela 6 - Características das turbinas "stage 1" e "stage 2" testadas pela $\mathrm{KTH}$.

Tabela 7 - Parâmetros aerodinâmicos e geométricos da turbina "stage 1" da KTH.

Tabela 8 - Comparação entre os valores obtidos para o coeficiente de perda total de pressão $y_{\text {tot }}$ das turbinas da KTH.

Tabela 9 - Características básicas da grade cuja deflexão angular na saída foi investigada pela NASA.

Tabela 10 - Características geométricas da grade transônica 10.1.2 investigada pelo DFVLR e IFS.

Tabela 11 - Parâmetros de serviço das turbinas a vapor testadas. $\quad 131$

Tabela 12 - Geometria dos bocais para as turbinas testadas.

Tabela 13 - Geometria das palhetas rotativas para as duas turbinas a vapor testadas.

Tabela 14 - Parâmetros aerodinâmicos e eficiência calculada versus eficiência medida em bancada de teste para as duas turbinas.

Tabela 15 - Propriedades do R245fa (1,1,1,3,3-Pentafluoropropano). 140 Tabela 16 - Variação das propriedades do R245fa com a pressão relativa obtidas a partir da equação RKS para $T_{\text {red }}=1,014$.

Tabela 17 - Composição típica do gás natural (à esquerda) e do gás exausto do motor EHR CAT G3520C - DM5854 (à direita).

Tabela 18 - Operação do Sistema de troca térmica para o ciclo subcrítico com variação na temperatura do evaporador.

Tabela 19 - Operação do Sistema de troca térmica para o ciclo 
supercrítico.

Tabela 20 - Condições de serviço para o expansor operando em ciclo subcrítico.

Tabela 21 - Condições de serviço para o expansor operando em ciclo supercrítico.

Tabela 22 - Resultados das simulações para o expansor com bocal de perfil convergente operando em ciclo subcrítico parâmetros de desempenho.

Tabela 23 - Resultados das simulações para o expansor com bocal convergente operando em ciclo subcrítico - parâmetros geométricos. 164

Tabela 24 - Resultados das simulações para o expansor com bocal convergente operando em ciclo subcrítico parâmetros aero-termodinâmicos.

Tabela 25 - Resultados das simulações para o expansor com bocal convergente operando em ciclo subcrítico diagramas de velocidade.

Tabela 26 - Resultados das simulações para o expansor com bocal convergente-divergente operando em ciclo subcrítico parâmetros de desempenho.

Tabela 27 - Resultados das simulações para o expansor com bocal convergente-divergente operando em ciclo subcrítico -

parâmetros geométricos.

Tabela 28 - Resultados das simulações para o expansor com bocal convergente-divergente operando em ciclo subcrítico parâmetros aero-termodinâmicos.

Tabela 29 - Resultados das simulações para o expansor com bocal convergente-divergente operando em ciclo subcrítico diagrama de velocidades.

Tabela 30 - Resultados das simulações para o expansor com bocal convergente-divergente operando em ciclo supercrítico parâmetros de desempenho.

Tabela 31 - Resultados das simulações para o expansor com bocal convergente-divergente operando em ciclo supercrítico - 
parâmetros geométricos.

Tabela 32 - Resultados das simulações para o expansor com bocal convergente-divergente operando em ciclo supercrítico parâmetros aero-termodinâmicos.

Tabela 33 - Resultados das simulações para o expansor com bocal convergente-divergente operando em ciclo supercrítico diagrama de velocidades.

Tabela 34 - Discriminação de perdas para o estágio com bocal convergente operando em ciclo subcrítico.

Tabela 35 - Discriminação de perdas para o estágio com bocal convergente-divergente operando em ciclo subcrítico e supercrítico. 


\section{Nomenclatura}

$a$ - constante da equação RKS;

$A$ - coeficientes equação RKS;

$A_{b l}$ - constante para a camada limite turbulenta;

$A_{x}$ - área meridional;

$b$ - constantes da equação RKS;

$B$ - coeficientes equação RKS;

$c$ - velocidade absoluta (estágio);

$c_{0}$ - velocidade de disparo;

$C$ - comprimento da corda;

$C_{f, a x}$ - parâmetro de circulação axial;

$C_{p}-$ calor específico a pressão constante;

$C_{v}-$ calor específico a volume constante;

$C_{x}$ - projeção axial da corda;

$C_{w 1}$ - coeficiente de força da esteira;

$D$ - diâmetro do topo das palhetas;

$D_{s}$ - diâmetro específico;

$D_{s u c}$ - fator de difusão na superfície de sucção;

$D_{t o t}$ - fator de difusão total;

$d_{\max }$ - espessura máxima da palheta;

$e$ - entalpia específica;

$E$ - energia específica;

$F$ - força;

$F L$ - ângulo de alargamento;

$h$ - altura da palheta;

$H$ - fator de forma da camada limite;

$i$ - ângulo de incidência;

$j$ - expoente isentrópico pressão-temperatura;

$k$ - expoente isentrópico pressão-volume;

$K_{s}$ - rugosidade superficial;

$K_{t}-$ fator de aceleração axial;

$l$ - comprimento da linha média de curvatura; 
$L$ - vazamento;

La - Número de Laval;

$M$ - número de Mach;

$m$ - coeficientes equação RKS;

$\dot{m}$ - vazão mássica;

$n$ - expoente do perfil de velocidade da camada limite;

$N$ - expoente para a variação radial da velocidade tangencial;

$N_{s}$ - velocidade específica;

$o$ - largura da garganta;

$p$ - pressão;

$P$ - potência;

$\dot{q}-$ taxa de calor transferido;

$Q$ - Vazão volumétrica;

$R$ - constante do gás;

$R_{c}$ - raio de curvatura da superfície do perfil;

$R e$ - número de Reynolds;

$s$ - entropia específica;

$S$ - coeficiente de pressão;

$S F$ - fator de tamanho;

$t$ - espaçamento entre palhetas;

$T$ - temperatura;

$t_{b}$ - espessura do bordo de fuga;

$t_{e}$ - espessura do bordo de fuga projetada na direção tangencial;

$u$ - velocidade periférica;

$v$ - volume específico;

$V$ - velocidade (grade);

$V_{s d}$ - velocidade do som;

$V R$ - relação de volumes do estágio;

$x$ - parâmetro do escoamento de Prandtl-Mayer;

$X$ - fator adimensional relacionado à derivada de $\mathrm{Z}$ em relação à temperatura;

$y$ - coeficiente de perda de pressão;

$Y$ - fator adimensional relacionado à derivada de $\mathrm{Z}$ em relação à pressão;

$w$ - velocidade relativa (estágio);

$z$ - parâmetro do escoamento de Prandtl-Mayer; 
$Z$ - fator de compressibilidade;

$Z_{N}$ - número de palhetas estacionárias;

$Z_{R}-$ número de palhetas rotativas;

\section{Símbolos gregos:}

$\alpha$ - ângulo da velocidade absoluta com a direção tangencial;

$\alpha(T)$ - função na equação RKS;

$\beta$ - ângulo da velocidade relativa com a direção tangencial;

$\chi$ - fator de correção;

$\delta$ - espessura de deslocamento da camada limite;

$\delta u$ - carregamento da palheta (grade);

$\Delta$ - folga axial entre disco e carcaça;

$\Delta_{b}$ - folga axial entre palhetas rotativas e estacionárias;

$\Delta_{s}$ - folga axial entre aro da roda e carcaça;

$\Delta_{r}$ - folga radial entre topo da palheta e carcaça;

$\Delta \lambda_{\text {ind }}$ - desvio angular induzido na entrada da grade;

$\Delta \lambda_{\text {dev }}$ - deflexão angular na saída da grade;

$\mathcal{E}$ - fração de admissão;

$\gamma$ - massa específica;

$\Gamma$ - derivada fundamental da dinâmica do gás;

$\eta$ - eficiência;

$\vartheta$ - espessura de quantidade de movimento da camada limite;

$\lambda$ - ângulo (grade);

$\lambda_{s}$ - ângulo de assentamento da palheta;

$\lambda_{\infty}$ - ângulo médio do vetor velocidade da grade;

$\mu$ - taxa de aceleração da grade;

v ângulo de Prandtl-Mayer;

$\rho$ - grau de reação do estágio;

$\sigma$ - solidez da grade.

$\sigma_{x}-$ solidez axial

$\tau_{s}$ - tensão de cisalhamento; 
$\varpi$ - viscosidade absoluta;

$\xi$ - coeficiente de perda referente à energia cinética ideal;

$\Psi$ - coeficiente aerodinâmico.

$\Psi_{N}$ - coeficiente de velocidade do bocal;

$\Psi_{R}$ - coeficiente de velocidade do rotor;

$\Psi_{Z}$ - coeficiente de Zweiffel;

$\omega$ - fator acêntrico.

$\Omega$ - velocidade angular.

$\Omega_{a}, \Omega_{b}-$ constantes da equação RKS;

$\zeta$ - coeficiente de perda referente à energia cinética real.

\section{Subscritos:}

0 - condição de estagnação;

1 - estação a montante da grade ou a montante do bocal (estágio);

2 - estação a jusante da grade ou entre bocal e rotor (estágio);

2te - estação na saída da grade, entre os bordos de fuga;

3 - estação a jusante do rotor (estágio);

$3 D$ - tridimensional;

$A R$ - referente à razão de aspecto;

$b$ - da palheta;

$c$ - referente ao ponto crítico do fluido;

$c r-$ referente ao escoamento crítico $(\mathrm{Mach}=1) ;$

dep - desvio isotérmico em relação à condição de gás ideal;

evap - referente ao evaporador;

is - isentrópico;

in - referente à entrada no trocador de calor;

max-máximo;

med - médio;

min-mínimo;

$M$ - característico da máquina;

$N$ - referente ao bocal;

out - referente à saída do trocador de calor;

$p$ - referente à superfície de pressão ou referente ao perfil; 
pa-admissão parcial;

pm - bombeamento;

$p r$ - referente à grade a montante;

$r$ - componente radial;

red - reduzida (em relação ao ponto crítico);

$R$ - referente ao rotor;

rel-escoamento relativo;

$s$ - referente à superfície de sucção ou secundária;

$s c$ - sopragem;

$t$ - referente ao topo da palheta.

$T-S$ - total a estático;

$T-T$ - total a total;

tot - total;

$u$ - componente tangencial;

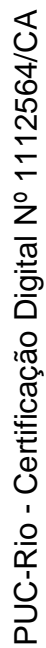

$x$ - componente axial;

$w$ - atrito na roda.

\section{Sobrescritos:}

* - relativo à condição de gás ideal.

' - relativo à obstrução da camada limite. 
1

\section{Introdução}

\subsection{Recuperação de Calor Através do Ciclo Rankine Orgânico}

Nos últimos anos temos visto crescer rapidamente o interesse na utilização de fontes não convencionais de energia, como por exemplo, fontes renováveis (biomassa, solar, geotérmica) e recuperação de energia térmica rejeitada em diferentes níveis de temperatura.

O processo em questão consiste em uma máquina térmica que recebe calor de uma fonte quente disponível, produz energia elétrica e descarta calor para o ambiente, operando segundo um ciclo Rankine, cujo fluido de trabalho é orgânico, conforme mostrado na figura 1. O fluido orgânico pode ser um hidrocarboneto parafínico ou aromático, um fluido refrigerante comercial (como o R125, R134a, R236fa ou R245fa), amônia ou mistura água-amônia, ou ainda uma nova geração de fluidos a base de silício. Estes fluidos são mais adequados para aplicação em recuperação de calor em baixas ou médias temperaturas, uma vez que, neste caso, o ciclo Rankine tradicional utilizando água começa a perder a atratividade por necessitar de um grau de superaquecimento elevado, com impacto negativo na sua eficiência [1].

Recentemente o assunto teve o interesse renovado principalmente a partir de 2009, chegando a ter uma participação de $0,3 \%$ nos artigos técnicos publicados nas editoras especializadas nos últimos dois anos. 

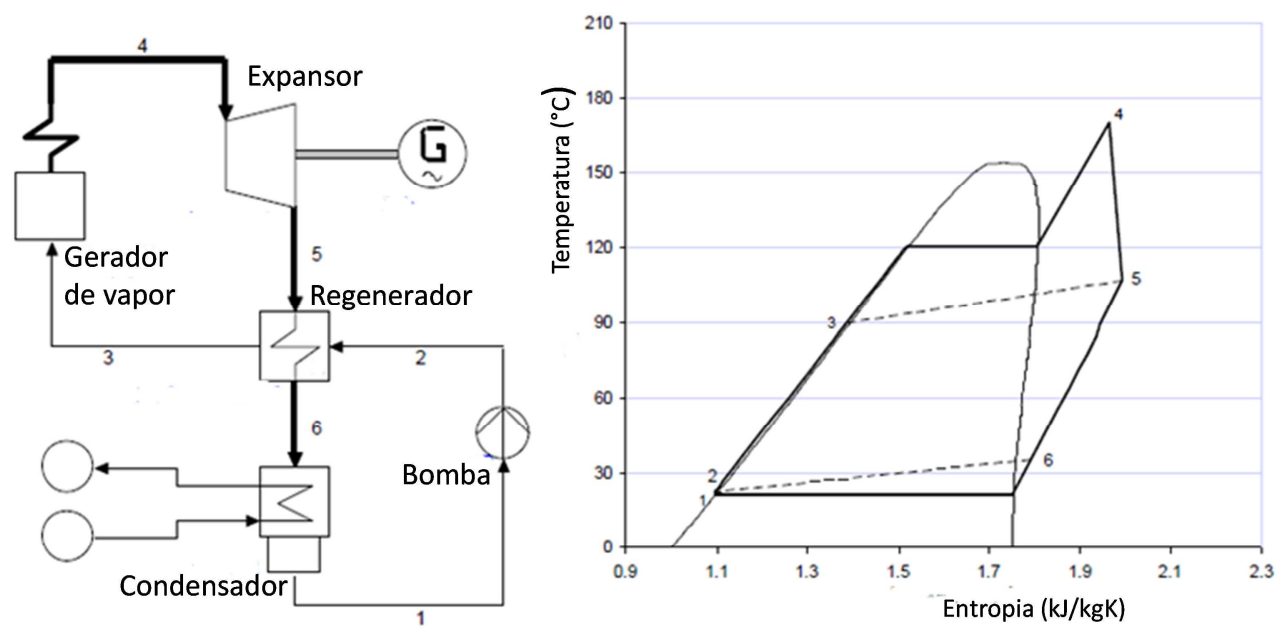

Figura 1 - Planta de geração baseada no ciclo Rankine orgânico [1].

Uma particularidade importante relativa às características termodinâmicas dos fluidos orgânicos é a possibilidade de se ter uma curva de vapor saturado no diagrama temperatura - entropia com inclinação positiva (dito fluido seco) ou infinita (dito fluido isentrópico). Este fato resulta em superaquecimento no exausto do expansor, evitando-se desta forma o clássico problema do controle de título do vapor na saída de turbina.

Adicionalmente, a expansão termodinâmica dos fluidos orgânicos é caracterizada por uma elevada relação de volumes, por um salto de entalpia reduzido e pela complexidade do comportamento de gás real, acarretando em grandes variações de área e possibilidade de escoamento transônico e supersônico nos canais do expansor.

Os fatos acima mencionados favorecem a especificação de um pequeno grau de superaquecimento para o ciclo orgânico, além de possibilitar a utilização de uma turbina de contrapressão, compacta, com poucos estágios e baixo custo, em oposição à turbina condensante utilizada no ciclo tradicional com água, e que possui um número grande de estágios. 


\subsection{Histórico}

Os principais fatos históricos relativos ao desenvolvimento do ciclo Rankine orgânico são reportados por Colonna et al. [1]. Em 1859 William Rankine publicou o "Manual of the Steam Engine and Other Prime Movers", estabelecendo o ciclo termodinâmico para geração de energia com base na utilização da água como fluido de trabalho. Ainda no século XIX, após alguns eventos de explosão de caldeiras de alta pressão, houve regulação na utilização nos ciclos a vapor, resultando em restrição ao uso particular. Este fato promoveu o advento dos motores de combustão externa utilizados para acionamento de pequenas embarcações (lanchas), utilizando o petróleo como fluido de trabalho, lubrificante e também como combustível. Algumas outras iniciativas se sucederam como o motor de Frank Ofeldt que queimava querosene e usava álcool extraído de madeira como fluido de trabalho. Também é reportado o motor a éter de Du Tremblay (1850), utilizado um ciclo combinado com água e éter, este último como "bottoming cycle" do anterior. No século $\mathrm{XX}$ as iniciativas se sucedem: em 1935 o professor Luigi D’Amelio utiliza uma turbina de impulso operando com cloreto de etila para gerar energia a partir da captação do calor do sol na África. A eficiência líquida verificada no ciclo era 3,6\%. Outros trabalhos semelhantes foram aplicados a pequenas plantas geotérmicas, utilizando diferentes fluidos e diferentes geometrias para a turbina.

Mais tarde, na década de 1960 ocorre o advento do moderno ciclo orgânico a partir de trabalhos no laboratório de energia solar de Zvi Tabor e Bronicki em Israel, onde é produzido um sistema operando com tolueno e gerando $3 \mathrm{kWe}$, apresentando baixa eficiência, mas alta confiabilidade. Com o advento da crise do petróleo na década de 1970 é construída a primeira usina termo-solar no Mar Morto com potência de $150 \mathrm{kWe}$.

Na década de 1970 se destaca a escola italiana a partir de aplicações com energia solar e recuperação de calor industrial no Politécnico de Milão com os professores Angelino, Macchi e Gaia, cuja visão pioneira há 40 anos reflete o que está acontecendo na atualidade. 
Na década de 1980 ocorre a contribuição da escola finlandesa com trabalhos voltados a aplicações de recuperação de calor, a energia solar e os sistemas de pequeno porte desenvolvidos na Lappeenranta University of Technology pelo professor Larjola. Destaca-se também o trabalho no veículo automotor de submersão profunda MIR para exploração do fundo do mar utilizando o combustível hidrazina, $25 \mathrm{kWe}$ e $50000 \mathrm{rpm}$. Sua maior contribuição para o desenvolvimento do ciclo Rankine orgânico foi o conceito do turbo-gerador hermético de alta rotação.

Outras iniciativas da década de 1980 podem ainda ser citadas como, por exemplo, nos Estados Unidos o ciclo de $600 \mathrm{~kW}$ da Sundstrand projetado para recuperação de calor exausto de motores diesel e de pequenas turbinas a gás, além da mini usina solar para estação espacial da Sundstrand e Barber Nichols. Na França foi construída uma turbina de $50 \mathrm{~kW}$ de 2 estágios com admissão parcial projetada por A. Vernau para operação com ciclo orgânico solar. Devem ser acrescentadas ainda as aplicações automotivas nos Estados Unidos, motivadas pela crise do petróleo, onde foi utilizado ciclo supercrítico e turbina axial de 3 estágios e 55000 rpm, incrementando a eficiência global em $16 \%$.

Uma informação relevante é o crescimento das usinas com base no ciclo Rankine orgânico ao longo das últimas décadas, totalizando na atualidade cerca de 370 unidades instaladas com 1500 MW de potência acumulada, conforme mostrado na figura 2. O potencial para crescimento deste segmento é considerado ainda muito grande.
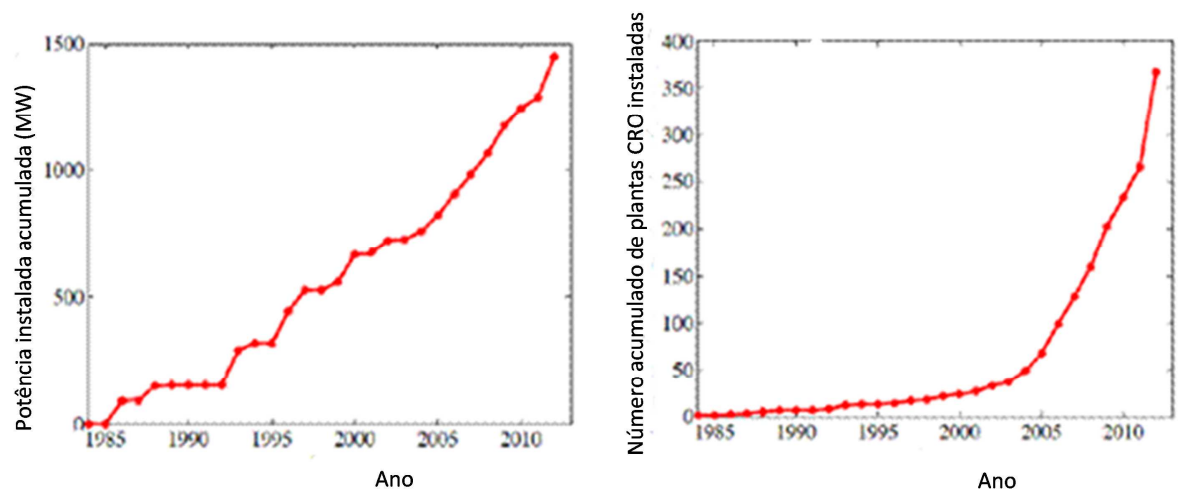

Figura 2- Crescimento das usinas de geração instaladas utilizando o ciclo Rankine orgânico [1]. 


\subsection{Revisão Bibliográfica}

Nesta seção é apresentada uma revisão bibliográfica geral sobre o ciclo Rankine orgânico, tendo em vista acompanhar o rumo do desenvolvimento do tema em questão, de forma a identificar o estado da arte, as lacunas e a fronteira do conhecimento. Um histórico bibliográfico mais breve sobre temas específicos que também são objeto deste trabalho, como o tratamento adequado para o comportamento de gás real, além da estimativa de desempenho e os critérios para otimização do expansor serão apresentados nos próximos capítulos.

O trabalho de Lee e Kim [2] analisa o projeto do ciclo orgânico para recuperação do calor do exausto de uma micro-turbina a gás. No ciclo Rankine de recuperação de calor, compara-se o desempenho utilizando como fluido de trabalho o refrigerante R-123 ou vapor d'água, mostrando parâmetros de operação bastante diferentes: No caso do R-123 a temperatura na entrada do expansor é limitada a $150^{\circ} \mathrm{C}$ por questões de estabilidade térmica, enquanto que com vapor d'água pode chegar a $274^{\circ} \mathrm{C}$. Assim sendo, observa-se uma maior retirada de calor da corrente de exausto da micro-turbina a gás e uma menor eficiência do ciclo com o R123 em comparação ao vapor d'água. A conclusão do trabalho é que com o ORC a maior quantidade de calor recuperado sobrepuja a menor eficiência do ciclo, resultando numa maior produção de potência elétrica (44 kW com R123 contra $33 \mathrm{~kW}$ com vapor d'água). É destacado que há uma diferença quanto à localização do "pinch-point": sua ocorrência se dá na entrada do evaporador no caso do ciclo com água, ou na entrada do economizador (descarga da bomba), no caso do ciclo com refrigerante.

Invernizzi et al. [3] estabelecem critérios para seleção do fluido mais apropriado para recuperação de calor do exausto de micro-turbinas a gás, abrangendo aspectos técnicos e ambientais. Uma análise termodinâmica certifica que as condições mais favoráveis para o ciclo do ponto de vista de recuperação de calor são obtidas, produzindo informações para o projeto preliminar da turbina (número de estágios, diâmetro e rotação). Uma série de fluidos pré-selecionados são classificados em termos de suas temperaturas críticas, e caracterizados pelo 
fator acêntrico e por um parâmetro de complexidade molecular que é proporcional à inclinação da linha de vapor saturado no diagrama temperatura - entropia. É mostrado que existe uma otimização da potência elétrica gerada pelo ciclo em função da temperatura de evaporação, considerando a temperatura crítica do fluido e a temperatura da fonte quente (exausto da micro-turbina).

O trabalho de Schuster et al. [4] descreve o potencial de aumento de eficiência na utilização de um ciclo orgânico supercrítico. $O$ apelo é que o ciclo supercrítico se aproxima de um ciclo triangular onde é possível efetuar uma recuperação de calor da fonte quente a uma diferença de temperatura constante, reduzindo-se a destruição de exergia comparativamente ao ciclo subcrítico.

O trabalho de Wang e Zhao [5] explora a possibilidade de utilizar misturas azeotrópicas de fluidos onde a evaporação ocorre com temperatura crescente, sendo mostrado um ganho de eficiência no ciclo utilizando superaquecimento e regeneração. Para este último processo é utilizado com um trocador de calor interno onde o exausto da turbina aquece o líquido pressurizado antes da entrada no evaporador.

No trabalho de Desai e Bandyopadhyay [6] são enfatizadas as seguintes virtudes do ciclo Rankine orgânico para fontes de calor até $370^{\circ} \mathrm{C}$ : longa campanha operacional, baixo custo de manutenção, operação totalmente automática e bom desempenho em carga parcial. São abordados ganhos de eficiência no ciclo através da introdução de regeneração e extração na turbina.

Larjola [7] propõe uma inovação no projeto conceitual da turbomáquina do ciclo Rankine orgânico tendo em vista ter uma planta de baixo custo e que demande uma manutenção mínima. A solução convencional consiste em um gerador elétrico padrão acionado por uma turbina axial através de uma caixa de engrenagens redutora. O sistema inclui uma bomba de alimentação separada, bomba de vácuo, sistema de lubrificação e requer vários selos com demanda elevada de manutenção. Para contrapor a estes problemas o artigo descreve um projeto de desenvolvimento de um turbo-gerador-bomba de alta rotação e lubrificado pelo fluido de trabalho como motor para o ciclo Rankine orgânico. 
Nesta concepção as turbomáquinas estão sempre diretamente acopladas dispensando o uso da caixa de engrenagens. Além disso, o equipamento é hermético, eliminando a possibilidade de vazamento do fluido de processo.

Além das turbomáquinas axiais, outras concepções também são descritas na literatura para aplicação no ciclo orgânico, como por exemplo, a turbina radial [8], um expansor tipo "scroll” [9], além de uma turbina centrífuga (saída radial) [10], e um expansor de deslocamento positivo [11].

No trabalho de Uusitalo et al. [12] é abordada a aplicação da família de fluidos siloxanos no ORC baseado na tecnologia de alta rotação. São apontadas as seguintes vantagens: ausência de toxicidade, boa estabilidade térmica, inflamabilidade limitada, propriedades termodinâmicas adequadas para aplicação em altas e médias temperaturas e boas propriedades lubrificantes. Uma dificuldade percebida, entretanto, é a pressão de condensação negativa (da ordem de 10 mbar) que irá demandar cuidados adicionais para manutenção do vácuo no sistema.

Uma previsão de eficiência fundamentada no projeto preliminar de um estágio de turbina axial operando com fluidos não convencionais é abordado por Macchi e Perdichizzi [13] com base nos parâmetros adimensionais velocidade específica e razão isentrópica de volumes. Um parâmetro adicional que caracteriza as dimensões reais da turbina é acrescentado com o objetivo de quantificar adequadamente as maiores perdas de máquinas pequenas.

No trabalho de Quoilin e Lemort [14] são abordadas as questões relativas à otimização do ciclo, à modelagem transiente e às estratégias de controle para sistemas operando com o ciclo Rankine orgânico. É enfatizado que os modelos dinâmicos devem ser desenvolvidos para implementação de estratégias de controle adequadas e que as estratégias baseadas na variação do "set-point" permitem aumento da potência gerada em mais de $4 \%$.

Pode-se afirmar que o avanço tecnológico no desenvolvimento do ciclo Rankine Orgânico é expressivo, concentrando-se no desenvolvimento de novos 
fluidos para aplicação em temperaturas mais elevadas, nas técnicas de controle da planta para operação em carga parcial e na redução de custo e aumento de eficiência dos equipamentos de fluxo e de troca térmica [15]. Várias concepções diferentes, volumétricas ou dinâmicas, são adotadas para o expansor, dependendo do porte da planta. O estado da arte para o expansor do ciclo Rankine orgânico de princípio dinâmico é a utilização de turbinas de múltiplos estágios de diferentes configurações, como a turbina axial ou a turbina de fluxo radial centrífugo. Esta última [16] é constituída por vários estágios acomodados em um único disco em balanço, cuja geometria propicia naturalmente o aumento de volume requerido na direção do escoamento, sem demandar grandes variações na altura das palhetas.

A fronteira do conhecimento consiste na expansão transônica e supersônica eficiente de gases densos, cujo comportamento é bastante distinto daquele apresentado pelos gases ideais. Os problemas apresentados nesta expansão serão pormenorizados na seção 4.1.4. O grande desafio atual para viabilizar a utilização de um expansor de estágio único para aplicação no ciclo Rankine orgânico, seja de fluxo axial ou radial, é o projeto de um bocal convergente-divergente de alto desempenho operando com gases densos. Para pesquisar este problema e definir soluções as instituições universitárias mais avançadas no assunto atualmente investem na construção de túneis de vento de alta velocidade especialmente concebidos para operar com fluidos orgânicos [17]. Uma lacuna existente é o mapeamento da utilização mais eficiente para cada concepção construtiva de expansor (dinâmica ou volumétrica) em função das diferentes aplicações definidas pelas possíveis condições do ciclo.

Neste trabalho será investigada a aplicação do expansor axial para acionamento direto do gerador elétrico de dois polos no ciclo Rankine orgânico utilizado em recuperação de rejeito térmico de um motor de combustão interna da classe de 2 MW. A utilização da admissão parcial é antecipada tendo em vista a otimização do desempenho do expansor nas condições de baixa rotação (acionamento direto) e pequeno porte (150 a $200 \mathrm{~kW})$. A aplicação estudada é descrita em detalhes na seção a seguir, em conjunto com as contribuições apresentadas pelo presente trabalho. 


\subsection{Descrição da Aplicação Proposta}

Neste trabalho será desenvolvido um estudo analítico acerca da aplicação do ciclo Rankine Orgânico na recuperação do rejeito rérmico de um motor de combustão interna. A configuração recomendada por Schuster et al. [4] para esta aplicação utiliza um circuito intermediário com óleo térmico que estará em contato com a fonte de calor, conforme mostrado na figura 3. Desta maneira evitase submeter o fluido orgânico a temperaturas excessivas que poderiam resultar na sua degradação térmica ou em risco de incêndio.

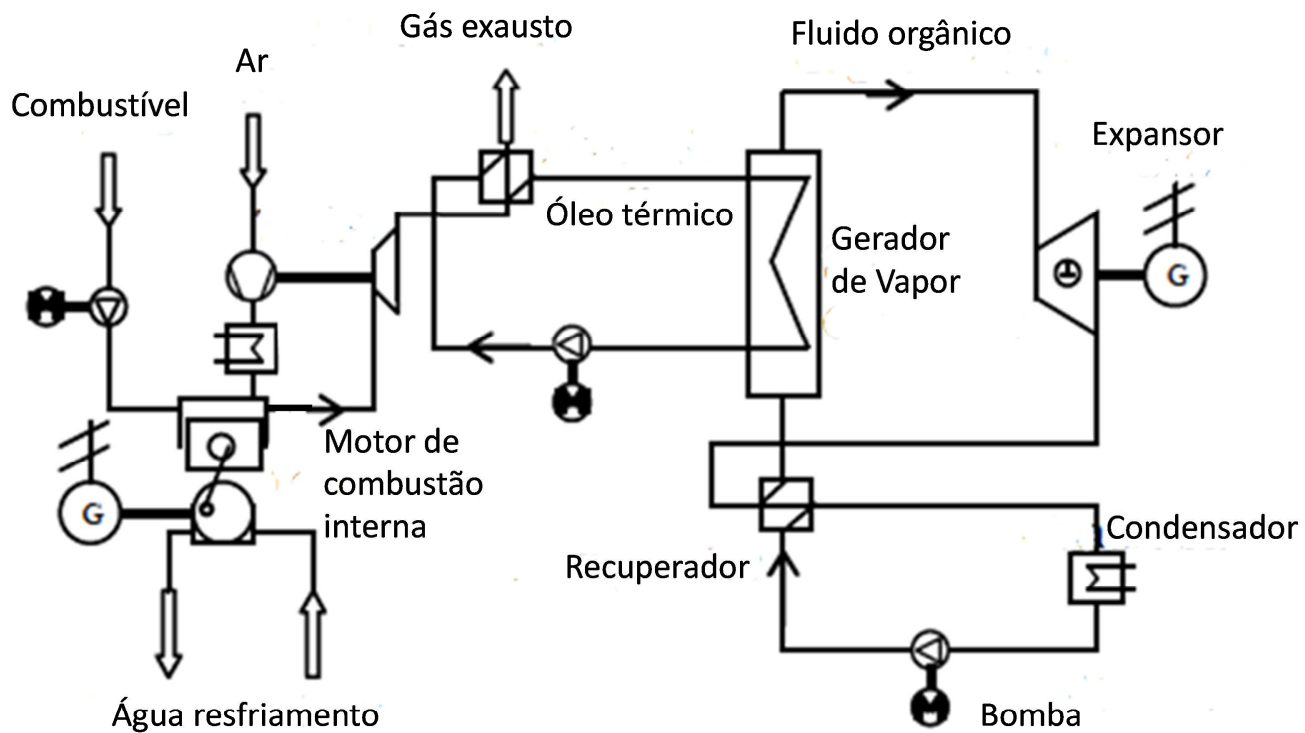

Figura 3 - Esquema de recuperação de calor do exausto de um motor de combustão interna [4].

O recuperador de calor do ciclo orgânico mostrado na figura 3 não é de fato necessário em aplicações de aproveitamento de rejeito térmico, uma vez que a fonte quente pode por si mesma suprir a demanda de pré-aquecimento do líquido em alta pressão. Na figura 4 é mostrada a distribuição de temperaturas do gás exausto do motor, do circuito intermediário de óleo térmico e do fluido orgânico para o ciclo subcrítico. O gás exausto aquece o óleo térmico, que por sua vez 
fornece calor ao gerador de vapor. No caso do ciclo subcrítico, o pré-aquecimento, evaporação e superaquecimento são claramente distinguidos, o que não acontece no caso do ciclo supercrítico. Este fato tem consequência sobre as perdas de exergia do sistema e, portanto, na eficiência do ciclo. Neste sistema de troca térmica são considerados dois "pinch points": o primeiro entre o gás de exausto do motor e o óleo térmico, denominado PP1, e o segundo entre o óleo térmico e o fluido orgânico, denominado PP2. A diferença de temperatura associada a cada um dos "pinch points" é mantida em valor constante para todas as condições estudadas, como critério do projeto térmico do sistema.

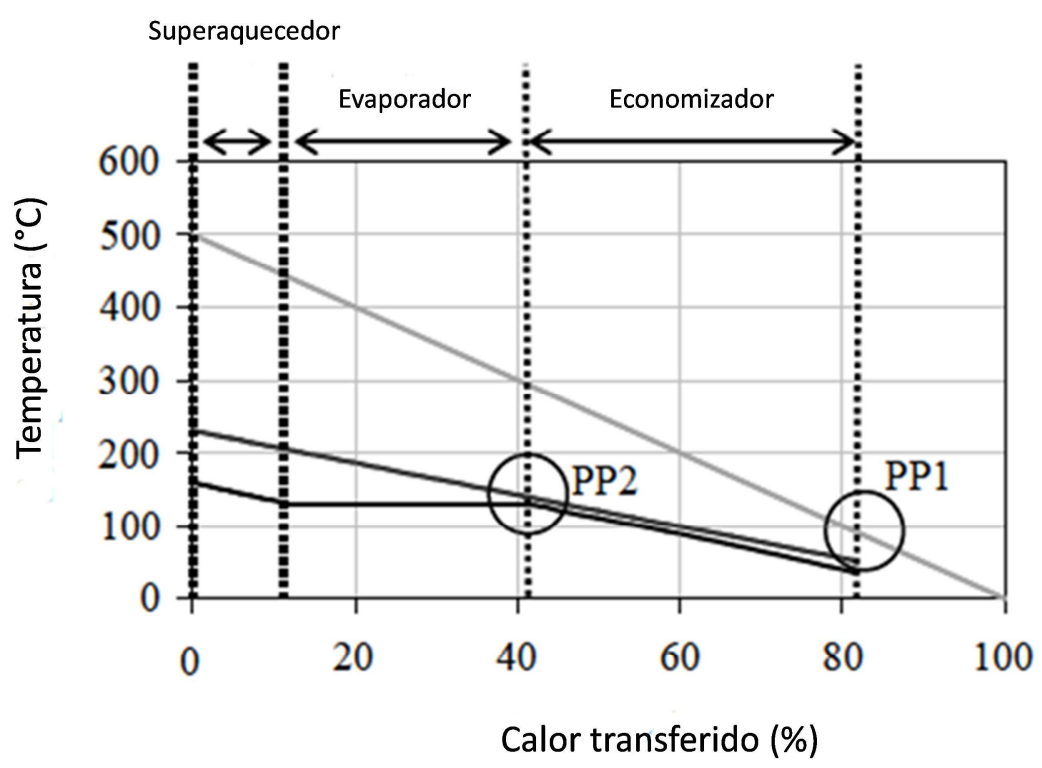

Figura 4 - Evolução das temperaturas do gás exausto do motor (linha superior), do óleo térmico (linha intermediária) e do fluido orgânico (linha inferior) em ciclo subcrítico [4].

Será considerada a utilização de um expansor axial de estágio único e admissão parcial acionando diretamente um gerador síncrono de dois polos, sob a motivação de se aplicar um equipamento mais simples, de maior facilidade de fabricação, de tecnologia disponível na indústria nacional e de menor custo para o sistema em questão. Este equipamento é largamente utilizado na indústria do petróleo, petroquímica e sucro-alcooleira utilizando vapor d'água como fluido motriz para acionamento de bombas centrífugas e geradores elétricos. Os dados 
técnicos relevantes do motor EHR CAT G3520C em estudo, utilizando gás natural como combustível, estão mostrados na tabela 1, conforme informações de catálogo.

Tabela 1 - Informações técnicas do motor EHR CAT G3520C - DM5854.

\begin{tabular}{|l|r|}
\hline Potência mecânica (kW) & 1992 \\
\hline Consumo de combustível (Nm3/h) & 543 \\
\hline Vazão de ar de combustão (Nm3/h) & 9420 \\
\hline Temperatura do gás exausto (ํ) & 511 \\
\hline Vazão de gás exausto (Nm3/h) & 9960 \\
\hline Calor Rejeitado pelo exausto - LHV até 120ํㅡ (kW) & 1535 \\
\hline Calor Rejeitado para a água de resfriamento (kW) & 1162 \\
\hline
\end{tabular}

O presente trabalho apresenta uma investigação sobre a influência da temperatura do evaporador na produção de energia elétrica pelo ciclo de recuperação de calor do exausto do motor em questão, utilizando o fluido R245fa [18]. A temperatura do evaporador irá impactar simultaneamente a eficiência do ciclo Rankine [19] bem como a eficiência do expansor [20], resultando em um problema de otimização integrada do ciclo termodinâmico e do projeto do expansor. Desta forma a condição ótima de operação deverá será determinada simultaneamente com a geometria mais adequada da turbina, de modo a maximizar a produção de energia do ciclo de recuperação de calor.

Para atender ao objetivo traçado serão realizadas simulações do desempenho do expansor na condição de projeto e em regime permanente. A otimização do desempenho do expansor para uma dada condição operacional demanda a determinação do diagrama de velocidades do estágio e sua correspondente geometria, de forma a se atingir o maior potencial de eficiência. $\mathrm{O}$ cálculo do diagrama de velocidades, por sua vez, requer a utilização de um modelo de perdas para o escoamento através das grades de palhetas axiais. Os fundamentos necessários para esta etapa são discutidos no capítulo 2.

Adicionalmente, um modelo termodinâmico que permita a determinar com precisão as variações da entalpia, entropia e volume específico ao longo das 
seções internas do expansor será necessário para determinação da sua geometria. A evolução das variáveis de estado estará relacionada com as velocidades atingidas em cada seção através da conversão da energia térmica disponível em energia cinética nos canais internos do equipamento. A utilização de fluidos não convencionais torna esta avaliação bastante complexa em virtude do comportamento de gás denso.

As contribuições do presente trabalho ao desenvolvimento do ciclo Rankine orgânico e seu expansor estão relacionadas a seguir:

- O desenvolvimento de um modelo para estimativa de perdas no escoamento através de grades de turbinas axiais, apresentado no capítulo 3;

- O estabelecimento de relações aero-termodinâmicas para o expansor, contemplando a condição de gás real, apresentado na seção 4.1;

- A análise da utilização da turbina axial de admissão parcial para a aplicação proposta através de um algoritmo de otimização de projeto, bem como o estudo da temperatura ótima do evaporador para o ciclo subcrítico, apresentados na seção 4.2 . 


\section{2}

\section{Desempenho de Turbinas Axiais}

\subsection{Introdução}

O mais remoto antecedente histórico de uma turbina é um dispositivo denominado "aeolipile" construída por volta de 12 AC que girava através do princípio da reação, atribuído a Hero de Alexandria. Turbinas de impulso foram utilizadas pelos romanos em rodas de água por volta de $70 \mathrm{AC}$. O conceito de impulso foi aplicado para a construção de uma turbina a vapor desenvolvida pelo engenheiro italiano Giovanni Branca em 1629, utilizada para acionamento de uma prensa de estampagem através de engrenagens cônicas. Na era moderna [21] quatro engenheiros podem ser considerados pioneiros da tecnologia da turbina a vapor axial: Carl Gustav De Laval, Charles Parsons, Auguste Rateau e Charles Curtis, através do lançamento de patentes entre 1883 e 1897. A turbina de impulso atribuída a De Laval está ilustrada na figura 5.
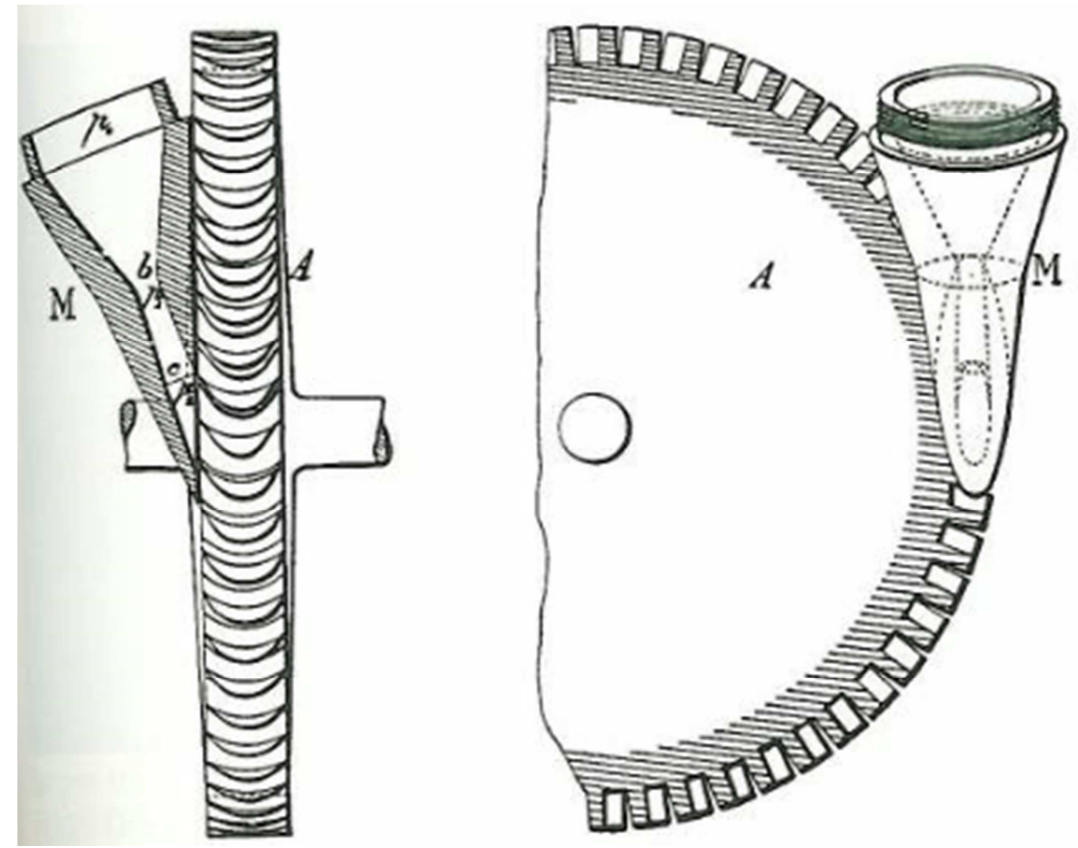

Figura 5 - Roda de turbina de impulso De Laval e bocal de expansão [21]. 


\subsubsection{Geometria e Configurações}

O estágio axial é constituído por duas fileiras sucessivas de palhetas, sendo a primeira estacionária e a seguinte rotativa. A primeira fileira, denominada bocal, tem como função produzir um jato de alta velocidade a partir do fluido disponível em alta pressão. Este jato incidirá sobre a fileira rotativa, transferindo para ela parte de sua energia, que irá acionar o eixo. A figura 6 mostra uma vista longitudinal de estágio axial onde as seções de interesse estão indicadas a seguir:

seção 1 - a montante do bocal;

seção 2 - entre o bocal e o rotor;

seção 3 - a jusante do rotor.

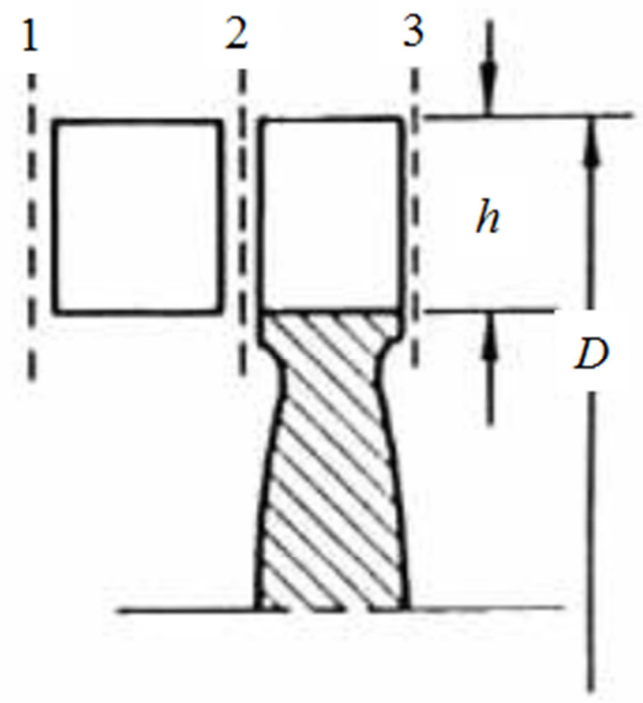

Figura 6 - Vista longitudinal do estágio axial [22].

A geometria e a nomenclatura de uma fileira de palhetas estão mostradas nas figuras 7 e 8 respectivamente. Os principais parâmetros geométricos estão relacionados a seguir:

$D$ - diâmetro do topo das palhetas;

$h$ - altura da palheta

$t$ - espaçamento das palhetas;

$t_{b}$ - espessura do bordo de fuga; 
$t_{e}$ - espessura do bordo de fuga projetada na direção tangencial;

$C$ - corda;

$C_{x}-$ projeção axial da corda;

$l$ - comprimento da linha média de curvatura;

$\lambda_{s}$ - ângulo de assentamento da palheta.

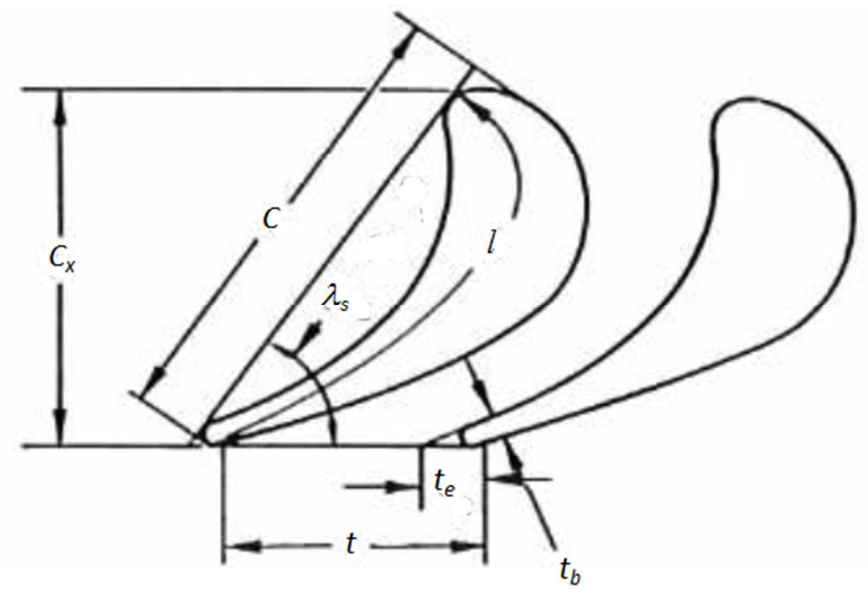

Figura 7 - Vista transversal de uma fileira de palhetas componente de um estágio de turbina axial [22].

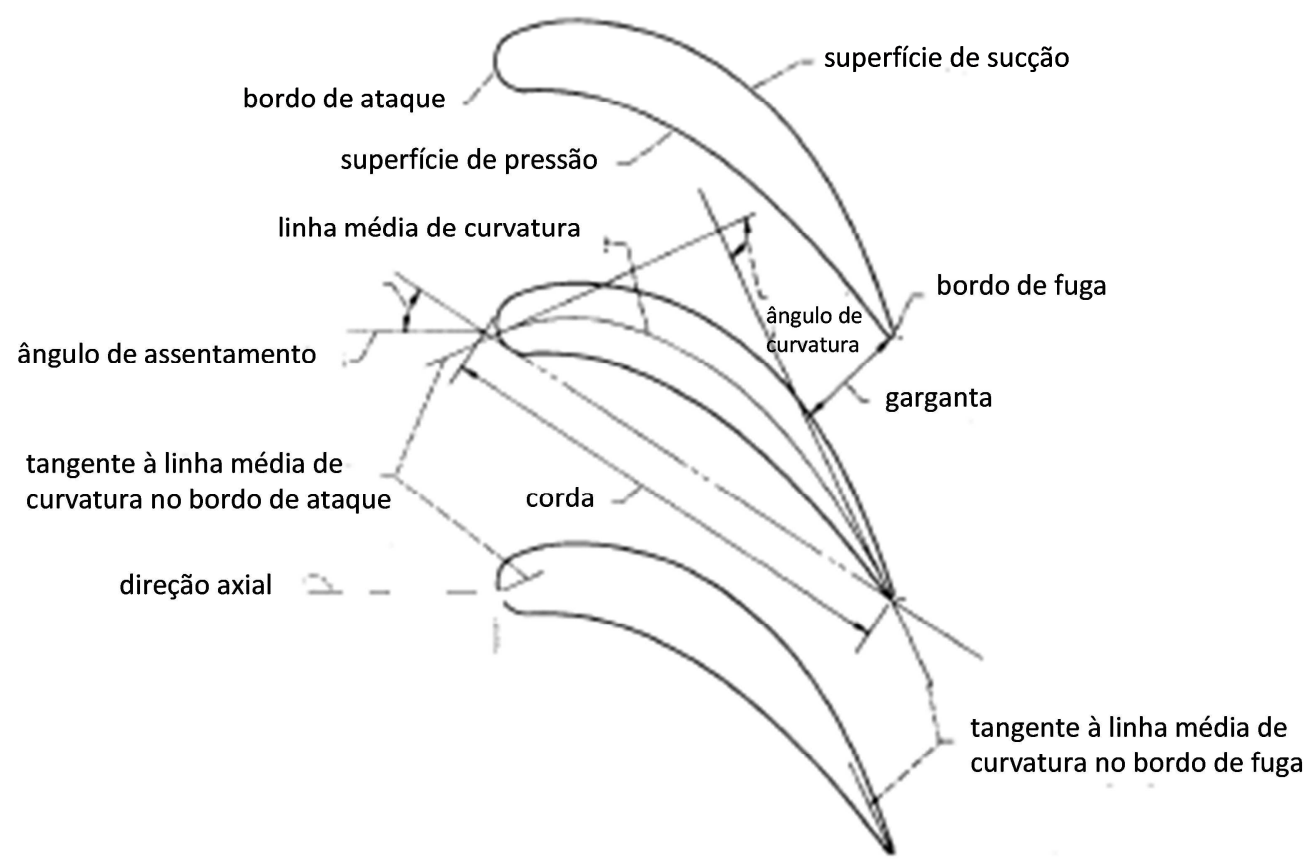

Figura 8 - Nomenclatura da fileira de palhetas do estágio axial [23]. 
Na configuração mostrada na figura 6 a altura das palhetas é constante ao longo do estágio. Algumas configurações alternativas são possíveis para um fluxo axial, como por exemplo o arranjo com palheta cuja altura é gradualmente aumentada ou o arranjo com palheta sobreposta, conforme mostrado na figura 9 . Em ambos os casos a área do escoamento na saída do rotor é aumentada, cuja consequência será discutida nas seções seguintes.
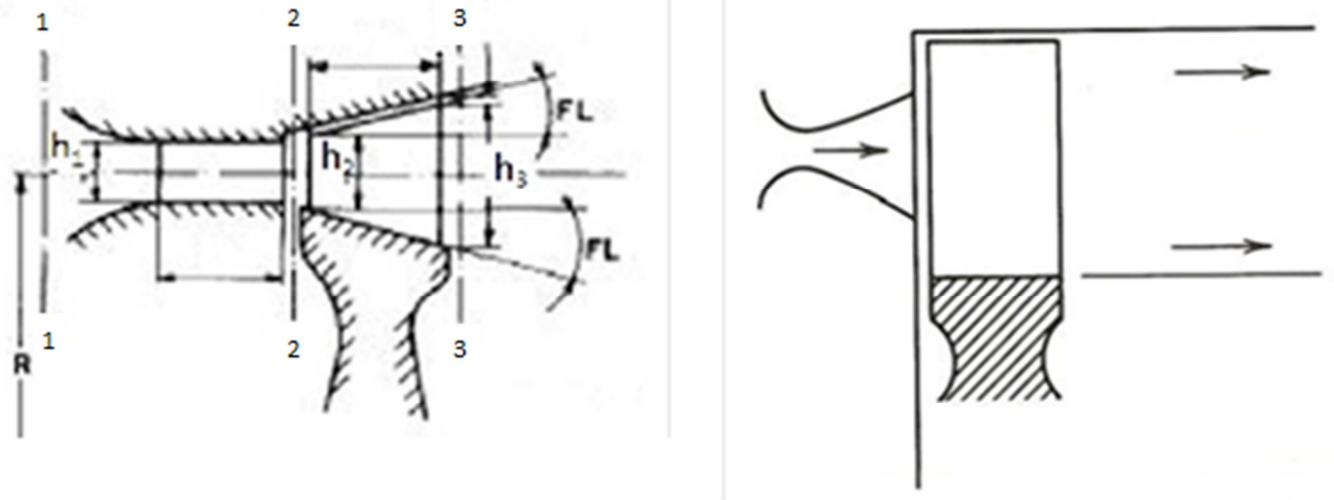

Figura 9 - Arranjo com altura da palheta gradualmente aumentada através do ângulo $F L$ (esquerda) [13] e arranjo com palheta sobreposta (direita) [22]. 


\subsubsection{Definições}

A eficiência isentrópica de uma turbina é usualmente definida como a razão entre a energia transferida ao eixo e a energia térmica disponível no fluido de trabalho, conforme a expressão abaixo:

$$
\eta=\frac{E}{E_{i s}}
$$

Uma vez que as perdas nos mancais seguem relações de similaridade diferentes que as perdas que governam a eficiência das turbinas, torna-se conveniente não contabilizá-las na potência produzida. Assim sendo a energia transferida será obtida pela diferença de entalpias entre as condições totais na entrada e saída, indicadas pelo algarismo 0 no subscrito, antecedendo à identificação da seção correspondente conforme descrito na figura 6:

$$
E=e_{01}-e_{03}
$$

As diferentes definições de eficiência da turbina são dadas pelo ponto de referência para as pressões. As condições de entrada são comumente referidas à pressão total, enquanto que para as condições de saída a pressão total ou a pressão estática podem ser adotadas. Assim a eficiência estática refere-se à energia correspondente à expansão desde a pressão total de entrada até a pressão estática de saída, enquanto que a eficiência total refere-se à expansão da pressão total de entrada até a pressão total de saída. A diferença entre as definições de eficiência total e a eficiência estática, portanto, é a contabilização ou não da energia cinética residual disponível no exausto da máquina na energia ideal disponível para a turbina.

Neste trabalho será adotada a referência estática, sendo a energia disponível para expansão do fluido dada pela expressão seguinte, válida para gás ideal:

$$
E_{i s}=\frac{k^{*}}{k^{*}-1} R T_{01}\left[1-\left(\frac{p_{3}}{p_{01}}\right)^{\frac{k^{*}-1}{k^{*}}}\right]
$$


Esta escolha se justifica pelo fato de se considerar a turbina de estágio único, onde a energia cinética no exausto não será utilizada em um estágio subsequente ou sequer recuperada por um difusor. Assim sendo a energia específica $E_{i s}$ fornecida ao equipamento é avaliada entre a pressão total de admissão e a pressão estática no exausto, conforme exposto na equação (2.3).

Uma parcela da energia total é convertida em energia cinética através da expansão no rotor, conforme a expressão abaixo:

$$
E_{i s-R}=\frac{k^{*}}{k^{*}-1} R T_{2}\left[1-\left(\frac{p_{3}}{p_{2}}\right)^{\frac{k^{*}-1}{k^{*}}}\right]
$$

Neste ponto é introduzida a velocidade de disparo $c_{0}$ ("spouting velocity"), definida como a velocidade do jato teoricamente obtida a partir da expansão isentrópica desde a pressão total na admissão até a pressão estática na saída, conforme a seguinte expressão:

$$
c_{0}=\sqrt{2 E_{i s}}
$$




\subsubsection{Conceito de Similaridade}

Considerações de similaridade são tipicamente empregadas em problemas de escoamento de fluidos de forma a reduzir o número de variáveis envolvidas. Os parâmetros adimensionais oferecem um método exato para reconhecer características importantes de serviço e de geometria em uma turbina [22]. O resultado destas considerações é que máquinas que são geometricamente similares, que possuem triângulos de velocidades similares e que operam com fluidos que têm a mesma natureza termodinâmica terão as mesmas características fluidodinâmicas e, portanto, apresentarão a mesma eficiência.

A derivação formal do conceito é baseada em argumentos de análise dimensional, concluindo-se que a eficiência da máquina depende de cinco parâmetros de similaridade adimensionais e independentes, a saber, o número de Reynolds, o número de Laval, a razão de calores específicos ou expoente isentrópico, o grau de reação do estágio, a velocidade específica e o diâmetro específico, conforme a expressão abaixo:

$$
\eta=f\left(\operatorname{Re}_{M}, L a_{M}, k, \rho, N_{s}, D_{s}\right)
$$

O grau de reação isentrópico do estágio $\rho$ é definido pela fração da energia correspondente à expansão no rotor em relação à energia total disponível.

$$
\rho=\frac{E_{i s-R}}{E_{i s}}
$$

O número de Reynolds da máquina $R e_{M}$, que representa a relação entre as forças de inércia e as forças viscosas no escoamento, é definido com base na velocidade periférica $u_{t}$ e o diâmetro $D$ referentes ao topo das palhetas, conforme a seguinte expressão:

$$
\operatorname{Re}_{M}=\frac{\gamma_{3} u_{t} D}{\varpi_{3}}
$$

O número de Laval da máquina $L a_{M}$ é dado conforme a seguinte expressão, válida para gás ideal. Seu significado está relacionado aos efeitos da 
compressibilidade do meio, sendo definido como a razão entre a velocidade periférica no topo das palhetas $u_{t}$ e a velocidade crítica (velocidade do escoamento sônico obtido de uma expansão isentrópica a partir de uma temperatura de estagnação $\left.T_{01}\right)$ :

$$
L a_{M}=\frac{u_{t}}{\sqrt{\frac{2 k^{*}}{k^{*}+1} R T_{01}}}
$$

A velocidade específica é o parâmetro que indica as condições de serviço nas quais a turbina deverá operar, sendo definida por:

$$
N_{s}=\frac{\Omega Q_{3}^{1 / 2}}{E_{i s}^{3 / 4}}
$$

E o diâmetro específico é o adimensional que introduz a dimensão física da turbina, é definido por:

$$
D_{s}=\frac{D E_{i s}^{1 / 4}}{Q_{3}^{1 / 2}}
$$

Sendo $\Omega$ é a velocidade angular do rotor, $D$ o diâmetro no topo das palhetas e $E_{i s}$ a energia específica ideal disponível para expansão. No caso de turbinas a vazão volumétrica $Q_{3}$ utilizada refere-se à saída do rotor, por ser mais representativa da sua geometria. 


\subsection{Diagrama de Velocidades}

O diagrama de velocidades contém a informação sobre os vetores velocidade em seções situadas a montante e a jusante de cada fileira de palhetas da turbina, conforme ilustrado na figura 10. Ao calcular os diagramas de velocidade, a variação circunferencial no escoamento não é considerada, sendo os vetores velocidade representativos de uma média circunferencial do escoamento, ou seja, em condições de escoamento uniforme, obtida após a mistura da corrente livre com as porções de baixa energia originadas, por exemplo, a partir do contato com as superfícies. A velocidade periférica da palheta é denominada $u$, as velocidades do fluxo no referencial absoluto são denominadas $c$ e as velocidades do fluxo no referencial rotativo são denominadas $w$. Os ângulos das velocidades absolutas e relativas em relação à direção tangencial são denominados $\alpha$ e $\beta$, respectivamente.

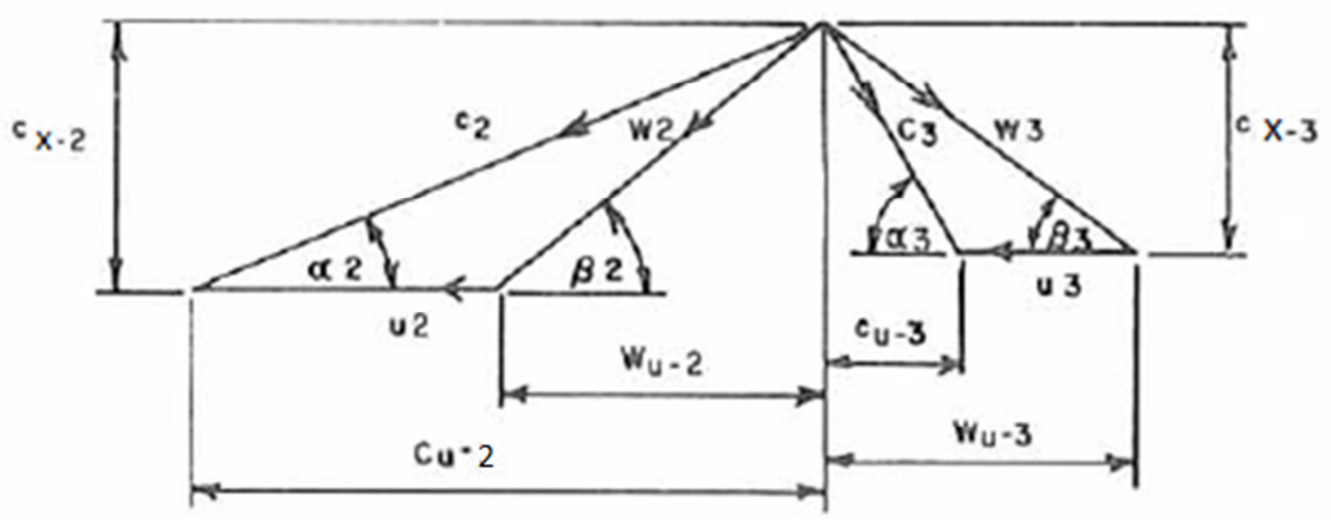

Figura 10 - Diagrama de velocidades do estágio de turbina axial [22].

O diagrama é calculado para uma dada posição radial do escoamento de forma a representar as condições médias encontradas ao longo da altura da palheta. Para uma palheta com uma relação $h / D$ relativamente baixa (menor que 0,08) esta premissa será razoável, sendo usual adotar como diâmetro característico o diâmetro médio. Uma consideração mais correta será calcular o diagrama de velocidades em um diâmetro característico $D_{M}$ definido de modo a dividir em duas partes iguais a área da seção axial:

$$
D_{M}=D \sqrt{1-2 \frac{h}{D}+2\left(\frac{h}{D}\right)^{2}}
$$




\subsubsection{Relações Cinemáticas e Eficiência}

Neste trabalho será considerado que o diâmetro característico é constante ao longo do estágio, ou seja, $u_{2}=u_{3}$, sendo então a velocidade periférica da palheta denominada $u$. Um parâmetro característico do diagrama de velocidades é a razão de velocidades $u / c_{0}$ definida pela razão entre a velocidade da roda e velocidade de disparo, cuja relação com os parâmetros adimensionais $N_{s}$ e $D_{s}$ é dada a seguir:

$$
\frac{u}{c_{0}}=\frac{N_{s} D_{s}}{2 \sqrt{2}} \sqrt{1-2 \frac{h}{D}+2\left(\frac{h}{D}\right)^{2}}
$$

A energia cinética a jusante de cada uma das grades da turbina é determinada a partir da energia cinética a montante, da parcela de energia cinética convertida a partir da expansão e pelas perdas no escoamento. As relações cinemáticas são dadas por Baljé [22] a partir da utilização deste conceito. As perdas do escoamento são retratadas pelos coeficientes de velocidade do rotor e dos bocais, que representam a relação entre as respectivas velocidades de saída real e ideal. Assim sendo a velocidade de saída dos bocais $c_{2}$ é dada por:

$$
\frac{c_{2}}{c_{0}}=\psi_{N} \sqrt{(1-\rho)}
$$

O vetor velocidade na entrada no rotor observado pelo referencial girante será determinado pela diferença vetorial entre a velocidade de saída do bocal e a velocidade periférica da roda, assim a velocidade relativa de aproximação ao rotor é dada por:

$$
\frac{w_{2}}{c_{0}}=\sqrt{\left(c_{2} / c_{0}\right)^{2}+\left(u / c_{0}\right)^{2}-2\left(c_{2} / c_{0}\right)\left(u / c_{0}\right) \cos \alpha_{2}}
$$

Enquanto que a velocidade relativa de saída do rotor é dada por:

$$
\frac{w_{3}}{c_{0}}=\psi_{R} \sqrt{\left(w_{2} / c_{0}\right)^{2}+f_{c} \rho}
$$

O coeficiente $f_{c}$ foi introduzido para considerar o efeito da compressibilidade do meio sobre o salto de entalpia disponível para o rotor, conforme mostrado na 
figura 12. O ângulo de entrada do escoamento relativo ao rotor é determinado conforme a expressão seguinte:

$$
\operatorname{ctg} \beta_{2}=\operatorname{ctg} \alpha_{2}-\frac{u / c_{0}}{\left(c_{2} / c_{0}\right) \operatorname{sen} \alpha_{2}}
$$

A fração de admissão $\varepsilon$ será obtida a partir do ângulo de saída do escoamento relativo ao rotor e o diâmetro específico $D_{s}$ :

$$
\varepsilon=\frac{1}{\pi \sqrt{2}\left(w_{3} / c_{0}\right) \operatorname{sen} \beta_{3} D_{s}^{2}(h / D)(1-(h / D))}
$$

O fator de aceleração axial no rotor $K_{t}$, definido como a relação entre as componentes axiais das velocidades de saída e entrada, estará relacionado com a relação das áreas transversais e dos volumes específicos por:

$$
K_{t}=\frac{c_{x 3}}{c_{x 2}}=\frac{w_{3} \operatorname{sen} \beta_{3}}{c_{2} \operatorname{sen} \alpha_{2}}=\frac{A_{x 2} / A_{x 3}}{v_{2} / v_{3}}
$$

Conhecendo-se a geometria da palheta e a relação de volumes através do rotor, o ângulo de saída do escoamento relativo será obtido da equação (2.19). Para um meio incompressível é usual adotar uma geometria sem variação de altura, que resultará em velocidade axial constante ao longo da palheta. Quando a compressibilidade do meio torna-se relevante, poderá ser interessante adotar uma geometria de palheta alargada ou com sobreposição de modo que sua altura na saída seja maior que a altura na entrada. Neste caso o fator de aceleração $K_{t}$ não será unitário e o projeto terá um grau de liberdade adicional para que o ângulo de saída do rotor $\beta_{3}$ seja ajustado de forma a reduzir a energia cinética residual, esta última obtida a partir de:

$$
\left(\frac{c_{3}}{c_{0}}\right)^{2}=\left(\frac{u}{c_{0}}\right)^{2}+\left(\frac{w_{3}}{c_{0}}\right)^{2}-2\left(\frac{w_{3}}{c_{0}}\right)\left(\frac{u}{c_{0}}\right) \cos \beta_{3}
$$

E o ângulo da velocidade absoluta de saída do rotor por:

$$
\operatorname{sen} \alpha_{3}=\frac{\left(w_{3} / c_{0}\right)}{\left(c_{3} / c_{0}\right)} \operatorname{sen} \beta_{3}
$$


Por fim a energia específica transferida à palheta do rotor $E$ será obtida a partir da variação da quantidade de movimento tangencial do fluido:

$E=u\left(c_{u 2}-c_{u 3}\right)$

E consequentemente a eficiência estática do estágio será dada por:

$$
\eta_{T-S}=\frac{E}{c_{0}^{2} / 2}
$$

Enquanto que a eficiência total do estágio pode ser obtida subtraindo-se da energia ideal a parcela correspondente à energia cinética na saída:

$$
\eta_{T-T}=\frac{E}{\left(c_{0}^{2} / 2-c_{3}^{2} / 2\right)}
$$

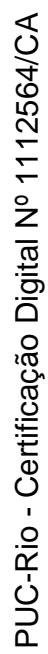

Explicitando-se a eficiência estática em termos dos parâmetros do diagrama de velocidades é obtida a expressão abaixo:

$$
\eta_{T-S}=2\left(\frac{u}{c_{0}}\right)\left[\frac{c_{2}}{c_{0}} \cos \alpha_{2}+\frac{w_{3}}{c_{0}} \cos \beta_{3}-\left(\frac{u}{c_{0}}\right)\right]
$$

Para uma solidez previamente determinada, o número de palhetas do bocal e do rotor será determinado a partir da relação corda diâmetro, conforme as seguintes expressões:

$$
\begin{aligned}
& Z_{N}=\frac{\varepsilon \pi \sqrt{1-2\left(\frac{h}{D}\right)+2\left(\frac{h}{D}\right)^{2}}}{\frac{C_{N}}{D}\left(\frac{t}{C}\right)_{N}} \\
& Z_{R}=\frac{\pi \sqrt{1-2\left(\frac{h}{D}\right)+2\left(\frac{h}{D}\right)^{2}}}{\frac{C_{R}}{D}\left(\frac{t}{C}\right)_{R}}
\end{aligned}
$$


Os números de Reynolds locais para o bocal $R e_{N}$ e para o rotor $R e_{R}$ com base no comprimento da linha média de curvatura da palheta $l$ são dados respectivamente por:

$$
\begin{aligned}
\operatorname{Re}_{N} & =\operatorname{Re}_{M} \frac{C_{N}}{D}\left(\frac{l}{C}\right)_{N} \frac{c_{2} / c_{0}}{u / c_{0}} \sqrt{1-2\left(\frac{h}{D}\right)+2\left(\frac{h}{D}\right)^{2}} \frac{\varpi_{3} \gamma_{2}}{\varpi_{2} \gamma_{3}} \\
\operatorname{Re}_{R} & =\operatorname{Re}_{M} \frac{C_{R}}{D}\left(\frac{l}{C}\right)_{R} \frac{w_{3} / c_{0}}{u / c_{0}} \sqrt{1-2\left(\frac{h}{D}\right)+2\left(\frac{h}{D}\right)^{2}}
\end{aligned}
$$

Os números de Reynolds locais são relacionados ao número de Reynolds da máquina $R e_{M}$, calculado com base na velocidade periférica e o diâmetro relativos ao topo das palhetas, conforme a seguinte expressão:

$$
\operatorname{Re}_{M}=\frac{\gamma_{3} u D}{\varpi_{3} \sqrt{1-2\left(\frac{h}{D}\right)+2\left(\frac{h}{D}\right)^{2}}}
$$




\subsubsection{Variação Radial}

No caso de palhetas de dimensões expressivas o diagrama de velocidades deverá ser verificado para diversas posições radiais além do diâmetro característico, minimamente para as regiões terminais: a base e o topo da palheta. A variação radial nos diagramas ocorre em virtude da variação radial da velocidade periférica da palheta bem como no balanço de forças que deve haver no escoamento. Na presença de uma componente tangencial da velocidade, o fluxo circunferencial resultante terá que ser mantido por uma força de pressão. Esta força de pressão irá equilibrar a força centrífuga e manter o escoamento do fluido ao longo da sua trajetória curvilínea. Uma análise do escoamento tridimensional para condições de escoamento incompressível é dada por Glassman [23]. Para escoamento axial ou quase axial a curvatura e o ângulo de inclinação da linha de corrente meridional são muito pequenos, podendo ser desprezados frente à força centrífuga, o que resulta na equação simplificada de equilíbrio radial:

$$
\frac{1}{\gamma} \frac{d p}{d r}=\frac{c_{u}^{2}}{r}
$$

Acrescentando-se as premissas de que entalpia total e a entropia não variam ao longo da direção radial, uma equação para a distribuição das componentes tangenciais e axiais da velocidade ao longo da posição radial é obtida:

$$
\frac{c_{u}^{2}}{r}+\frac{1}{2} \frac{d\left(c_{u}^{2}\right)}{d r}+\frac{1}{2} \frac{d\left(c_{x}^{2}\right)}{d r}=0
$$

Usualmente a distribuição da componente tangencial é especificada como uma função exponencial da razão entre o raio e o raio médio:

$$
\frac{c_{u}}{c_{u, \text { med }}}=\left(\frac{r}{r_{\text {med }}}\right)^{N}
$$

O que resulta numa distribuição para a componente axial dada por:

$$
\frac{c_{x}}{c_{x, \text { med }}}=\left\{1-\operatorname{ctg}^{2}\left(\alpha_{\text {med }}\right)\left(\frac{N+1}{N}\right)\left[\left(\frac{r}{r_{\text {med }}}\right)^{N}-1\right]\right\}^{1 / 2}
$$


Um caso de interesse não coberto pela equação anterior é a condição em que o ângulo $\alpha$ da velocidade absoluta é radialmente constante, o que resulta em:

$$
\frac{c_{u}}{c_{u, \text { med }}}=\frac{c_{x}}{c_{x, \text { med }}}=\left(\frac{r}{r_{\text {med }}}\right)^{-\cos ^{2} \alpha}
$$

A figura 11 mostra a distribuição radial das componentes da velocidade absoluta e seu ângulo para $\alpha_{m e d}=30^{\circ}$. São mostradas curvas para diferentes valores do expoente de distribuição de velocidade tangencial $N$ e também para o caso $\alpha=$ constante. Pode ser verificado que conforme $N$ se afasta do valor -1 as variações radiais da velocidade axial e do ângulo de fluxo se tornam mais pronunciadas. Alguns valores do expoente $N$ não podem sequer ser utilizados para palhetas cuja relação $h / D$ é elevada. Conforme o valor adotado para o expoente $N$ o projeto tem a seguinte denominação:

$$
\begin{aligned}
& \mathrm{N}=-1 \text { - vórtice livre; } \\
& \mathrm{N}=-2 \text { - super vórtice; } \\
& \mathrm{N}=0 \text { - vórtice constante; } \\
& \mathrm{N}=1 \text { - fluxo circular. }
\end{aligned}
$$

Tendo em vista os aspectos discutidos o projeto mais usual é o vórtice livre. Quando esta condição é especificada simultaneamente na saída das palhetas estacionária e rotativa não há variação radial do trabalho específico e da velocidade axial. Desta forma, no projeto vórtice livre o trabalho específico e a vazão mássica obtidos do diagrama de velocidades da seção média são válidos para representar todo o escoamento através das palhetas, sendo esta simplicidade a razão principal para o seu largo uso. O projeto vórtice livre possui, entretanto, alguns aspectos desfavoráveis como a demanda por uma palheta torcida para o rotor, o baixo grau reação na base da palheta, que pode levar a uma baixa eficiência, e um alto grau de reação no topo da palheta, que pode resultar em vazamento excessivo através da folga com as partes estacionárias. 

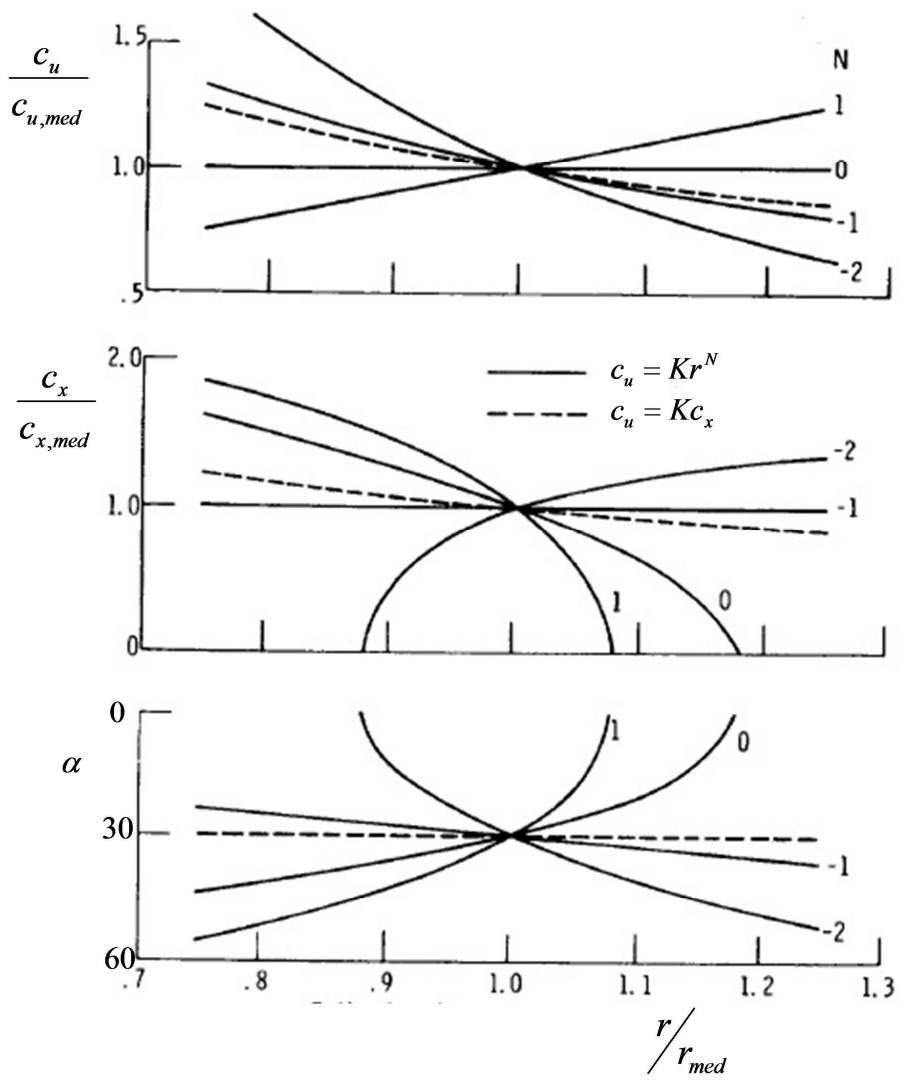

Figura 11 - Distribuição radial da velocidade e ângulo de fluxo para $\alpha_{\text {med }}=30^{\circ}[23]$.

Quando algum dos aspectos desfavoráveis acima mencionados torna-se proibitivo, pode-se buscar alternativa nos projetos vórtice constante $(N=0)$ ou fluxo circular $(N=1)$ que aliviam a torção da palheta do rotor e a baixa reação na base da palheta. Tais soluções, no entanto, em virtude das maiores variações radiais, têm limitações para aplicação em palhetas de grande relação $h / D$.

Um procedimento de projeto que resulta em ângulos de entrada e saída do rotor radialmente constantes, ou seja, onde a palheta rotativa não apresenta torção, é apresentado em [24]. Este projeto elimina totalmente a torção na palheta do rotor, o qual tem a fabricação facilitada, além do que há uma melhoria no grau de reação na base. Em contrapartida, as variações radiais da velocidade axial do bocal aumentam em relação ao projeto de vórtice livre, demandando uma maior torção na palheta estacionária. 


\subsubsection{Evolução Aero-Termodinâmica}

Conforme discutido na seção 2.2.1, o diagrama de velocidades será influenciado pela variação do volume específico experimentada no escoamento através das grades estacionárias e rotativas da turbina. A equação (2.19) em particular mostra o impacto da relação de volumes sobre o fator de aceleração axial $K_{t}$. Em se tratando de um meio compressível, portanto, a relação de volumes terá que ser quantificada de modo a permitir o cálculo dos diagramas de velocidades. Adicionalmente será necessária a avaliação dos números de Mach do escoamento absoluto e relativo, o que demandará o conhecimento do estado termodinâmico nas estações da turbina. As condições de pressão e temperatura nas estações internas da turbina, por sua vez, estarão atreladas às velocidades de fluxo desenvolvidas pelo processo de expansão.

O processo típico de expansão no estágio axial é mostrado na figura 12, onde a evolução aero-termodinâmica do fluido é indicada no diagrama entalpia entropia. O nível de entalpia $e_{0, \text { rel }}$ está relacionado à condição de estagnação referente ao escoamento relativo no rotor. Os subscritos $s$ e $s s$ referem-se a processos isentrópicos utilizados como referência para definição de perdas e eficiências.

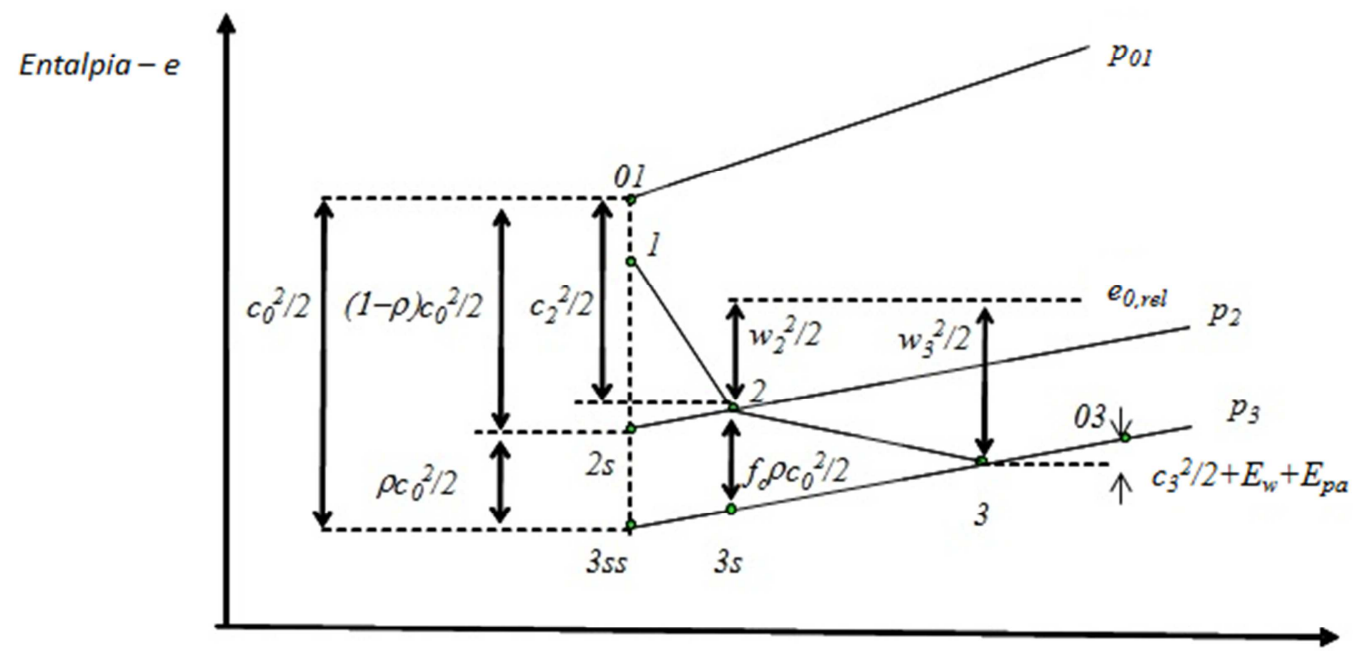

Entropia -s

Figura 12 - Diagrama entalpia - entropia para um estágio de turbina axial. 
Na saída da turbina a velocidade absoluta $c_{3}$ é comparativamente pequena, sendo a energia cinética residual considerada perdida devido à ausência de um difusor. Somando-se a esta, as perdas por atrito na roda e por admissão parcial totalizam a diferença de entalpia entre os pontos 3 e 03 .

As relações de entalpia mostradas a seguir relacionam a conversão de energia térmica em energia cinética entre duas estações da turbina. Assim, para as entalpias dos pontos $2,2 s$ e $3 s s$ :

$$
\begin{aligned}
& e_{3 s s}=e_{01}-\frac{c_{0}^{2}}{2} \\
& e_{2}=e_{01}-\frac{c_{0}^{2}}{2}\left(\frac{c_{2}}{c_{0}}\right)^{2} \\
& e_{2 s}=e_{01}-(1-\rho) \frac{c_{0}^{2}}{2}
\end{aligned}
$$

A entalpia do ponto de estagnação referente ao escoamento relativo no rotor será dada por:

$$
e_{0, r e l}=e_{2}+\frac{c_{0}^{2}}{2}\left(\frac{w_{2}}{c_{0}}\right)^{2}
$$

As entalpias para o pontos 3 e 03 serão dadas por:

$$
\begin{aligned}
& e_{3}=e_{2}-\frac{c_{0}^{2}}{2}\left[\left(\frac{w_{3}}{c_{0}}\right)^{2}-\left(\frac{w_{2}}{c_{0}}\right)^{2}\right] \\
& e_{03}=e_{3}+\frac{c_{0}^{2}}{2}\left[\left(\frac{c_{3}}{c_{0}}\right)^{2}+\Delta \eta_{w}+\Delta \eta_{p a}\right]
\end{aligned}
$$




\subsection{Estimativa de Perdas em Turbinas Axiais}

Qualquer estudo de otimização de projeto de turbinas depende da contabilização de perdas no escoamento. Nos tempos atuais, apesar da possibilidade de se calcular estas perdas através dos modernos recursos de dinâmica de fluidos computacional, que lida com escoamento viscoso tridimensional, ainda persiste uma necessidade estável para uma análise preliminar [25]. Nesta fase do projeto, a análise do escoamento na linha de corrente média permite uma avaliação rápida das perdas no escoamento, do desempenho e da geometria básica da turbina. Adicionalmente, em turbinas de pequena capacidade, cujas palhetas possuem uma altura comparativamente pequena em relação ao diâmetro, os efeitos tridimensionais são pouco relevantes e o escoamento aproxima-se bastante deste modelo mais simplificado. A análise resultante do projeto preliminar fornece também uma determinação inicial da geometria do estágio, que pode ser usada como ponto de partida para processos de otimização de perfil de palhetas modernamente empregados.

As perdas no escoamento podem ser definidas de diversas maneiras. O coeficiente de perda de energia cinética $\xi$ referido à velocidade ideal de saída da grade é definido por:

$$
\xi \frac{V_{2, i s}^{2}}{2}=\frac{V_{2, i s}^{2}}{2}-\frac{V_{2}^{2}}{2}
$$

Outras definições alternativas são o coeficiente de perda de energia cinética $\zeta$ referido à velocidade real de saída da grade, dado por:

$$
\zeta \frac{V_{2}^{2}}{2}=\frac{V_{2, i s}^{2}}{2}-\frac{V_{2}^{2}}{2}
$$

Ou ainda o coeficiente de perda de pressão total $y$, definido como:

$$
y=\frac{p_{01}-p_{02}}{p_{02}-p_{2}}
$$


Sendo as estações a montante e a jusante da grade denominadas respectivamente por 1 e 2 .

Os dois coeficientes de perda de energia cinética mencionados estão relacionados conforme a seguinte expressão:

$$
\xi=\frac{\zeta}{1+\zeta}
$$

A relação entre o coeficiente de perda de pressão total $y$ e o coeficiente de perda de energia cinética $\xi$ referido à velocidade ideal de saída da grade será evidentemente influenciada pela compressibilidade do escoamento. Em condições incompressíveis será óbvio que $y=\zeta=\xi /(1-\xi)$, caso contrário a relação será dada pela expressão abaixo, válida para gases ideais:

$$
\xi=\frac{\left(p_{01} / p_{02}\right)^{\frac{k-1}{k}}-1}{\left(p_{01} / p_{2}\right)^{\frac{k-1}{k}}-1}=\frac{\left(\frac{1+y}{1+y\left(p_{2} / p_{01}\right)}\right)^{\frac{k-1}{k}}-1}{\left(p_{2} / p_{01}\right)^{\frac{k-1}{k}}-1}
$$

Por fim, o coeficiente de velocidade $\Psi$ é definido por:

$$
\Psi=\frac{V_{2}}{V_{2 i s}}
$$

Em regime de escoamento bidimensional, onde a variação radial não é considerada, o coeficiente de velocidade $\Psi$ está relacionado com o coeficiente de perda total de energia cinética de acordo com a seguinte expressão:

$$
\Psi=\sqrt{1-\xi_{t o t}}=\sqrt{\frac{1}{1+\zeta_{t o t}}}
$$




\subsubsection{Campo de Escoamento e Mecanismos de Perda}

O escoamento através de um canal entre palhetas de uma turbina é muito complexo, tanto em termos da descrição do domínio do fluxo como em termos dos processos físicos presentes, conforme mostra a figura 13. Em turbinas axiais o escoamento é sempre tri-dimensional, viscoso e transiente, podendo ser incompressível ou compressível, com regimes subsônicos, transônicos e supersônicos, que podem estar presentes simultaneamente em diferentes regiões [26]. O escoamento viscoso geralmente tem uma alta turbulência na corrente livre que pode conter múltiplas escalas de tempo e comprimento. Regiões de fluxo laminar, transicional e turbulento, separação e perfis viscosos plenamente desenvolvidos podem todas estar simultaneamente presentes devido à multiplicidade de escalas de comprimento introduzidas pela complicada geometria do campo de escoamento. As regiões turbulentas e viscosas apresentam tensões complexas devido à presença da tridimensionalidade, grandes gradientes de pressão em todas as direções, rotação, curvatura, ondas de choque e interação entre camadas limite e esteiras.

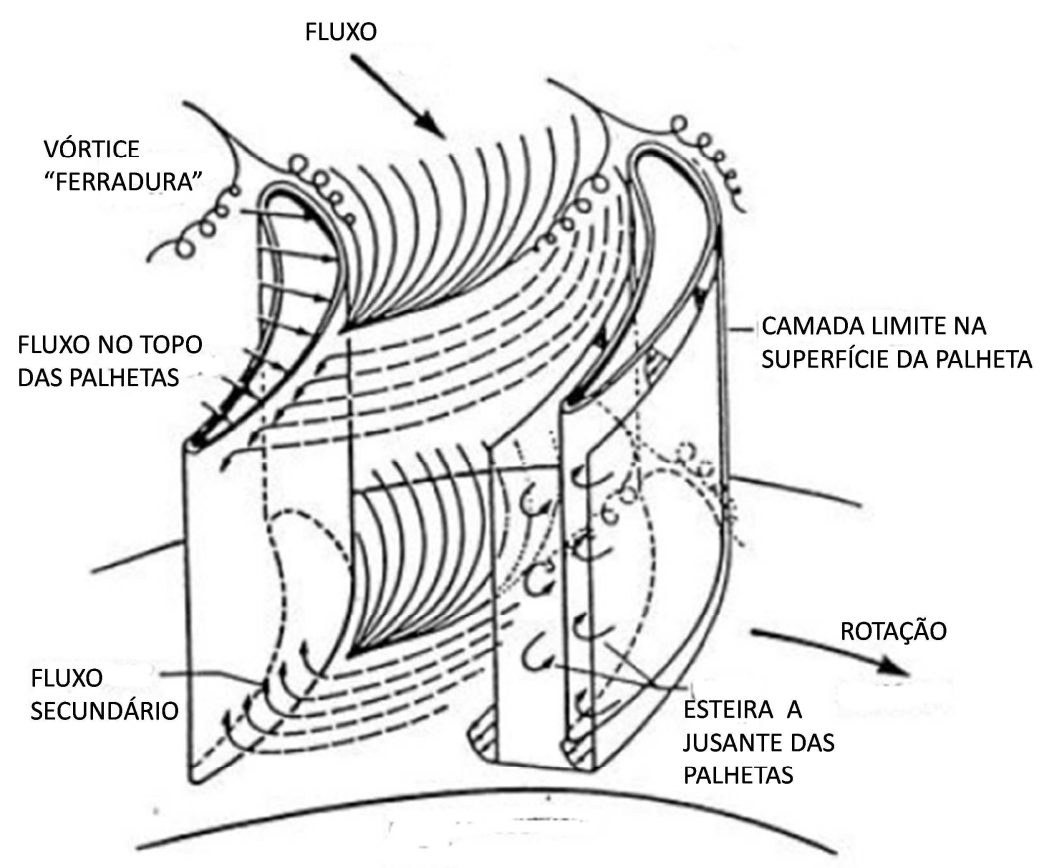

Figura 13 - Estrutura do escoamento através da passagem entre palhetas da turbina [26]. 


\subsubsection{Perdas no Perfil}

A perda por atrito nas superfícies do perfil é classicamente calculada a partir da determinação da distribuição de pressões e velocidades ao redor das palhetas por argumentos de escoamento potencial. De posse desta informação é possível obter as espessuras de deslocamento e quantidade de movimento da camada limite de cada superfície, que são medidas da perda no perfil. Para aplicar este procedimento, entretanto, é necessário conhecer previamente a geometria do perfil em detalhes, caracterizada pela forma da linha média e a distribuição de espessura.

$\mathrm{Na}$ fase de projeto preliminar, onde as informações citadas ainda não estão disponíveis, será necessário adotar uma abordagem alternativa com base nos parâmetros que governam o crescimento da camada limite, principalmente o gradiente de pressão. O escoamento será caracterizado simplesmente pelos ângulos do fluxo a montante e a jusante da grade, pelo fator de aceleração axial $K_{t}$ e pela solidez da grade $\sigma$, definida como a relação entre a corda e o espaçamento das palhetas. Baljé e Binsley [27] aplicaram a equação de Truckenbrodt [28] para a espessura de quantidade de movimento da camada limite incompressível e turbulenta com gradiente de pressão como ponto de partida para avaliar as perdas do perfil, conforme a equação abaixo:

$$
\vartheta_{2}\left(\frac{\gamma_{2} V_{2} \vartheta_{2}}{\mu_{2}}\right)^{\frac{1}{n}}=V_{2}^{-3-\frac{2}{n}} A_{b l} \int_{x=0}^{x=l} V^{3+\frac{2}{n}} d x
$$

A integração da equação acima supondo uma variação linear da velocidade da corrente livre nas superfícies entre os valores de entrada e saída da grade resulta na seguinte expressão:

$$
\frac{\vartheta}{l}=\frac{\left(\frac{A_{b l}}{4+2 / n}\right)^{\frac{n}{n+1}}}{\left(\operatorname{Re}_{l, 2}\right)^{1 / n+1}}\left[\frac{1-\left(\frac{1}{\mu}\right)^{4+2 / n}}{1-\frac{1}{\mu}}\right]^{\frac{n}{n+1}}
$$


Sendo a taxa de aceleração da grade $\mu=V_{2} / V_{1}$ e as constantes $A_{b l}=0,016$ e $n=4$ válidas para o regime turbulento. Baljé conclui então pela expressão abaixo, válida para um número de Reynolds de 200000, sendo o valor 0,0021 atribuído para a constante a partir de ajustes a resultados experimentais:

$$
\frac{\vartheta}{l}=0,0021\left[\frac{1-\left(\frac{1}{\mu}\right)^{4,5}}{1-\frac{1}{\mu}}\right]^{0,8}
$$

As premissas que levaram a esta expressão possivelmente representem o que ocorre em uma grade de alta solidez, uma vez que não leva em conta a diferença de velocidades entre as superfícies do perfil e a consequente difusão. Os resultados assim obtidos para a espessura de quantidade de movimento tendem a ser conservativos, sendo inclusive denominados pelo autor como "perda mínima".

O crescimento da espessura de quantidade de movimento na camada limite sob gradiente de pressão é dado pela equação integral de Von Karman:

$$
\frac{d \vartheta}{d x}=\frac{\tau_{s}}{W^{2}}-\left(\frac{2 \vartheta}{V}+\frac{\delta}{V}\right) \frac{d V}{d x}
$$

Sendo $\vartheta$ a espessura da quantidade de movimento, $\delta$ a espessura de deslocamento, $\tau_{s}$ a tensão cisalhante na parede e $V$ a velocidade da corrente livre. A partir daí justifica-se que o crescimento da espessura de quantidade de movimento seja controlado por um fator de difusão $D$ introduzido por Lieblein et al. [29]:

$$
D=-\frac{\vartheta}{V} \frac{d V}{d x}
$$

Este parâmetro é particularmente significante próximo à condição de separação, quando a parcela da tensão cisalhante torna-se pequena e o fator de forma $H$, razão entre $\vartheta$ e $\delta$, assume um valor constante. 
Em grades de palhetas de turbinas, a aceleração e a deflexão simultâneas do escoamento fazem com que a velocidade da corrente livre na vizinhança da superfície do perfil seja diferente da velocidade média no canal, cujos efeitos são discutidos em termos da teoria das grades de palhetas. Para obtenção de resultados aplicáveis para bombas, compressores e turbinas, é conveniente a introdução dos ângulos da grade $\lambda$, conforme ilustrado na figura 14. Estas quantidades são diretamente inter-relacionadas aos ângulos $\alpha$ e $\beta$ usados para definir os vetores velocidade absoluta e relativa, respectivamente. Ou seja, para o bocal $\lambda_{1}=\alpha_{1} \mathrm{e}$ $\lambda_{2}=\alpha_{2}$, enquanto que para o rotor $\lambda_{1}=180-\beta_{2}$ e $\lambda_{2}=\beta_{3}$.

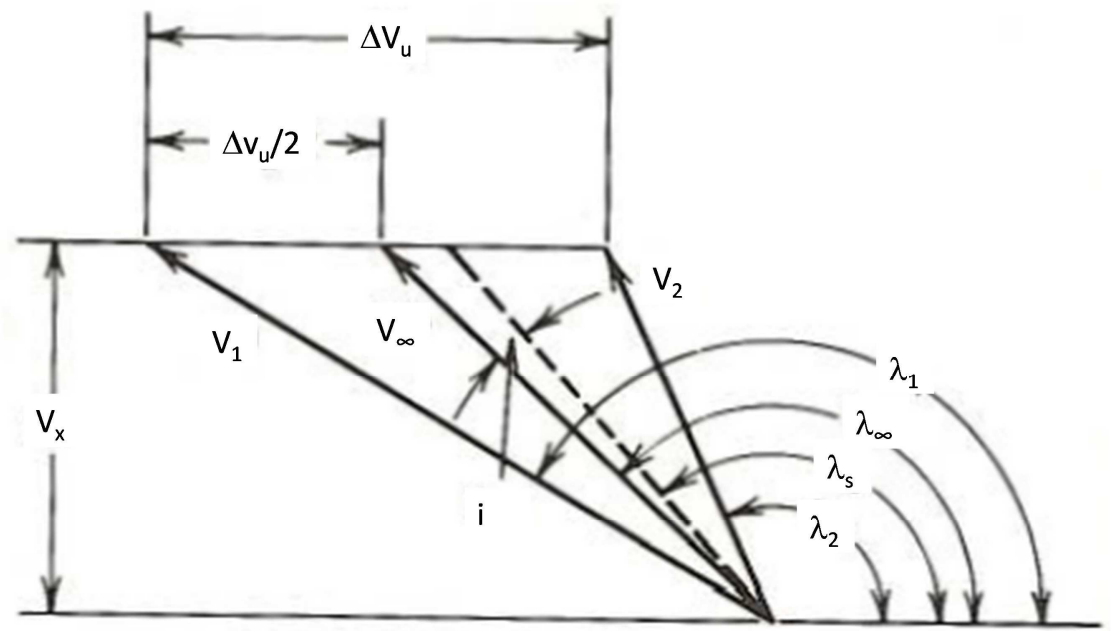

Figura 14 - Vetores velocidade e notações da grade [27].

É importante discutir o efeito da razão espaçamento - corda em uma fileira de palhetas de turbina, uma vez que este é um fator que influencia fortemente sua eficiência. Se o espaçamento é pequeno, o fluido tende a receber o máximo direcionamento das palhetas, mas a área de atrito será muito grande. Por outro lado, se as mesmas palhetas estão agora bem mais espaçadas a área de atrito será pequena, mas por conta do direcionamento deficiente as perdas resultantes da separação do escoamento serão grandes. 
Considerando o escoamento através da passagem entre duas palhetas com altura unitária, a força tangencial exercida pelo fluido ao escoar através da palheta será dada pela seguinte expressão:

$$
F_{u}=t \gamma_{2} V_{x 2}\left(V_{u 1}-V_{u 2}\right)
$$

Esta força tangencial exercida pelo fluido deverá ser igual à força devida à distribuição de pressão estática ao redor da palheta. A figura 15 mostra uma distribuição típica de pressão nas faces de sucção e pressão em função da distância axial. A área entre as duas curvas representa a força total atuando sobre o escoamento na direção tangencial, portanto:

$$
F_{u}=C_{x} \int_{0}^{1}\left(p_{s}-p_{p}\right) d\left(x / C_{x}\right)
$$
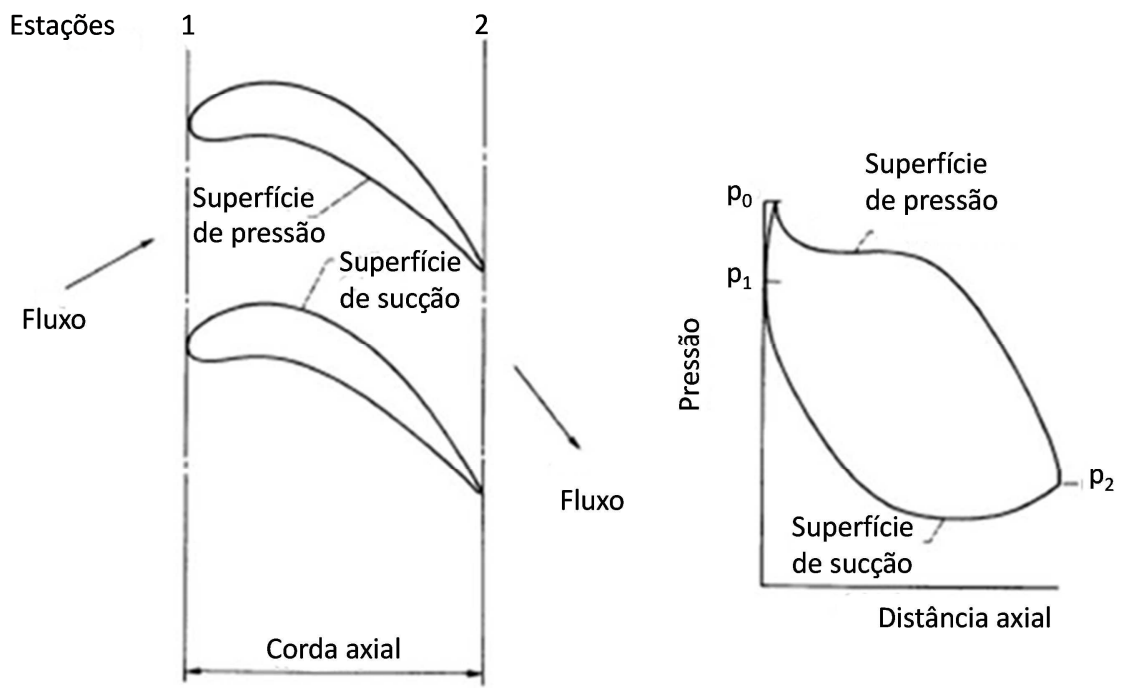

Figura 15 - Distribuição de pressão típica nas faces de pressão e de sucção da palheta [23].

Como a força tangencial é a mesma nas equações (2.54) e (2.55) pode ser eliminada, chegando-se à seguinte relação para a solidez axial:

$$
\sigma_{x}=\frac{\gamma_{2} V_{x 2}\left(V_{u 1}-V_{u 2}\right)}{\int_{0}^{1}\left(p_{s}-p_{p}\right) d\left(x / C_{x}\right)}
$$


Estas considerações levaram Zweiffel a formular um critério para estabelecer o valor ótimo para a solidez de uma grade de palhetas com grande deflexão angular [30]. O argumento de Zweiffel é que a distribuição de velocidade ao redor da grade pode ser aproximada por um perfil retangular onde a pressão estática na superfície de pressão é constante e igual à pressão total na entrada da palheta e a pressão estática na superfície de sucção é constante e igual à pressão estática na saída da palheta, levando à definição de um coeficiente de carga aerodinâmica:

$$
\Psi_{Z}=\frac{\int_{0}^{1}\left(p_{s}-p_{p}\right) d\left(x / C_{x}\right)}{p_{01}-p_{2}}
$$

De maneira similar pode ser obtido um segundo coeficiente aerodinâmico, sendo que agora o valor mínimo da pressão estática na superfície de sucção é assumido como valor constante para a pressão nesta superfície, resultando em:

$$
\Psi=\frac{\int_{0}^{1}\left(p_{s}-p_{p}\right) d\left(x / C_{x}\right)}{p_{01}-p_{s, \min }}
$$

Considerando um escoamento sem perdas e incompressível, a equação de Bernoulli pode ser aplicada para transformar a diferença de pressão em energia cinética por unidade de volume, resultando na seguinte relação entre os coeficientes $\Psi$ e $\Psi_{Z}$ :

$$
\Psi_{Z}=\Psi D^{2}
$$

Sendo $D$ é um fator de difusão relativo à superfície de sucção dado por:

$$
D=\frac{V_{s, \max }}{V_{2}}
$$

É importante observar que o coeficiente aerodinâmico $\Psi$ deve ser sempre menor que o valor unitário, enquanto o coeficiente de Zweiffel $\Psi_{Z}$, por outro lado, pode exceder o valor unitário. $\mathrm{O}$ fator de difusão $D$ representa uma medida da desaceleração do escoamento na superfície de sucção. Esta desaceleração é 
indicativa da susceptibilidade da ocorrência de separação no escoamento sobre a superfície da palheta.

O coeficiente de carga aerodinâmica $\Psi_{Z}$, conforme definido por Zweiffel, fornece um critério para definição da solidez ótima a partir dos ângulos de entrada e saída da grade, uma vez que representa a razão entre os valores real e ideal para a carga tangencial real da palheta e deve assumir um valor constante de aproximadamente 0,8 para resultar em perda mínima:

$$
\Psi_{Z}=\frac{2 \operatorname{sen}^{2} \lambda_{2}}{\operatorname{sen} \lambda_{s}} \frac{t}{C}\left(\cot \lambda_{2}-\cot \lambda_{1}\right)
$$

Práticas usuais de projeto [23] recomendam um valor de 0,9 a 1,0 para o coeficiente $\Psi_{Z}$, ligeiramente maior que o valor originalmente proposto por Zweiffel. A equação acima mostra ainda que para um particular diagrama de velocidades, onde os ângulos de entrada e saída estão pré-determinados, qualquer um dos parâmetros de solidez $\sigma_{x} \Psi_{Z}$ ou $\sigma_{x} \Psi D^{2}$ será constante. Observando que o coeficiente aerodinâmico $\Psi$ não pode exceder o valor unitário e, sendo aproximadamente constante para o diagrama de velocidades selecionado, pode ser verificado que a redução da solidez resulta primariamente no aumento da difusão na superfície de sucção, e consequentemente, um maior coeficiente de atrito pode ser antecipado para este caso. 


\subsubsection{Perdas Secundárias}

As perdas secundárias podem ser atribuídas a dois diferentes mecanismos de escoamento. O primeiro é o crescimento da camada limite ao longo das paredes nas seções do topo e da base das palhetas (paredes terminais) em função do escoamento da entrada para a saída da grade. O segundo é um efeito do gradiente de pressão transversal, que tende a mover as partículas do fluido com baixa velocidade na camada limite das superfícies terminais através do canal a partir da superfície de pressão da palheta em direção à superfície de sucção da palheta adjacente [31]. O coeficiente de perda das paredes terminais é definido de tal modo que ele representa a diferença entre a perda total na grade e a perda do perfil, conforme indicado por evidências experimentais. Também são contabilizados efeitos decorrentes da mistura de escoamentos secundários ao escoamento principal e da formação de vórtices, incluindo a ingestão da camada limite da grade precedente. Uma vez que as perdas secundárias respondem por uma importante fração da perda total, um grande esforço é empreendido para sua quantificação, principalmente devido à complexidade do escoamento nos internos da turbina. Os efeitos da perda nas paredes terminais podem ser rateados assumindo que estas perdas estão igualmente distribuídas ao longo da altura da palheta. Este rateio será válido somente enquanto a altura das palhetas for grande o bastante para que as camadas limites das duas paredes terminais não se misturem. 


\subsubsection{Demais Fontes de Perdas}

\subsection{Folga no Topo}

Uma vez que é inevitável a presença de uma folga entre o conjunto rotativo e as partes estacionárias, uma parte do fluido vaza através do topo das palhetas, reduzindo o trabalho realizado pela máquina.

A perda por vazamento é afetada primeiramente pela natureza da geometria do topo da palheta, isto é, pela dimensão da folga radial, pelos recessos na carcaça e pela eventual presença de uma cinta no topo. Em palhetas não cintadas, o grau de reação afeta a perda por vazamento, uma vez que um maior diferencial de pressão causa um maior vazamento de fluido com alta energia cinética através da folga no topo, da face de pressão em direção à face de sucção da palheta. Adicionalmente ocorre um descarregamento aerodinâmico da palheta, uma vez que a deflexão do fluxo no topo é reduzida pela presença da folga. A introdução de um recesso na carcaça acima da roda, concomitantemente com o aumento da sua altura da palheta e a introdução de uma cinta no topo é um recurso muitas vezes utilizado para redução do vazamento.

Sumarizando, o vazamento através da folga de topo representa um problema de fluxo complicado, influenciado por vários fatores e não facilmente quantificado com precisão de maneira consistente. A folga de topo requerida para a turbina depende primariamente do diâmetro e a perda aumenta com o aumento da razão entre a folga e a altura da palheta. Para um dado diâmetro, portanto, a perda aumenta com a redução da razão $h / D$. Existe então uma dificuldade crescente para manter um valor reduzido para a relação folga altura da palheta conforme o porte da turbina, e portanto a altura da palheta se torna menor. 


\subsection{Atrito no Disco}

Outra fonte de perda que deve ser abordada é a perda por atrito na roda, que ocorre em virtude do atrito do fluido com a sua superfície e da circulação de fluido entre o disco rotativo e a carcaça estacionária. A fina camada de fluido adjacente ao disco é centrifugada em direção ao raio externo e retorna via parede estacionária para o raio interno, constituindo desta forma um efeito circulatório contínuo. Um coeficiente de torque pode ser estabelecido dependendo do regime de escoamento (laminar ou turbulento) e da folga (grande ou pequena) entre a roda e a carcaça. 


\subsection{Admissão Parcial}

O estágio axial de plena admissão é normalmente utilizado na maioria das aplicações. Algumas condições não usuais podem ocorrer para as quais o estágio de admissão parcial pode ser a melhor escolha. Quando a vazão volumétrica é muito pequena, o projeto de um estágio de admissão total resulta em uma altura da palheta extremamente pequena. Neste caso, as perdas de um estágio de admissão parcial com palhetas longas podem ser superadas pelas perdas por vazamento e baixo número de Reynolds de um estágio com admissão total. Adicionalmente o arranjo de admissão parcial permite a liberdade de um maior diâmetro e maiores valores para a relação de velocidades $u / c_{0}$.

Em um arranjo de admissão parcial ocorrem perdas devido ao enchimento e esvaziamento dos canais do rotor [32]. A natureza destas perdas é melhor compreendida observando-se a figura 16. Sob certas posições relativas entre a grade do bocal e a grade do rotor o fluxo na saída do arco de admissão irá expandir repentinamente no canal do rotor incorrendo em perdas por expansão súbita como, por exemplo, entre os pontos 1 e 2 . O valor médio da velocidade relativa de saída do rotor, portanto, será menor do que ocorreria em uma turbina de admissão total.

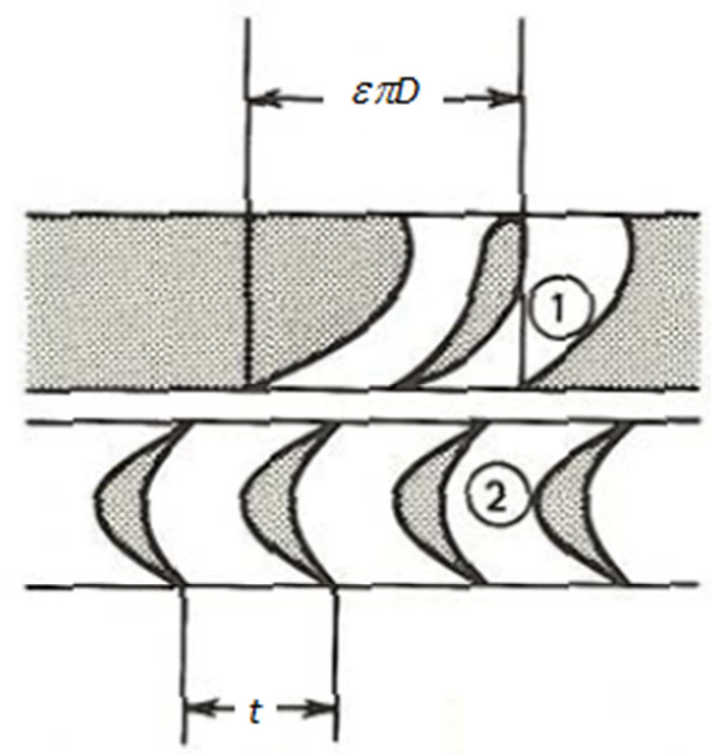

Figura 16 - Bocal e rotor em arranjo de admissão parcial [32]. 
Num arranjo de admissão parcial ocorrem perdas adicionais devido à mistura do fluido em alta velocidade descarregado pelos bocais com o fluido estagnado na região do rotor que começa a ficar exposta ao arco de admissão. Há que ser considerado ainda as perdas por bombeamento que ocorrem fora do arco de admissão. Ainda deve ser observado que quando a pressão estática fora da zona de admissão é menor que dentro da zona de admissão, ou seja, quando o grau de reação é maior que zero, perdas por vazamento da região ativa para a inativa ocorrem 


\subsection{Incidência Desfavorável}

As perdas por incidência desfavorável ocorrem quando o fluido ataca a palheta sob um ângulo diferente do ótimo. Esta perda de maneira geral acontece em operação fora das condições de projeto, uma vez que nas condições de projeto os ângulos de fluxo estão ajustados aos ângulos das palhetas. A incidência pode ser positiva ou negativa conforme ilustrado na figura 17. Este fato é bastante relevante uma vez que a perda por incidência é diferente para ângulos negativos ou positivos, como mostra a figura 24 , uma vez que a incidência positiva tende a provocar separação prematura na superfície de sucção.

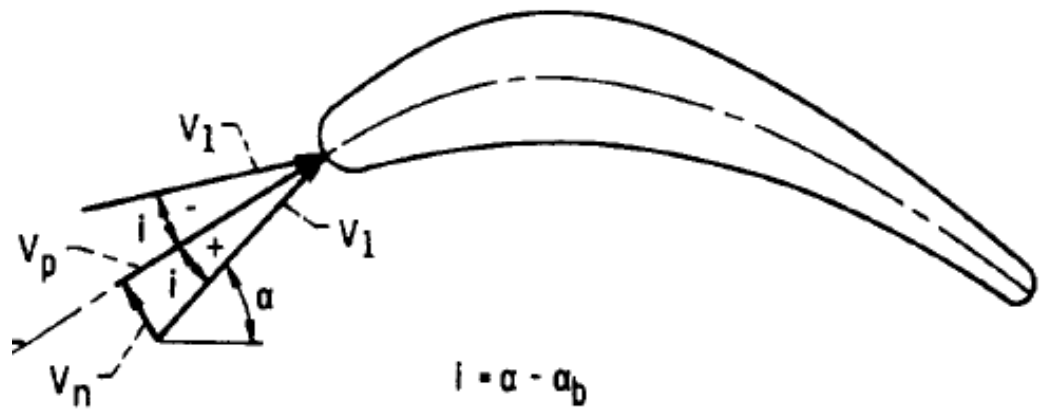

Figura 17 - Nomenclatura da incidência na palheta [23].

Pode ser observado na figura 18 que o intervalo de incidência onde as perdas são baixas é mais amplo nas palhetas com alta taxa de aceleração (alta reação) que naquelas com baixa taxa de aceleração (baixa reação). Outro aspecto importante é que a perda mínima não ocorre sob incidência zero, mas sob um certo valor de incidência negativa. Isto ocorre porque a linha de corrente de estagnação se curva em direção oposta à curvatura da palheta ao incidir sobre o bordo de ataque. Desta forma uma deflexão é induzida no fluxo ao atacar a palheta em virtude do fenômeno da circulação que ocorre ao redor das palhetas. Deste modo a incidência perfeita ocorre sob um determinado valor de incidência negativa, normalmente na faixa de $-4^{\circ}$ a $-8^{\circ}$. 


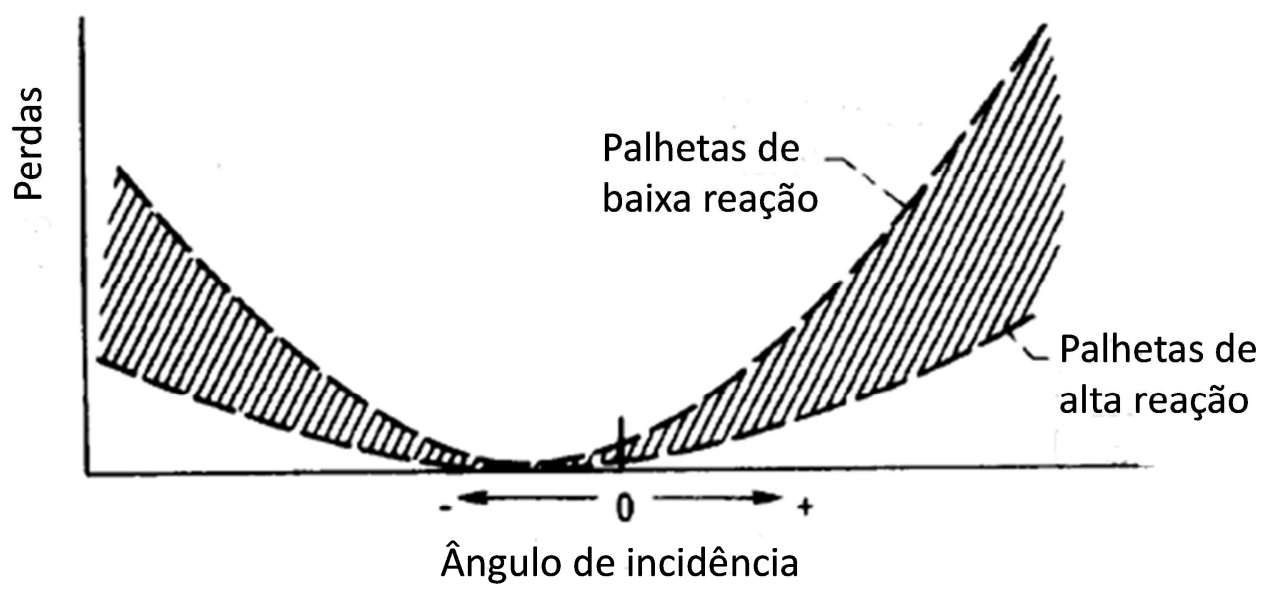

Figura 18 - Característica da perda por incidência [23]. 


\subsubsection{Deflexão do Escoamento na Saída da Grade}

Na simulação do desempenho de uma turbina será importante considerar a deflexão do escoamento em relação ao ângulo de saída da palheta para velocidades subsônicas e supersônicas. Em regime transônico, a utilização de palhetas convergentes é tradicionalmente aplicada até um número de Mach na saída de 1,3 ou 1,4 [23]. A jusante da garganta é possível a ocorrência de uma expansão adicional, através da deflexão do escoamento por meio de ondas de expansão isentrópicas e oblíquas, denominadas ondas de Mach. Neste processo, denominado sobre-expansão, a velocidade supersônica é atingida. Nestas condições a palheta deverá ser projetada com uma superfície plana entre a garganta e o bordo de fuga da superfície de sucção de modo a evitar a aceleração do escoamento na cauda da palheta com deflexão negativa, formação de bolha supersônica [33] e o consequente aumento das perdas. O principal problema da superfície plana é que ela requer um valor baixo de fator de difusão e consequentemente uma alta solidez, além de possuir o bordo de fuga relativamente comprido e estruturalmente frágil.

Adotada esta geometria, a largura da garganta $o$ será calculada a partir do espaçamento das palhetas e do ângulo de saída da palheta:

$$
\left(\frac{o}{t}\right)=\left(1-\frac{t_{e}}{t}\right) \operatorname{sen} \lambda_{2 b}
$$

Uma vez que a fileira de palhetas opera como um bocal, onde o fluxo acelera até a área mínima, a determinação da abertura da garganta torna-se um aspecto bastante crítico no projeto da turbina, de forma a garantir que a vazão mássica desejada seja obtida.

A presente etapa consiste então em definir o ângulo de saída das palhetas que seja capaz de produzir o ângulo de fluxo definido previamente a partir dos diagramas de velocidade. A sobre-expansão que ocorre na porção não guiada da saída da palheta irá provocar uma deflexão angular do escoamento desde a garganta até o bordo de fuga. Quando a razão entre a pressão estática na saída pela 
pressão total na entrada através de uma fileira de palhetas é menor que o valor crítico, ocorre a expansão para velocidades supersônicas. Neste caso pode acontecer um padrão complexo de escoamento com a ocorrência simultânea de regiões de velocidade subsônica e supersônica, ou então uma região única de velocidade supersônica pode ser obtida a jusante da palheta.

Uma alternativa para modelar a expansão produzida pelas ondas de oblíquas é a teoria de Prandtl-Mayer para o escoamento compressível de um gás perfeito ao redor de uma quina, conforme aplicado por Kochendorfer e Mettlee [34]. Segundo este conceito a deflexão do jato é dada por:

$$
\Delta \lambda=m-n
$$

Sendo o parâmetro $m$ relacionado ao número de Mach ao final da expansão por:

$$
\frac{1}{1+\frac{k^{*}-1}{2} M^{2}}=\left(\frac{p}{p_{0}}\right)^{\frac{k^{*}-1}{k^{*}}}=\frac{1}{k^{*}+1}\left[1+\cos \left(2 m \sqrt{\frac{k^{*}-1}{k^{*}+1}}\right)\right]
$$

E o parâmetro $n$ dado por:

$$
\operatorname{tg}(n)=\sqrt{\frac{k^{*}+1}{k^{*}-1}} \operatorname{tg}\left(m \sqrt{\frac{k^{*}-1}{k^{*}+1}}\right)
$$

Este método, no entanto, por considerar o escoamento de um meio semiinfinito produz resultados superestimados da deflexão para o problema em questão. Outra possibilidade seria considerar um meio finito girando através do bordo de fuga, o que resultaria na formação de uma esteira de dimensões consideráveis na superfície de sucção, cujos resultados também não se aproximam da realidade.

A separação na superfície de sucção que aparenta ocorrer na região de saída da palheta sujeita a uma expansão do tipo Prandtl-Mayer pode ser evitada através da utilização do método das características [23]. Esta abordagem é a teoricamente correta para o escoamento interno, uma vez que são consideradas as reflexões na 
superfície da sucção da sequência de ondas de expansão geradas a partir da rotação do escoamento ao redor do bordo de fuga, conforme exemplificado na figura 19, para uma relação pressão estática sobre pressão total de 0,42.

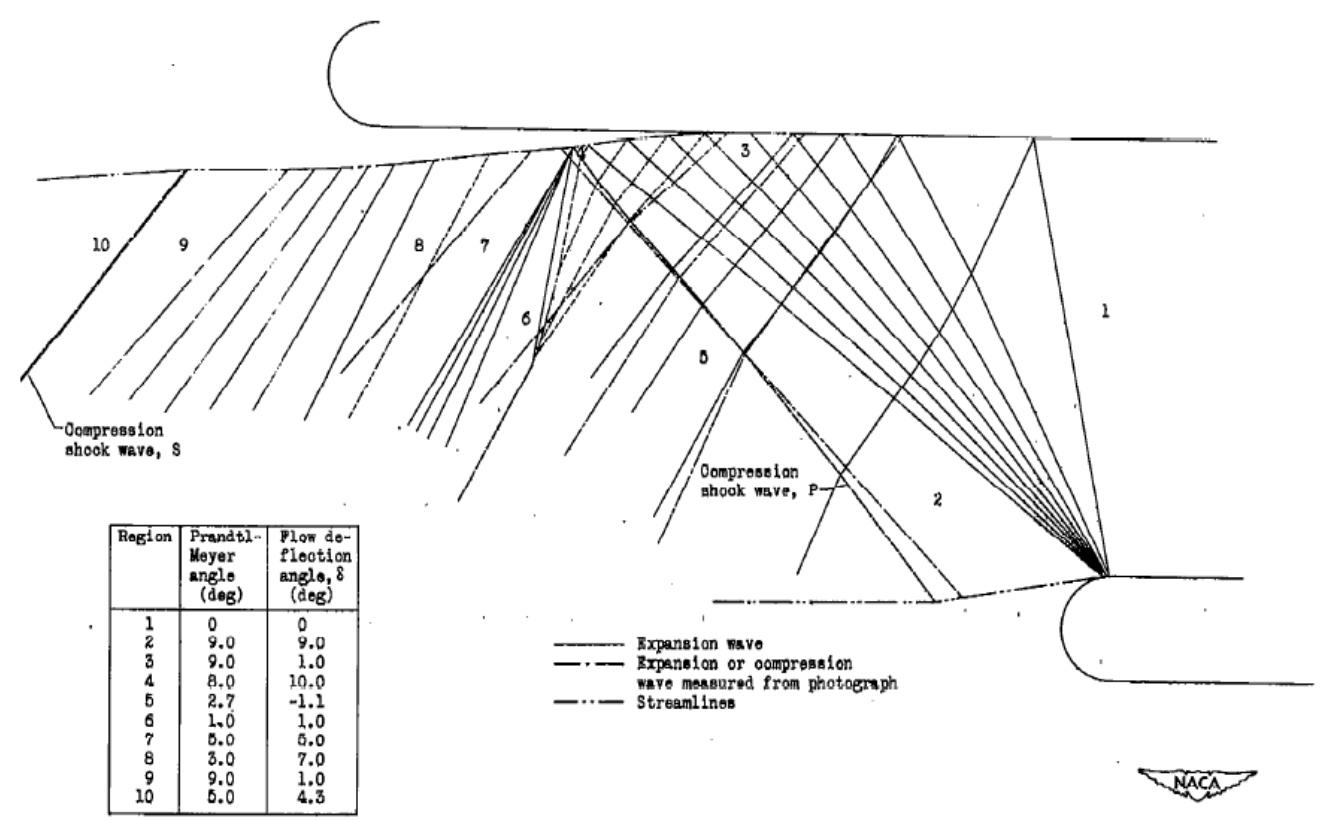

Figura 19 - Sobre-expansão na saída da grade conforme avaliação do método das características para uma razão de pressões $p_{2} / p_{02}=0,42$ [35].

O método das características, entretanto, por exigir cálculos de alta complexidade, não é a ferramenta mais adequada para um estudo de otimização de eficiência da turbina, no nível de projeto preliminar. Desta forma uma abordagem mais simplificada deverá ser adotada para este trabalho, conforme será exposto na seção 2.4.2.3. 


\subsubsection{Revisão de Alguns Métodos de Previsão de Perdas}

\subsubsection{Soderberg}

Em 1949 Soderberg correlacionou as perdas em termos da razão espaçamento corda, do número de Reynolds, da razão de aspecto, da razão de espessura e da geometria da palheta, conforme descrito por Horlock [36], que ressalta que o trabalho embora se fundamente em uma quantidade pequena de parâmetros tem acurácia comparável com outros métodos mais complexos.

Soderberg utilizou o critério de Zweiffel para obter o valor ótimo para a razão espaçamento - corda, cuja base é um coeficiente aerodinâmico obtido a partir da carga tangencial, cujo valor é deve ser aproximadamente 0,85 , conforme a expressão abaixo:

$$
\Psi_{Z}=\frac{2 \operatorname{sen}^{2} \lambda_{2}}{\operatorname{sen} \lambda_{s}} \frac{t}{C}\left(\cot \lambda_{2}-\cot \lambda_{1}\right)
$$

Para palhetas projetadas sob o critério de Zweiffel, com razão de aspecto $h / C=3$, operando com número de Reynolds de 100000, o coeficiente de perda nominal $\zeta^{*}$ será relacionado à deflexão do escoamento $\Delta \lambda=\lambda_{1}-\lambda_{2}$, para diferentes valores de $d_{\max } / C$, conforme mostrado na figura 20.

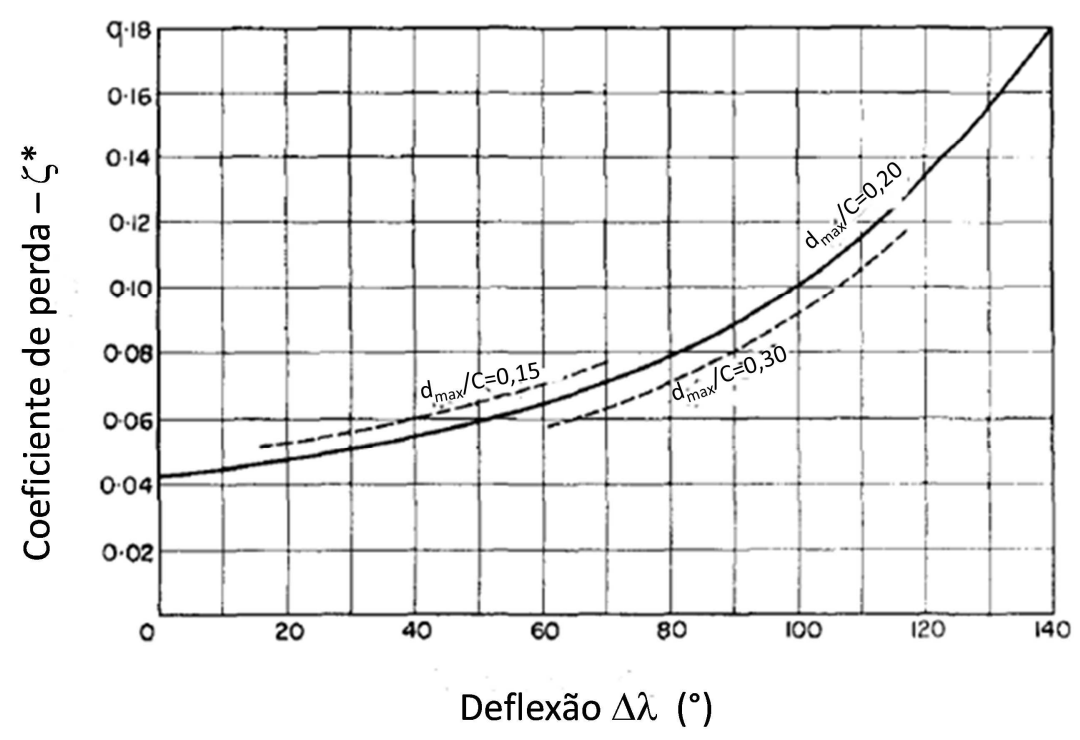

Figura 20 - Correlação perda versus deflexão de Soderberg [36]. 
A expressão abaixo se ajusta extremamente bem à curva para a razão espessura corda $d_{\max } / C=0,2$ e para uma deflexão menor que $120^{\circ}$ :

$$
\zeta^{*}=0,04+0,06\left(\frac{\Delta \lambda}{100}\right)^{2}
$$

As correções do coeficiente de perda com a razão de aspecto $h / C$ é dada abaixo para o bocal e o rotor, respectivamente:

$$
\begin{aligned}
& 1+\zeta_{1 N}=\left(1+\zeta_{N}^{*}\right)\left[0,993+0,021\left(C_{x} / h\right)_{N}\right] \\
& 1+\zeta_{1 R}=\left(1+\zeta_{R}^{*}\right)\left[0,975+0,075\left(C_{x} / h\right)_{R}\right]
\end{aligned}
$$

Enquanto que a correção do número de Reynolds, calculado com base na velocidade de saída da grade e no diâmetro hidráulico do canal na seção da garganta, é dada por:

$$
\zeta=\left(\frac{10^{5}}{\operatorname{Re}}\right)^{0,25} \zeta_{1}
$$

Vale destacar que os coeficientes de perda apresentados referem-se à energia cinética real na saída da grade. Dixon [30] afirma que o método de Soderberg fornece uma estimativa de eficiência de turbina com um erro menor que 3\% sobre um intervalo largo de número de Reynolds e razão de aspecto quando correções adicionais são incluídas para considerar os efeitos do vazamento pelo topo das palhetas e do atrito do disco. O expediente recomendado para incorporar uma correção para o vazamento de palhetas é simplesmente multiplicar a eficiência calculada para o estágio pela razão entre a área da palheta e a área total, isto é, a soma da área da palheta com a área da folga. 


\subsubsection{Ainley \& Mathieson}

Um método para previsão das perdas através de uma grade de turbina foi desenvolvido por Ainley \& Mathieson em 1951 [37]. O modelo de perdas de perfil é baseado em testes em uma variedade de grades de turbinas, sintetizados nos gráficos mostrados da figura 21 , válidos para uma relação espessura máxima corda $d_{\text {max }} / C=0,2$ e para um número de Reynolds referido à corda $R e_{C}=200000$. Pode ser observado que para cada configuração de fluxo da palheta existe uma solidez ótima correspondente que irá minimizar a perda no perfil.

(a) Palhetas de bocais $\left(\lambda_{1}=90^{\circ}\right)$

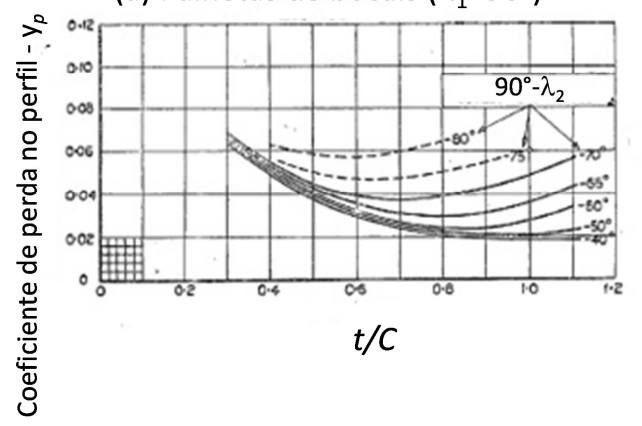

(b) Palhetas de impulso $\left(\lambda_{1}=180^{\circ}-\lambda_{2}\right)$

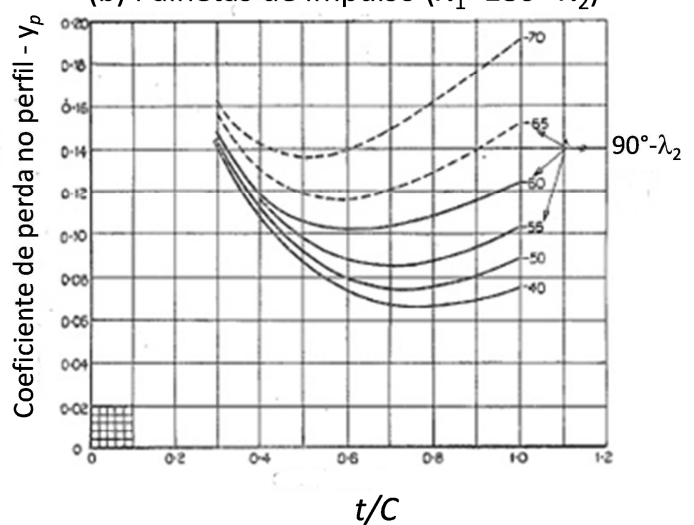

Figura 21 - Coeficiente de perda de pressão total no perfil $y_{p}$ de palhetas de bocais (a) e de palhetas de impulso (b) em função do ângulo de saída de fluxo em relação à direção axial $\left(90^{\circ}-\lambda_{2}\right)$ e da razão espaçamento corda $t / C$, conforme referência [37].

Para uma grade genérica a perda pode ser obtida por interpolação entre as perdas da palheta bocal $y_{p a}\left(\lambda_{1}=90^{\circ}\right)$ e da palheta de impulso $y_{p b}\left(\lambda_{1}=180^{\circ}-\lambda_{2}\right)$, conforme a expressão abaixo:

$$
y_{p}=\left[y_{p a}+\left(y_{p b}-y_{p a}\right)\left(\frac{\lambda_{1}-90}{90-\lambda_{2}}\right)^{2}\right]\left(\frac{d_{\max } / C}{0,2}\right)^{\left(\frac{\lambda_{1}-90}{90-\lambda_{2}}\right)}
$$


O efeito da espessura do bordo de fuga sobre a perda no perfil é mostrada na figura 22. A espessura do bordo de fuga é considerada medida perpendicularmente à linha de curvatura da palheta.

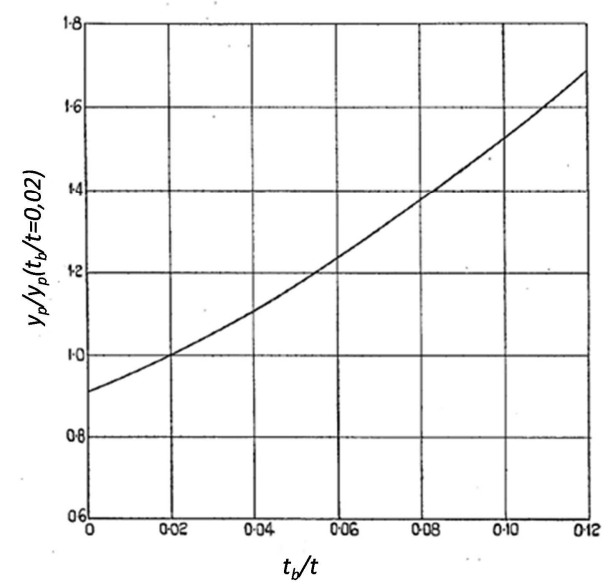

Figura 22 - Efeito da razão espessura do bordo de fuga espaçamento $\left(t_{b} / t\right)$ sobre as perdas no perfil [37].

As perdas secundárias originalmente propostas por Ainley \& Mathieson são muito fracamente dependentes da razão de aspecto $h / C$, o que suscitou modificações ao método. Em 1971 Dunham \& Came [38] reformularam o método original introduzindo a expressão abaixo para o cálculo da perda secundária:

$$
y_{s}=\frac{0,0334}{h / C}\left(\frac{\operatorname{sen} \lambda_{2}}{\operatorname{sen} \lambda_{1 b}}\right)\left(\frac{\operatorname{sen}^{2} \lambda_{2}}{\operatorname{sen} \lambda_{\infty}}\right)\left[4\left(\operatorname{ctg} \lambda_{2}-\operatorname{ctg} \lambda_{1}\right)^{2}\right]
$$

Sendo $\lambda_{\infty} \mathrm{o}$ ângulo médio do escoamento dado conforme a expressão abaixo:

$$
\operatorname{ctg} \lambda_{\infty}=\frac{\left(\operatorname{ctg} \lambda_{1}+\operatorname{ctg} \lambda_{2}\right)}{2}
$$

Segundo Dunham \& Came a perda total é dada pela expressão abaixo, contemplando a perda por vazamento pelo topo da palheta $y_{t}$, a correção pelo número de Reynolds baseado na corda $R e_{C}$ e a correção pela espessura do bordo de fuga $\chi_{t e}$ dada pela figura 28 :

$$
y_{t o t}=\left[\left(y_{s}+y_{s}\right)\left(\frac{\operatorname{Re}_{C}}{200000}\right)^{-0,2}+y_{t l}\right] \chi_{t e}
$$


Em 1982 o método de Ainley \& Mathieson recebeu nova modificação com o trabalho de Kacker \& Okapuu [39]. A contribuição destes autores, entretanto, teve como principal objetivo introduzir o efeito de um alto número de Mach sobre o escoamento através das palhetas. Em primeiro lugar, a perda de perfil é reduzida a 2/3 do valor original, justificada pelos avanços no projeto aerodinâmico. A redução da espessura da camada limite com o aumento do número de Mach é considerada multiplicando-se a perda básica no perfil por um coeficiente de redução denominado $K_{p}$, válido para $M_{2}>0,2$, dado conforme a expressão abaixo:

$$
K_{p}=1-1,25\left(M_{2}-0,2\right)\left(\frac{M_{1}}{M_{2}}\right)^{2}
$$

Por outro lado, um termo adicional que leva em conta as perdas por formação de ondas de choque na incidência sobre a grade é adicionado à perda básica no perfil, sendo $M_{l, H}$ o número de Mach a montante da base da palheta.

$$
y_{\text {shock }}=0,75\left(M_{1, H}-0,4\right)^{1,75}\left(\frac{p_{1}}{p_{2}}\right)\left(1-2 \frac{h}{D}\right) \frac{1-\left(1+\frac{k-1}{2} M_{1}^{2}\right)^{\frac{k}{k-1}}}{1-\left(1+\frac{k-1}{2} M_{2}^{2}\right)^{\frac{k}{k-1}}}
$$

Uma nova expressão é introduzida para a perda devida à espessura do bordo de fuga contemplando a formação de ondas de choque na saída. Para a perda secundária, uma expressão similar à proposta por Dunham \& Came é adotada, incorporando-se entretanto o coeficiente de redução $K_{p}$.

$$
y_{s}=\frac{0,04}{h / C} \chi_{A R}\left[4\left(\operatorname{ctg} \lambda_{2}-\operatorname{ctg} \lambda_{1}\right)^{2}\left(\frac{\operatorname{sen} \lambda_{2}}{\operatorname{sen} \lambda_{1 b}}\right)\left(\frac{\operatorname{sen}^{2} \lambda_{2}}{\operatorname{sen} \lambda_{\infty}}\right)\left[1-\frac{1-K_{p}}{\left(h / C_{x}\right)^{2}}\right]\right.
$$

O fator de correção para a razão de aspecto é aplicado quando $h / C<2$, conforme a expressão abaixo:

$$
\chi_{A R}=1-0,25 \sqrt{2-h / C}
$$




\subsubsection{Stewart et Al.}

Em 1960 Stewart et al [40] apresentaram resultados de várias investigações considerando as características da camada limite desenvolvida no escoamento através de palhetas de turbinas e sua relação com a perda observada, sendo demonstrado que esta pode ser obtida diretamente a partir da espessura de quantidade de movimento. A espessura de quantidade de movimento, por sua vez, é demonstrada estar correlacionada com o fator de difusão total da palheta, definido conforme a expressão abaixo:

$$
D_{t o t}=\left(1-\frac{V_{p, \text { min }}}{V_{1}}\right)+\left(1-\frac{V_{2}}{V_{s, \text { max }}}\right)
$$

A partir da premissa de um diagrama de carregamento da palheta similar ao proposto por Zweiffel, considerando escoamento incompressível, bidimensional, com velocidade axial constante e sem perdas, o fator de difusão pode ser determinado como função da solidez e da taxa de aceleração através da palheta. Isto é feito assumindo-se uma distribuição retangular de velocidade na palheta, sendo atribuído o valor da velocidade de saída à velocidade na superfície de sucção enquanto a velocidade na superfície de pressão tem seu valor ajustado para produzir o valor desejado para o coeficiente de Zweiffel. A partir desta consideração, o fator de difusão resultante será dado pela equação abaixo:

$$
D_{\text {tot }}=1-\mu \sqrt{1-\Psi_{Z}}
$$

Segundo Stewart, a espessura da quantidade de movimento pode ser correlacionada de forma generalizada ao fator de difusão, independentemente da geometria da grade e dos ângulos de escoamento. A correlação mostrada na figura 23 foi obtida a partir de resultados experimentais de testes de grades bidimensionais em baixa velocidade [41], bem como a partir de dados de projeto de palhetas rotativas transônicas, sendo proposta a seguinte expressão:

$$
\frac{\vartheta}{l}=\frac{0,003}{1-1,4 D_{t o t}}
$$


Para considerar o efeito do número de Reynolds é recomendada a correção abaixo, típica para a camada limite turbulenta:

$$
\frac{(\vartheta / l)}{(\vartheta / l)_{\text {ref }}}=\left(\frac{\operatorname{Re}_{l}}{\operatorname{Re}_{l, r e f}}\right)^{-1 / 5}
$$

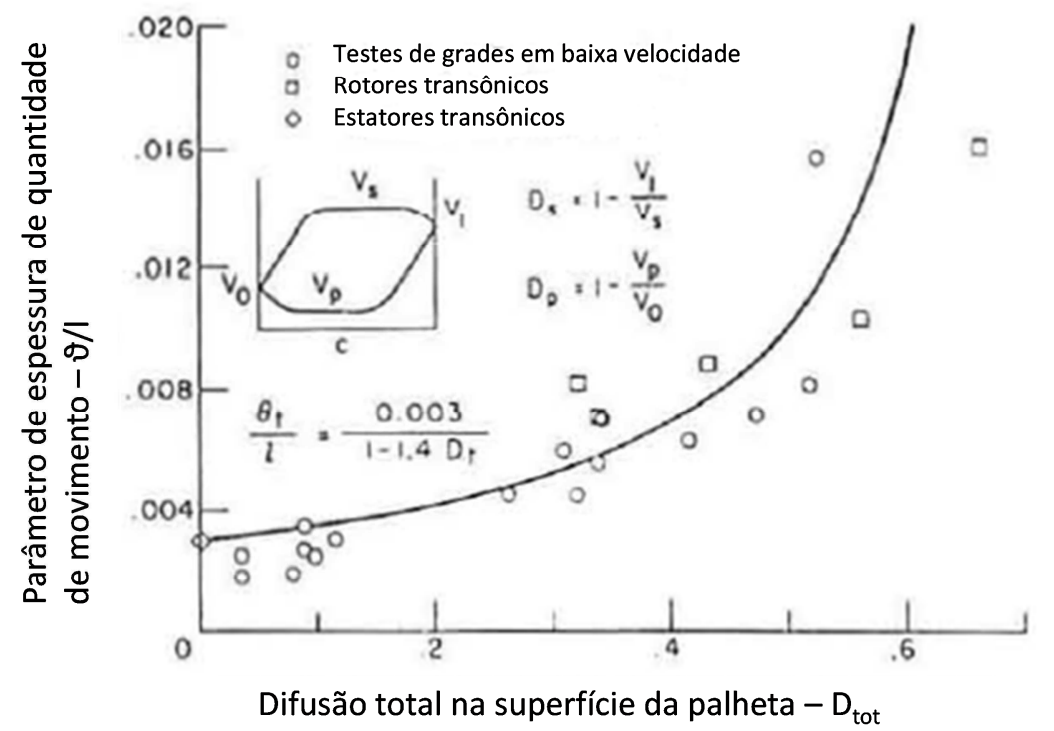

Figura 23 - Correlação espessura de quantidade de movimento versus fator de difusão total proposta por Stewart et al [40].

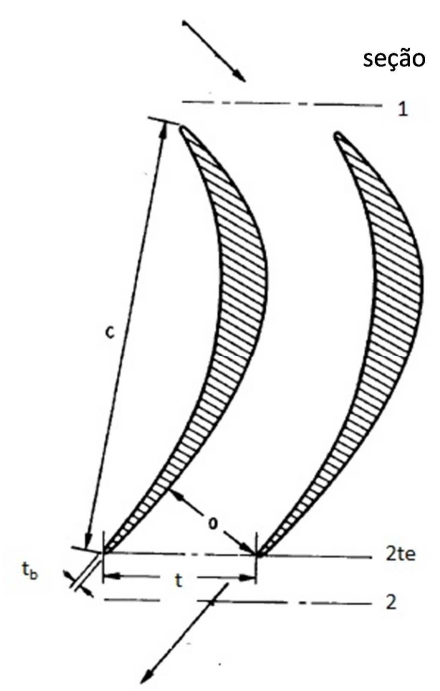

Figura 24 - Seção localizada na saída da palheta, justo entre os bordos de fuga, denominada seção $2 t e$. 
A consideração do efeito de obstrução do bordo de fuga será feita com o uso da figura 24, que mostra a seção da palheta e a nomenclatura utilizada. Um novo diagrama de velocidade de saída será construído na seção 2te, a qual está localizada justo no interior da região do bordo de fuga da palheta. A área reduzida devido à presença do bordo de fuga resultará numa diferença entre as velocidades na seção 2 te e na seção 2 , esta última localizada a jusante da palheta.

Para a determinação do coeficiente de perda nas paredes do perfil, Stewart [42] estabelece um procedimento obtido a partir de considerações de conservação de massa e de quantidade de movimento nas direções tangencial e axial entre a seção 2 te e a seção 2 , conforme as equações abaixo:

$$
\begin{aligned}
& \left(1-\frac{t_{e}}{t}-\delta^{\prime}\right)\left(\mathcal{W}_{x}\right)_{2 t e}=\left(W_{x}\right)_{2} \\
& \left(1-\frac{t_{e}}{t}-\delta^{\prime}-\vartheta^{\prime}\right)\left(W_{x} V_{u}\right)_{2 t e}=\left(W_{x} V_{u}\right)_{2} \\
& p_{2 t e}+\left(1-\frac{t_{e}}{t}-\delta^{\prime}-\vartheta^{\prime}\right)\left(W_{x}^{2}\right)_{2 t e}=p_{2}+\left(W_{x}^{2}\right)_{2}
\end{aligned}
$$

Neste processo ocorre a mistura da corrente livre com a camada limite e também a ocupação do espaço vazio decorrente da obstrução causada pela espessura do bordo de fuga, considerando-se que ao final uma velocidade uniforme é atingida a jusante da grade. Para escoamento incompressível a solução das equações (2.83) a (2.85) resulta na seguinte expressão para $\xi_{p}$ :

$$
\xi_{p}=1-\frac{\cos ^{2} \lambda_{2 t e} \frac{\left(1-\delta^{\prime}-\vartheta^{\prime}-\frac{t_{e}}{t}\right)^{2}}{\left(1-\delta^{\prime}-\frac{t_{e}}{t}\right)^{2}}+\operatorname{sen}^{2} \lambda_{2 t e}\left(1-\delta^{\prime}-\frac{t_{e}}{t}\right)^{2}}{1+2 \operatorname{sen}^{2} \lambda_{2 t e}\left[\left(1-\delta^{\prime}-\frac{t_{e}}{t}\right)^{2}-\left(1-\delta^{\prime}-\vartheta^{\prime}-\frac{t_{e}}{t}\right)\right]}
$$

Sendo: $\vartheta^{\prime}=\frac{\vartheta}{l} \frac{l}{C} \frac{C}{t \operatorname{sen} \lambda_{2 t e}}, \quad \delta^{\prime}=H \vartheta^{\prime}$ e $H$ o fator de forma. 
Considerando um perfil de velocidade da camada limite turbulenta dado pela lei de potência conforme a expressão abaixo:

$$
\frac{V}{V_{\infty}}=y^{n}
$$

Stewart [42] deduziu a seguinte expressão abaixo para o fator de forma $H$ da camada limite:

$$
H=\frac{\frac{1}{n+1}+\frac{3 J}{3 n+1}+\frac{5 J^{2}}{5 n+1}+\cdots}{\frac{1}{(n+1)(2 n+1)}+\frac{J}{(3 n+1)(4 n+1)}+\frac{J^{2}}{(5 n+1)(6 n+1)}+\cdots}
$$

Na referência [43] é recomendado utilizar o expoente $n=1 / 7$, a partir de um estudo experimental sobre a camada limite desenvolvida em uma grade de palhetas estacionárias de turbina. $\mathrm{O}$ parâmetro $J$ caracteriza a compressibilidade do escoamento, conforme a seguinte expressão:

$$
J=1-\frac{T}{T_{0}}=\frac{1}{1+\frac{1}{\frac{(k-1)}{2} M^{2}}}
$$

A participação da perda nas paredes terminais (no topo e na base das palhetas) é considerada através da avaliação de uma espessura de quantidade de movimento tridimensional, determinada a partir da denominada "regra da área" conforme Stewart et al. [44]. É suposto um fator de atrito para as paredes terminais idêntico ao das paredes do perfil, o que resulta na seguinte expressão:

$$
\vartheta_{3 D}^{\prime}=\left(1+\frac{\operatorname{sen} \lambda_{s}}{\sigma \frac{l}{C} \frac{h}{C}}\right) \vartheta^{\prime}
$$

A correspondente espessura tridimensional de deslocamento é dada por:

$$
\delta_{3 D}^{\prime}=H \vartheta_{3 D}^{\prime}
$$


Neste procedimento é recomendada a utilização das espessuras tridimensionais $\vartheta_{3 D}^{\prime}$ e $\delta_{3 D}$ nas equações (2.83) a (2.85). No caso de escoamento supersônico à jusante da grade, situação na qual o ângulo do fluxo $\lambda_{2 t e}$ e o ângulo da palheta $\lambda_{2 b}$ não mais coincidem, uma equação de conservação de massa entre a garganta e a seção de saída assumindo-se escoamento isentrópico deve ser acrescentada [44]. A solução para escoamento compressível requer a adimensionalização das equações (2.83) a (2.85) através da divisão pela pressão total a montante da grade $p_{0}$. Sendo especificados o número de Mach e ângulo de fluxo na seção 2 a jusante da grade, as incógnitas a resolver são o número de Mach e o ângulo de fluxo na seção de saída $\left(M_{2 t e}\right.$ e $\left.\lambda_{2 t e}\right)$ e a razão de pressões totais $p_{02} / p_{0}$. Por fim o coeficiente de perda de energia cinética total é determinado através da expressão abaixo, válida para gás ideal:

$$
\xi=\frac{\left(\frac{p_{0}}{p_{02}}\right)^{\frac{k^{*}-1}{k^{*}}}-1}{\left(\frac{p_{0}}{p_{2}}\right)^{\frac{k^{*}-1}{k^{*}}}-1}
$$




\subsubsection{Baljé}

Em 1968 Baljé [45] reformulou seu método de estimativa de desempenho de grades axiais a partir de pesquisas experimentais em grades realizadas nos Estados Unidos e na Alemanha. A expressão para a solidez ótima da grade é reapresentada considerando o efeito da compressibilidade do meio, determinada conforme o critério de Zweiffel, adotando-se o valor para o coeficiente aerodinâmico $\Psi_{Z}=0$,9:

$$
\Psi_{Z}=\frac{\left(\frac{2 K_{t}}{1+K_{t}}\right)\left(1+A_{x 1} / A_{x 2}\right)\left(\frac{t}{C}\right) \delta u}{\left[\left(\frac{2 K_{t}}{1+K_{t}}\right)^{2}+\left(\cot \lambda_{\infty}+\frac{\delta u}{2}\right)^{2}\right] \operatorname{sen} \lambda_{s}}
$$

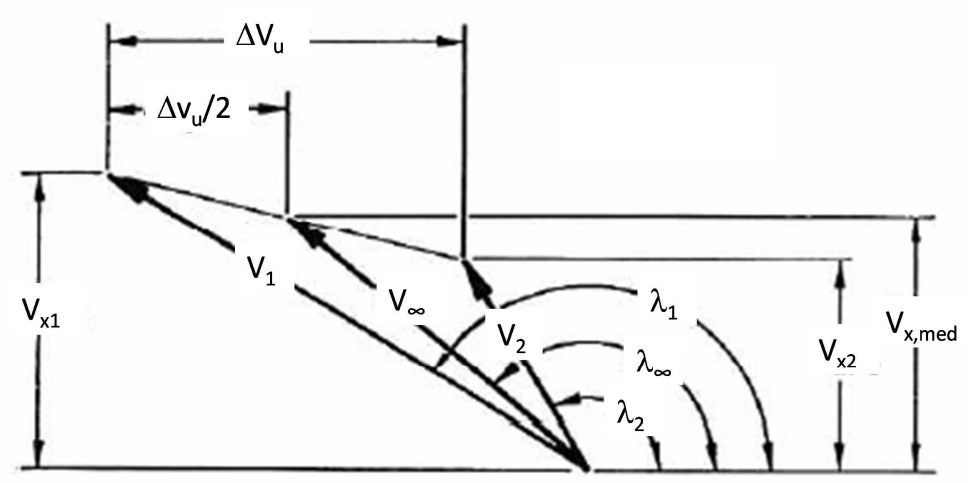

Figura 25 - Vetores velocidade em escoamento compressível através da grade axial [45].

Conforme mostrado na figura 25, o escoamento através da grade de palhetas em regime compressível é caracterizado através dos parâmetros $\delta u$ e $\lambda_{\infty}$, sendo $\delta u$ o carregamento da palheta definido por:

$$
\delta u=\frac{\Delta V_{u}}{V_{x, \text { med }}}
$$

E relacionado com a geometria da grade conforme a expressão:

$$
\frac{\delta u}{2}=\frac{1}{1+K_{t}}\left(K_{t} \operatorname{ctg} \lambda_{2}-\operatorname{ctg} \lambda_{1}\right)
$$


E $\lambda_{\infty}$ é o ângulo médio de vetor velocidade dado por:

$$
\operatorname{ctg} \lambda_{\infty}=\frac{1}{1+K_{t}}\left(K_{t} \operatorname{ctg} \lambda_{2}+\operatorname{ctg} \lambda_{1}\right)
$$

Uma distribuição típica de velocidades nas superfícies da palheta mostra uma aceleração inicial seguida de uma desaceleração na superfície de sucção, enquanto que a superfície de pressão experimenta uma desaceleração rápida. $\mathrm{O}$ crescimento da espessura de quantidade de movimento é, portanto, controlado pela relação $V_{s-m a x} / V_{l}$ na superfície de sucção e pela relação $V_{p-\min } / V_{l}$ na superfície de pressão. O modelo de escoamento pode ser então representado pela superposição de um fluxo circulatório ao redor do aerofólio sobre o fluxo uniforme que atravessa a grade, conforme ilustrado na figura 26.

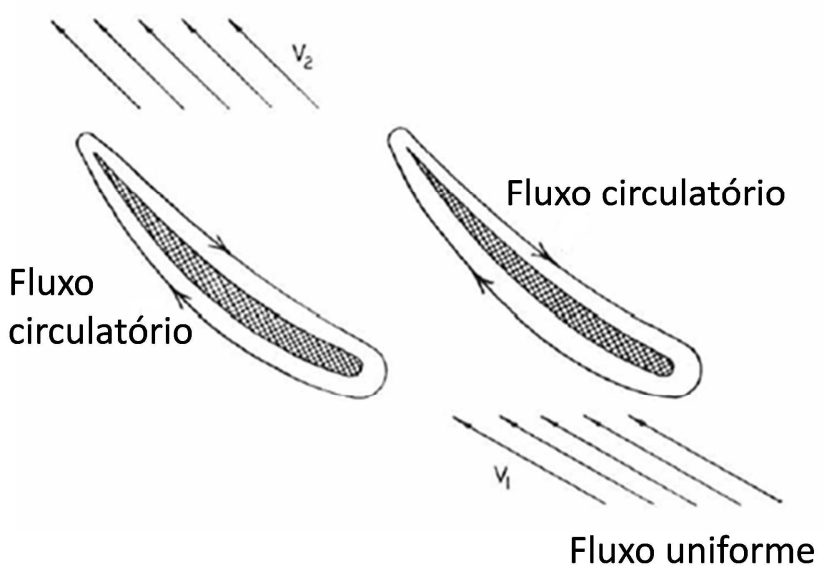

Figura 26 - Modelo de escoamento através da grade resultante da superposição de um fluxo circulatório ao fluxo uniforme [45].

Baljé mostra em seu trabalho que estas relações de velocidades dependem do parâmetro de circulação $C_{f a x}$, que pode ser interpretado como a componente axial de um coeficiente de força atuando em direção perpendicular ao vetor velocidade de entrada, que está relacionado à geometria da grade conforme a expressão abaixo:

$$
C_{f a x}=\frac{2 \delta u}{\sigma\left[1+\left(\operatorname{ctg} \lambda_{\infty}-\frac{\delta u}{2}\right)^{2}\right]}=\mu^{2} \Psi_{Z} \operatorname{sen} \lambda_{s}
$$


Sendo $\mu$ a taxa de aceleração da grade dada por:

$$
\mu=\sqrt{\frac{\left[\left(\frac{2 K_{t}}{1+K_{t}}\right)^{2}+\left(\cot \lambda_{\infty}+\frac{\delta u}{2}\right)^{2}\right]}{\left[\left(\frac{2}{1+K_{t}}\right)^{2}+\left(\cot \lambda_{\infty}-\frac{\delta u}{2}\right)^{2}\right]}}=\frac{K_{t} \operatorname{sen} \lambda_{1}}{\operatorname{sen} \lambda_{2}}
$$

As relações aproximadas para as velocidades extremas nas superfícies de sucção e de pressão em meio incompressível, obtidas a partir de experimentos em grades de palhetas de compressores axiais, são dadas respectivamente por:

$$
\begin{aligned}
& \frac{V_{s, \text { max }}}{V_{1}}=1+0,9 \frac{d_{\text {max }}}{C}+0,3 C_{f a x}, \text { para } \mathrm{x} / 1 \approx 0,3 \\
& \frac{V_{p, \text { min }}}{V_{1}}=0,9-\frac{0,02}{C_{f a x}}, \text { para } \mathrm{x} / 1 \approx 0,9
\end{aligned}
$$

Sendo $d_{\max }$ a espessura máxima da corda, que para grades típicas pode ser estimada pela expressão abaixo:

$$
\frac{d_{\max }}{C}=\frac{\delta u \Psi_{Z}}{9}=\frac{2 \Psi_{Z}}{9} \frac{1}{1+K_{t}}\left(K_{t} \operatorname{ctg} \lambda_{2}-\operatorname{ctg} \lambda_{1}\right)
$$

Investigações adicionais mostram que a relação $V_{s-\max } / V_{l}$ a é o parâmetro de maior influência no controle da espessura total da quantidade de movimento (face de pressão e face de sucção), conforme o fator de difusão equivalente $D_{e}$ :

$$
D_{e}=1,025 \frac{V_{s, \max }}{V_{2}}=\frac{1,025}{\mu}\left(1+0,9 \frac{d_{\max }}{C}+0,3 C_{f a x}\right)
$$

A partir de dados experimentais obtidos a partir de testes de grades de palhetas em túnel de vento, a espessura total de quantidade de movimento $\vartheta / l \mathrm{em}$ condições de referência (número de Reynolds baseado no comprimento da corda $C$ igual a 400000) foi correlacionada com o fator de difusão $D_{e}$ conforme a seguinte expressão:

$$
\frac{\vartheta}{l}=\frac{0,013}{2,62-D_{e}}-0,004
$$


Para avaliação em condições de escoamento compressível, Baljé [46] sugere a seguinte correção com o número de Mach:

$$
\frac{(\vartheta / l)_{\text {compressivel }}}{(\vartheta / l)_{\text {incompressivel }}}=\left(1+0,12 M_{2, i s}^{2}\right)^{-0,65}
$$

Para avaliação em condições alternativas, Baljé em [27] sugere a seguinte relação com o número de Reynolds, válida quando este é maior que o valor crítico de 40000, abaixo do qual as perdas aumentam drasticamente devido à separação da camada limite laminar:

$$
\frac{(\vartheta / l)}{(\vartheta / /)_{\text {ref }}}=\frac{71}{\left(\log _{10} \operatorname{Re}\right)^{2,58}}+1-\tanh \left(1,96508 \log _{10} \operatorname{Re}-8,51713\right)
$$

$\mathrm{Na}$ expressão acima a espessura de quantidade de movimento $\vartheta / l \mathrm{em}$ condições de referência é relativa a um número de Reynolds baseado no comprimento da linha média igual a 200000.

A correção para o número de Reynolds apresentada é válida para superfícies hidraulicamente lisas, isto é, quando a rugosidade é limitada a um valor admissível dado por:

$$
\left(K_{s} / l\right)_{c r i t}=\frac{100}{\operatorname{Re}}
$$

Valores típicos para rugosidade são 1 a $3 \mu \mathrm{m}$ para aço polido ou 30 a $100 \mu \mathrm{m}$ para fundidos sem tratamento superficial.

Quando o valor crítico é excedido, $७ / l$ deverá ser corrigido com a rugosidade relativa $K_{s} l l$ pela expressão seguinte:

$$
\frac{(\vartheta / l)}{(\vartheta / l)_{\text {ref }}}=\left(\frac{\left(K_{s} / l\right)}{\left(K_{s} / l\right)_{c r i t}}\right)^{\frac{1}{6}}
$$


A determinação da perda nas paredes do perfil $\xi_{p}$ segue a seguinte expressão:

$$
\xi_{p}=\frac{1,93 \operatorname{sen}^{2} \lambda_{2} \sigma(\vartheta / l)(l / C)\left[1+\left(\operatorname{ctg} \lambda_{\infty}+\frac{\delta u}{2}\right)^{2}\right]^{1,5}}{\left[1-1,08 \sigma(\vartheta / l)(l / C) \sqrt{1+\left(\operatorname{ctg} \lambda_{\infty}+\frac{\delta u}{2}\right)^{2}}\right]^{3}}
$$

$\mathrm{O}$ coeficiente de perda secundária referido à componente axial da velocidade de saída da grade é apresentado de forma gráfica a partir de resultados experimentais obtidos por Wolf na Alemanha, conforme mostrada na figura 27, onde é comparada com a regra da área de Stewart, revelando-se uma certa coerência entre os dois métodos.

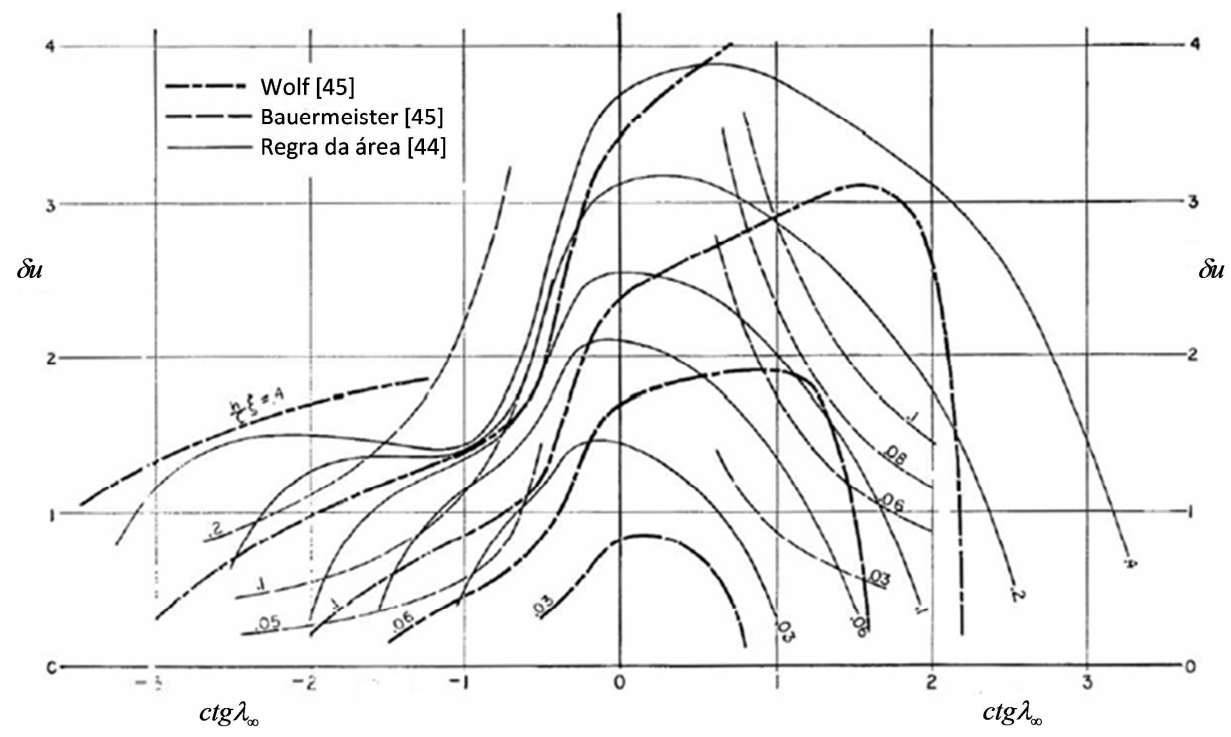

Figura 27 - Coeficiente de perda secundária referido à componente axial da velocidade de saída da grade [45].

A perda secundária dada pela figura 27 será típica para a primeira grade da turbina. Sob a presença de uma grade precedente, o coeficiente $\xi_{s}$ deverá sofrer um acréscimo em relação à expressão anterior dado por:

$$
\frac{\xi_{s}}{\xi_{s-\min }}=65833\left(\frac{\delta_{0}}{h}\right)^{3}-5800\left(\frac{\delta_{0}}{h}\right)^{2}+181,42\left(\frac{\delta_{0}}{h}\right)+1
$$


Esta correção leva em conta o efeito da ingestão da camada limite na parede terminal da grade precedente, cuja espessura de deslocamento é estimada pela seguinte expressão:

$$
\frac{\delta_{0}}{h}=\frac{\xi_{s-p r}}{22\left[1+\left(\operatorname{ctg} \lambda_{\infty-p r}+\frac{\delta u_{p r}}{2}\right)^{2}\right]}=\frac{\xi_{s-p r} \operatorname{sen}^{2} \lambda_{2-p r}}{22}
$$

Para palhetas de altura muito pequena as camadas limites da parede de topo e da parede da base poderão se entrelaçar, invalidando as premissas adotadas. O critério sugerido por Baljé [45] para garantir que as perdas de perfil e paredes terminais possam ser somadas é limitar a relação $\mathrm{h}_{\mathrm{bl}} / \mathrm{h}<0.5$ conforme a expressão a seguir:

$$
\frac{h_{b l}}{h}=\frac{\Delta \lambda\left(1+\frac{1}{\mu}\right) 0,0022}{\left(\frac{\delta_{0}}{h} \frac{h}{t}\right)^{0,75}} \frac{\delta_{0}}{h}
$$

Em [27] Baljé apresenta valores para estimativa de parâmetros geométricos para grades típicas. $\mathrm{O}$ ângulo de assentamento da palheta $\lambda_{\mathrm{s}}$ é dado por:

$$
\operatorname{tg} \lambda_{s}=\frac{2}{\operatorname{ctg} \lambda_{1}+\operatorname{ctg} \lambda_{2}}
$$

Sendo $\lambda_{1}-\lambda_{2}>55^{\circ}$ a razão comprimento da linha de curvatura corda $l / C$ é dada pela equação seguinte, caso contrário é recomendado adotar $l / C=1$ :

$$
\frac{l}{C}=0,7222+0,00505\left(\lambda_{1}-\lambda_{2}\right)
$$

As perdas por atrito devido à rotação do disco são dadas pela expressão abaixo em termos da geometria do estágio, razão de velocidades, grau de admissão e coeficiente de torque:

$$
\Delta \eta_{w}=\frac{\frac{1}{2}\left(1+\frac{\gamma_{2}}{\gamma_{3}}\right) C_{d}(1-2(h / D))^{5}\left(u / c_{0}\right)^{3}}{4 \varepsilon \pi \frac{h}{D}\left(1-\frac{h}{D}\right)\left(1-2 \frac{h}{D}+2\left(\frac{h}{D}\right)^{2}\right)^{3 / 2}\left(w_{3} / c_{0}\right) \operatorname{sen} \beta_{3}}
$$


Quatro diferentes regimes de escoamento para um disco girando submerso em um fluido viscoso devem ser considerados, sendo estabelecidas as seguintes relações empíricas correspondentes para os coeficientes de torque:

$$
\begin{aligned}
& C_{d 1}=\frac{2 \pi}{B \operatorname{Re}_{d}} \\
& C_{d 2}=\frac{3,7 B^{0,1}}{\operatorname{Re}_{d}^{1 / 2}} \\
& C_{d 3}=\frac{0,08}{B^{1 / 6} \operatorname{Re}_{d}^{1 / 4}} \\
& C_{d 4}=\frac{0,102 B^{0,1}}{\operatorname{Re}_{d}^{1 / 5}}
\end{aligned}
$$

Sendo o número de Reynolds do disco $R e_{d}$ dado por:

$$
\operatorname{Re}_{d}=\operatorname{Re}_{M} \frac{(1-2(h / D))^{2}}{2}
$$

E o parâmetro $\left.B=\frac{\Delta}{D} \frac{2}{(1-2(h / D)}\right)$, sendo $\Delta$ a folga axial entre disco e carcaça.

Na equação (2.114) deve ser utilizado para o coeficiente de torque $C_{d}$ o maior valor dentre os quatro anteriores, ou seja, $C_{d}=\operatorname{Max}\left(C_{d 1}, C_{d 2}, C_{d 3}, C_{d 4}\right)$. No caso de palhetas cintadas, a perda por atrito deverá ser multiplicada por $(1+5(b / D))$ para considerar esta contribuição, sendo $b$ é a largura da cinta do topo das palhetas.

As perdas por enchimento e esvaziamento dos canais do rotor que ocorrem em um arranjo de admissão parcial são dadas por uma redução do coeficiente de velocidade do rotor em relação ao valor que ocorreria em uma turbina de admissão total:

$$
\psi_{R, p a}=\psi_{R, t o t}\left(1-\frac{t_{R}}{2 a}\right)
$$


Sendo $t_{R}$ o espaçamento das palhetas do rotor e $a$ o arco de admissão, cuja relação é dada abaixo em termos da fração de admissão $\varepsilon$ e o número de palhetas do $\operatorname{rotor} Z_{R}$ :

$$
\frac{t_{R}}{2 a}=\frac{\left(\frac{t}{C}\right)_{R}\left(\frac{C}{D}\right)_{R}}{2 \pi \varepsilon \sqrt{1-2 \frac{h}{D}+2\left(\frac{h}{D}\right)^{2}}}=\frac{1}{2 \varepsilon Z_{R}}
$$

Num arranjo de admissão parcial ocorrem perdas adicionais devidas à energia requerida para soprar o fluido estagnado na carcaça da turbina para a corrente ativa, ou seja, a energia necessária para acelerar o fluido do estado de estagnação com relação à carcaça para o estado de estagnação com relação às palhetas rotativas. A perda de energia decorrente é dada pela expressão abaixo em termos de decréscimo de eficiência, sendo $f$ um coeficiente de mistura $(f=1.4)$ :

$$
\Delta \eta_{s c}=\frac{f\left(C_{x R} / D\right)\left(u / c_{0}\right)^{3}}{\pi \varepsilon \frac{c_{2}}{c_{0}} \operatorname{sen} \alpha_{2} \sqrt{\left(1-2 \frac{h}{D}+2\left(\frac{h}{D}\right)^{2}\right)}}
$$

Há que ser considerado ainda as perdas por bombeamento que ocorrem fora do arco de admissão, em função do estabelecimento de um fluxo recirculante que entra pela base da palheta e sai pelo topo, cujas perdas são apresentadas a seguir novamente em termos de decréscimo de eficiência:

$$
\Delta \eta_{p m}=\frac{0,1435(1-\varepsilon)\left(u / c_{0}\right)^{3} \sqrt{\left(1-2 \frac{h}{D}+2\left(\frac{h}{D}\right)^{2}\right)}}{\pi \varepsilon\left(w_{3} / c_{0}\right) \operatorname{sen} \beta_{3} \operatorname{Re}_{M}^{1 / 7}(h / D)^{0,4}}
$$

As perdas por bombeamento podem ser eliminadas fechando-se a área anular a jusante das palhetas rotativas na região inativa.

As expressões a seguir quantificam a fração vazada para a região inativa em um arranjo de admissão parcial, pelo topo das palhetas, na direção circunferencial 
entre palhetas do bocal e do rotor, na direção radial entre o disco e a carcaça, bem como o vazamento dinâmico, dados respectivamente por:

$$
\begin{aligned}
& L_{A}=\frac{C_{F} \sqrt{\rho}}{\pi \varepsilon \frac{w_{3}}{c_{0}} \frac{h}{D}\left(1-\frac{h}{D}\right) \operatorname{sen} \beta_{3}} \frac{\Delta_{b}}{D} \frac{h}{D} \\
& L_{B}=\frac{C_{F} \sqrt{1-\left(1-\psi_{N}{ }^{2}\right)(1-\rho)}}{\pi \varepsilon \frac{w_{3}}{c_{0}} \frac{h}{D}\left(1-\frac{h}{D}\right) \operatorname{sen} \beta_{3}} \frac{\Delta_{b}}{D} \frac{h}{D} \\
& L_{C}=\frac{C_{F} \sqrt{\rho}}{\frac{w_{3}}{c_{0}} \operatorname{sen} \beta_{3}} \frac{\Delta_{s}}{D} \frac{\left(1-2 \frac{h}{D}\right)}{\frac{h}{D}\left(1-\frac{h}{D}\right)} \\
& L=L_{A}+L_{B}+L_{C}+L_{D} \\
& L_{D}=C_{D} A_{D} \frac{h}{D} \frac{C_{R}}{D} \frac{w_{3}}{\frac{w_{0}}{c_{0}}} \operatorname{sen} \beta_{3}
\end{aligned}
$$

Sendo $\Delta_{b}$ a folga axial entre palhetas rotativas e estacionárias, $\Delta_{s}$ a folga axial entre o aro da roda e a carcaça, $C_{F}=0,66, C_{D}=0,35$ e $A_{D}=0,6$. 


\subsubsection{Craig \& Cox}

Craig e Cox produziram um método de previsão de perdas em turbinas axiais com base em análise de testes em grades lineares, em turbinas protótipos e em turbinas industriais [47]. O método foi concebido para prever o desempenho em uma larga faixa de número de Reynolds, número de Mach, razão de aspecto e outras variáveis relevantes com uma acurácia menor que $\pm 1,25 \%$ no cálculo da eficiência.

A perda no perfil consiste de um coeficiente básico $\zeta_{p 0}$ representativo do regime incompressível, corrigido por fatores multiplicativos relacionados ao número de Reynolds $\chi_{R e}$, à incidência $\chi_{i}$ e a espessura do bordo de fuga $\chi_{t e}$. Efeitos adicionais para o número de Mach $\Delta \zeta_{p, M}$ e para a espessura do bordo de fuga $\Delta \zeta_{p, t e}$ são acrescentados, conforme a expressão abaixo:

$$
\zeta_{p}=\chi_{\mathrm{Re}} \chi_{t e} \chi_{i} \zeta_{p 0}+\Delta \zeta_{p, M}+\Delta \zeta_{p, t e}
$$

O parâmetro básico de perda no perfil $\zeta_{p o}(t / l) \operatorname{sen} \lambda_{2}$ é dado graficamente como função do parâmetro de sustentação modificado $F_{L}(t / l)$ e da razão de contração $C R$ e da solidez (figura 28). O parâmetro de sustentação $F_{L}$ depende da deflexão do escoamento e a razão de contração $C R$ representa a razão da largura de entrada pela largura na garganta. Para utilização dos gráficos da figura 28 é recomendado considerar que o ângulo de entrada de fluxo $\lambda_{1}$ corresponde à condição de incidência ótima na palheta e o ângulo de saída do fluxo $\lambda_{2}$ deve ser considerado na situação de baixa velocidade. A figura 29 mostra a razão de contração para perfis típicos como função da solidez e dos ângulos de fluxo e a variação da perda de perfil adicional para escoamento supersônico $\Delta \zeta_{p, M}$ com o número de Mach isentrópico na saída da grade, válida para palhetas convergentes com superfície de sucção plana a jusante da garganta. 

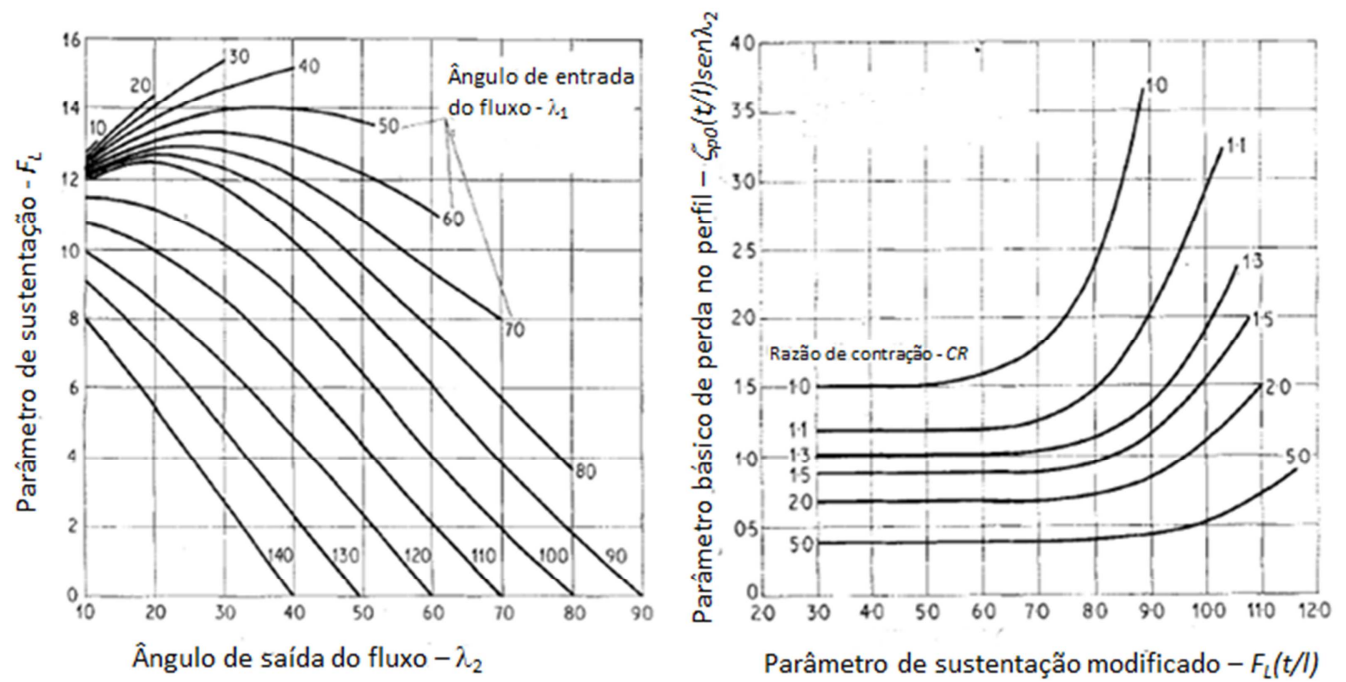

Figura 28 - Parâmetro de sustentação (esquerda) e parâmetro básico de perda no perfil (direita), conforme Craig e Cox [47].
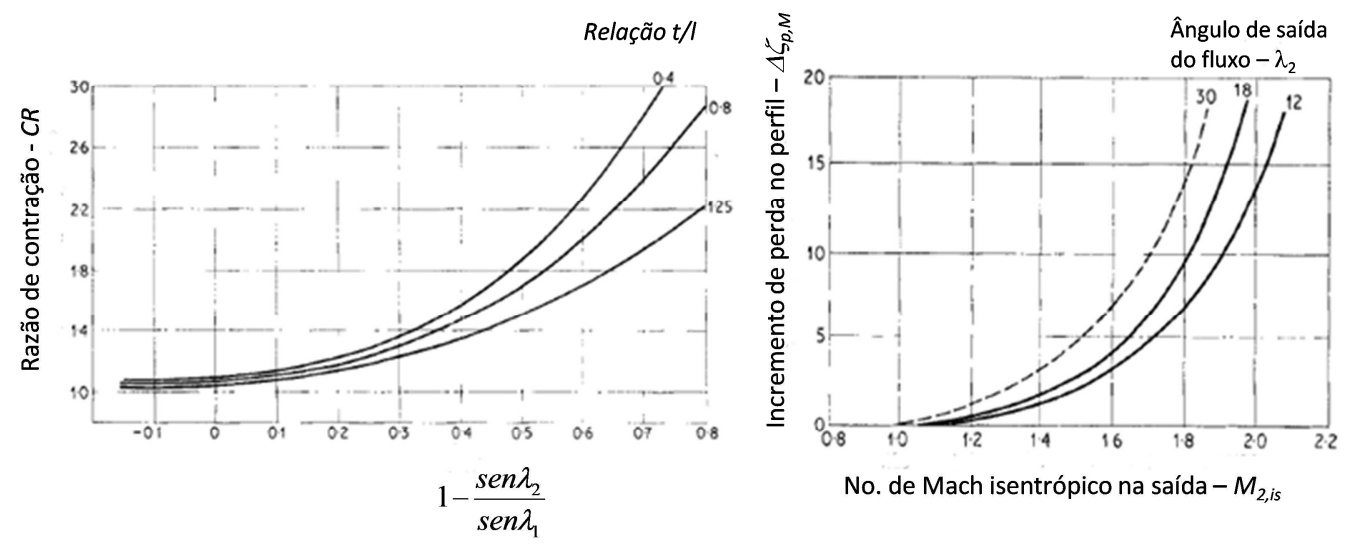

Figura 29 - Razão de contração (esquerda) e acréscimo na perda de perfil com o número de Mach na saída da grade (direita) [47].

As perdas secundárias são avaliadas a partir de um coeficiente básico $\zeta_{s, b}$, corrigido por fatores multiplicativos relacionados ao número de Reynolds $\chi_{R e}$, e a razão de aspecto $\chi_{A R}$, conforme a seguinte expressão:

$$
\zeta_{s}=\chi_{\mathrm{Re}} \chi_{A R} \zeta_{s, b}
$$


A figura 30 mostra o coeficiente básico de perda secundária como função do fator de sustentação $F_{L}$, da solidez e do quadrado da razão de velocidades da grade e fator de correção para a razão de aspecto $h / l$.

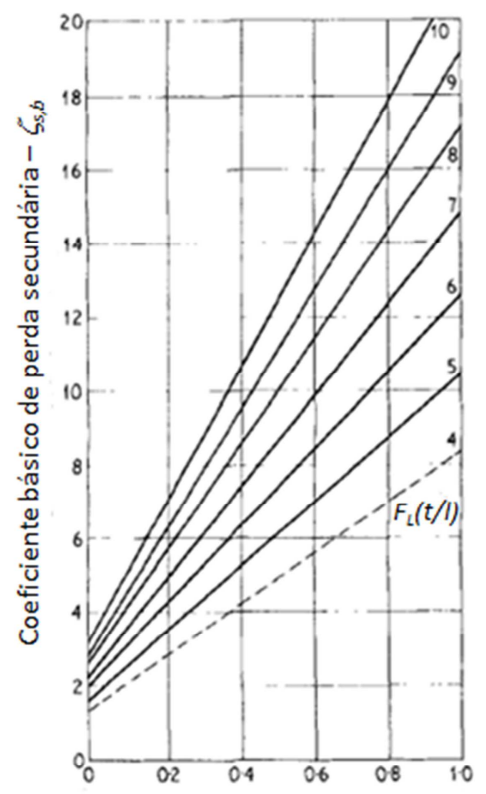

Quadrado da relação de velocidades através da palheta $-\left(V_{1} / V_{2}\right)^{2}$

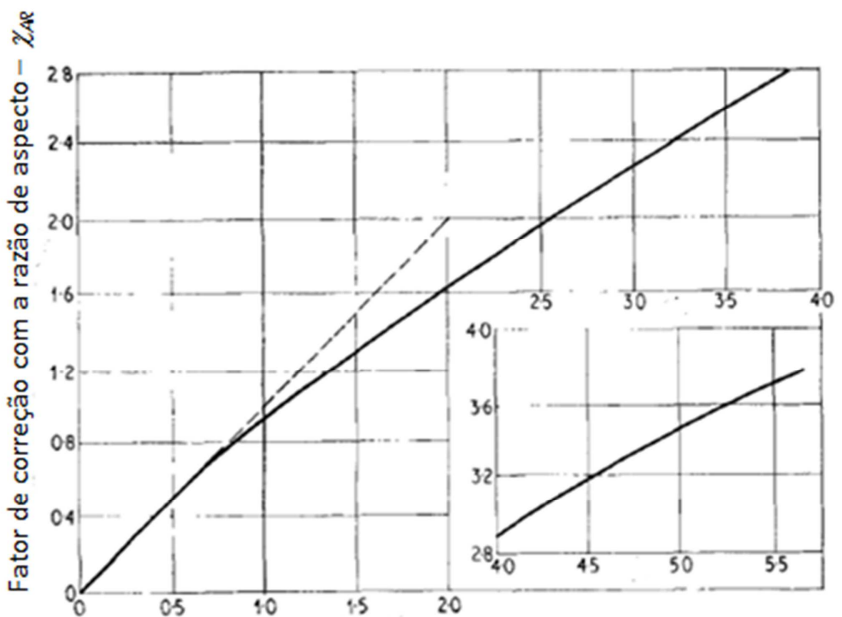

Inverso da razão de aspecto $-I / h$

Figura 30 - Coeficiente básico de perda secundária (esquerda) e fator de correção para a razão de aspecto (direita) [47].

Os coeficientes de perda dados por Craig e Cox referem-se à velocidade real na saída da grade e são expressos em porcentagem. A correção pelo número de Reynolds paradoxalmente utiliza a largura da garganta como parâmetro característico. O método aborda ainda as perdas por incidência desfavorável, as perdas em passagens difusivas e cavidades entre estágios e as perdas por vazamento no topo de palhetas cintadas e com sobreposição. Esta última é dada como função da sobreposição entre as palhetas $h_{3} / h_{2}$, da relação entre folga radial e altura da palheta $\Delta_{\ell} / h$ e de um coeficiente de vazamento pelo topo definido pela expressão $\left(w_{3, \text { is }}{ }^{2}-w_{2}^{2}\right) / w_{3}^{2}$. 


\section{Proposição de Modelo de Perdas para Grades de Turbinas}

Nesta seção será proposta uma metodologia desenvolvida a partir dos trabalhos de Stewart et al. e de Baljé, apresentados respectivamente nas seções 2.3.2.3 e 2.3.2.4, tendo em vista obter uma maior acurácia na estimativa do desempenho de uma grade de turbina axial. A inspiração nos trabalhos citados é justificada pelo fato de se validar uma abordagem fortemente fundamentada nos conceitos teóricos da mecânica dos fluidos. Os métodos tradicionais de Ainley \& Mathiesson e Craig \& Cox, apresentados respectivamente nas seções 2.3.2.2 e 2.3.2.5, apesar da possível acurácia e da fama que gozam, apresentam algumas lacunas conceituais que não encorajaram sua utilização no presente trabalho.

O ponto de melhoria comum aos métodos de Stewart et al. e de Baljé identificados neste trabalho é a correlação entre o fator de difusão e a geometria do escoamento na grade. Quanto maior a acurácia desta correlação, maior será o potencial do método produzir resultados que representam com realismo a física do problema.

A expressão utilizada por Stewart para o fator de difusão, conforme exposta na equação (2.80), obtida a partir de uma suposição de distribuição retangular de velocidade, é satisfatória para demonstrar de forma qualitativa que é possível obter uma curva da perda versus solidez a partir dos conceitos básicos da teoria da camada limite. Apesar de contemplar a influência das características da grade, como a solidez e a taxa de aceleração, é reconhecido pelo autor que tal expressão produz valores discutíveis para a solidez ótima da grade [40]. Adicionalmente Baljé [27] comenta que a expressão proposta por Stewart possui duas deficiências: não seria possível trabalhar com um coeficiente de Zweiffel maior que 1 e que uma alta taxa de aceleração produziria valores negativos para o fator de difusão. 
A correlação utilizada por Baljé para o fator de difusão [45], conforme exposta na equação (2.99), por sua vez tem como base testes experimentais em grades de compressores axiais, principalmente os realizados pela NASA por Lieblein [29]. Baljé conclui pelo seu bom resultado para uso generalizado em grades axiais, com possível exceção para as grades de impulso, cuja perda possivelmente resulta subestimada. Um fato importante é que esta correlação foi ajustada para valores do parâmetro de circulação $C_{f a x}$ no intervalo de zero a 1 , enquanto que em grades de turbinas este parâmetro pode chegar a valores maiores que 5, mesmo em regime incompressível, o que torna a validade da extrapolação discutível.

Stewart[48] já havia especulado a aplicação da abordagem utilizada com sucesso por Lieblein [29] em grades de compressores para aplicação em grades de turbinas, sendo comentado que em geral as palhetas de turbinas requerem uma deflexão angular muito maior que o exigido em palhetas de compressores. Este requisito resulta em uma geometria com maior ângulo de curvatura, ângulos de entrada e saída mais acentuados, maior solidez e maior carregamento. Além das diferenças na geometria, as palhetas de turbinas também trabalham com a taxa de aceleração num intervalo bem mais amplo que as palhetas de compressores, o que definitivamente terá influência sobre a distribuição de velocidades nas superfícies do perfil e na extensão da superfície onde ocorre a difusão.

As dificuldades descritas por Stewart para estabelecer uma correlação entre fator de difusão e espessura de quantidade de movimento constituem a motivação para a proposição de uma modificação aos métodos mencionados, de forma que se possa alcançar uma estimativa mais precisa da perda em grades de turbinas, principalmente tendo-se em conta considerar a influência da solidez. Para este fim serão utilizados os dados experimentais obtidos pela NASA em testes de grades de turbina operando em túnel de vento em baixa velocidade conforme trabalho de Dunavant e Erwin [41]. Estes dados fizeram parte das informações utilizadas por Stewart para produzir a correlação da espessura de quantidade de movimento versus fator da difusão, conforme retratada na equação (2.81). 


\subsection{Análise de Teste de Grade Disponível na Literatura [41]}

Neste trabalho uma série de cinco diferentes perfis representativos de palhetas subsônicas é ensaiada em túnel de vento, compreendendo um intervalo de ângulo de curvatura $\Delta \lambda_{c}$ de $65^{\circ}$ a $120^{\circ}$ e de razão espessura corda $d_{\max } / C$ de 10 a $25 \%$, montados em grades com solidez de 1,5 e 1,8.

Tabela 2 - Compilação dos resultados de Dunavant e Erwin [41] para $\sigma=1,5$.

\begin{tabular}{|c|c|c|c|c|c|c|c|c|c|c|c|c|c|c|c|c|}
\hline$\Delta \lambda_{c}$ & $\sigma$ & $d_{\max } / C$ & I/C & $\lambda_{1}$ & $\lambda_{2}$ & $\delta \mathrm{u}$ & $\operatorname{ctg} \lambda_{\infty}$ & $\mathrm{C}_{\mathrm{w} 1}$ & $\mu$ & $S_{\max }$ & $\mathrm{S}_{2}$ & $D_{\text {suc }}$ & g/l & $\Delta \mathrm{V}_{\mathrm{u}} / \sigma \mathrm{V}_{1}$ & $\Delta \mathrm{V}_{\mathrm{u}} / \sigma(\mathrm{\sigma} / \mathrm{C}) \mathrm{V}_{1}$ & $\mathrm{C}_{\mathrm{fax}}$ \\
\hline 65 & 1,5 & 0,1 & 1,025 & 90 & 47,7 & 0,91 & 0,45 & 0,012 & 1,35 & 3,35 & 1,90 & 0,2469 & 0,0032 & 0,61 & 0,59 & 1,21 \\
\hline 65 & 1,5 & 0,1 & 1,025 & 90 & 44,3 & 1,02 & 0,51 & 0,016 & 1,43 & & & & 0,0037 & 0,68 & 0,67 & 1,37 \\
\hline 65 & 1,5 & 0,1 & 1,025 & 90 & 40,7 & 1,16 & 0,58 & 0,015 & 1,53 & 3,70 & 2,35 & 0,203 & 0,0031 & 0,78 & 0,76 & 1,55 \\
\hline 65 & 1,5 & 0,1 & 1,025 & 90 & 34,5 & 1,46 & 0,73 & 0,017 & 1,77 & 4,45 & 3,13 & 0,1613 & 0,0027 & 0,97 & 0,95 & 1,94 \\
\hline 65 & 1,5 & 0,1 & 1,025 & 90 & 28,8 & 1,82 & 0,91 & 0,019 & 2,08 & 6,10 & 4,55 & 0,1363 & 0,0022 & 1,21 & 1,18 & 2,43 \\
\hline 65 & 1,5 & 0,1 & 1,025 & 90 & 23,1 & 2,34 & 1,17 & 0,024 & 2,55 & 8,20 & 7,00 & 0,0761 & 0,0018 & 1,56 & 1,52 & 3,13 \\
\hline 65 & 1,5 & 0,1 & 1,025 & 105 & 65,7 & 0,72 & 0,09 & 0,012 & 1,06 & 2,65 & 1,19 & 0,3299 & 0,0052 & 0,46 & 0,45 & 0,90 \\
\hline 65 & 1,5 & 0,1 & 1,025 & 105 & 60,1 & 0,84 & 0,15 & 0,013 & 1,11 & 2,95 & 1,35 & 0,3235 & 0,0051 & 0,54 & 0,53 & 1,05 \\
\hline 65 & 1,5 & 0,1 & 1,025 & 105 & 56,4 & 0,93 & 0,20 & 0,015 & 1,16 & & & & 0,0054 & 0,60 & 0,59 & 1,16 \\
\hline 65 & 1,5 & 0,1 & 1,025 & 105 & 53 & 1,02 & 0,24 & 0,016 & 1,21 & 3,25 & 1,52 & 0,3161 & 0,0053 & 0,66 & 0,64 & 1,27 \\
\hline 65 & 1,5 & 0,1 & 1,025 & 105 & 44,2 & 1,30 & 0,38 & 0,020 & 1,39 & 4,70 & 2,05 & 0,3396 & 0,0051 & 0,83 & 0,81 & 1,61 \\
\hline 65 & 1,5 & 0,1 & 1,025 & 105 & 37,8 & 1,56 & 0,51 & 0,022 & 1,58 & 5,70 & 2,60 & 0,3246 & 0,0043 & 1,00 & 0,98 & 1,94 \\
\hline 65 & 1,5 & 0,1 & 1,025 & 120 & 75,9 & 0,83 & $-0,16$ & 0,013 & 0,89 & 2,55 & 0,85 & 0,4226 & 0,0080 & 0,48 & 0,47 & 0,83 \\
\hline 65 & 1,5 & 0,1 & 1,025 & 120 & 69,5 & 0,95 & $-0,10$ & 0,014 & 0,92 & 2,82 & 0,92 & 0,4288 & & 0,55 & 0,54 & \\
\hline 65 & 1,5 & 0,1 & 1,025 & 120 & 63,2 & 1,08 & $-0,04$ & 0,015 & 0,97 & 3,60 & 1,00 & 0,473 & 0,0078 & 0,62 & 0,61 & 1,08 \\
\hline 65 & 1,5 & 0,1 & 1,025 & 120 & 60,3 & 1,15 & 0,00 & 0,016 & 1,00 & 3,90 & 1,10 & 0,4689 & 0,0079 & 0,66 & 0,65 & 1,15 \\
\hline 65 & 1,5 & 0,1 & 1,025 & 120 & 53,8 & 1,31 & 0,08 & 0,019 & 1,07 & 5,00 & 1,20 & 0,5101 & 0,0080 & 0,76 & 0,74 & 1,31 \\
\hline 80 & 1,5 & 0,1 & 1,082 & 90 & 39,4 & 1,22 & 0,61 & 0,018 & 1,58 & 3,50 & 2,63 & 0,1332 & 0,0034 & 0,81 & 0,75 & 1,62 \\
\hline 80 & 1,5 & 0,1 & 1,082 & 90 & 32,5 & 1,57 & 0,78 & 0,018 & 1,86 & 4,60 & 3,60 & 0,1153 & 0,0024 & 1,05 & 0,97 & 2,09 \\
\hline 80 & 1,5 & 0,1 & 1,082 & 90 & 29,6 & 1,76 & 0,88 & 0,019 & 2,02 & & & & 0,0021 & 1,17 & 1,08 & 2,35 \\
\hline 80 & 1,5 & 0,1 & 1,082 & 90 & 26,7 & 1,99 & 0,99 & 0,032 & 2,23 & 6,10 & 5,00 & 0,0946 & 0,0030 & 1,33 & 1,23 & 2,65 \\
\hline 80 & 1,5 & 0,1 & 1,082 & 90 & 24,3 & 2,21 & 1,11 & 0,045 & 2,43 & 7,30 & 6,30 & 0,071 & 0,0035 & 1,48 & 1,36 & 2,95 \\
\hline 80 & 1,5 & 0,1 & 1,082 & 90 & 16,3 & 3,42 & 1,71 & 0,079 & 3,56 & 15,50 & 14,00 & 0,0496 & 0,0029 & 2,28 & 2,11 & 4,56 \\
\hline 80 & 1,5 & $\overline{0,1}$ & 1,082 & 105 & 45,5 & 1,25 & 0,36 & 0,019 & 1,35 & 3,45 & 1,98 & 0,2424 & 0,0048 & 0,81 & 0,74 & 1,56 \\
\hline 80 & 1,5 & 0,1 & 1,082 & 105 & 42 & 1,38 & 0,42 & 0,018 & 1,44 & & & & 0,0040 & 0,89 & 0,82 & 1,71 \\
\hline 80 & 1,5 & 0,1 & 1,082 & 105 & 39,3 & 1,49 & 0,48 & 0,020 & 1,53 & 3,95 & 2,51 & 0,2029 & 0,0040 & 0,96 & 0,89 & 1,85 \\
\hline 80 & 1,5 & 0,1 & 1,082 & 105 & 32,5 & 1,84 & 0,65 & 0,021 & 1,80 & 4,60 & 3,37 & 0,1441 & 0,0030 & 1,18 & 1,09 & 2,29 \\
\hline 80 & 1,5 & 0,1 & 1,082 & 105 & 29,8 & 2,01 & 0,74 & 0,021 & 1,94 & 4,80 & 3,95 & 0,0929 & 0,0026 & 1,30 & 1,20 & 2,51 \\
\hline 80 & 1,5 & 0,1 & 1,082 & 105 & 23,2 & 2,60 & 1,03 & 0,044 & 2,45 & 7,00 & 6,10 & 0,0665 & 0,0034 & 1,67 & 1,55 & 3,24 \\
\hline 80 & 1,5 & 0,1 & 1,082 & 120 & 60,6 & 1,14 & $-0,01$ & 0,021 & 0,99 & 3,00 & 1,14 & 0,3836 & 0,0098 & 0,66 & 0,61 & 1,14 \\
\hline 80 & 1,5 & 0,1 & 1,082 & 120 & 53,8 & 1,31 & 0,08 & 0,022 & 1,07 & 3,30 & 1,28 & 0,3772 & 0,0088 & 0,76 & 0,70 & 1,31 \\
\hline 80 & 1,5 & 0,1 & 1,082 & 120 & 47,4 & 1,50 & 0,17 & 0,028 & 1,18 & 3,75 & 1,55 & 0,3571 & 0,0093 & 0,86 & 0,80 & 1,50 \\
\hline 80 & 1,5 & 0,1 & 1,082 & 120 & 41,2 & 1,72 & 0,28 & 0,025 & 1,31 & 4,50 & 1,85 & 0,3588 & 0,0067 & 0,99 & 0,92 & 1,72 \\
\hline 80 & 1,5 & 0,1 & 1,082 & 120 & 35,3 & 1,99 & 0,42 & 0,033 & 1,50 & 5,30 & 2,50 & 0,3132 & 0,0068 & 1,15 & 1,06 & 1,99 \\
\hline 95 & 1,5 & 0,15 & 1,115 & 105 & 29,5 & 2,04 & 0,75 & 0,024 & 1,96 & 5,50 & 4,30 & 0,1158 & 0,0028 & 1,31 & 1,18 & 2,53 \\
\hline 95 & 1,5 & 0,15 & 1,115 & 105 & 26,2 & 2,30 & 0,88 & 0,028 & 2,19 & 6,50 & 5,25 & 0,1013 & 0,0026 & 1,48 & 1,33 & 2,86 \\
\hline 95 & 1,5 & 0,15 & 1,115 & 105 & 23,1 & 2,61 & 1,04 & 0,034 & 2,46 & 7,90 & 6,50 & 0,0929 & 0,0025 & 1,68 & 1,51 & 3,25 \\
\hline 95 & 1,5 & 0,15 & 1,115 & 105 & 19,4 & 3,11 & 1,29 & 0,037 & 2,91 & 9,80 & 8,40 & 0,0742 & 0,0020 & 2,00 & 1,79 & 3,87 \\
\hline 95 & 1,5 & 0,15 & 1,115 & 105 & 15,5 & 3,87 & 1,67 & 0,037 & 3,61 & 13,00 & 11,20 & 0,0718 & 0,0013 & 2,49 & 2,24 & 4,82 \\
\hline 95 & 1,5 & 0,15 & 1,115 & 120 & 44,8 & 1,58 & 0,21 & 0,018 & 1,23 & 3,20 & 1,71 & 0,269 & 0,0053 & 0,91 & 0,82 & 1,58 \\
\hline 95 & 1,5 & 0,15 & 1,115 & 120 & 41,9 & 1,69 & 0,27 & 0,018 & 1,30 & 3,30 & 1,76 & 0,2697 & 0,0048 & 0,98 & 0,88 & 1,69 \\
\hline 95 & 1,5 & 0,15 & 1,115 & 120 & 35,6 & 1,97 & 0,41 & 0,018 & 1,49 & 3,40 & 2,22 & 0,192 & 0,0036 & 1,14 & 1,02 & 1,97 \\
\hline 95 & 1,5 & 0,15 & 1,115 & 120 & 31,6 & 2,20 & 0,52 & 0,018 & 1,65 & 3,55 & 2,65 & 0,136 & 0,0030 & 1,27 & 1,14 & 2,20 \\
\hline 95 & 1,5 & 0,15 & 1,115 & 120 & 26,3 & 2,60 & 0,72 & 0,021 & 1,95 & 5,00 & 4,10 & 0,0945 & 0,0025 & 1,50 & 1,35 & 2,60 \\
\hline 95 & 1,5 & 0,15 & 1,115 & 135 & 60,5 & 1,57 & $-0,22$ & 0,017 & 0,81 & 2,60 & 0,75 & 0,4629 & 0,0118 & 0,74 & 0,66 & 1,04 \\
\hline 95 & 1,5 & 0,15 & 1,115 & 135 & 57,1 & 1,65 & $-0,18$ & 0,017 & 0,84 & 2,70 & 0,75 & 0,473 & 0,0105 & 0,78 & 0,70 & 1,10 \\
\hline 95 & 1,5 & 0,15 & 1,115 & 135 & 53,5 & 1,74 & $-0,13$ & 0,016 & 0,88 & & & & 0,0093 & 0,82 & 0,74 & 1,16 \\
\hline 95 & 1,5 & 0,15 & 1,115 & 135 & 50,2 & 1,83 & $-0,08$ & 0,015 & 0,92 & 2,75 & 0,88 & 0,4343 & 0,0079 & 0,86 & 0,78 & 1,22 \\
\hline 95 & 1,5 & 0,15 & 1,115 & 135 & 47,1 & 1,93 & $-0,04$ & 0,016 & 0,97 & 2,80 & 0,95 & 0,4175 & 0,0078 & 0,91 & 0,82 & 1,29 \\
\hline 95 & 1,5 & 0,15 & 1,115 & 135 & 40,6 & 2,17 & 0,08 & 0,016 & 1,09 & 3,35 & 1,15 & 0,4141 & 0,0061 & 1,02 & 0,92 & 1,44 \\
\hline 110 & 1,5 & 0,15 & 1,18 & 120 & 31,5 & 2,21 & 0,53 & 0,016 & 1,66 & 3,80 & 2,95 & 0,1189 & 0,0025 & 1,28 & 1,08 & 2,21 \\
\hline 110 & 1,5 & 0,15 & 1,18 & 120 & 26 & 2,63 & 0,74 & 0,020 & 1,98 & 5,10 & 4,40 & 0,0712 & 0,0022 & 1,52 & 1,29 & 2,63 \\
\hline 110 & 1,5 & 0,15 & 1,18 & 120 & 23 & 2,93 & 0,89 & 0,021 & 2,22 & 6,20 & 5,35 & 0,0711 & 0,0018 & 1,69 & 1,44 & 2,93 \\
\hline 110 & 1,5 & 0,15 & 1,18 & 120 & 17,2 & 3,81 & 1,33 & 0,033 & 2,93 & 10,60 & 9,40 & 0,0583 & 0,0016 & 2,20 & 1,86 & 3,81 \\
\hline 110 & 1,5 & 0,15 & 1,18 & 120 & 15 & 4,31 & 1,58 & 0,044 & 3,35 & 15,00 & 13,25 & 0,0601 & 0,0017 & 2,49 & 2,11 & 4,31 \\
\hline 110 & 1,5 & 0,15 & 1,18 & 135 & 47 & 1,93 & $-0,03$ & 0,062 & 0,97 & 2,55 & 1,15 & 0,3284 & 0,0281 & 0,91 & 0,77 & 1,29 \\
\hline 110 & 1,5 & 0,15 & 1,18 & 135 & 39,1 & 2,23 & 0,12 & 0,033 & 1,12 & 2,60 & 1,42 & 0,261 & 0,0111 & 1,05 & 0,89 & 1,49 \\
\hline 110 & 1,5 & 0,15 & 1,18 & 135 & 35,5 & 2,40 & 0,20 & 0,025 & 1,22 & 2,60 & 1,68 & 0,1962 & 0,0071 & 1,13 & 0,96 & 1,60 \\
\hline 110 & 1,5 & 0,15 & 1,18 & 135 & 28,6 & 2,83 & 0,42 & 0,024 & 1,48 & 2,95 & 2,32 & 0,1132 & 0,0047 & 1,34 & 1,13 & 1,89 \\
\hline 110 & 1,5 & 0,15 & 1,18 & 135 & 23,5 & 3,30 & 0,65 & 0,024 & 1,77 & 4,25 & 3,60 & 0,0796 & 0,0032 & 1,56 & 1,32 & 2,20 \\
\hline
\end{tabular}


Os resultados dos testes estão compilados nas tabelas 2 e 3 , onde são mostrados o ângulo de curvatura da palheta $\Delta \lambda_{c}$, a solidez $\sigma$, a relação espessura corda $d_{\max } / C$, os ângulos de entrada e saída do fluxo $\lambda_{1}$ e $\lambda_{2}$, os parâmetros da grade $\delta u$ e $\operatorname{ctg} \lambda_{\infty}$, o coeficiente de força da esteira $C_{w 1}$, a taxa de aceleração da grade $\mu$, os coeficientes de pressão dinâmica máximo $S_{\max }$ e no bordo de fuga $S_{2}$, o fator de difusão na superfície de sucção $D_{s u c}$ e os parâmetros de circulação $\Delta V_{u} /\left(\sigma V_{l}\right), \Delta V_{u} /\left(\sigma V_{l} l / C\right)$ e $C_{f a x}$. Observa-se que os ensaios cobrem uma ampla faixa de operação, desde condições de sub-impulso até de alta aceleração. Os coeficientes de pressão dinâmica $S_{\max }$ e $S_{2}$ observados na superfície de sucção são adimensionalizados utilizando-se a pressão dinâmica a montante da grade. $\mathrm{O}$ coeficiente de força da esteira $C_{w 1}$ é representativo da perda no escoamento. A partir destes parâmetros foram calculados o fator de difusão na superfície de sucção $D_{s u c}$ e a razão espessura de quantidade de movimento corda $\vartheta / C$, seguindose procedimento definido por Stewart [48] para condições de escoamento incompressível, conforme as expressões a seguir:

$$
\begin{aligned}
& D_{s u c}=1-\frac{V_{2 t e}}{V_{s, \max }}=1-\sqrt{\frac{S_{2}}{S_{\text {max }}}} \\
& \frac{\vartheta}{C}=\frac{C_{w 1}}{2 \mu^{2}}
\end{aligned}
$$

Os resultados dos testes estão mostrados na figura 31 , onde a razão $\boldsymbol{\vartheta} / /$ foi plotada em escala colorida num mapa sob as coordenadas da grade $\delta u$ e $\operatorname{ctg} \lambda_{\infty}$ e confrontados com a previsão pelo método de Baljé. Deve ser ressaltado que a comparação para o parâmetro $\vartheta / l$ não é diretamente aplicável, uma vez que as curvas de Baljé foram construídas assumindo-se um coeficiente de Zweiffel constante igual a 0,9 , enquanto que nos testes [41] foi identificada uma grande variação de $\Psi_{Z}$ entre os valores de 0,36 até 1,68.

A tentativa de correlação entre $\vartheta / l$ e o fator de difusão $D_{s u c}$ determinado no teste resulta em sucesso parcial conforme mostrado na figura 33. Os pontos que não apresentaram boa correlação referem-se às palhetas de maior curvatura (todos os casos com $\Delta \lambda_{c}=120^{\circ}$ e alguns dos casos com $\Delta \lambda_{c}=110^{\circ}$ ). 
Tabela 3 - Compilação dos resultados de Dunavant e Erwin [41] para $\sigma=1,8$.

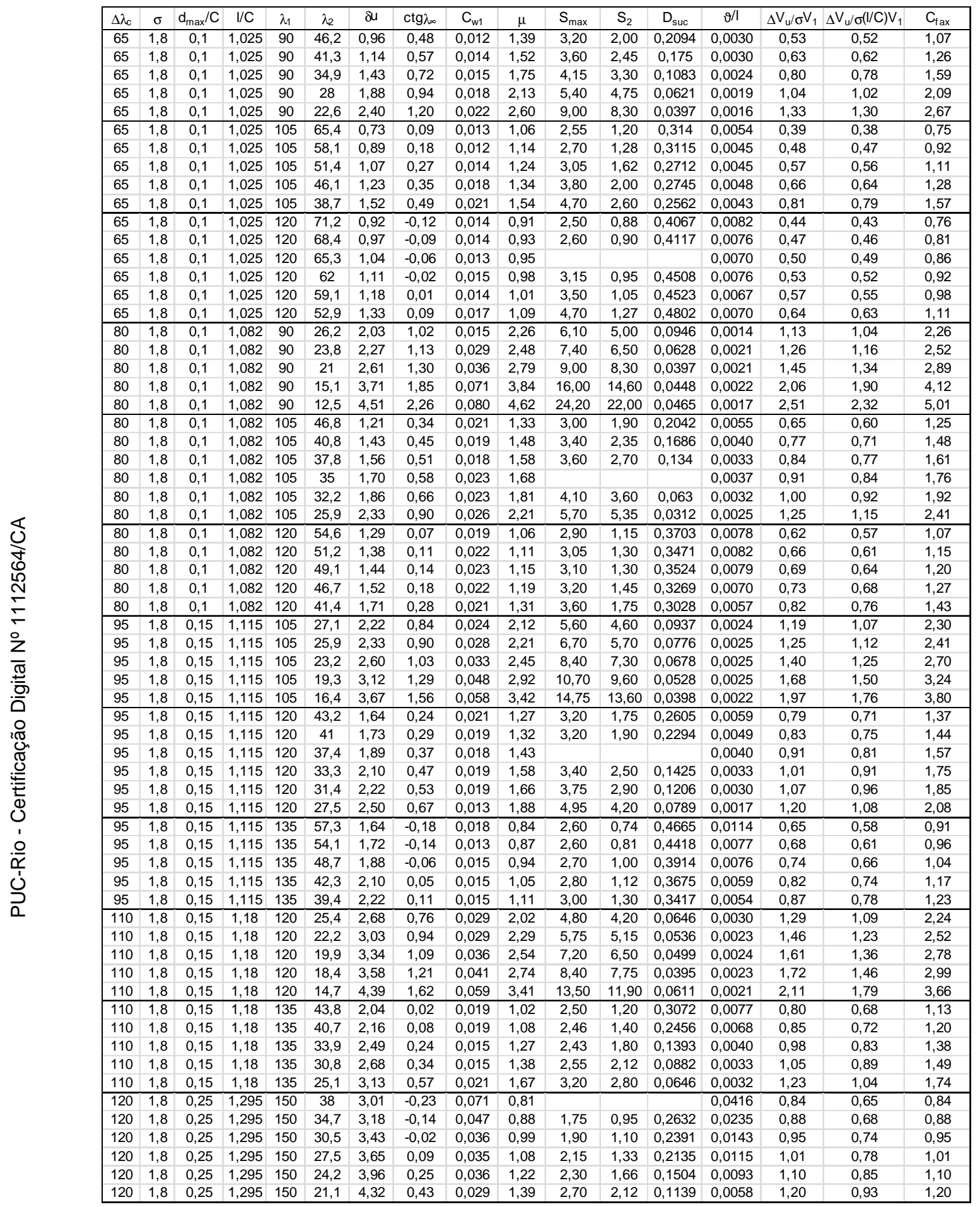




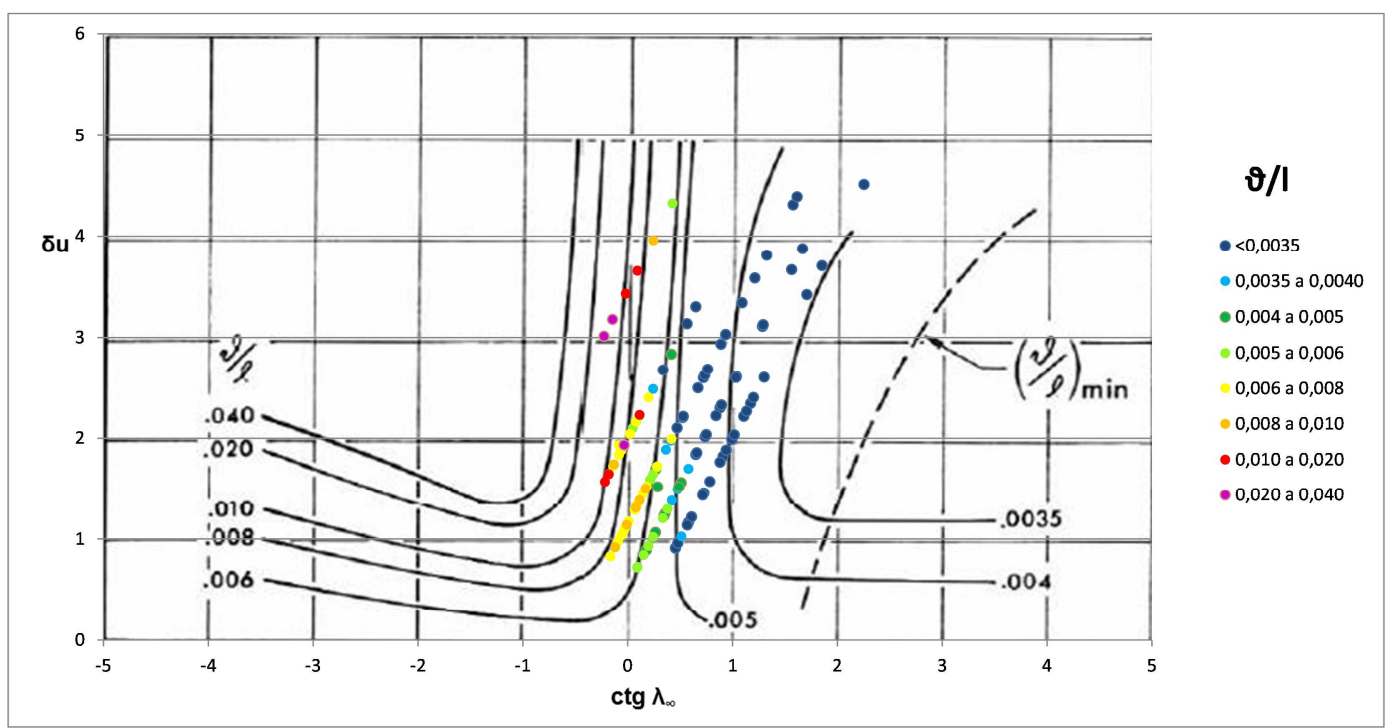

Figura 31 - Resultados dos testes de Dunavant e Erwin [41] confrontados com a previsão pelo método de Baljé [45].

Stewart [48] observa que nos casos onde a correlação não é bem sucedida os diagramas de distribuição de pressão apresentaram dois trechos segmentados com difusão na superfície de sucção ou então apresentaram difusão na superfície de pressão. O padrão normal verificado na maioria dos casos nas demais grades mostra a ocorrência de difusão contínua ao longo da superfície de sucção enquanto que na superfície de pressão não há difusão, conforme ilustrado na figura 32. Assim fica evidenciado que para os casos onde não há boa correlação, o fator de difusão $D_{\text {suc }}$ conforme avaliado pela equação (3.1), não mais representa o parâmetro adequado para caracterizar o problema. Para contornar esta deficiência deveria ser avaliado um novo fator de difusão total $D_{t o t}$, produzido a partir da soma das diversas parcelas de difusão encontradas ao longo das superfícies do perfil nos experimentos. Uma correlação satisfatória, entretanto, não pôde ser obtida, uma vez que este expediente simplificado ignora as diferenças de número de Reynolds e também as diferenças de curvatura côncava e convexa entre as superfícies de pressão e sucção. 

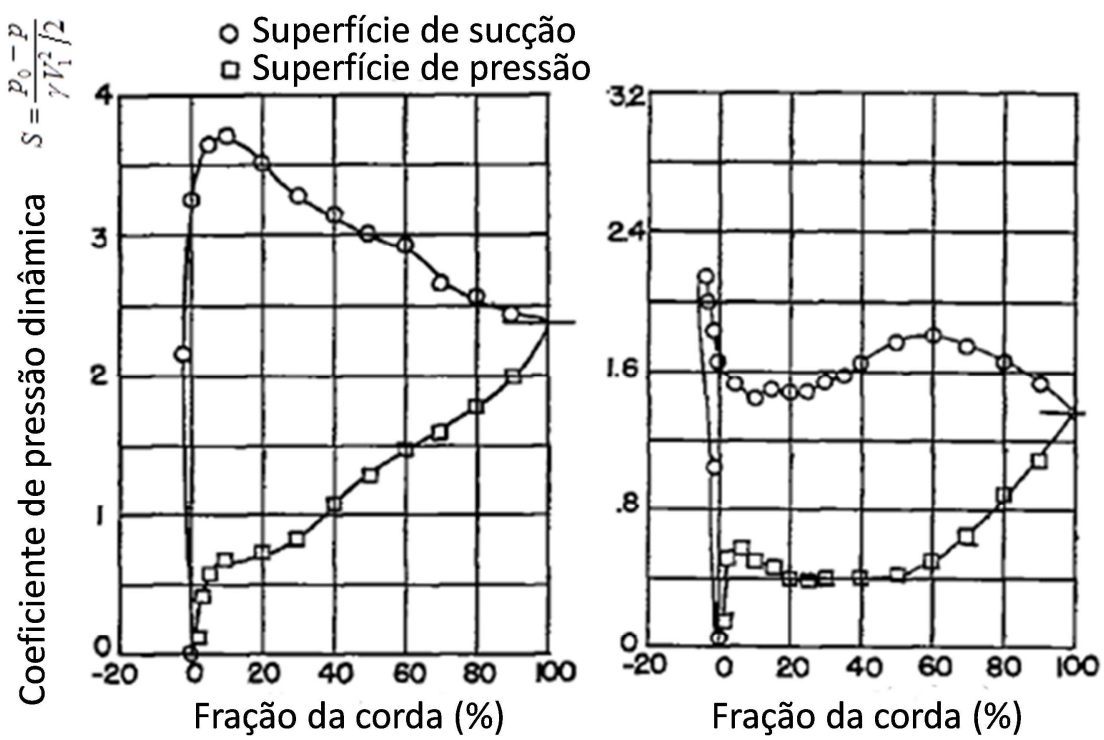

Figura 32 - Distribuição de pressão dinâmica ao redor da palheta: padrões normal (esquerda) e alterado (direita), conforme verificados nos testes [41].

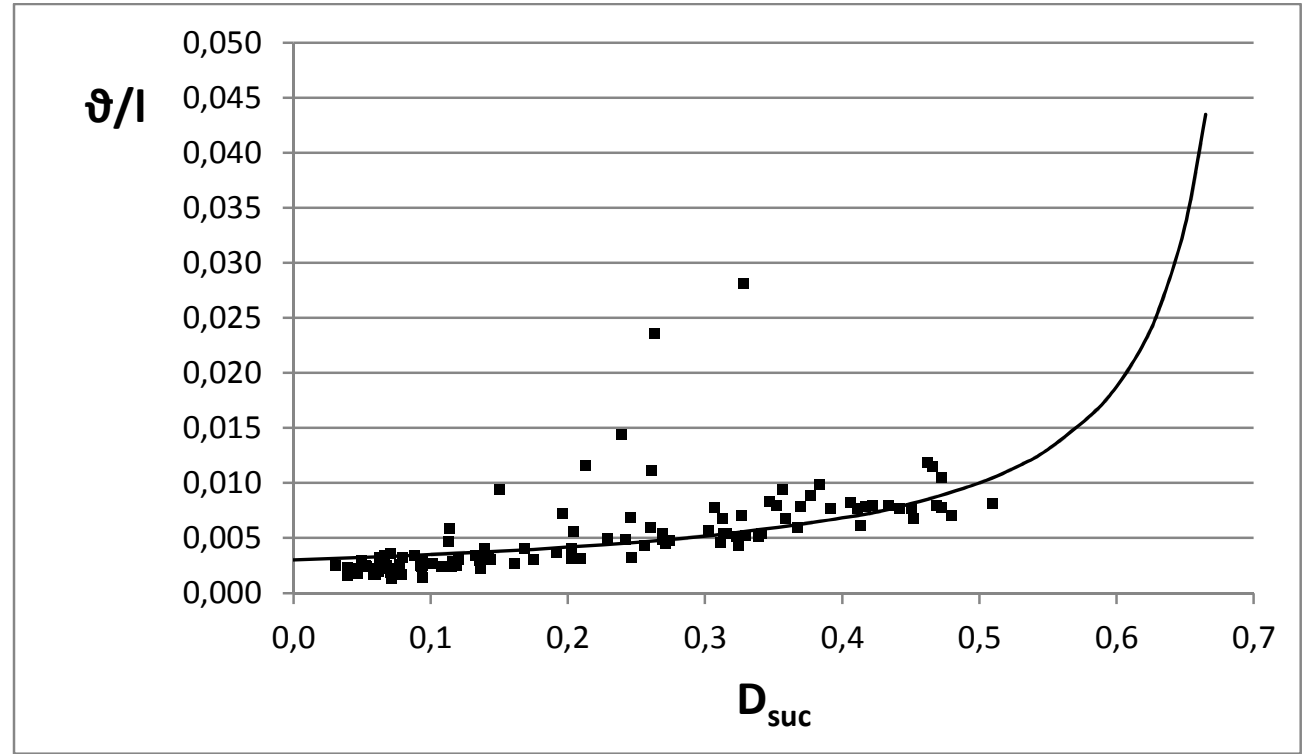

Figura 33 - Correlação entre $\boldsymbol{\vartheta} / l$ e o fator de difusão na superfície de sucção, conforme obtidos nos testes de Dunavant e Erwin [41].

A partir daí foi especulado obter um fator de difusão total equivalente a partir do estabelecimento de uma correlação linear entre a razão de velocidades na superfície de sucção $V_{s, \max } / V_{l}$ e um parâmetro de circulação, conforme idealizado por Baljé [45]. Esta correlação é justamente o elo que possibilita a estimativa de 
perda de uma grade de geometria arbitrária. A seguir os dados experimentais serão rearranjados substituindo-se o fator de difusão obtido das medições por um fator equivalente, calculado a partir de uma correlação linear com um parâmetro de circulação. Para o cálculo do fator de difusão total será considerada a velocidade no bordo de fuga na superfície de sucção $V_{2 t e}$, obtida a partir das informações disponíveis acerca do raio de curvatura do bordo de fuga para as diversas palhetas. Os dados dos testes de Dunavant e Erwin [41] fornecem um excelente fonte de informação para estabelecer uma correlação entre a razão de velocidades na superfície de sucção $V_{s, \max } / V_{1}$ e um parâmetro de circulação. Para esta análise serão apenas excluídos os ensaios onde foi observado o padrão alterado, apresentando difusão na superfície de pressão ou então trechos duplos de difusão na superfície de sucção, conforme mostrado na figura 32.

A figura 34 mostra a correlação dos dados do teste com o parâmetro de circulação $C_{f a x}$ utilizado por Baljé, conforme exposto na equação (2.97). A correlação linear mostra-se satisfatória embora seja encontrado um coeficiente angular aproximadamente duas vezes maior que o apresentado por Balje [45]. Este fato explica porque a correlação original proposta por Baljé apresenta baixa sensibilidade à solidez, fato que levou o autor a se valer da utilização do critério de Zweiffel para contornar o problema.

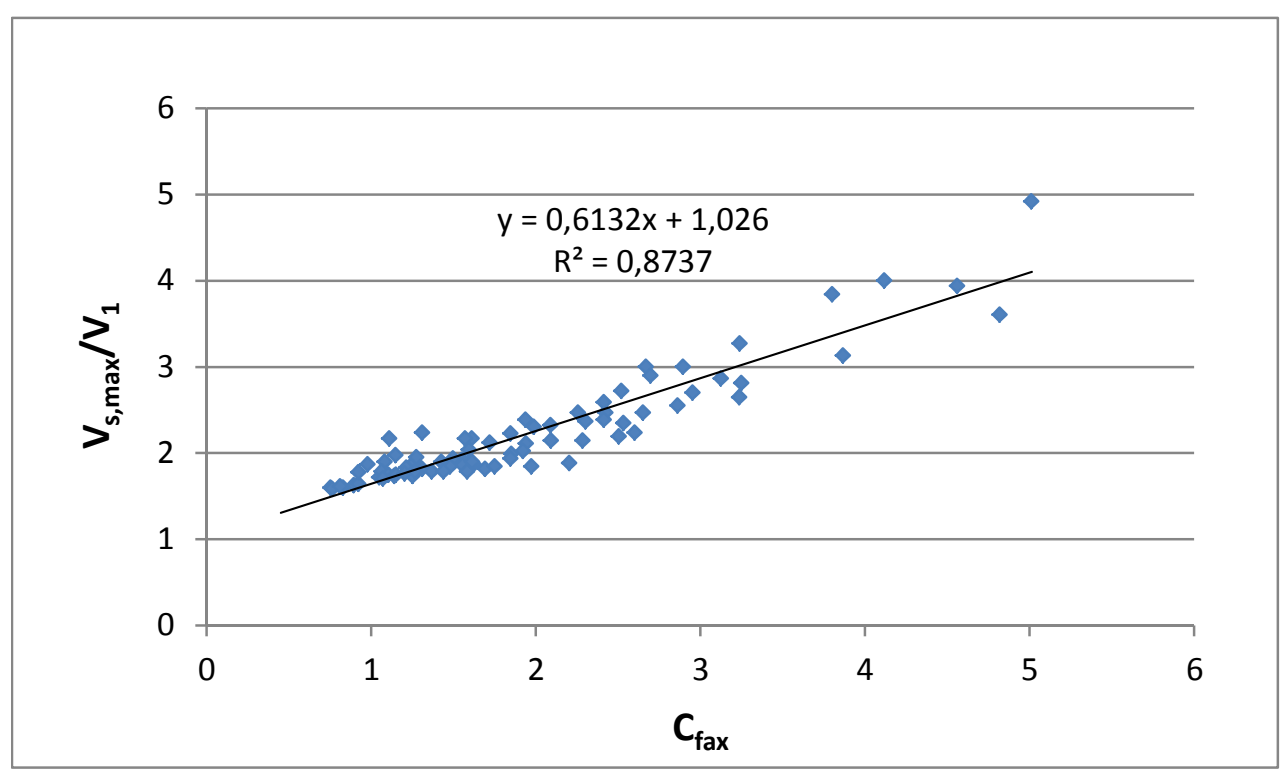

Figura 34 - Correlação entre $V_{s, \max } / V_{l}$ e o parâmetro de circulação $C_{f a x}$ utilizado por Baljé [45] para os testes de Dunavant e Erwin [41]. 
Na figura 35 os dados do teste são reapresentados com um fator de difusão equivalente $D_{\text {tot }}$ obtido a partir da razão de velocidades na superfície de sucção $V_{s, \max } / V_{l}$ conforme a equação (2.99) modificada para um coeficiente angular de 0,6 . Uma significante melhoria na correlação pode ser observada, entretanto ainda pode ser constatada alguma indefinição na região de alta difusão.

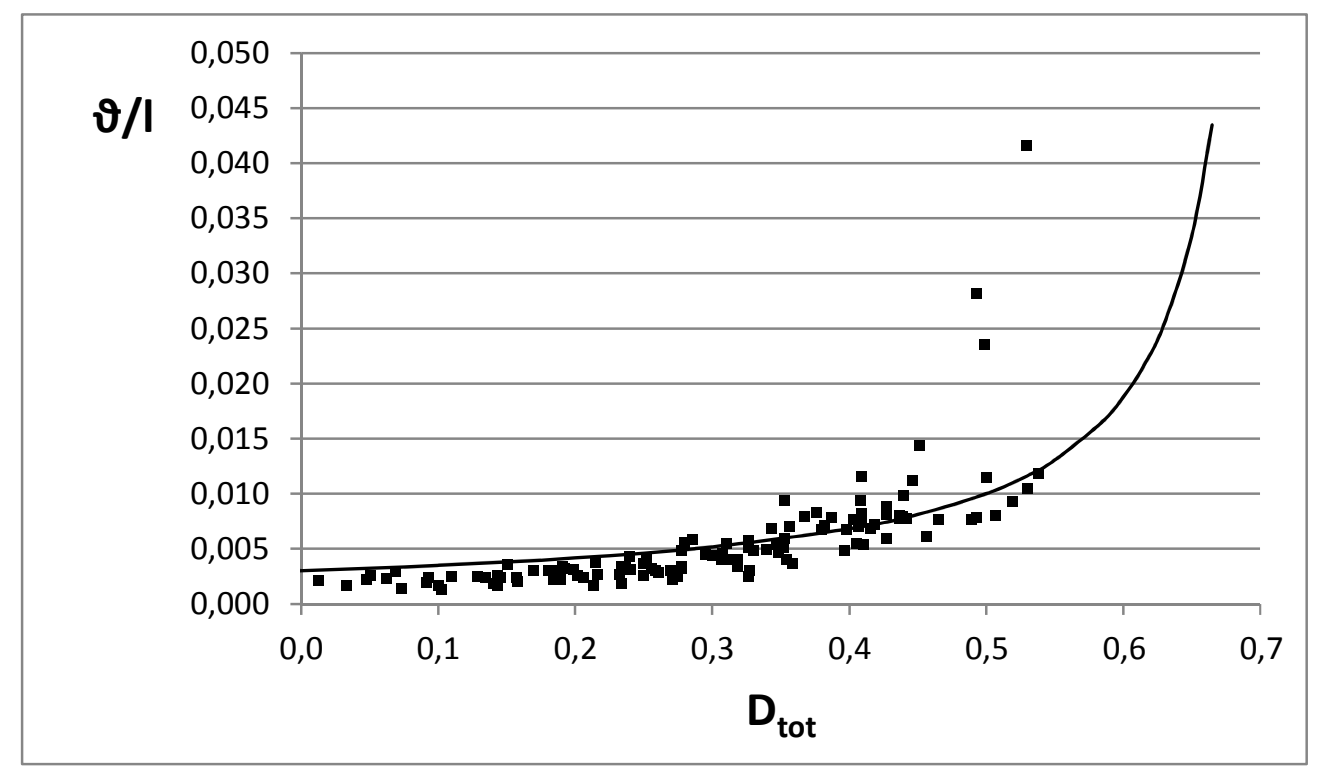

Figura 35 - Correlação entre $\boldsymbol{\vartheta} / l$ e o fator de difusão equivalente calculado com base no parâmetro de circulação $C_{f a x}$ utilizado por Baljé para aos testes de Dunavant e Erwin [41].

Uma nova tentativa é efetuada utilizando o parâmetro de circulação $\Delta V_{u} /\left(\sigma V_{1}\right)$ proposto inicialmente por Lieblein [29]. A figura 42 mostra uma correlação linear satisfatória entre a razão de velocidades na superfície de sucção $V_{s, \max } / V_{l}$ e o parâmetro de circulação de Lieblein. A relação entre os parâmetros de circulação propostos por Lieblein e por Baljé é dada por:

$$
\frac{\Delta V_{u}}{\sigma V_{1}}=\frac{C_{f a x}}{2 \operatorname{sen} \lambda_{1}}
$$

O parâmetro $\Delta V_{u} /\left(\sigma V_{l}\right)$ por não estar projetado na direção axial como o $C_{f a x}$ irá produzir maiores valores para o fator de difusão das grades de impulso, o que propicia uma expectativa positiva para melhorar a correlação entre $\vartheta / l$ e $D_{t o t}$ na região de alta difusão. 


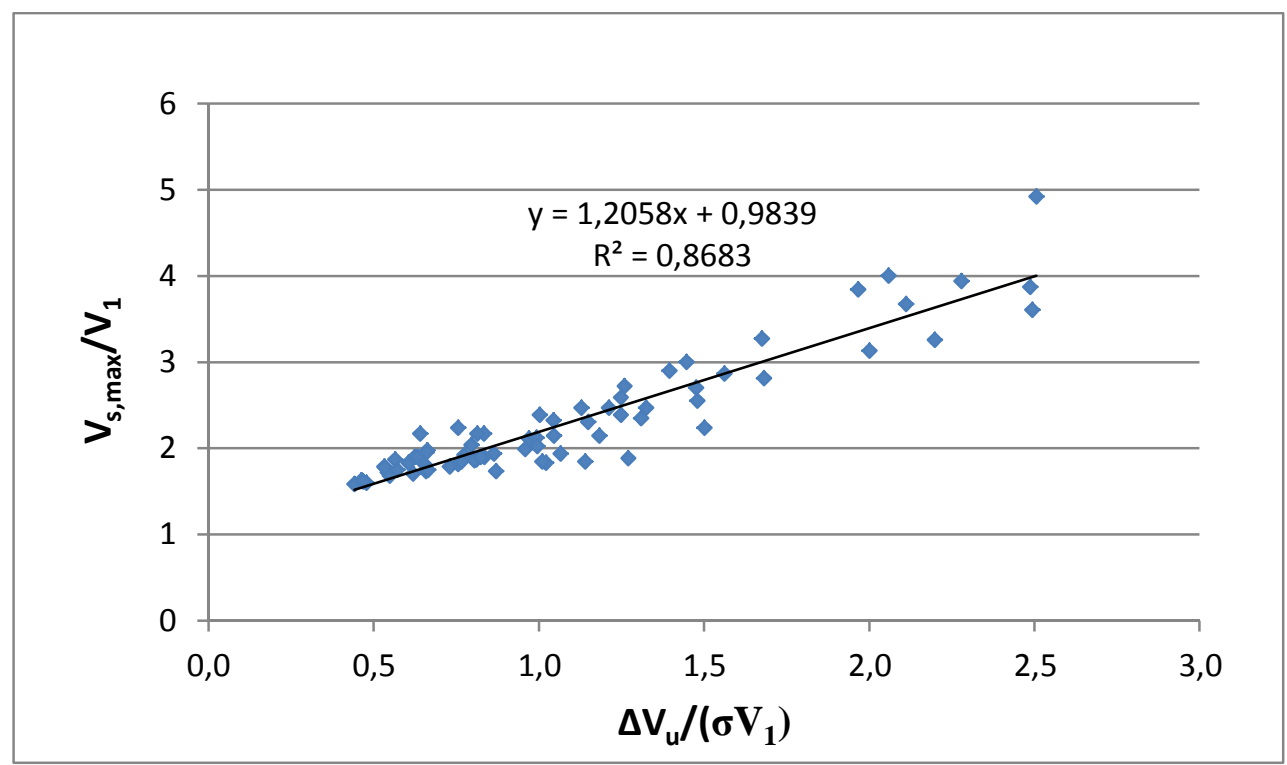

Figura 36 - Correlação entre $V_{s, \max } V_{l}$ e o parâmetro de circulação de Lieblein para os testes de Dunavant e Erwin [41].

O resultado é confirmado na figura 37 onde é constatado que os dados experimentais se aproximaram de maneira bastante satisfatória da correlação proposta por Stewart conforme a equação (2.81).

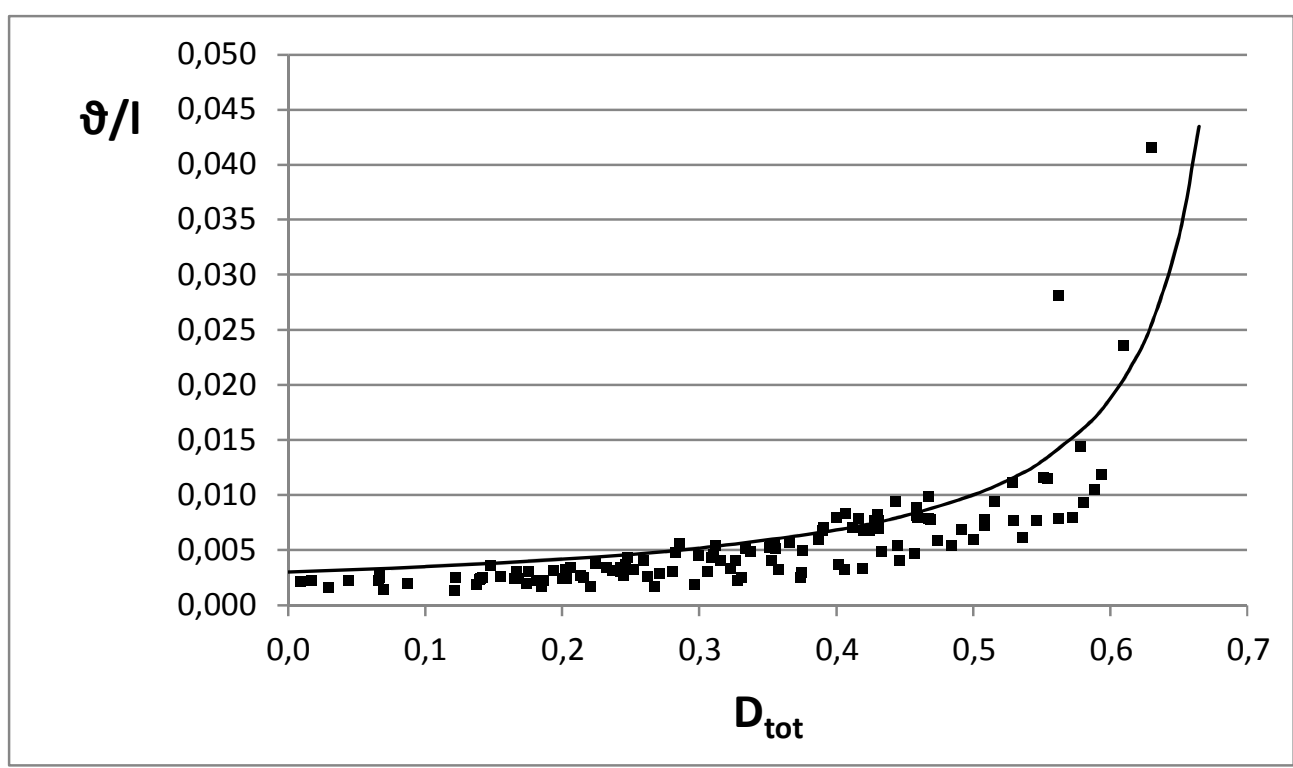

Figura 37 - Correlação entre $\theta / l$ e o fator de difusão equivalente calculado com base no parâmetro de circulação $\Delta V_{u} /\left(\sigma V_{l}\right)$ para os testes de Dunavant e Erwin [41]. 
A utilização do parâmetro de circulação $\Delta V_{u} /\left(\sigma V_{l} l / C\right)$, onde a corda é substituída pelo comprimento da linha de curvatura da palheta é proposta neste trabalho. A justificativa é que este procedimento é considerado mais adequado principalmente para palhetas de grande curvatura, onde a integral de linha que representa a circulação através das palhetas fica melhor caracterizada pela utilização da dimensão $l$. A figura 38 mostra a correlação linear obtida a partir da utilização deste parâmetro de circulação com os dados dos testes. Na figura 39 pode ser observada a correlação entre $\vartheta / l$ e o fator de difusão equivalente calculado com base no parâmetro de circulação $\Delta V_{u} /\left(\sigma V_{l} l / C\right)$.

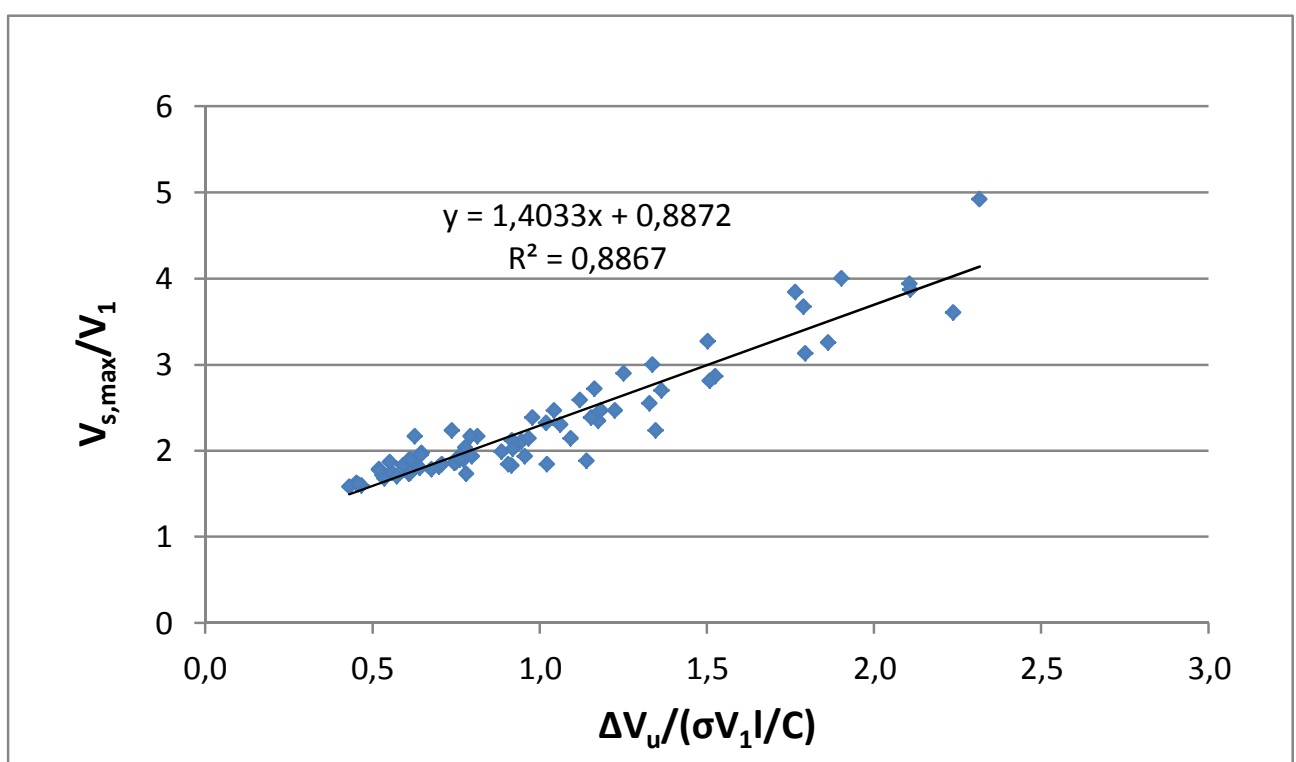

Figura 38 - Correlação entre $V_{s, \max } / V_{l}$ e o parâmetro de circulação $\Delta V_{u} /\left(\sigma V_{l} l / C\right)$ com base no comprimento da linha média de curvatura da palheta para os testes de Dunavant e Erwin [41].

Comparando-se a aplicação dos dois parâmetros de circulação estudados pode ser observado que, quando se utiliza o parâmetro com base no comprimento da linha de curvatura da palheta, a curva $\vartheta / l$ versus $D_{t o t}$ passa um pouco mais à direita dos três pontos com maior valor de perda. Este fato à primeira vista poderia sugerir uma superioridade do parâmetro com base na corda sobre o parâmetro com base no comprimento da linha de curvatura. Deve ser considerado, entretanto, que os três pontos mencionados correspondem a grades que não são otimizadas para o serviço, sendo esperada para estes casos a ocorrência de uma 
perda adicional por incidência desfavorável. Em particular no ponto onde $\vartheta / l=0,028$ é reportada a ocorrência de separação laminar por Dunavant e Erwin [41]. Observa-se ainda que estes três pontos não foram utilizados por Stewart ao construir a sua correlação, sendo substituídos por pontos de projeto de rotores transônicos, conforme ilustrado na figura 23. Reforçando este argumento, pode ser observada também a superioridade do parâmetro com base no comprimento da linha de curvatura para o ponto com o valor de $\vartheta / l=0,014$ correspondente a palheta com $\Delta \lambda_{c}=120^{\circ}$ na sua condição de incidência ótima.

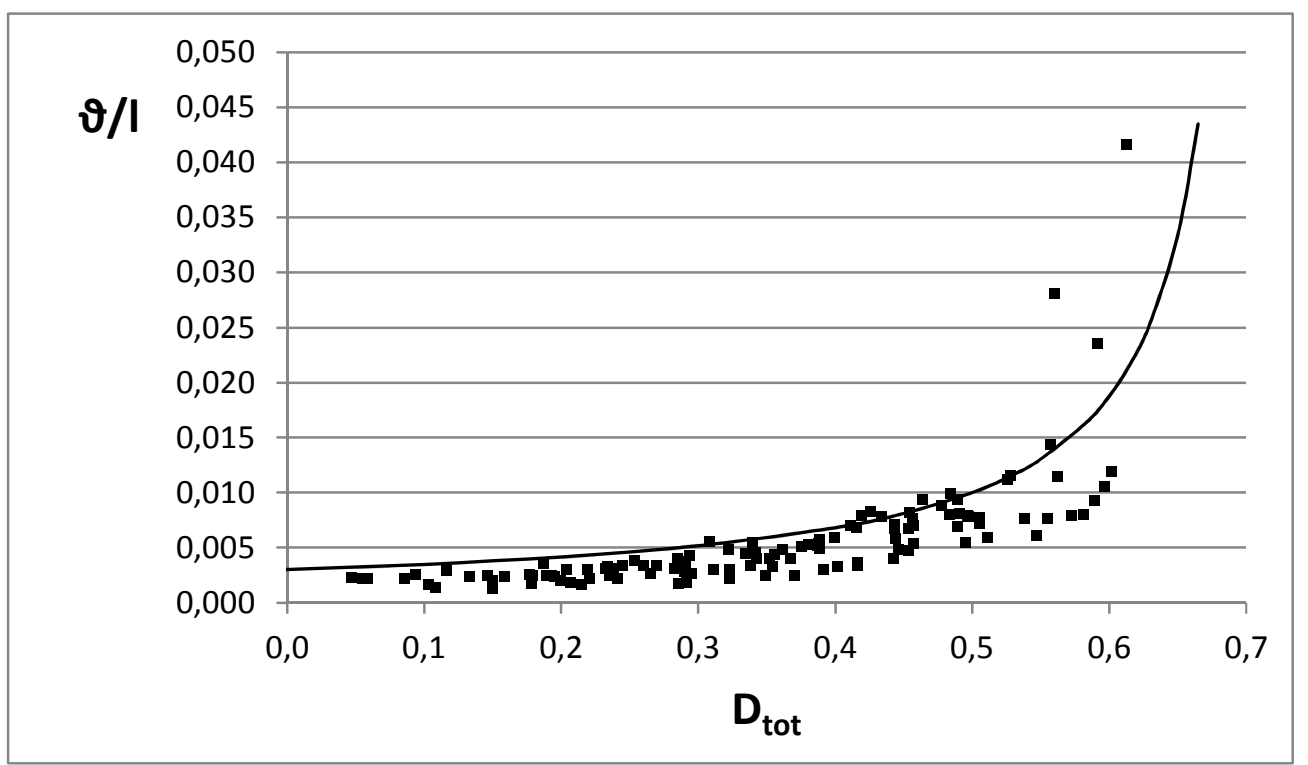

Figura 39 - Correlação entre $\theta / l$ e o fator de difusão calculado com base no parâmetro de circulação $\Delta V_{u} /\left(\sigma V_{l} l / C\right)$ para os testes da referencia [41].

Os dados de Dunavant e Erwin [41] não produzem experimentos em que o parâmetro de circulação se aproxima de zero, situação para a qual se deve confiar na dependência estabelecida por Baljé [45] com a espessura da palheta, restando então apenas atualizar o valor do coeficiente angular e utilizar o parâmetro de circulação mais adequado para grades de turbinas. A conclusão desta investigação é, portanto, que o método proposto deverá considerar a seguinte expressão para a razão de velocidades na superfície de sucção $V_{s, \max } / V_{l}$ :

$$
\frac{V_{s, \text { max }}}{V_{1}}=1+0,9 \frac{d_{\text {max }}}{C}+1,4 \frac{\Delta V_{u}}{\sigma V_{1} l / C}
$$


Considerado o efeito da compressibilidade, o parâmetro de circulação será dado pela seguinte expressão:

$$
\frac{\Delta V_{u}}{\sigma V_{1} l / C}=\frac{\left(K_{t} \operatorname{ctg} \lambda_{2}-\operatorname{ctg} \lambda_{1}\right) \operatorname{sen} \lambda_{1}}{\sigma l / C}
$$

Para o calculo do fator de difusão será necessário determinar a relação entre a velocidade terminal no bordo de fuga e a velocidade a jusante da grade $V_{2 t e} / V_{2}$ dada pela seguinte expressão, válida para escoamento incompressível [42]:

$$
\frac{V_{2 t e}}{V_{2}}=\sqrt{\left(\frac{\left(1-\delta^{\prime}-\frac{t_{e}}{t}\right) \cos \lambda_{2}}{1-\delta^{\prime}-\vartheta^{\prime}-\frac{t_{e}}{t}}\right)^{2}+\left(\frac{\operatorname{sen} \lambda_{2}}{1-\delta^{\prime}-\frac{t_{e}}{t}}\right)^{2}}
$$

Uma vez que a correlação entre $\vartheta / l$ e $D_{t o t}$ dada pela expressão (2.81) foi ajustada integralmente para os dados da experiência [41], o valor de $\vartheta / l$ assim obtido será suposto válido para $R e_{l}=400000$ e escoamento incompressível. As correções para escoamento compressível, para efeitos viscosos e para a rugosidade superficial deverão seguir as expressões (2.104), (2.105) e (2.107), respectivamente.

A utilização do parâmetro de circulação $\Delta V_{u} /\left(\sigma V_{l} l / C\right)$ com o valor de 1,4 adotado para o coeficiente angular mostrou discriminar com melhor realismo as pequenas diferenças entre as grades de alta difusão. $\mathrm{O}$ resultado do modelo proposto é mostrado na figura 40 onde as linhas para valores constantes de $\vartheta / l$ estão plotadas num mapa sob as coordenadas da grade $\delta u$ e $c t g \lambda_{\infty}$ e confrontados com a previsão pelo método de Baljé [45]. Em ambos os casos é atribuído o valor de 0,9 para o coeficiente de Zweiffel, sendo neste caso a comparação direta totalmente procedente.

Pode-se observar na figura 40 que o modelo proposto apresenta linhas de valor constante para $\vartheta / l$ que se inclinam para a direita conforme aumenta o valor de $\delta u$, enquanto que no modelo de Baljé esta inclinação é quase vertical, mostrando influência predominante da taxa de aceleração da grade. O novo 
modelo proposto parece então contemporizar de forma mais realista os aspectos da deflexão angular do escoamento e da taxa de aceleração na composição das perdas da grade.

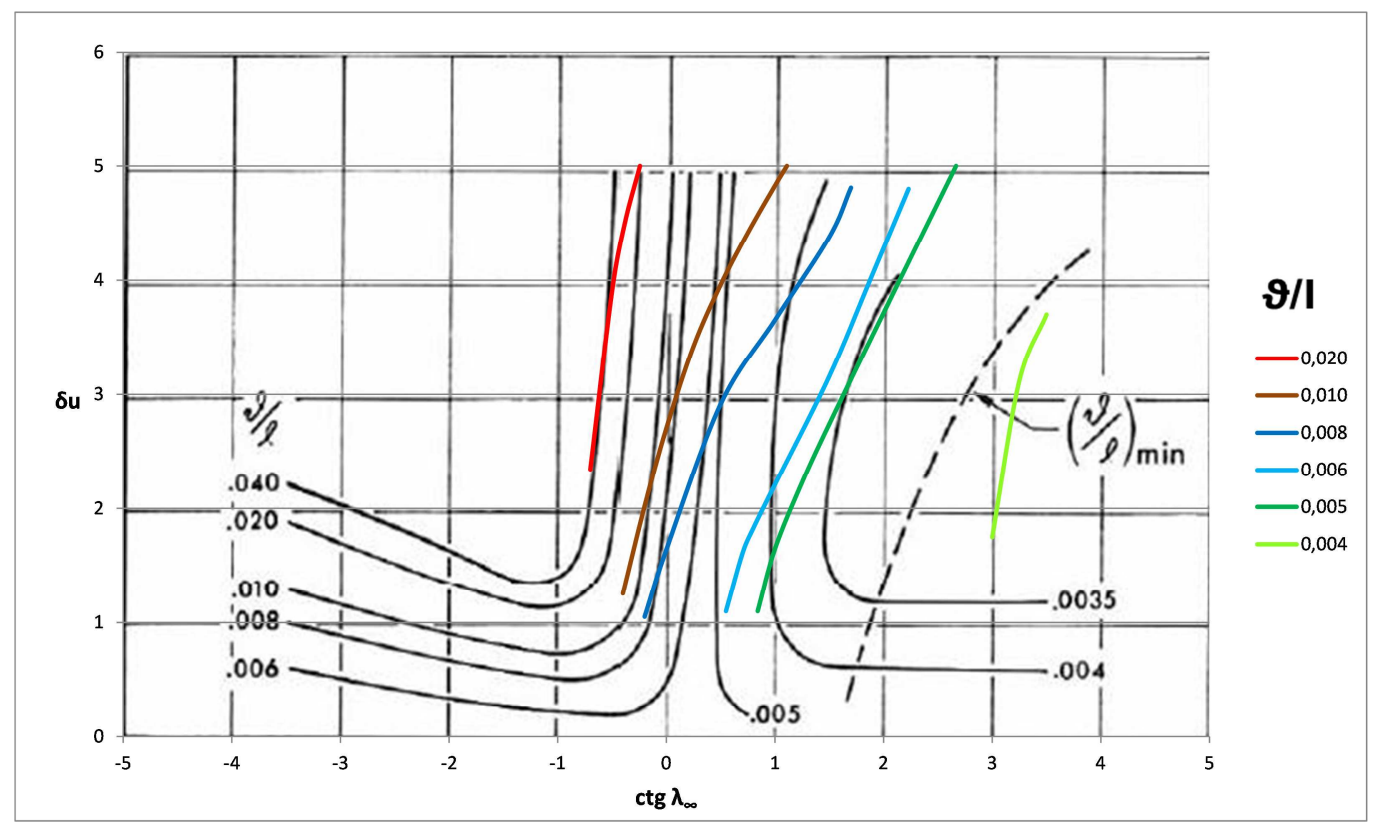

Figura 40 - Comparação entre os resultados do modelo de perdas proposto no presente trabalho com o modelo original de Baljé [45]. 


\subsection{Perda por Sobre-Expansão}

Para determinação do coeficiente de perda total, o método proposto se vale das equações de conservação (2.83) a (2.85) apresentadas por Stewart para o escoamento compressível na saída da grade. A correlação atribuída a Aungier utilizada por Da Lio [49] para otimização de eficiência de turbina axial aplicada como expansor de ciclo Rankine orgânico foi selecionada para avaliar a perda por sobre-expansão em palhetas convergentes. A perda por sobre-expansão é dada em termos de um termo aditivo de perda de pressão total em função do número de Mach na saída da grade $M_{2 t e}$, conforme a expressão seguinte:

$$
\Delta y_{p, M}=\left(\frac{M_{2 t e}-1}{M_{2 t e}}\right)^{2}
$$

A correlação proposta por Aungier apresenta resultado superior para as perdas por sobre expansão que a correlação de Craig \& Cox, embora nem sempre pareça representar adequadamente os dados experimentais reportados por Riess et al. [55] e Chu [56]. Neste trabalho é proposto que a perda por sobre-expansão seja modelada como uma espessura de quantidade de movimento adicional que surge no escoamento a jusante da garganta até a seção de saída 2te. Esta parcela adicional pode ser avaliada a partir de um coeficiente de perda de energia cinética $\Delta \xi_{p, M}$ similar ao proposto por Craig e Cox na figura 29 ou à correlação de Aungier dada pela equação (3.7), considerando o fator de energia da camada limite de 1,8 na seguinte equação:

$$
\vartheta_{p, M}^{\prime}=\frac{\Delta \xi_{p, M}\left(1-\delta_{3 D}^{\prime}-\frac{t_{e}}{t}\right)}{1,8}
$$

A partir do acréscimo da parcela devida à sobre-expansão $\vartheta_{p, M}^{\prime}$ são calculadas a espessura de quantidade de movimento e a espessura de deslocamento tridimensionais na saída da grade (seção 2te). A determinação do ângulo de saída da palheta $\lambda_{2 b}$ é obtida a partir de uma equação de conservação de massa entre a seção da garganta e a seção a jusante da grade. 


\subsection{Geometria da Grade}

Pode ser constatado que o modelo proposto é fortemente dependente do conhecimento de alguns parâmetros geométricos básicos da grade como o ângulo de assentamento da palheta $\lambda_{s}$, a razão comprimento da curvatura - corda $l / C$, a razão espessura máxima - corda $d_{\max } / C$ e ainda os ângulos de entrada e saída da palheta $\lambda_{l b}$ e $\lambda_{2 b}$. A geometria da grade deverá, portanto, ser estimada de forma a produzir a deflexão no escoamento esperada desde o ângulo de entrada $\lambda_{1}$ até o ângulo de saída $\lambda_{2}$, conforme especificada pelo diagrama de velocidades.

A partir dos resultados dos testes de Dunavant e Erwin [41] fica claro que existe um limite mínimo para o ângulo do fluxo de saída da grade. Para valores pequenos de $\lambda_{2}$ a porção retilínea da superfície convexa não mais é capaz de guiar o fluxo no bordo de fuga. A partir daí pode ser esperada a separação do fluxo da superfície de fuga para ângulos de saída menores que $15^{\circ}$, embora este valor possa ainda ser considerado um limite normal de projeto para $\lambda_{2}$.

O desvio angular do fluxo na saída da grade em condições de escoamento incompressível $\Delta \lambda_{d e v}$ é mapeado para a série de palhetas testadas [41] como função do ângulo de saída do fluxo e do ângulo de curvatura da palheta. O fenômeno ocorre como consequência da difusão na superfície de sucção que resulta em uma velocidade média na garganta maior que na seção de saída entre os bordos de fuga. Esta condição resulta na impossibilidade de manter um ângulo de saída de fluxo alinhado com o ângulo de saída de uma palheta com superfície de sucção retilínea à jusante da garganta em escoamento incompressível. Para aplicação no presente trabalho serão utilizadas as correlações quadráticas obtidas dos experimentos mencionados, expressas em função da deflexão angular através da grade $\Delta \lambda=\lambda_{1}-\lambda_{2}$ e do ângulo de saída do fluxo $\lambda_{2}$, conforme as expressões a seguir:

$$
\begin{aligned}
& \Delta \lambda_{d e v}=6,393579-0,098245\left(90-\lambda_{2}\right)+0,000671\left(90-\lambda_{2}\right)^{2} \\
& \Delta \lambda_{d e v}=5,153757-0,039629\left(90-\lambda_{2}\right)+0,000224\left(90-\lambda_{2}\right)^{2} \\
& \Delta \lambda_{d e v}=3,9
\end{aligned}
$$


As equações (3.9) a (3.11) são válidas para $\Delta \lambda=75,5^{\circ}, \Delta \lambda=84^{\circ}$ e $\Delta \lambda=98^{\circ}$, respectivamente. Para valores intermediários de $\Delta \lambda$ a deflexão angular deverá ser obtida a partir de interpolação das referidas equações, que serão válidas para $M_{2 t e}<0,5$. Para $M_{2 t e}=1$ considera-se que não há deflexão angular e para $0,5<M_{2 t e}<1$ a deflexão é encontrada interpolando-se entre os valores referentes ao escoamento incompressível e ao escoamento sônico, conforme recomendado por Ainley e Mathiesson [37]. No caso de escoamento supersônico a deflexão angular deverá ser calculada conforme descrito na seção 3.2.

Outro aspecto estudado por Dunavant e Erwin [41] é a deflexão induzida no fluxo ao se aproximar da entrada da grade que ocorre em virtude da circulação ao redor das palhetas. $\mathrm{O}$ valor da deflexão induzida é obtido a partir de medições em orifícios de pressão finamente espaçados instaladas no bordo de ataque da palheta. A palheta é girada mudando seu ângulo de assentamento até que a pressão total seja observada no orifício situado no término da linha média de curvatura e os orifícios adjacentes em ambos os lados registrem a mesma queda de pressão. Esta deflexão $\Delta \lambda_{\text {ind }}$ ocorre no sentido contrário ao da curvatura da palheta e é mostrado que ela depende principalmente do ângulo de entrada do fluxo $\lambda_{1}$ e também da solidez da grade $\sigma$. Para avaliação de grades genéricas, a correlação para o desvio induzido (em graus) ao ângulo de entrada na grade obtida por extrapolação das mencionadas experiências é dada por:

$$
\Delta \lambda_{\text {ind }}=50-10 \sigma-0,2 \lambda_{1}
$$

Caso $\lambda_{1}$ seja menor que $90^{\circ}$ deve ser substituído por $180^{\circ}-\lambda_{1}$ na equação anterior. Em todos os casos a deflexão induzida $\Delta \lambda_{\text {ind }}$ deverá ser limitada a valores positivos. O ângulo de saída da palheta $\lambda_{2 b}$ será dado determinado em função da deflexão do escoamento na saída da palheta, conforme descrito nesta seção. O ângulo de entrada da palheta $\lambda_{1 b}$ será dado por:

$$
\lambda_{1 b}=\lambda_{1}+\Delta \lambda_{\text {ind }}
$$

O ângulo de assentamento da palheta $\lambda_{s}$, por sua vez, pode ser relacionado aos ângulos de entrada e saída e a solidez da grade, para geometrias típicas. Conforme procedimento de Stewart [50], uma estimativa para $\lambda_{s}$ é obtida considerando que a 
superfície de sucção é construída a partir de um arco de círculo entre dois trechos retilíneos, situados na entrada e na saída da palheta e alinhados com os respectivos ângulos. O parâmetro $R_{c}$ representa o raio do arco de círculo para um espaçamento unitário entre as palhetas, sendo dado por:

$$
R_{c}=\frac{\sigma_{x}-\frac{1}{2}\left(\left|\operatorname{sen} 2 \lambda_{2 b}\right|+\left|\operatorname{sen} 2 \lambda_{1 b}\right|\right)}{\left|\cos \lambda_{2 b}-\cos \lambda_{1 b}\right|}
$$

E o ângulo de assentamento $\lambda_{\mathrm{s}}$ :

$$
\operatorname{tg} \lambda_{s}=\frac{\sigma_{x}}{\left(\cos \lambda_{2 b}\left|\cos \lambda_{2 b}\right|+\cos \lambda_{1 b}\left|\cos \lambda_{1 b}\right|\right)-R_{c}\left(\operatorname{sen} \lambda_{2 b}-\operatorname{sen} \lambda_{1 b}\right)}
$$

Sob esta premissa temos o comprimento da superfície de sucção dado por:

$$
\left(\frac{l}{C}\right)_{s}=\left(\frac{R_{c}}{\sigma}\right)\left(\left|\lambda_{1 b}-\lambda_{2 b}\right|\right)+\frac{\left|\cos \lambda_{2 b}\right|+\left|\cos \lambda_{1 b}\right|}{\sigma}
$$

A superfície de pressão será construída a partir de um arco de círculo cuja corda é igual a $C$ e o ângulo de saída é igual a $\lambda_{2 b}$, sendo seu comprimento dado por:

$$
\left(\frac{l}{C}\right)_{p}=\frac{\left(\lambda_{s}-\lambda_{2 b}\right)}{\operatorname{sen}\left(\lambda_{s}-\lambda_{2 b}\right)}
$$

O comprimento da linha média é então determinado pela média aritmética das duas superfícies:

$$
\frac{l}{C}=\frac{1}{2}\left[\left(\frac{l}{C}\right)_{p}+\left(\frac{l}{C}\right)_{p}\right]
$$

E a espessura máxima da palheta será dada por:

$$
\begin{gathered}
\frac{d_{\max }}{C}=\frac{R_{c} \operatorname{sen} \lambda_{s}}{\sigma_{x}}-\frac{1}{2 \operatorname{sen}\left(\lambda_{s}-\lambda_{2 b}\right)}+ \\
+\sqrt{\left[\frac{1}{2 \operatorname{sen}\left(\lambda_{s}-\lambda_{2 b}\right)}-\frac{\left(R_{c}+\operatorname{sen} \lambda_{2 b}\right) \operatorname{sen} \lambda_{s}}{\sigma_{x}}\right]^{2} \cos ^{2} \lambda_{2 b}+\left[\frac{1}{2 \operatorname{sen}\left(\lambda_{s}-\lambda_{2 b}\right)}+\frac{\left(\cos \lambda_{2 b} \operatorname{ctg} \lambda_{2 b}-R_{c}\right) \operatorname{sen} \lambda_{s}}{\sigma_{x}}\right]^{2} \operatorname{sen}^{2} \lambda_{2 b}}
\end{gathered}
$$




\subsection{Comparação com os Demais Métodos}

Uma análise comparativa entre as perdas obtidas a partir dos métodos abordados na seção anterior (Soderberg, Ainley \& Mathieson modificado por Dunham \& Came, Craig \& Cox e Baljé) além da modificação proposta no presente trabalho é apresentada nesta seção. A exemplo do estudo apresentado por Lozza [51], três geometrias típicas de palhetas são abordadas: bocal ou palheta rotativa de reação com baixo coeficiente de fluxo $\left(\lambda_{1}=90^{\circ}\right.$ e $\left.\lambda_{2}=15^{\circ}\right)$; bocal ou palheta rotativa de reação com alto coeficiente de fluxo $\left(\lambda_{1}=90^{\circ}\right.$ e $\left.\lambda_{2}=30^{\circ}\right)$ e palheta de impulso com alta deflexão $\left(\lambda_{1}=150^{\circ}\right.$ e $\left.\lambda_{2}=30^{\circ}\right)$. Para estas três configurações foi considerada uma grade de altura constante e o fator de aspecto $h / C$ foi permitido variar desde 0,5 a 3,0. A análise apresentada por Lozza [51] considerou a determinação da solidez ótima segundo o critério particular de cada um dos métodos de estimativa de perdas considerado. A intenção do presente trabalho é produzir um modelo de perdas confiável capaz não só de determinar uma eficiência ótima para um estágio de turbina axial, mas também caracterizar sua geometria básica. Desta forma o critério de comparação entre os diferentes métodos abordados considerou a mesmo valor para a solidez da grade, que para todos os casos estudados foi determinada de acordo com o critério de Zweiffel. A análise considera ainda um regime de escoamento incompressível com número de Reynolds da corda $R e_{C}=400000$ e espessura do borda de fuga projetada na direção tangencial igual a $10 \%$ do espaçamento entre palhetas, $t_{e} / t=0,1$. Nas figuras 41 a 43 são apresentadas as perdas totais para os três casos de palhetas estudados, considerando a contribuição da perda de perfil, perda secundária e perda devido à espessura do bordo de fuga, ressaltando-se que esta última não é contabilizada no método de Soderberg. 


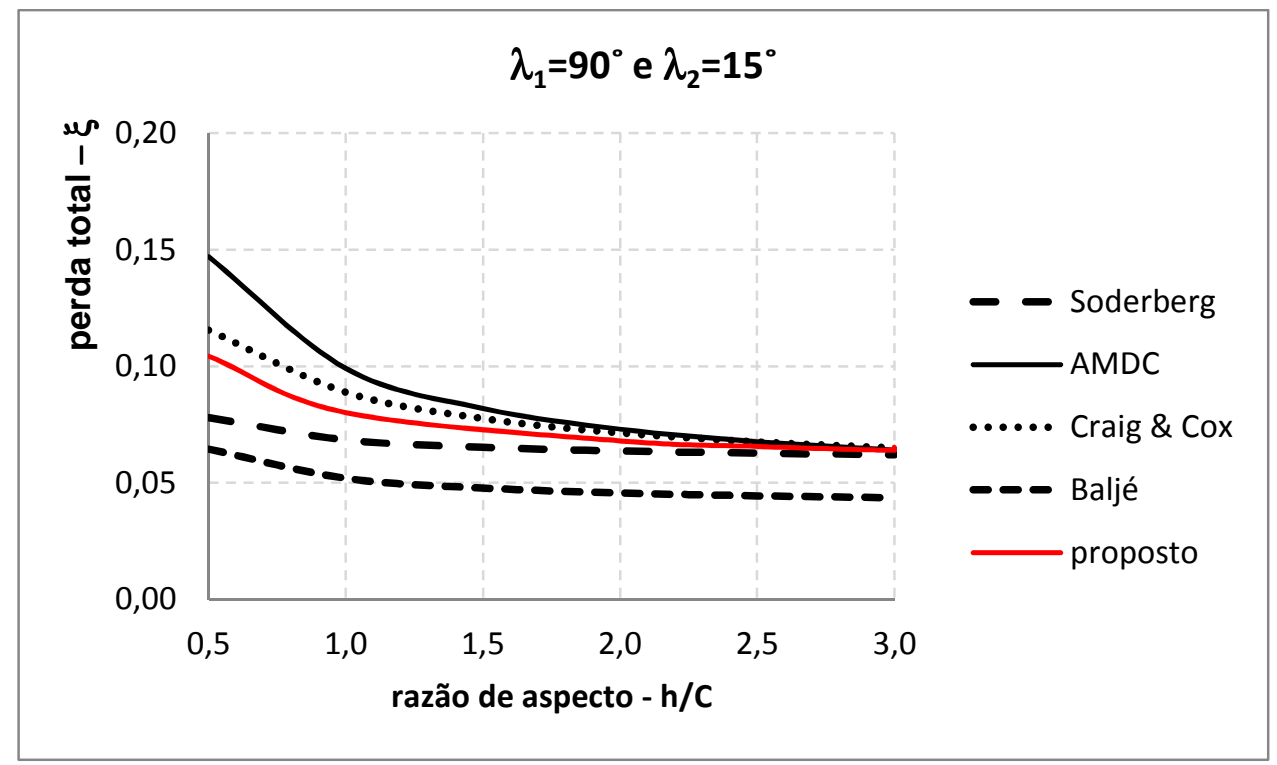

Figura 41 - Perda total em palheta de reação com baixo coeficiente de fluxo $\left(\lambda_{1}=90^{\circ}\right.$ e $\left.\lambda_{2}=15^{\circ}\right)$.

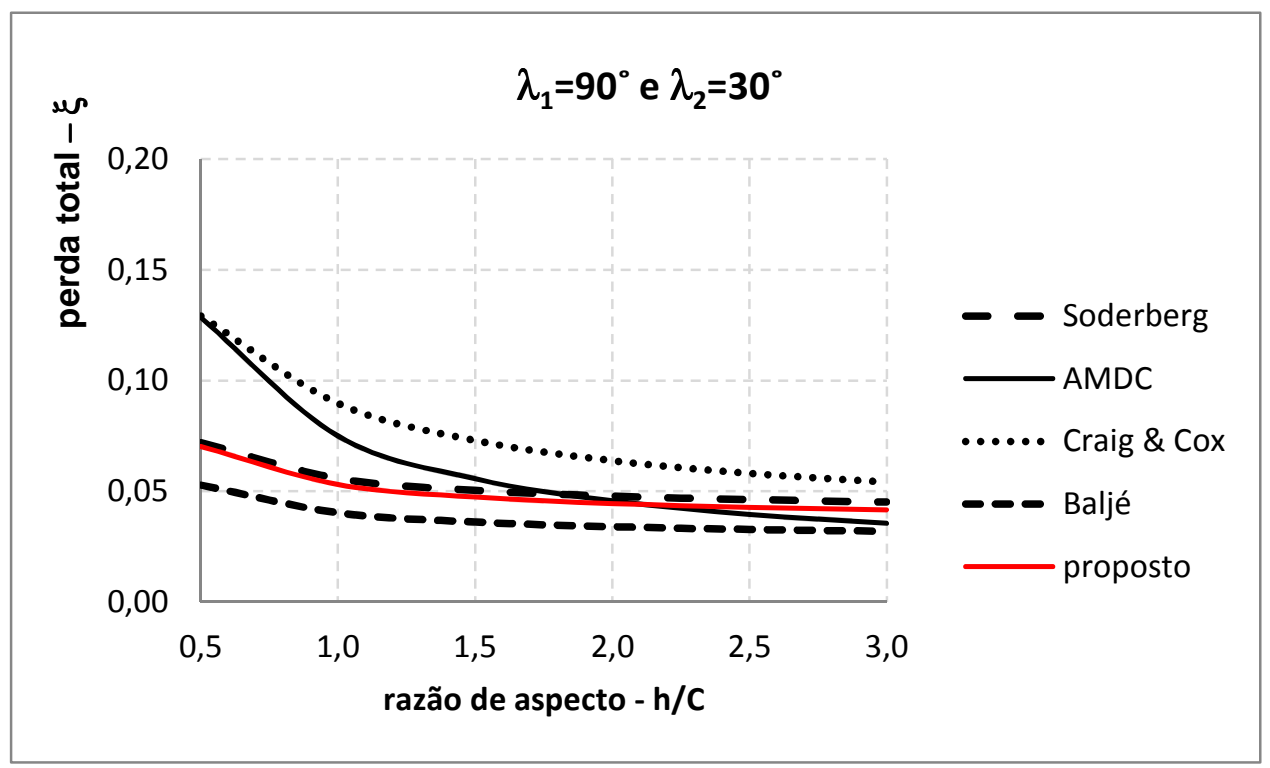

Figura 42 - Perda total em palheta de reação com alto coeficiente de fluxo $\left(\lambda_{1}=90^{\circ}\right.$ e $\left.\lambda_{2}=30^{\circ}\right)$. 


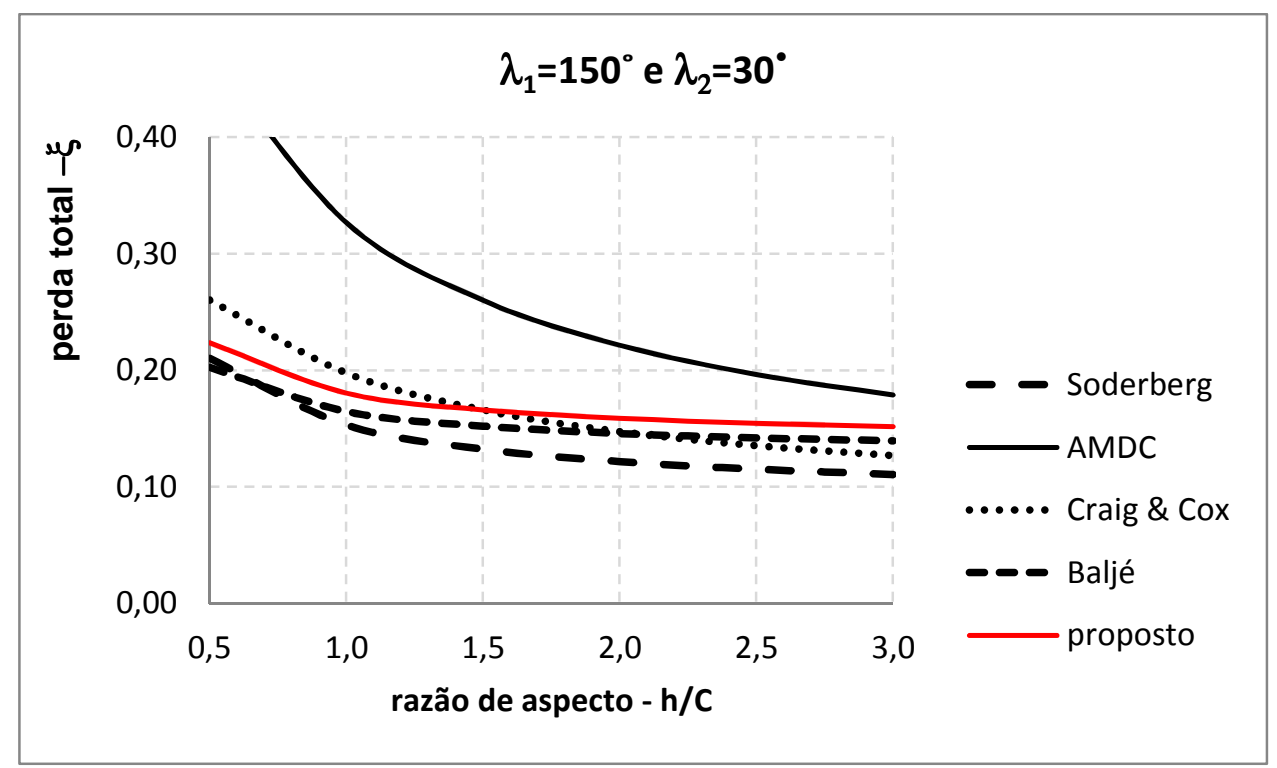

Figura 43 - Perda total em palheta de impulso $\left(\lambda_{1}=150^{\circ}\right.$ e $\left.\lambda_{2}=30^{\circ}\right)$.

De uma maneira geral pode ser observada uma boa coerência entre os resultados produzidos pelos diferentes métodos, embora haja em alguns casos diferenças que são quantitativamente significativas. Para a palheta de reação com $\lambda_{2}=30^{\circ}$, o método de Craig \& Cox fornece uma estimativa cerca de $28 \%$ superior aos demais. O método AMDC, concebido para utilização em turbinas a gás, produz estimativas de perdas bastante superiores aos demais métodos para a palheta de impulso. A estimativa de perdas secundárias em alguns casos é maior nos métodos de Craig \& Cox e AMDC. Para os três casos analisados o método de Baljé produziu sempre os menores valores para as previsões de perdas. A modificação proposta resultou em aproximar os resultados do método de Baljé em direção aos demais métodos. Adicionalmente a sensibilidade do coeficiente de perda na grade em relação à solidez é incrementada, sendo compatibilizada aos valores reportados por Miser et al. [50], a saber, cerca de 10\% de incremento na perda para um desvio de $\pm 30 \%$ com relação à solidez ótima. Face ao exposto, as mencionadas diferenças parecem ter sido contemporizadas de maneira satisfatória pelo presente trabalho. 


\subsection{Validação com Resultados Experimentais Publicados}

\subsubsection{Turbinas de Impulso de Ohlsson}

Ohlsson [52] publica resultados de eficiência de rotores e bocais, números de Mach e ângulos de fluxo em uma série de turbinas de impulso de estágio único com valores extremamente baixos da razão de aspecto $h / C$, construídas e testadas no laboratório de turbinas a gás do MIT, conforme ilustrado na figura 44. Os bocais são construídos com palhetas convergentes e os rotores possuem um ângulo de giro de $115^{\circ}$ e projeto com sobreposição de palhetas, cuja altura excede em 0,25 polegadas a altura das palhetas estacionárias. As quatro turbinas foram testadas sob uma relação de pressões $p_{3} / p_{01}$ igual a 0,45 .

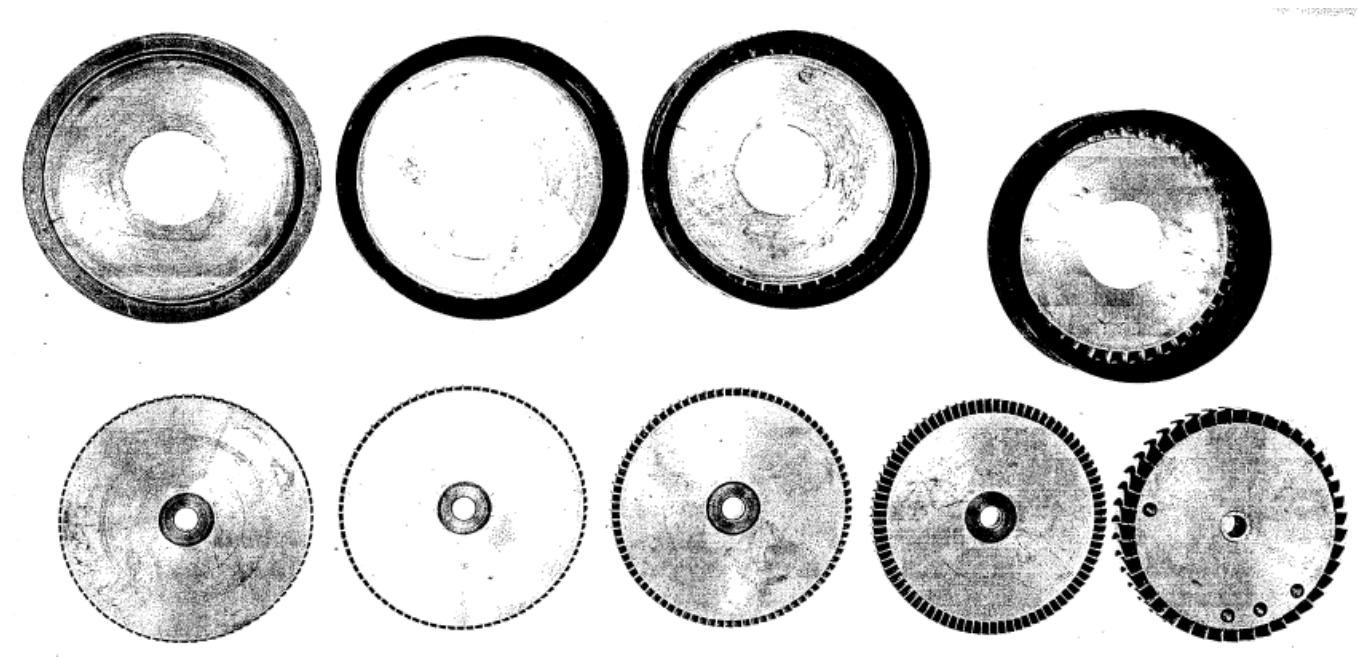

Figura 44 - Fotografia dos componentes das turbinas testadas por Ohlsson (rotores e bocais convergentes) [53].

A técnica desenvolvida por Ohlsson [53] consiste em medir o torque produzido pela turbina com seu rotor normal, e alternativamente com um rotor possuindo saída axial, ambas sob as mesmas condições de fluxo nos bocais. A partir das medições de torque do rotor com saída axial e do rotor normal é possível calcular os valores da quantidade de movimento tangencial na saída do bocal e na saída do rotor. 
A partir de valores publicados para a velocidade tangencial e dos ângulos de fluxo na saída do bocal e na saída do rotor foram calculados o fator de aceleração meridional $K_{t}$ e a taxa de aceleração da grade $\mu$. As características dos rotores testados são dadas na tabela 4 , onde pode se notar que as turbinas em questão são estágios de impulso no sentido original do termo. Os rotores $a$ e $b$ trabalham em condições de pressão estática praticamente constante e escoamento desacelerante ao longo do rotor. Os rotores $c$ e $d$ trabalham em condições de sub-impulso, com gradiente adverso de pressão.

Tabela 4 - Características dos rotores de impulso de Ohlsson [52].

\begin{tabular}{|l|c|c|c|c|c|c|c|c|c|c|c|}
\hline & $\lambda_{1}$ & $\lambda_{2}$ & $\sigma$ & $\mathrm{M}_{\mathrm{w} 3}$ & $\mathrm{~K}_{\mathrm{t}}$ & $\mu$ & $\Psi_{\mathrm{z}}$ & $\mathrm{h} / \mathrm{C}$ & $\mathrm{p}_{2} / \mathrm{p}_{3}$ & $\mathrm{Re}_{\mathrm{I}}$ & $\mathrm{t}_{\mathrm{e}} / \mathrm{t}$ \\
\hline rotor a & 145,7 & 35,1 & 2,0 & 0,621 & 0,958 & 0,9389 & 0,89 & 0,44 & 1,056 & $2,44 \mathrm{E}+05$ & 0,177 \\
rotor b & 149,0 & 36,9 & 2,0 & 0,615 & 0,987 & 0,8471 & 0,99 & 0,79 & 0,996 & $2,45 \mathrm{E}+05$ & 0,177 \\
rotor c & 143,6 & 39,9 & 2,0 & 0,399 & 0,662 & 0,61 & 1,29 & 0,18 & 0,953 & $1,50 \mathrm{E}+05$ & 0,177 \\
\hline rotor d & 140,4 & 44,6 & 2,0 & 0,227 & 0,431 & 0,39 & 1,88 & 0,11 & 0,916 & $8,02 \mathrm{E}+04$ & 0,177 \\
\hline
\end{tabular}

Os resultados dos coeficientes de perda de energia cinética no rotor $\xi_{\text {tot }}$ estão mostrados na tabela 5, mostrando uma boa coerência entre os resultados do modelo proposto com os valores experimentais apresentados [52] apenas para os rotores $a$ e $b$.

Tabela 5 - Resultados do coeficiente de perda de energia cinética total no rotor $\xi_{\text {tot }}$ para os rotores de impulso testados por Ohlsson [52].

\begin{tabular}{|l|c|c|c|c|}
\hline \multicolumn{1}{|c|}{ coeficiente de perda $\xi_{\text {tot }}$} & rotor a & rotor b & rotor c & rotor d \\
\hline medição experimental & 0,253 & 0,272 & 0,554 & 0,769 \\
\hline modelo proposto & 0,272 & 0,243 & 0,821 & 1,000 \\
\hline
\end{tabular}

Os rotores $c$ e $d$ não tiveram suas características de perda reproduzidas adequadamente pelo modelo proposto, fato atribuído a valores extremamente baixos para a razão de aspecto $h / C$ conforme mostrado na tabela 4 . Tais valores representam limites onde o modelo proposto no presente trabalho, cuja estimativa da perda secundária é fundamentada na regra da área, não mais pode ser aplicado com sucesso. 


\subsubsection{Turbinas Experimentais da KTH}

Trata-se de duas turbinas de estágio único utilizadas para pesquisas e trabalhos experimentais no Departamento de Tecnologia de Energia do Instituto Real de Tecnologia da Suécia (KTH) conforme descrito por Ning [54]. Ambos os estágios possuem o mesmo perfil, diferindo apenas na altura das palhetas. O perfil das palhetas e o triangulo de velocidades são ilustrados na figura 45. O desempenho da turbina foi levantado experimentalmente a partir de medições com sondas de pressão e temperatura, placa de orifício e torquímetro com acurácia de $1,1 \%$.

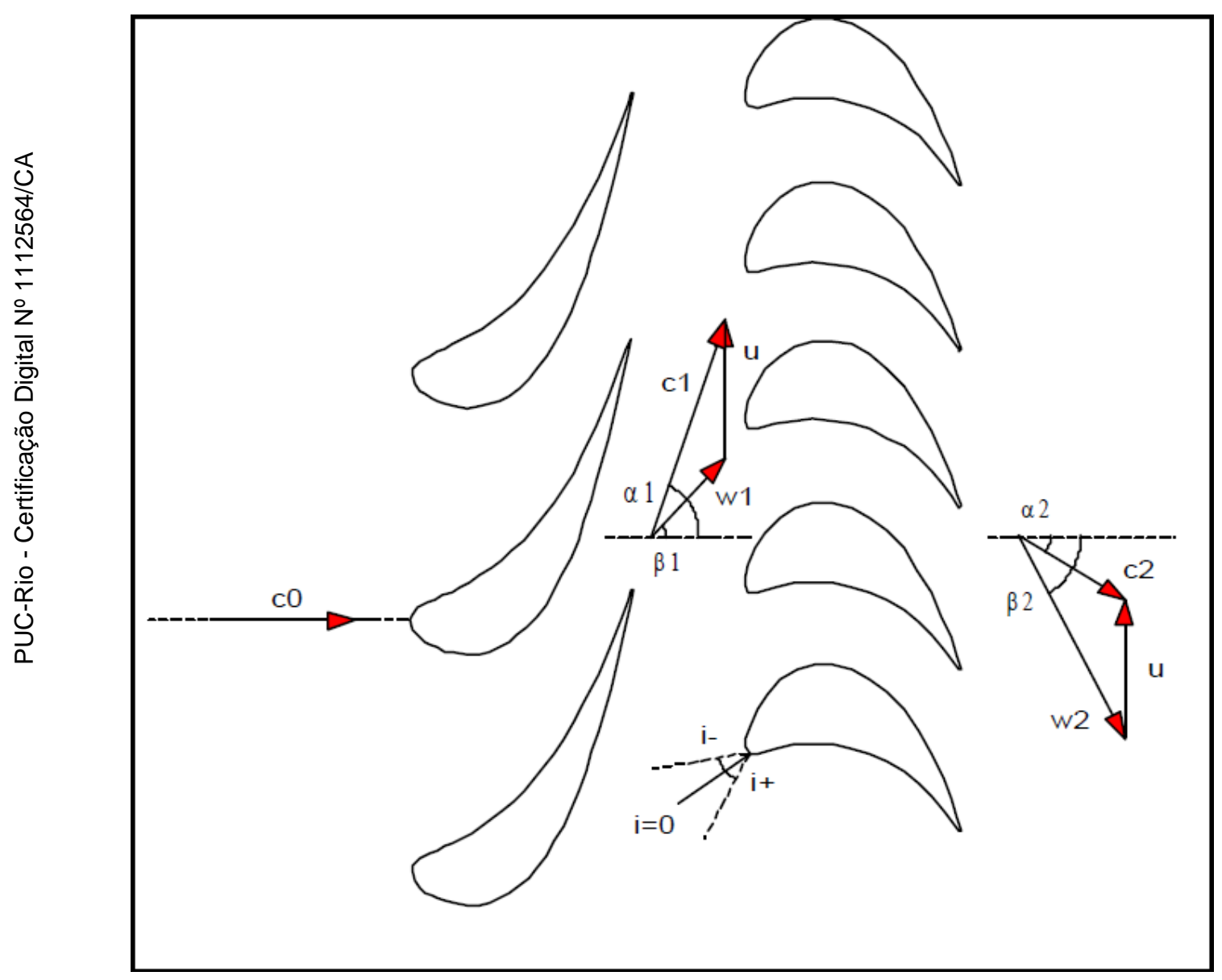

Figura 45 - Desenho e diagrama de velocidades das turbinas da KTH [54].

Os parâmetros geométricos e de serviço das turbinas são dados na tabela 6 , onde também estão mostrados os valores de eficiência medidos experimentalmente e estimados pelo método proposto no presente trabalho. 
Tabela 6 - Características das turbinas "stage 1" e "stage 2" da KTH [54].

\begin{tabular}{|l|c|c|c|c|c|c|c|c|c|c|}
\hline Turbina & $\mathrm{Ns}$ & $\mathrm{Ds}$ & $\mathrm{h} / \mathrm{D}$ & $\mathrm{h}_{3} / \mathrm{h}_{2}$ & $\sigma_{\mathrm{xN}}$ & $\sigma_{\mathrm{xR}}$ & $\mathrm{Z}_{\mathrm{N}}$ & $\mathrm{Z}_{\mathrm{R}}$ & $\eta_{\text {calculada }}$ & $\eta$ teste \\
\hline KTH stage 1 & 0,406 & 4,172 & 0,062 & 1,042 & 0,88 & 1,34 & 42 & 64 & 0,838 & 0,84 \\
\hline KTH stage 2 & 0,485 & 3,513 & 0,087 & 1,030 & 0,86 & 1,31 & 42 & 64 & 0,881 & 0,91 \\
\hline
\end{tabular}

No trabalho de Ning [54] é abordada a questão da definição da solidez ótima para as palhetas estacionárias e rotativas da turbina "stage 1". Na tabela 7 estão mostrados os parâmetros geométricos e de fluxo, onde pode ser observado que o valor utilizado para o coeficiente $\Psi_{z}$ do bocal é bastante menor que o recomendado pelo critério de Zweiffel, cuja utilização generalizada é questionada pelos autores. Para analisar a questão o autor faz uma simulação da variação das perdas do bocal e do rotor com a solidez, utilizando vários modelos (Kacker \& Okapuu, AMDC e Craig \& Cox), cujos gráficos foram reproduzidos e superpostos com a estimativa proposta no presente trabalho.

Tabela 7 - Parâmetros aerodinâmicos e geométricos da turbina "stage 1".

\begin{tabular}{|l|cccccccc|}
\hline & $\lambda_{1}$ & $\lambda_{2}$ & $\mathrm{M}_{2}$ & $\mu$ & $\mathrm{t} / \mathrm{C}$ & $\Psi_{\mathrm{z}}$ & $\mathrm{Re}_{\mathrm{I}}$ & $\mathrm{h} / \mathrm{C}$ \\
\hline bocal & 90,0 & 14,8 & 0,496 & 4,39 & 0,69 & 0,4852 & $5,05 \mathrm{E}+05$ & 0,59 \\
rotor & 144,0 & 27,0 & 0,270 & 1,31 & 0,72 & 0,9677 & $2,25 \mathrm{E}+05$ & 0,96 \\
\hline
\end{tabular}

O resultado da simulação dos bocais é mostrado nas figuras 46 (perdas no perfil) e 47 (perdas secundárias) sendo verificado que os resultados do método proposto neste trabalho se aproximam bastante aos de Craig \& Cox para este caso. Investigando-se então a condição que produz o valor de $\Psi_{z}=0,9$, observa-se que esta corresponderia a uma razão espaçamento corda $t / C=1,11$ que está fora do intervalo do gráfico. Nestas condições as perdas totais foram avaliadas pelo método proposto e excedem em $50 \%$ a perda mínima estimada, confirmando a conclusão de Ning [54] de que o critério de Zweiffel não é adequado para bocais com baixo coeficiente de fluxo. 


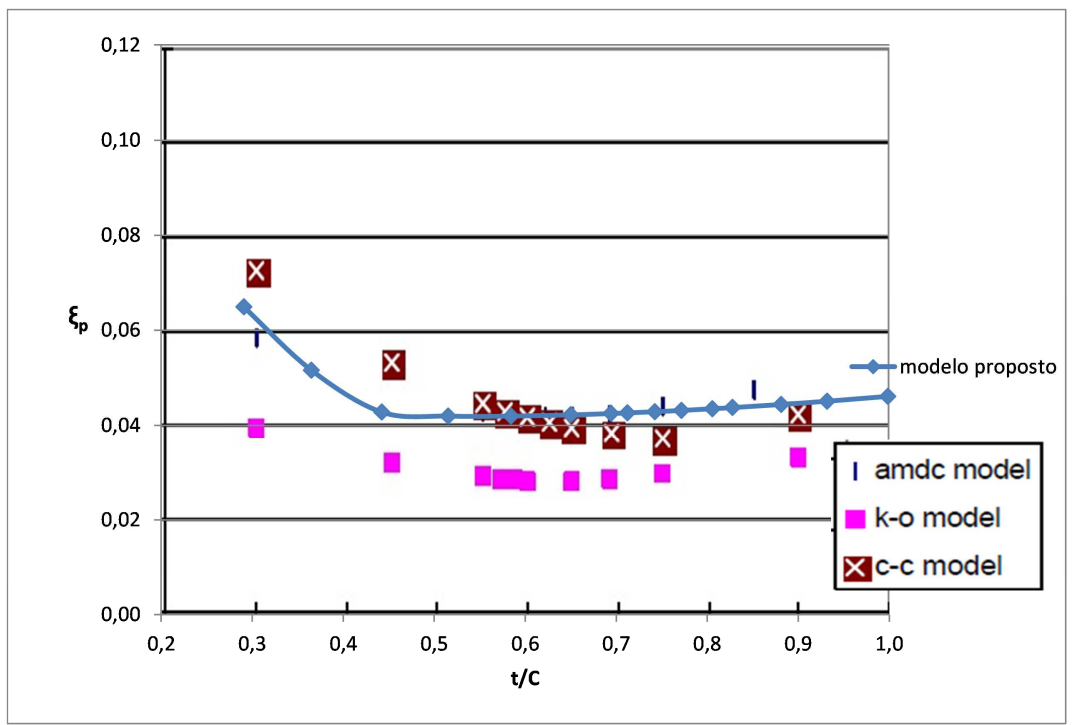

Figura 46 - Simulação do efeito da variação na solidez sobre as perdas no perfil do bocal da turbina "stage 1" da KTH [54].

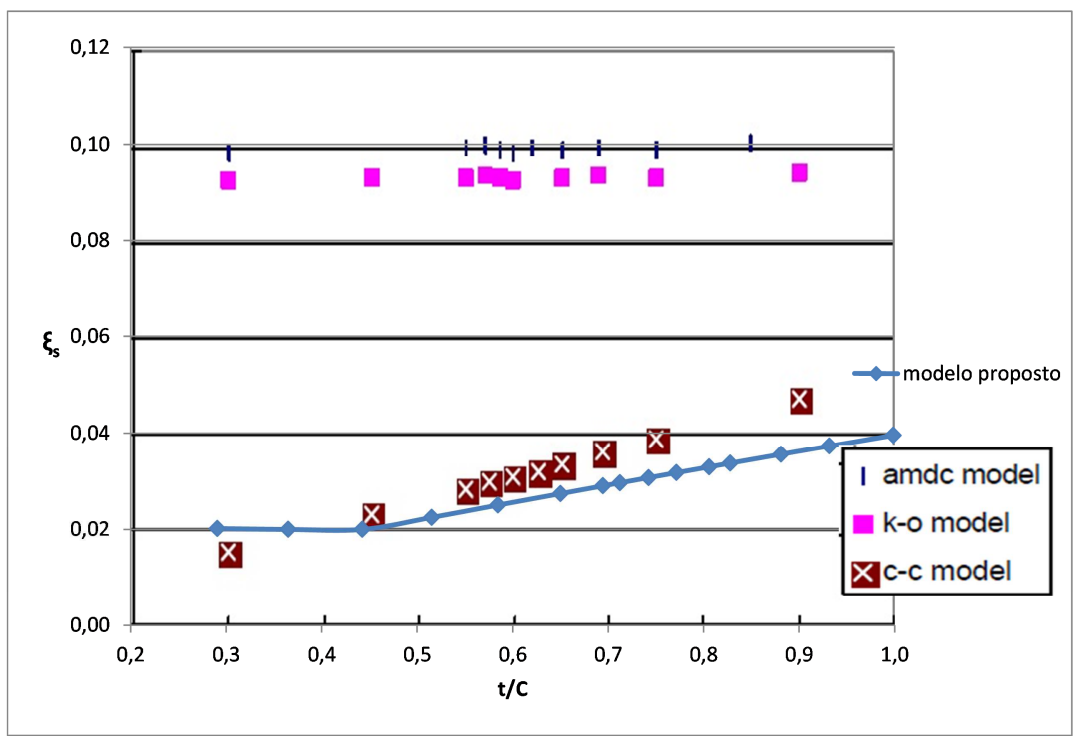

Figura 47 - Simulação do efeito da variação na solidez sobre as perdas secundárias do bocal da turbina "stage 1" da KTH [54].

Os resultados de perda no perfil e de perda secundária para o rotor estão mostrados nas figuras 48 e 49, respectivamente. Neste caso vale salientar a observação da seção anterior que o modelo Craig \& Cox produz resultados subestimados para a perda de perfil e superestimados para a perda secundária, sendo que a perda total, resultado da soma das anteriores, parece resultar correta. 


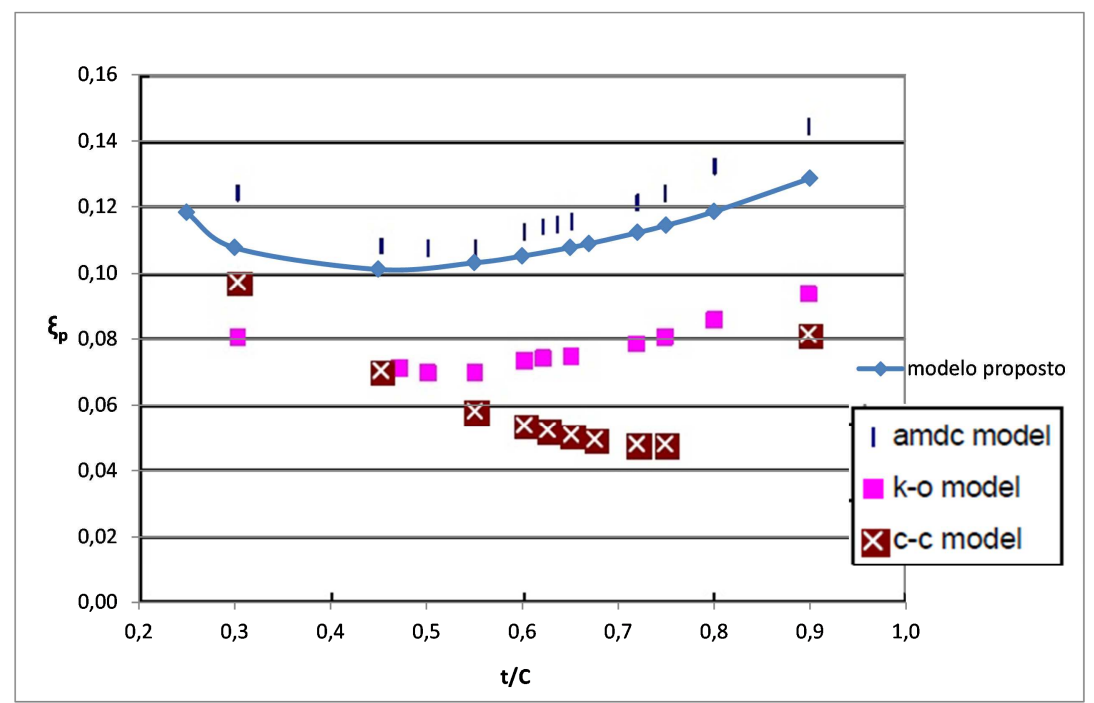

Figura 48 - Simulação do efeito da variação na solidez sobre as perdas de perfil do rotor da turbina "stage 1" da KTH [54].

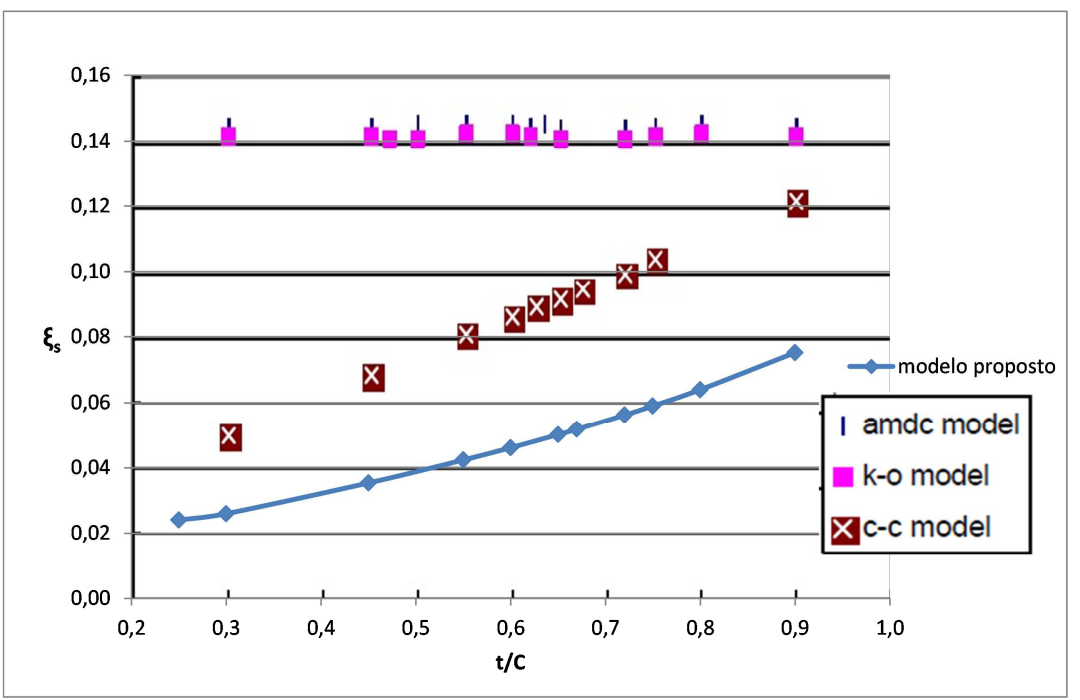

Figura 49 - Simulação do efeito da variação na solidez sobre as perdas secundárias do rotor da turbina "stage 1" da KTH.

A tabela 8 mostra os resultados do coeficiente de perda de pressão total $y_{\text {tot }}$ obtido a partir das estimativas dos diversos métodos e também da medição em laboratório para as duas turbinas em estudo. 
Tabela 8 - Comparação entre os valores obtidos para o coeficiente de perda total de pressão $y_{t o t}$ das turbinas da referência [54].

\begin{tabular}{|l|c|c|l|c|c|}
\hline \multicolumn{3}{|c|}{ Turbina stage 1 } & \multicolumn{2}{c|}{ Turbina stage 2 } \\
\hline \multicolumn{1}{|c|}{$\mathrm{y}_{\text {tot }}$} & bocal & rotor & \multicolumn{1}{|c|}{$\mathrm{y}_{\text {tot }}$} & bocal & rotor \\
\cline { 2 - 5 } medição experimental & 0,102 & 0,245 & medição experimental & 0,083 & 0,110 \\
modelo Kacker \& Okapuu & 0,122 & 0,370 & modelo Kacker \& Okapuu & 0,980 & 0,300 \\
modelo AMDC & 0,150 & 0,440 & modelo AMDC & 0,120 & 0,360 \\
modelo Craig \& Cox & 0,112 & 0,240 & modelo Craig \& Cox & 0,102 & 0,220 \\
modelo proposto & 0,082 & 0,208 & modelo proposto & 0,072 & 0,138 \\
\hline
\end{tabular}

Embora não concebido para utilização em operação fora do ponto de projeto, o modelo proposto foi aplicado na simulação o desempenho das palhetas do rotor da KTH para valores de incidência de $0^{\circ}$ a $-11,2^{\circ}$, produzindo resultados bastante coerentes, conforme apresentados na figura 56, confrontados com os resultados experimentais e dos demais modelos abordados por Ning [54].

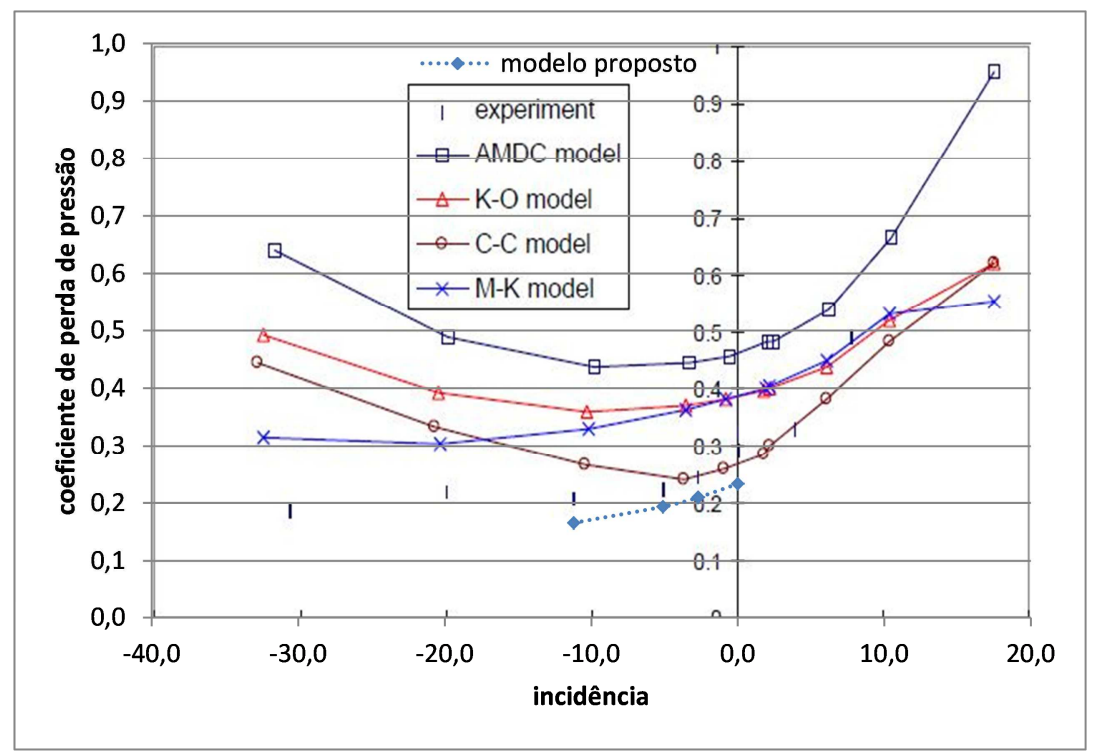

Figura 50 - Coeficientes de perda de pressão para o rotor da turbina da KTH [54] sob incidência variável. 


\subsubsection{Palhetas Estacionárias da NASA}

O aparato testado por Whitney et al. [43] e por Stewart et al. [44] consiste em uma grade anular de palhetas estacionárias com o rotor removido, sendo a pressão estática na saída variada de forma a cobrir um intervalo de razão de velocidade crítica de 0,8 a 1,4. As palhetas estacionárias utilizadas nesta investigação são tridimensionais, com um projeto típico de vórtice livre, tendo razão altura diâmetro do topo $h / D=0,15$ e ângulo de giro de $62^{\circ}$ no raio médio, conforme ilustrado na figura 51.

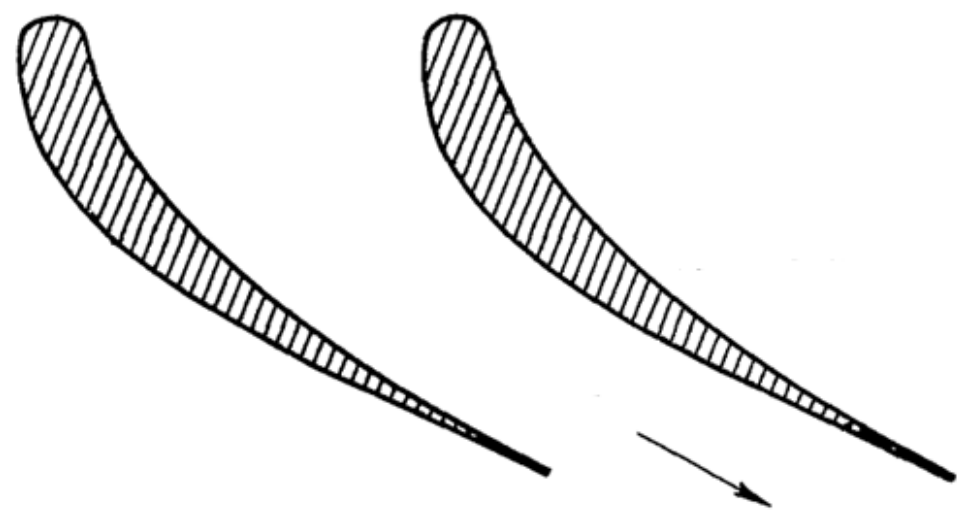

Figura 51 - Seção média da palheta estacionárias testada pela NASA [43].

O experimento fez uso de sondas de pressão total instaladas no raio médio imediatamente a jusante do bordo de fuga. Os parâmetros da camada limite foram então calculados através da integração da vazão mássica e da velocidade, a partir dos perfis obtidos para a pressão estática e a pressão total.

A figura 52 mostra os resultados do presente modelo para as condições de escoamento no raio médio confrontado com os resultados experimentais e a previsão teórica através de cálculos da camada limite compressível obtidos por Whitney et al. [43]. A variação da espessura de quantidade de movimento é atribuída em grande parte aos efeitos do número de Mach e do número de Reynolds. O aumento do número de Mach contribui para reduzir o fator de 
difusão, uma vez que o aumento da taxa de aceleração da grade supera o aumento da velocidade máxima na superfície de sucção, decorrente do incremento da circulação ao redor das palhetas. Adicionalmente o aumento simultâneo do número de Mach e do número de Reynolds causa a redução do coeficiente de atrito do escoamento com a superfície das palhetas.

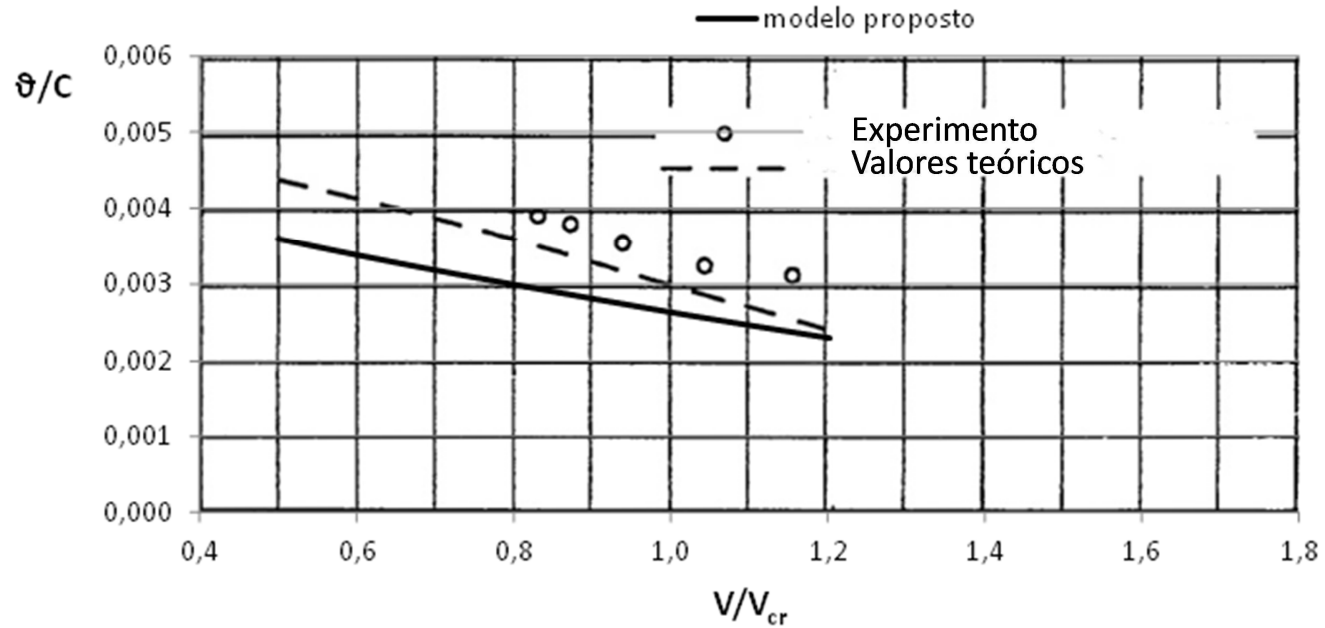

Figura 52 - Resultados experimentais e teóricos [43] mostrando a variação de $\theta / C$ com $V / V_{\text {cr }}$ para a palheta estacionária de ângulo de giro $62^{\circ}$, confrontados com os do modelo proposto no presente trabalho. 


\subsubsection{Deflexão do Jato}

Para validar o procedimento descrito na seção 3.2, segue uma comparação entre seus resultados e o experimento de Hauser et al. [35], onde a deflexão angular na saída de uma grade de palhetas bidimensional operando com ar foi determinada a partir de sondas de pressão estática e do princípio da conservação da quantidade de movimento, além do registro de fotografias Schlieren do escoamento a jusante das palhetas. A geometria básica da grade utilizada no referido experimento está mostrada na tabela 9.

Tabela 9 - Características básicas da grade cuja deflexão angular na saída foi investigada por Hauser et al. [35].

\begin{tabular}{|c|c|c|c|}
\hline$\lambda_{1 \mathrm{~b}}$ & $\lambda_{2 \mathrm{~b}}$ & $\sigma_{\mathrm{x}}$ & $\mathrm{t}_{\mathrm{e}} / \mathrm{t}$ \\
\hline $131,5^{\circ}$ & $34,2^{\circ}$ & 2,16 & 0,19 \\
\hline
\end{tabular}

A figura 53 mostra o resultado do método de avaliação da deflexão angular adotado no presente trabalho superposto aos resultados experimentais e demais métodos teóricos de avaliação propostos por Hauser et al. [35], em função da razão de velocidade crítica isentrópica na saída da grade. Observa-se que a deflexão do jato determinada pelo método experimental de conservação de quantidade de movimento (método 6) mantém uma valor praticamente constante de $-7^{\circ}$ até que a carga aerodinâmica da palheta, e consequentemente a velocidade tangencial atingem seus valores máximos. A partir daí o ângulo de deflexão varia conforme a redução adicional da pressão a jusante da grade até atingir um valor máximo de $15^{\circ}$. Os métodos denominados 1,2 e 3 têm como base, respectivamente, as seguintes premissas: expansão isentrópica com área de escoamento constante perpendicular à direção axial; conservação da quantidade de movimento tangencial e expansão isentrópica com área de escoamento decrescente; e conservação da quantidade de movimento tangencial e expansão não isentrópica. $\mathrm{O}$ método 3 revisado representa uma combinação dos métodos $1 \mathrm{e}$ 3, sendo recomendado [35] como a melhor opção, uma vez que é o que mais se aproxima dos valores experimentais calculados (método 6). Vale ressaltar que 
nenhum dos métodos teóricos propostos por Hauser et al. [35] leva em conta a obstrução resultante da camada limite.

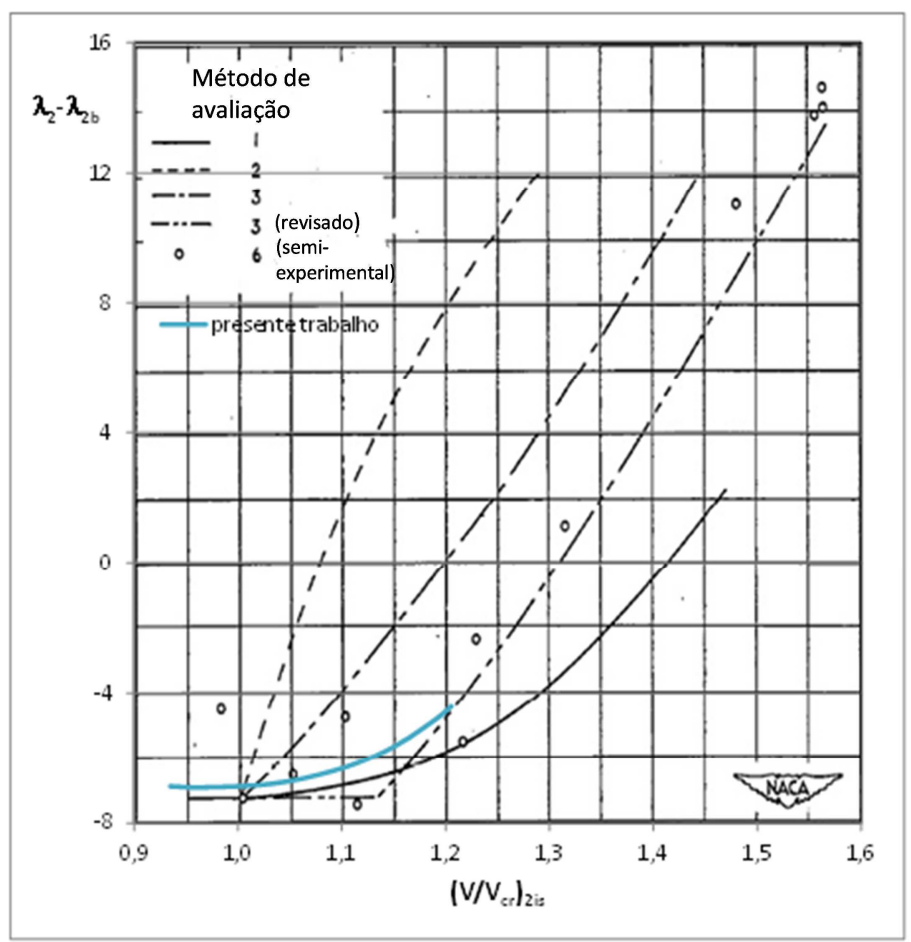

Figura 53 - Resultado do método de avaliação da deflexão angular (em graus) do presente trabalho superposto aos resultados experimentais [35].

Pode ser observado que a geometria da grade em questão, particularmente influenciada pelo valor significativo da obstrução do bordo de fuga $t_{e} / t$, estará engasgada quando é atingido o valor $\left(V / V_{c r}\right)_{2 i s}=1,20$ ou $M_{2 i s}=1,26$. Nesta condição o número de Mach axial na seção entre os bordos de fuga atinge o valor unitário $\left(M_{2 t e x}=1\right)$. A partir daí pode ser observado que um aumento adicional do número de Mach na saída da grade não é acompanhado de um aumento correspondente de quantidade de movimento tangencial, sendo então questionável a utilização desta grade para valores de $M_{2 i s}$ superiores a 1,26. 


\subsubsection{Grades de Turbinas em Regime Transônico}

Nesta seção são analisados resultados de testes em grades de turbinas operando em regime subsônico e transônico no DFVLR e IFS na Alemanha por Riess et al. [55]. A relevância destes testes é a quantificação das perdas por sobreexpansão que não foram adequadamente desenvolvidas nos trabalhos da NASA. As características da grade 10.1.2 estão mostradas na tabela 10.

Tabela 10 - Características geométricas da grade transônica 10.1.2 investigada pelo DFVLR e IFS [55].

\begin{tabular}{|c|c|c|c|c|}
\hline$\lambda_{s}$ & $\mathrm{t} / \mathrm{C}$ & $\lambda_{1}$ & $\mathrm{o} / \mathrm{t}$ & $\mathrm{t}_{\mathrm{b}} / \mathrm{t}$ \\
\hline $70^{\circ}$ & 0,6 & $130^{\circ}$ & 0,5458 & 0,0159 \\
\hline
\end{tabular}

Os resultados do presente modelo estão confrontados com os resultados experimentais do IFS em regime subsônico e do DFVLR em regime transônico na figura 54, mostrando o coeficiente de perda no perfil versus o número de Laval do escoamento uniforme na saída da grade. Pode-se observar a redução das perdas no perfil da grade estudada com aumento do número de Laval em regime subsônico e seu posterior crescimento ao se atingir o regime transônico. Este fenômeno foi adequadamente reproduzido pelo modelo adotado no presente trabalho, fazendo uso da equação (2.104) proposta por Baljé [46] para correção da espessura da quantidade de movimento com o número de Mach, e da equação (3.7) proposta por Aungier [49] para a perda por sobre-expansão.

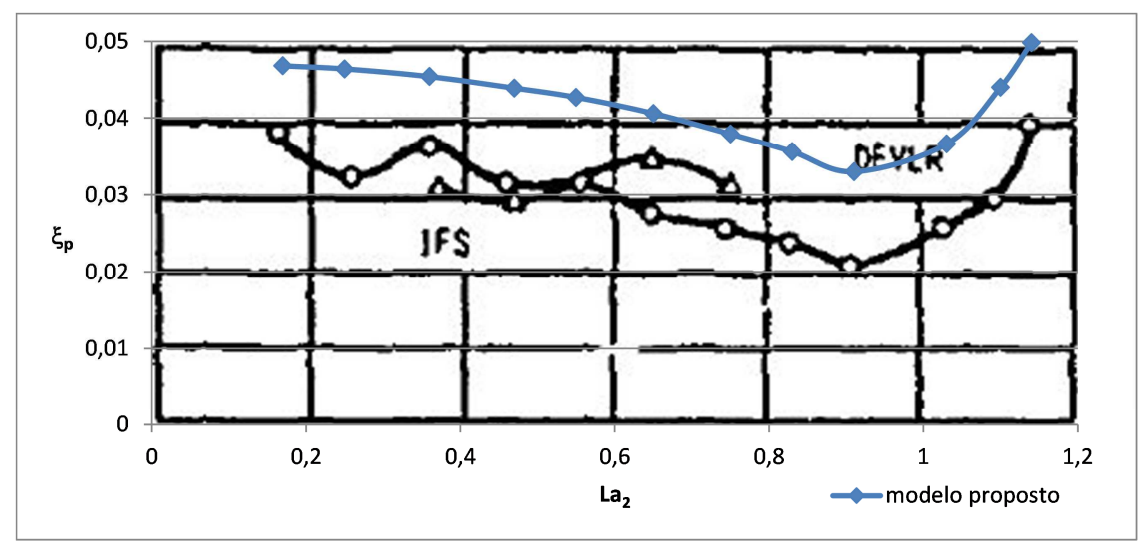

Figura 54 - Variação do coeficiente de perda no perfil com o número de Laval para a grade 10.1.2 [55]. 
As perdas por sobre expansão são também abordadas por Chu [56] através de investigação experimental em grades de bocais de turbinas a vapor com ângulo de saída $\lambda_{2 b}$ da ordem de $12^{\circ}$. Os resultados da investigação experimental mostram que o método de Craig \& Cox subestima as perdas por sobre expansão nesta situação. 


\subsubsection{Turbinas a Vapor de Admissão Parcial Testadas na Fábrica}

Alguns resultados disponíveis de testes de desempenho em turbinas a vapor de estágio único e admissão parcial são utilizados nesta seção para efeito de verificação da acurácia dos métodos de estimativa de perdas considerados. Os resultados utilizados foram obtidos a partir de ensaios executados em bancada de teste na fábrica na ocasião da aquisição das máquinas [57]. Estes testes têm como objetivo a aceitação da turbina pelo cliente e são executados de acordo com a norma ASME PTC-6 [58], que garante a precisão e confiabilidade dos resultados a partir da definição de desvios e flutuações admissíveis para as condições de teste e da instalação de instrumentos em redundância, em posição adequada na tubulação e com calibração aferida. A turbina foi testada acoplada a um freio hidráulico, através de uma caixa redutora e um acoplamento instrumentado com um medidor de torque, conforme ilustrado na figura 55.

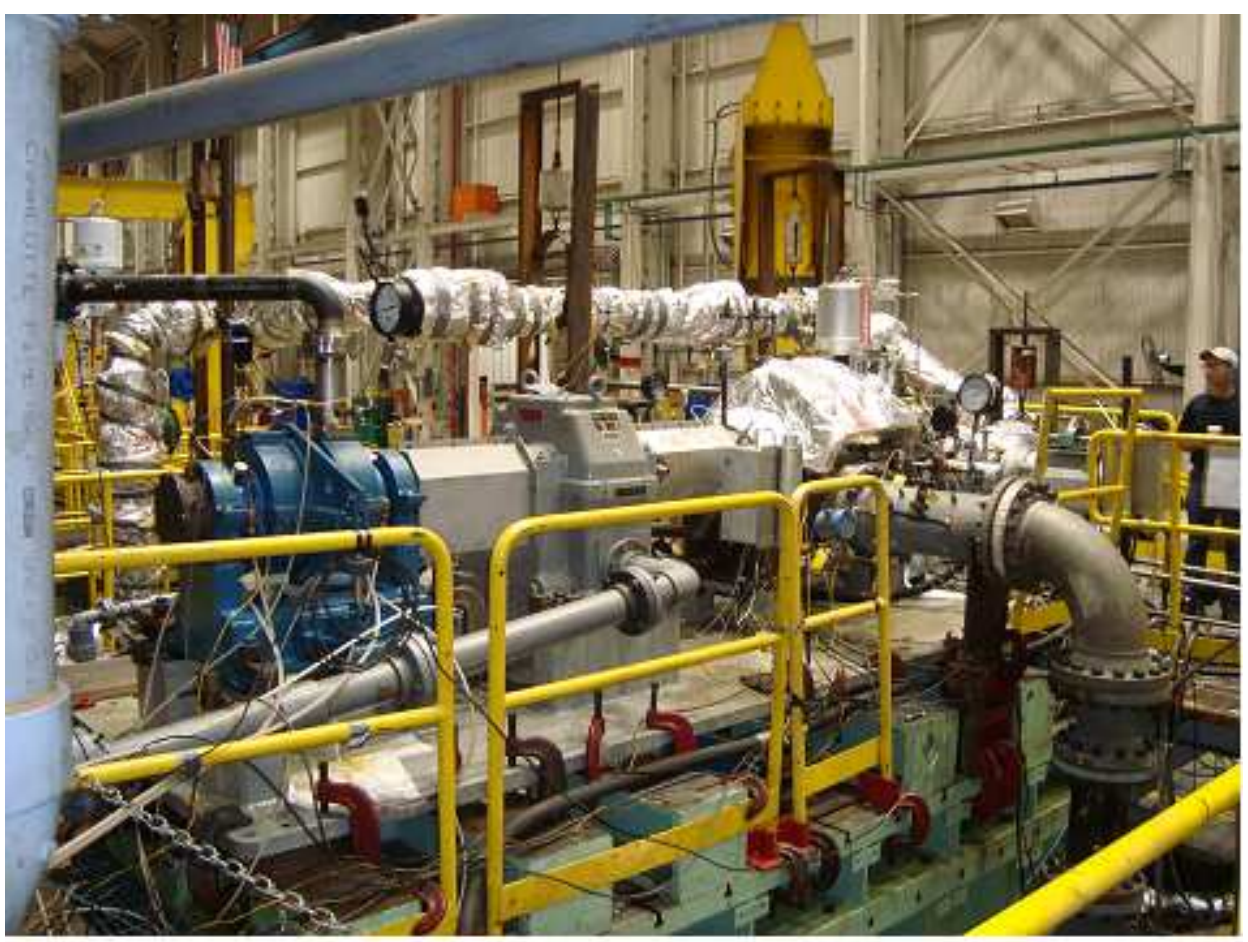

Figura 55 - Fotografia da turbina a vapor instalada na bancada de testes na fábrica [57]. 
A turbina \#1 admite vapor de média pressão e descarrega vapor de baixa pressão enquanto que a turbina \#2 admite vapor de alta pressão e descarrega vapor de média pressão. Ambas acionam compressores de processo em serviço de refino de petróleo, sendo a potência da turbina \#1 da ordem de $1350 \mathrm{~kW}$ e a da turbina \#2 de $1670 \mathrm{~kW}$.

A fotografia dos rotores das turbinas em estudo está mostrada na figura 56, onde podem ser observadas algumas diferenças construtivas. Na turbina \#1 as palhetas são empilhadas circunferencialmente sobre a roda, enquanto que a turbina \#2 tem as palhetas montadas na roda através de rebaixos de deslizamento axial.

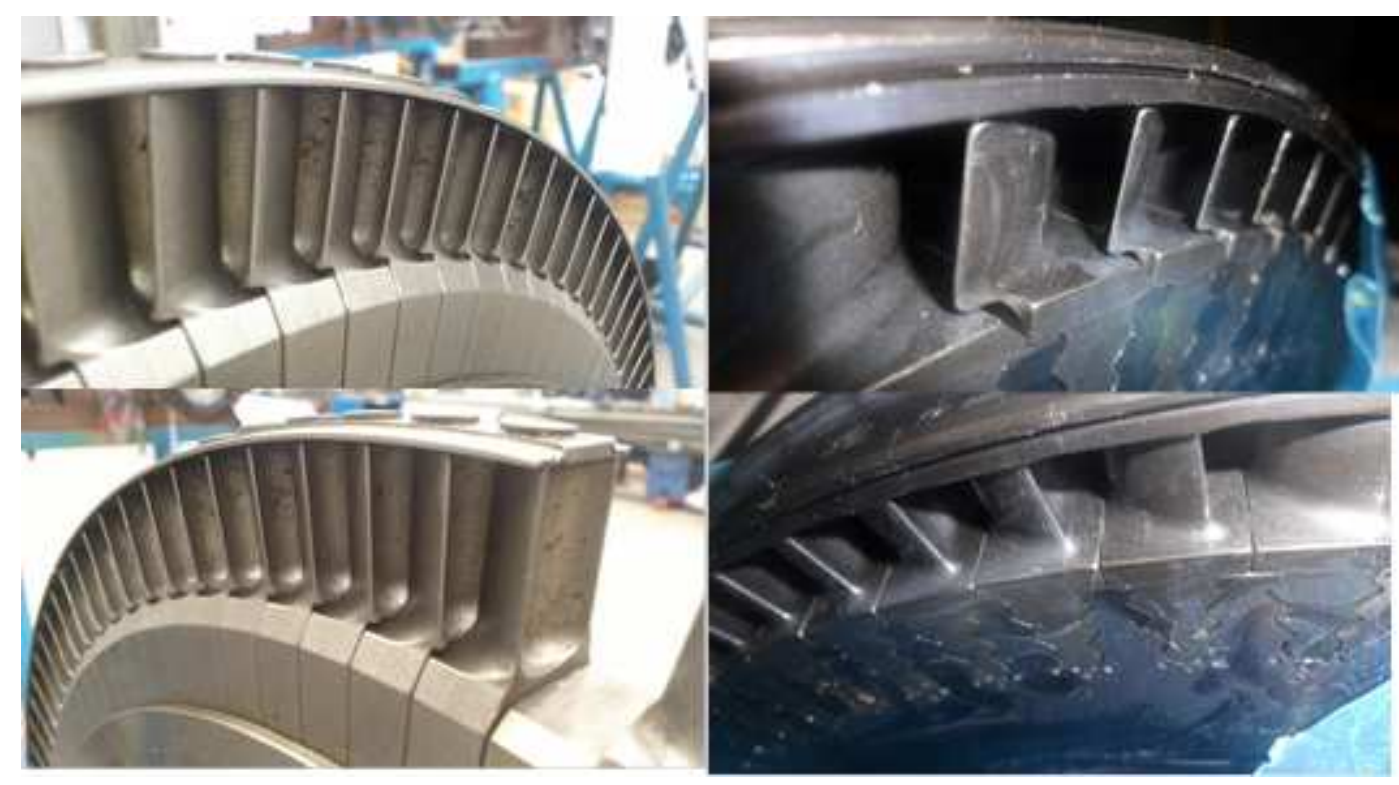

Figura 56 - Fotografias dos rotores da turbina \#1 (à direita) e da turbina \#2 (à esquerda) testadas na fábrica [57].

Um detalhe do desenho mostrando a folga entre bocais e rotor para ambas as configurações é mostrado na figura 57, onde pode ser verificada uma diferença relevante entre os dois projetos, cuja influência sobre o desempenho será discutida a seguir. 

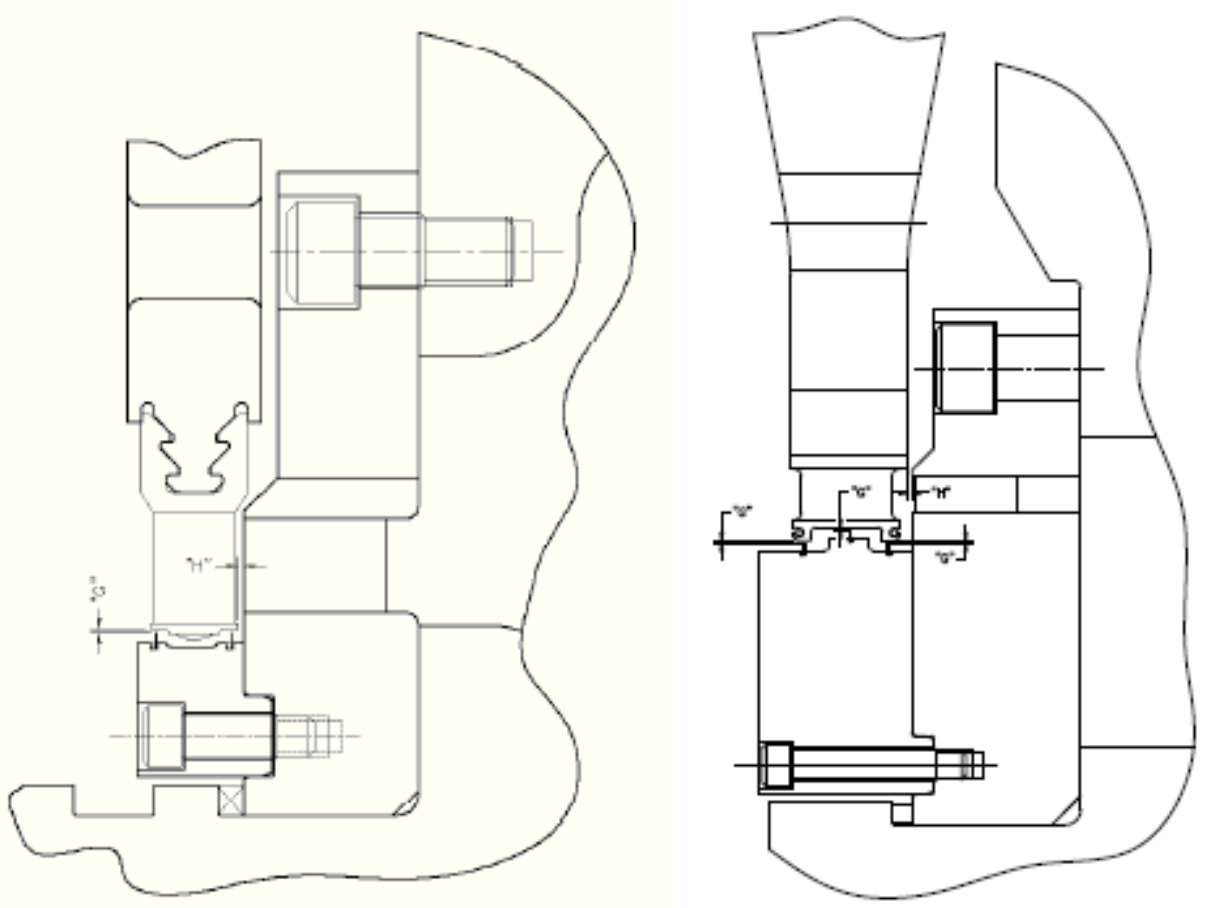

Figura 57 - Detalhe do desenho mostrando a folga entre as palhetas estacionárias e rotativas para a turbina \#1 (esquerda) e turbina \#2 (direita).

Para a simulação do desempenho das turbinas a vapor as considerações dos efeitos de gás real e de perda compressível se mostraram necessários, principalmente no caso da turbina \#2. As tabelas 11, 12, 13 e 14 mostram respectivamente os parâmetros de serviço, a geometria dos bocais, geometria do rotor e os parâmetros aerodinâmicos e eficiências. Sendo conhecidos os parâmetros de serviço e a geometria da turbina, o problema está em determinar o grau de reação do estágio que melhor reproduza os valores conhecidos do ângulo de saída da palheta rotativa e do grau de admissão.

Pode-se observar que a estimativa de eficiência pelo método proposto, incluídas as perdas por admissão parcial, se aproxima bastante satisfatoriamente dos resultados experimentais para ambas as turbinas analisadas. Deve ser destacado que o desempenho inferior da turbina \#2 pode ser atribuído a uma velocidade específica menor, mas principalmente ao elevado vazamento 
circunferencial para a região inativa, decorrente de uma maior folga entre as palhetas estacionárias e rotativas, conforme a equação (2.125) e a tabela 14.

Tabela 11 - Parâmetros de serviço das duas turbinas testadas [57].

\begin{tabular}{|c|c|c|c|c|}
\hline Turbina & $\mathrm{Ns}$ & $\mathrm{Ds}$ & $\mathrm{Re}_{\mathrm{M}}$ & $\mathrm{La}_{\mathrm{M}}$ \\
\hline$\# 1$ & 0,203 & 5,86 & $1,57 \mathrm{E}+07$ & 0,553 \\
\hline$\# 2$ & 0,117 & 10,32 & $4,50 \mathrm{E}+07$ & 0,556 \\
\hline
\end{tabular}

Tabela 12 - Geometria dos bocais para as duas turbinas testadas [57].

\begin{tabular}{|c|c|c|c|}
\hline Turbina & $\mathrm{Z}_{\mathrm{N}}$ & $\varepsilon$ & $\sigma_{\mathrm{x}}$ \\
\hline$\# 1$ & 18 & 0,41 & 1,13 \\
\hline$\# 2$ & 23 & 0,29 & 1,73 \\
\hline
\end{tabular}

Tabela 13 - Geometria das palhetas rotativas para as turbinas testadas [57].

\begin{tabular}{|c|c|c|c|c|c|c|c|}
\hline Turbina & $\beta_{3 \mathrm{~b}}$ & $\mathrm{Z}_{\mathrm{R}}$ & $\mathrm{h} / \mathrm{D}$ & $\mathrm{h} / \mathrm{C}$ & $\sigma_{\mathrm{x}}$ & $\mathrm{t}_{\mathrm{b}} / \mathrm{h}$ & $\mathrm{h}_{3} / \mathrm{h}_{2}$ \\
\hline$\# 1$ & $28^{\circ}$ & 96 & 0,062 & 1,41 & 1,42 & 0,03 & 1,21 \\
\hline$\# 2$ & $22^{\mathrm{o}}$ & 72 & 0,034 & 0,49 & 1,52 & 0,06 & 1,31 \\
\hline
\end{tabular}

Tabela 14 - Parâmetros aerodinâmicos e eficiências calculadas versus eficiência medida em bancada de teste na fábrica para as duas turbinas [57].

\begin{tabular}{|c|c|c|c|c|c|c|c|}
\hline Turbina & $\mathrm{u} / \mathrm{c}_{0}$ & $\rho$ & $\mathrm{M}_{\mathrm{c} 2}$ & $\mathrm{M}_{\mathrm{w} 2}$ & $\mathrm{~L}$ & $\eta$ calculada & $\eta$ teste \\
\hline$\# 1$ & 0,394 & 0,10 & 1,28 & 0,78 & 0,05 & 0,720 & 0,724 \\
\hline$\# 2$ & 0,414 & 0,13 & 1,24 & 0,70 & 0,13 & 0,637 & 0,643 \\
\hline
\end{tabular}




\section{4 Estudo de Otimização de Eficiência em Ciclo Rankine Orgânico}

\subsection{O Expansor de Fluido Orgânico}

Nesta seção serão discutidas as particularidades relativas ao serviço com fluido orgânico, tendo em vista a admissão de gás denso pelo expansor. Nestas condições será imprescindível estabelecer uma correlação precisa entre a energia resultante da expansão do fluido com a relação de pressões, bem como da relação de volumes necessária para avaliação do fator de aceleração axial $K_{t}$. Em função da elevada compressibilidade do meio, será crítica a avaliação dos números de Mach do escoamento absoluto e relativo, tendo em vista assegurar o elevado desempenho do expansor. 


\subsubsection{Considerações Sobre Gases Reais}

Para construir um modelo de escoamento do fluido orgânico no expansor será imprescindível considerar o comportamento de gás real. O trabalho de Luján et al. [59] destaca que os erros resultantes da aplicação da equação de gás perfeito para avaliação da energia específica do fluido orgânico são bastante relevantes, sendo recomendado um esquema de cálculo onde é considerada uma evolução isotérmica até uma condição de baixa pressão. A figura 58 mostra as regiões onde a não idealidade do gás é significativa nas proximidades do ponto crítico e da linha de vapor saturado.

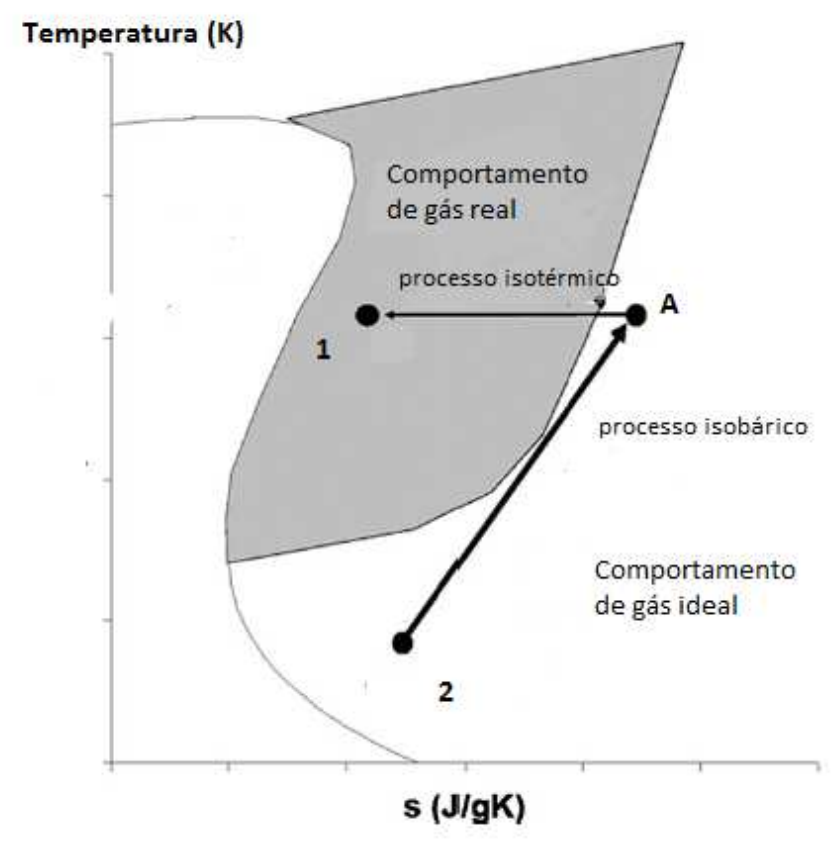

Figura 58 - Diagrama temperatura - entropia do fluido orgânico [59].

O modelo de gás real considera a não idealidade do gás através da introdução do fator de compressibilidade $\boldsymbol{Z}$ na equação dos gases perfeitos:

$$
Z=\frac{p v}{R T}
$$

Para caracterização completa do gás e cálculo de suas demais propriedades termodinâmicas é necessário considerar também os fatores $\boldsymbol{X}$ e $\boldsymbol{Y}$, obtidos a partir 
das derivadas parciais do fator de compressibilidade em relação à pressão e à temperatura, conforme definidos através das equações abaixo:

$$
\begin{aligned}
& X=\frac{T}{Z}\left(\frac{\partial Z}{\partial T}\right)_{p} \\
& Y=1-\frac{p}{Z}\left(\frac{\partial Z}{\partial p}\right)_{T}
\end{aligned}
$$

A partir daí pode ser obtida uma versão diferencial para a equação do gás real dada por:

$$
(1+X) \frac{d T}{T}=\frac{d v}{v}+Y \frac{d p}{p}
$$

Diversas propriedades termodinâmicas podem ser obtidas a partir dos fatores $X$ e $Y$, como a diferença entre os calores específicos:

$$
C_{p}-C_{v}=Z R \frac{(1+X)^{2}}{Y}
$$

É de interesse também a determinação de expoentes isentrópicos [60], como o expoente pressão-volume dado por:

$$
k=\frac{v}{p}\left(\frac{\partial p}{\partial v}\right)_{s}=\frac{C_{p}}{Y C_{v}}
$$

E o expoente pressão-temperatura dado por:

$$
j=\frac{p}{T}\left(\frac{\partial T}{\partial p}\right)_{s}=\frac{Y}{1+X} \frac{k-1}{k}
$$

A partir daí a velocidade do som pode ser calculada conforme a seguinte expressão:

$$
V_{s d}=\sqrt{-v^{2}\left(\frac{\partial p}{\partial v}\right)_{s}}=\sqrt{k Z R T}
$$


O desvio isotérmico de entalpia em relação à condição de gás ideal será mais facilmente obtido a partir da equação de estado com a integração no volume:

$$
e-e^{*}=R T \int_{1}^{Z} d Z+\int_{\infty}^{v}\left[T\left(\frac{\partial p}{\partial T}\right)_{v}-p\right] d v
$$

Da mesma forma, o desvio isotérmico de entropia em relação à condição de gás ideal será obtido a partir da equação de estado por:

$$
s-s^{*}=\int_{\infty}^{v}\left(\frac{\partial p}{\partial T}\right)_{v} d v
$$

O desvio isotérmico do calor específico em relação à condição de gás ideal será obtido derivando-se o desvio de entalpia em relação à temperatura, sob pressão constante:

$$
C_{p}-C_{p}^{*}=\left(\frac{\partial\left(e-e^{*}\right)}{\partial T}\right)_{p}
$$

Na figura 59 pode ser visualizado o processo de cálculo de diferenças de entalpia ou entropia entre os pontos 1 e 2, aplicável na expansão de gases em uma turbina, conforme expresso nas seguintes equações:

$$
\begin{aligned}
& e_{2}-e_{1}=\left(e_{2}-e_{B}^{*}\right)+\left(e_{B}^{*}-e_{A}^{*}\right)+\left(e_{A}^{*}-e_{1}\right) \\
& s_{2}-s_{1}=\left(s_{2}-s_{B}^{*}\right)+\left(s_{B}^{*}-s_{A}^{*}\right)+\left(s_{A}^{*}-s_{1}\right)
\end{aligned}
$$

É importante notar que a primeira e a terceira parcelas das equações (4.12) e (4.13) correspondem a um processo isotérmico, sendo calculadas a partir das funções de desvio em relação ao gás ideal, conforme descrito pelas equações (4.9) e (4.10). Já a segunda parcela nas equações de diferença de entalpia ou de entropia corresponde a um processo isobárico, a ser avaliado sob a condição de gás ideal, conforme as seguintes expressões:

$$
\begin{aligned}
& e_{B}^{*}-e_{A}^{*}=\int_{T} C_{p}^{*} d T \\
& s_{B}^{*}-s_{A}^{*}=\int_{T} C_{p}^{*} \frac{d T}{T}
\end{aligned}
$$




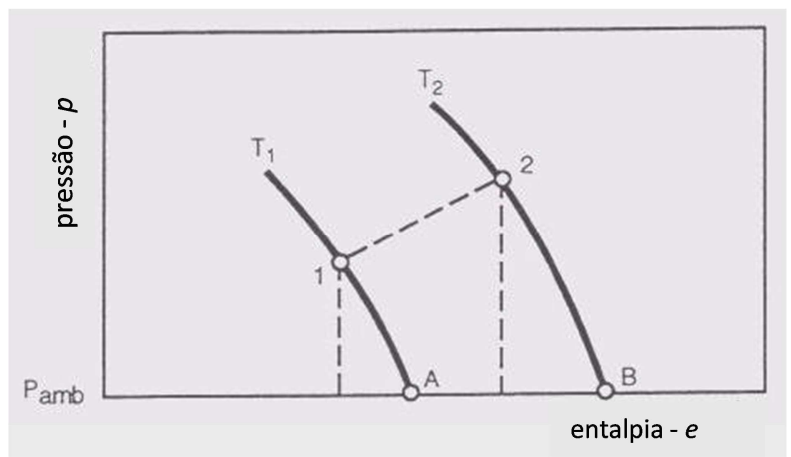

Figura 59 - Cálculo de diferença de entropia ou entalpia entre os pontos 1 e 2 para um gás real, através de duas trajetórias isotérmicas (1-A e B-2) e uma trajetória isobárica na condição de gás ideal (A-B).

O princípio dos estados correspondentes estabelece que o fator de compressibilidade e demais propriedades termodinâmicas são função das variáveis de estado reduzidas. A pressão e a temperatura reduzidas são obtidas pela adimensionalização com seus respectivos valores no ponto crítico, ou seja: $p_{\text {red }}=p / p_{c}$ e $T_{r e d}=T / T_{c}$. O ponto crítico caracteriza-se pelo máximo na curva de saturação, acima do qual não pode mais ser observada claramente a mudança da fase líquida para gasosa. As funções de desvio são geralmente adimensionalizadas como $\Delta e_{d e p} / R T_{c}, \Delta s_{d e p} / R$ e $\Delta C_{p, d e p} / R$. Para eliminar a influência da pressão sobre o desvio de entropia, é usual adotar a seguinte definição:

$$
\frac{\Delta s_{d e p}}{R}=\frac{\left(s-s^{*}\right)}{R}+\ln \left(\frac{p}{p^{*}}\right)
$$

Para uma expansão isentrópica do gás real com expoente isentrópico constante, as relações entre os valores de estagnação para os respectivos valores estáticos das variáveis de estado (temperatura, pressão e densidade) são dadas pelas expressões seguintes em função do número de Mach:

$$
\frac{T_{0}}{T}=\frac{1+\left(\frac{k^{*}-1}{k^{*}}\right) \frac{k}{2} Z M^{2}}{1+\frac{k^{*}-1}{k^{*}}\left(\frac{\Delta e_{d e p, 0} / R T_{c}-\Delta e_{d e p} / R T_{c}}{T_{0} / T_{c}}\right)}
$$




$$
\begin{aligned}
& \frac{p_{0}}{p}=\left(\frac{T_{0}}{T}\right)^{\frac{1+X}{Y} \frac{k}{k-1}} \\
& \frac{\gamma_{0}}{\gamma}=\left(\frac{T_{0}}{T}\right)^{\frac{1+X}{Y} \frac{1}{k-1}}
\end{aligned}
$$

Os expoentes isentrópicos no estado de gás real podem experimentar variações significativas com a temperatura e pressão que não foram consideradas na obtenção das equações (4.18) e (4.19). Para contornar esta deficiência, a alternativa é utilizar as expressões seguintes, que fazem uso do expoente $k^{*}$ no estado de gás ideal:

$$
\begin{aligned}
& \frac{p_{0}}{p}=e^{\left(\frac{\Delta s_{\text {dep }, 0}}{R}-\frac{\Delta s_{\text {dep }}}{R}\right)}\left(\frac{T_{0}}{T}\right)^{\frac{k^{*}}{k^{*}-1}}
\end{aligned}
$$

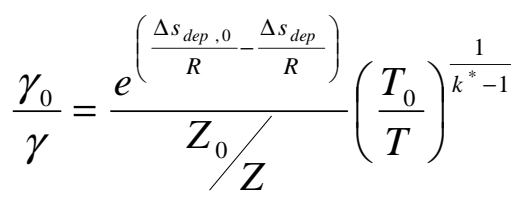

Tendo em vista obter uma maior precisão nas propriedades de saturação o princípio dos estados correspondentes é ampliado incorporando um terceiro parâmetro, que representa a influência da complexidade molecular em termos de geometria e polaridade. Este terceiro parâmetro $\omega$, denominado fator acêntrico, é definido em função da pressão de vapor reduzida para uma temperatura reduzida $T_{\text {red }}=0,7$ conforme a seguinte expressão:

$$
\omega=-\left(\log _{10} p_{\text {vap }, \text { red }, T r=0,7}+1\right)
$$

Luján et al. [59] indicam a utilização da equação de estado de RedlichKwong-Soave (RKS) para o cálculo das propriedades termodinâmicas do R245fa, conforme a relação $p-v$ - $T$ a seguir:

$$
p=\frac{R T}{v-b}-\frac{a \alpha(T)}{v(v+b)}
$$

O fator de compressibilidade será obtido a partir da seguinte equação cúbica:

$$
Z^{3}-Z^{2}+Z\left(A-B-B^{2}\right)-B=0
$$


Sendo:

$$
A=\frac{a p \alpha(T)}{R^{2} T^{2}} \text { e } B=\frac{b p}{R T}
$$

As constantes $a$ e $b$ são determinadas de forma a satisfazer a condição de estabilidade termodinâmica no ponto crítico, ou seja, a primeira e segunda derivadas da pressão com respeito ao volume são nulas, o que resulta em:

$$
a=\Omega_{a} \frac{R^{2} T_{c}^{2}}{p_{c}} \text { e } b=\Omega_{b} \frac{R T_{c}}{p_{c}}
$$

Sendo: $\Omega_{a}=\frac{1}{9\left(2^{1 / 3}-1\right)}=0,427480 \quad$ e $\Omega_{b}=\frac{2^{1 / 3}-1}{3}=0,086640$

A função adimensional $\alpha(T)$ é determinada de forma a satisfazer a condição de saturação em $T_{\text {red }}=0,7$, o que resulta em:

$$
\sqrt{\alpha(T)}=1+m\left(1-\sqrt{T_{r e d}}\right)
$$

Sendo o coeficiente $m$ ajustado em função do fator acêntrico $\omega$.

$$
m=0,480+1,547 \omega-0,176 \omega^{2}
$$

Para a equação RKS os fatores X e Y serão dados por:

$$
\begin{aligned}
& X=\frac{(Z-B) A\left(1+\frac{1+m}{\sqrt{\alpha}}\right)-[A+Z(1+2 B)] B}{3 Z^{3}-2 Z^{2}+Z\left(A-B-B^{2}\right)} \\
& Y=1+\frac{(Z-B) A-[A+Z(1+2 B)] B}{3 Z^{3}-2 Z^{2}+Z\left(A-B-B^{2}\right)}
\end{aligned}
$$

Enquanto que as funções de desvio em relação à condição de gás ideal serão dadas por:

$$
\frac{\Delta e_{d e p}}{R T_{c}}=T_{r e d}(Z-1)-\frac{\Omega_{a}}{\Omega_{b}}(1+m) \sqrt{\alpha} \ln \left(1+\frac{B}{Z}\right)
$$




$$
\begin{gathered}
\frac{\Delta s_{d e p}}{R}=\ln (Z-B)+\frac{\Omega_{a}}{\Omega_{b}} \sqrt{\alpha} \frac{\sqrt{\alpha}-(1+m)}{T_{\text {red }}} \ln \left(1+\frac{B}{Z}\right) \\
\frac{\Delta C_{p, d e p}}{R}=Z(1+X)-1+\frac{\Omega_{a}}{\Omega_{b}}(1+m)\left[\frac{B / Z}{1+B / Z} \frac{1+X}{T_{\text {red }}} \sqrt{\alpha}+\frac{1}{2} \frac{m}{\sqrt{T_{\text {red }}}} \ln \left(1+\frac{B}{Z}\right)\right]
\end{gathered}
$$




\subsubsection{Propriedades do R245fa}

O fluido refrigerante R245fa é usualmente selecionado como fluido de trabalho para o ciclo Rankine Orgânico em virtude do seu baixo potencial de agressão à camada de ozônio e de seu valor elevado de temperatura crítica. Suas propriedades são dadas na tabela 15 .

Tabela 15 - Propriedades do R245fa (1,1,1,3,3-Pentafluoropropano).

\begin{tabular}{|l|c|}
\hline peso molecular $(\mathrm{g} / \mathrm{mol})$ & 134,0479 \\
\hline pressão crítica $(\mathrm{MPa})$ & 3,64 \\
temperatura crítica $\left({ }^{\circ} \mathrm{C}\right)$ & 154,1 \\
\hline fator acêntrico & 0,3724 \\
\hline
\end{tabular}

Como já discutido na seção anterior, mesmo em situações não ideais será imprescindível avaliar as propriedades do gás no estado ideal para o cálculo termodinâmico dos processos de expansão. Na figura 60 está ilustrada a variação do calor específico a pressão constante no estado de gás ideal com a temperatura reduzida para o R245fa, obtida a partir da base de dados da NIST [61].

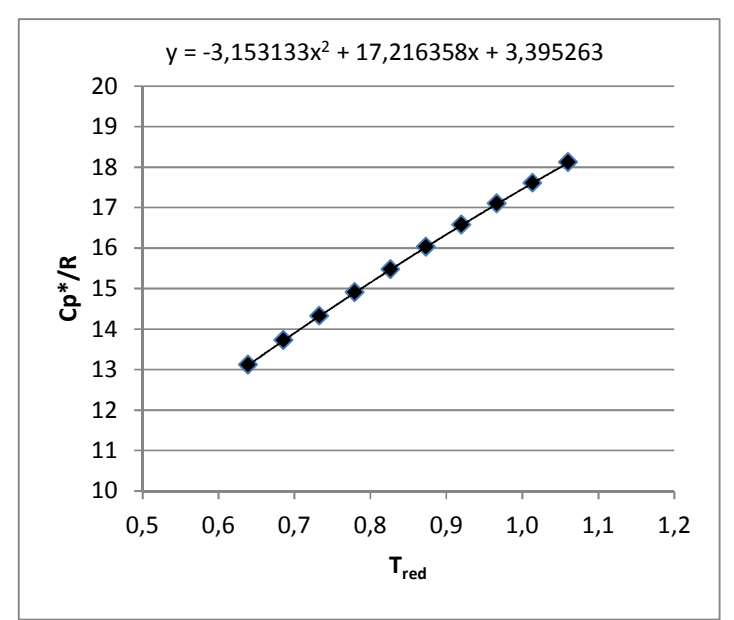

Figura 60 - Correlação do calor específico à pressão constante no estado de gás ideal com a temperatura reduzida para o fluido R245fa.

A correlação quadrática a seguir pode ser estabelecida com um erro inferior a $0,004 \%$ para temperaturas entre $0^{\circ} \mathrm{C}$ e $180^{\circ} \mathrm{C}$ :

$$
\frac{C_{p}^{*}}{R}=a_{0}+a_{1} T_{r e d}+a_{2} T_{r e d}^{2}
$$


A entalpia e a entropia no estado de gás ideal são obtidas por integração da equação do calor específico, resultando em:

$$
\begin{aligned}
& \frac{e^{*}}{R T_{c}}=a_{0} T_{r}+a_{1} \frac{T_{r e d}^{2}}{2}+a_{2} \frac{T_{r e d}^{3}}{3}+e_{0} \\
& \frac{s^{*}}{R}=a_{0} \ln \left(T_{r e d}\right)+a_{1} T_{r e d}+a_{2} \frac{T_{r e d}^{2}}{2}+s_{0}
\end{aligned}
$$

Sendo as constantes dadas por $a_{0}=3,395263, a_{1}=17,216358, a_{2}=-3,153133$, $e_{0}=9,935$ e $s_{0}=61,52$.

O expoente isentrópico $k^{*}$ na condição de gás ideal está mostrado como função da temperatura relativa na figura 61. Pode-se notar sua pequena variação com a temperatura (inferior a 3\%) na região de interesse, o que justifica a premissa da utilização de um valor constante para o expoente $k^{*}$ na obtenção das equações (4.17), (4.20) e (4.21). Sendo a variação de $C_{p} *$ com a temperatura aproximadamente linear, será suficiente para assegurar a precisão dos cálculos avaliar o expoente $k^{*}$ em uma temperatura de referência dada pela média aritmética $T_{e q}=\left(T_{A}+T_{B}\right) / 2$ para as equações oriundas de uma diferença de entalpia, ou pela média logarítmica $T_{e q}=\left(T_{A}-T_{B}\right) / \ln \left(T_{A} / T_{B}\right)$ para as equações oriundas de uma diferença de entropia.

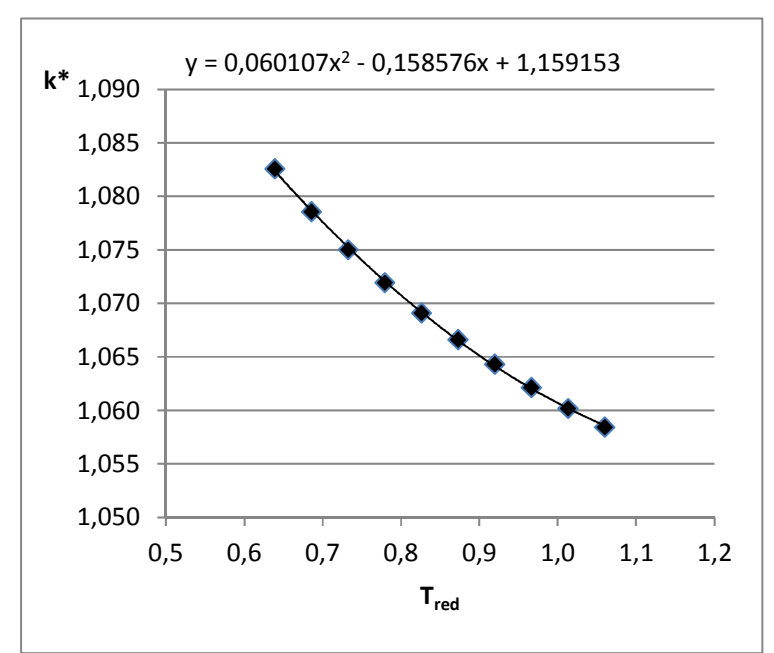

Figura 61- Variação do expoente isentrópico do R245fa na condição de gás ideal $k^{*}$ com a temperatura relativa. 
Os bons resultados obtidos na aplicação da equação de estado de RedlichKwong-Soave na simulação das propriedades termodinâmicas do R245fa podem ser verificados nas figuras 62 e 63 . A figura 62 ilustra a comparação das funções de desvio isotérmico de entalpia e de entropia obtidas a partir da equação RKS com a base de dados do NIST [61]. De maneira análoga, na figura 63 é mostrada a comparação do fator de compressibilidade e da velocidade do som. Em ambos os casos são analisadas a isotérmica supercrítica correspondente a $T_{\text {red }}=1,014$.
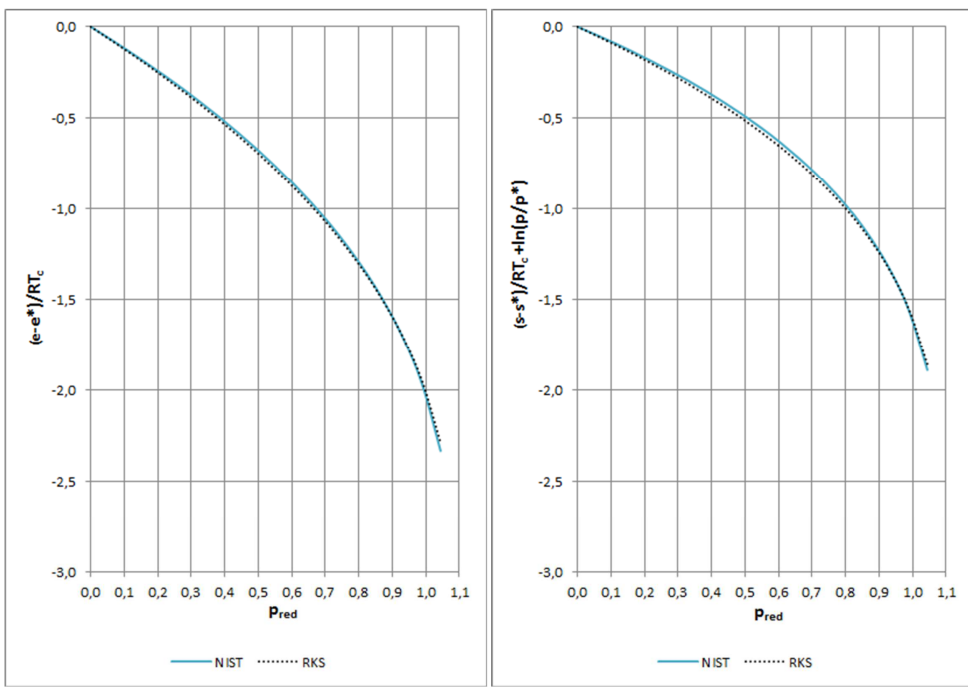

Figura 62 - Comparação das funções de desvio isotérmico de entalpia e entropia obtidas a partir da equação RKS com os dados da NIST $\left(\mathrm{T}_{\text {red }}=1,014\right)$.

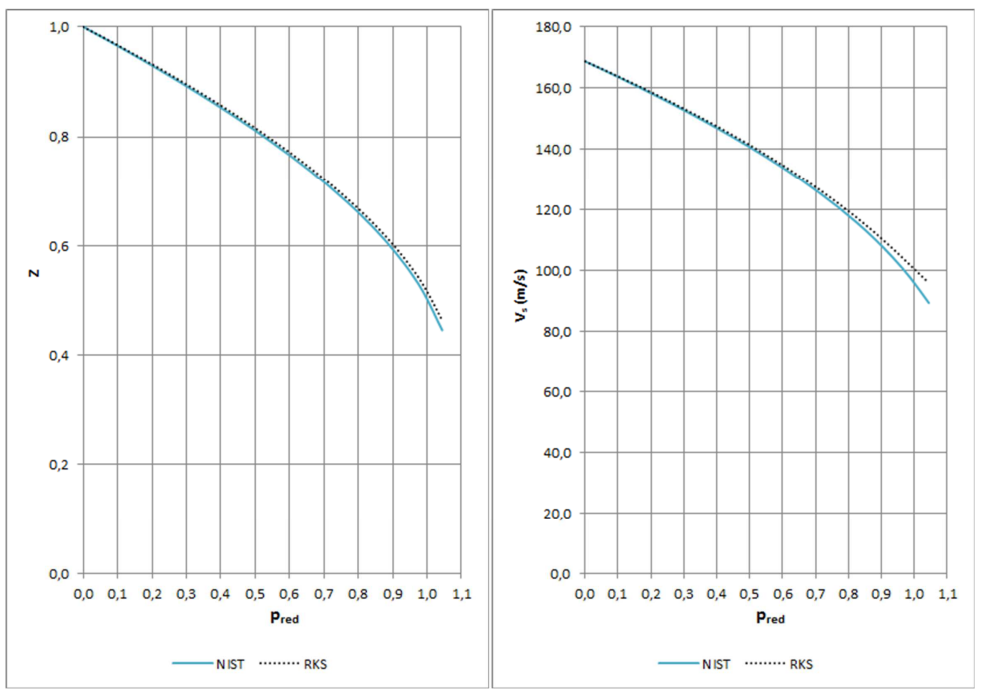

Figura 63 - Comparação do fator de compressibilidade $\mathrm{Z}$ e da velocidade do som obtidos a partir da equação RKS com dados da NIST $\left(\mathrm{T}_{\mathrm{r}}=1,014\right)$. 
Na tabela 16 estão listados os valores obtidos a partir da equação RKS, acrescentando-se ainda o expoente isentrópico na condição de gás real, onde pode ser observada sua variação expressiva com a pressão relativa. Em virtude disto a velocidade do som tem comportamento crescente com a redução de pressão.

Tabela 16 - Variação das propriedades do R245fa com a pressão relativa obtidas a partir da equação RKS para a isotérmica $T_{\text {red }}=1,014$.

\begin{tabular}{|c|c|c|c|c|c|}
\hline $\mathrm{p}_{\text {red }}$ & $\mathrm{Z}$ & $\Delta \mathrm{e}_{\text {dep }} / \mathrm{RT}_{\mathrm{c}}$ & $\Delta \mathrm{s}_{\text {dep }} / \mathrm{R}$ & $\mathrm{k}$ & $\mathrm{V}_{\mathrm{sd}}(\mathrm{m} / \mathrm{s})$ \\
\hline 0,0003 & 0,9999 & 0,000 & 0,000 & 1,060 & 168,75 \\
\hline 0,0549 & 0,9820 & $-0,066$ & $-0,047$ & 1,046 & 166,12 \\
\hline 0,1099 & 0,9635 & $-0,134$ & $-0,096$ & 1,031 & 163,39 \\
\hline 0,1648 & 0,9446 & $-0,203$ & $-0,146$ & 1,016 & 160,59 \\
\hline 0,2198 & 0,9253 & $-0,276$ & $-0,199$ & 1,001 & 157,71 \\
\hline 0,2747 & 0,9053 & $-0,351$ & $-0,254$ & 0,984 & 154,72 \\
\hline 0,3297 & 0,8848 & $-0,429$ & $-0,312$ & 0,967 & 151,65 \\
\hline 0,3846 & 0,8637 & $-0,510$ & $-0,373$ & 0,950 & 148,49 \\
\hline 0,4396 & 0,8417 & $-0,595$ & $-0,437$ & 0,932 & 145,19 \\
\hline 0,4945 & 0,8190 & $-0,684$ & $-0,505$ & 0,913 & 141,77 \\
\hline 0,5495 & 0,7952 & $-0,779$ & $-0,578$ & 0,894 & 138,21 \\
\hline 0,6044 & 0,7704 & $-0,879$ & $-0,656$ & 0,874 & 134,49 \\
\hline 0,6593 & 0,7442 & $-0,986$ & $-0,741$ & 0,853 & 130,59 \\
\hline 0,7143 & 0,7164 & $-1,101$ & $-0,833$ & 0,831 & 126,49 \\
\hline 0,7692 & 0,6867 & $-1,228$ & $-0,935$ & 0,809 & 122,15 \\
\hline 0,8242 & 0,6544 & $-1,368$ & $-1,051$ & 0,786 & 117,54 \\
\hline 0,8791 & 0,6187 & $-1,527$ & $-1,185$ & 0,763 & 112,61 \\
\hline 0,9341 & 0,5781 & $-1,715$ & $-1,346$ & 0,741 & 107,30 \\
\hline 0,9890 & 0,5295 & $-1,951$ & $-1,553$ & 0,726 & 101,63 \\
\hline 1,0440 & 0,4652 & $-2,288$ & $-1,859$ & 0,737 & 95,98 \\
\hline
\end{tabular}




\subsubsection{Relações Aero-Termodinâmicas}

A partir da consideração das inter-relações entre entalpia e energia cinética expostas nas equações (2.36) a (2.41), relações de expansão isentrópica e da equação de estado adotada, as variáveis de estado para todos os pontos relevantes para análise do estágio axial deverão ser determinados. Em seguida serão obtidos os números de Mach relativos à velocidade absoluta $c_{2} \mathrm{e}$ às velocidades relativas $w_{2}$ e $w_{3}$, bem como as relações de pressão, temperatura e volume específico no rotor.

Tais parâmetros serão obtidos em função do parâmetro $M_{0}$ que traduz a compressibilidade do meio, denominado número de Mach de referência, cuja relação com o número de Laval da máquina $L a_{M}$ é dada por:

$$
M_{0}=\frac{c_{0}}{\sqrt{k_{01}^{*} R T_{01}}}=\sqrt{\frac{k_{c r} Z_{c r} T_{c r}}{k_{01}^{*} T_{01}}} \frac{L a_{M}}{u / c_{0}} \sqrt{1-2 \frac{h}{D}+2\left(\frac{h}{D}\right)^{2}}
$$

Desta forma, as variáveis de estado que determinam os pontos relevantes para análise do estágio axial, conforme mostrados na figura 12 serão dadas pelas expressões a seguir:

$$
\begin{aligned}
& \frac{T_{3 s s}}{T_{01}}=\left[e^{\left(\frac{\Delta s_{d e p, 01}}{R} \frac{\Delta s_{d e p, 3 s s}}{R}\right)}\left(\frac{p_{3}}{p_{01}}\right)\right]^{\frac{k^{*}-1}{k^{*}}} \\
& \frac{p_{2}}{p_{3}}=e^{\left(\frac{\Delta s_{d e p, 2 s}}{R}-\frac{\Delta s_{d e p, 3 s s}}{R}\right)}\left(\frac{T_{2 s}}{T_{3 s s}}\right)^{\frac{k^{*}}{k^{*}-1}} \\
& \frac{T_{2 s}}{T_{3 s s}}=1+\frac{k^{*}-1}{2} \frac{k_{01}^{*}}{k^{*}} \frac{\rho M_{0}^{2}}{T_{3 s s} / T_{01}}-\frac{k^{*}-1}{k^{*}} \frac{\left(\frac{\Delta e_{d e p}}{R T_{c}}\right)_{2 s}-\left(\frac{\Delta e_{d e p}}{R T_{c}}\right)_{3 s s}}{T_{3 s s} / T_{c}} \\
& \frac{T_{2}}{T_{c}}=\frac{T_{01}}{T_{c}}\left(1-\frac{k^{*}-1}{2} \frac{k_{01}^{*}}{k^{*}}\left(\frac{c_{2}}{c_{0}}\right)^{2} M_{0}^{2}\right)+\frac{k^{*}-1}{k^{*}}\left[\left(\frac{\Delta e_{\text {dep }}}{R T_{c}}\right)_{01}-\left(\frac{\Delta e_{\text {dep }}}{R T_{c}}\right)_{2}\right]
\end{aligned}
$$


$\frac{T_{02, \text { rel }}}{T_{2}}=\left(1+\frac{k^{*}-1}{2} \frac{k_{01}^{*}}{k^{*}}\left(\frac{T_{01}}{T_{2}}\right)\left(\frac{w_{2}}{c_{0}}\right)^{2} M_{0}^{2}\right)-\frac{k^{*}-1}{k^{*}}\left[\frac{\left(\frac{\Delta e_{d e p}}{R T_{c}}\right)_{02, \text { rel }}-\left(\frac{\Delta e_{d e p}}{R T_{c}}\right)_{2}}{T_{2} / T_{c}}\right]$

$\left.\frac{p_{02, r e l}}{p_{2}}=e^{\left(\frac{\Delta \Delta_{d e p, 02, r e l}}{R}-\frac{\Delta s_{d e p, ~}}{R}\right.}\right)\left(\frac{T_{02, \text { rel }}}{T_{2}}\right)^{\frac{k^{*}}{k^{*}-1}}$

$\left.\frac{p_{02}}{p_{2}}=e^{\left(\frac{\Delta s_{\text {dep }, 02}}{R}-\frac{\Delta s_{\text {dep }, 2}}{R}\right.}\right)\left(\frac{T_{02}}{T_{2}}\right)^{\frac{k^{*}}{k^{*}-1}}$

$\frac{T_{02}}{T_{2}}=\left(1+\frac{k^{*}-1}{2} \frac{k_{01}^{*}}{k^{*}}\left(\frac{T_{01}}{T_{2}}\right)\left(\frac{c_{2}}{c_{0}}\right)^{2} M_{0}^{2}\right)-\frac{k^{*}-1}{k^{*}}\left[\frac{\left(\frac{\Delta e_{d e p}}{R T_{c}}\right)_{02}-\left(\frac{\Delta e_{d e p}}{R T_{c}}\right)_{2}}{T_{2} / T_{c}}\right]$

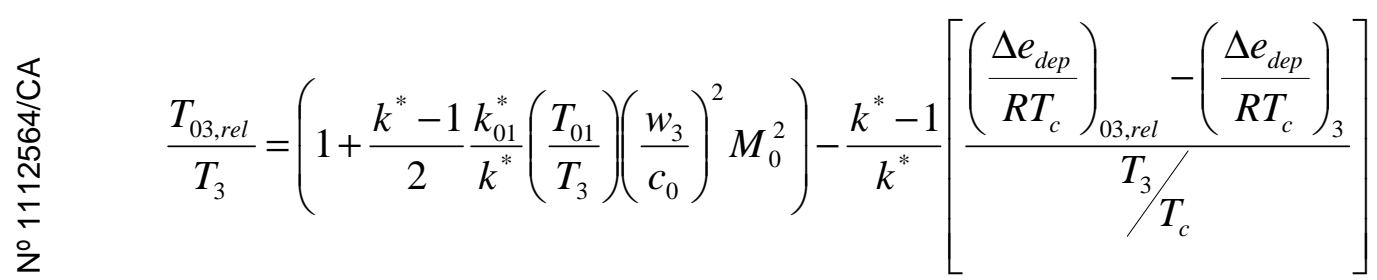

$\frac{p_{03, r e l}}{p_{3}}=e^{\left(\frac{\Delta s_{\text {dep }, 03, r e l}}{R}-\frac{\Delta s_{\text {dep }, 3}}{R}\right)}\left(\frac{T_{03, r e l}}{T_{3}}\right)^{\frac{k^{*}}{k^{*}-1}}$

$\frac{T_{3}}{T_{c}}=\frac{T_{2}}{T_{c}}+\frac{k^{*}-1}{k^{*}}\left\{\frac{k_{01}^{*}}{2} \frac{T_{01}}{T_{c}}\left[\left(\frac{w_{2}}{c_{0}}\right)^{2}-\left(\frac{w_{3}}{c_{0}}\right)^{2}\right] M_{0}^{2}+\left[\left(\frac{\Delta e_{d e p}}{R T_{c}}\right)_{2}-\left(\frac{\Delta e_{d e p}}{R T_{c}}\right)_{3}\right]\right\}$

$\frac{T_{3 s}}{T_{2}}=\left[e^{\left(\frac{\Delta s_{d e p, 2}}{R}-\frac{\Delta s_{d e p, 3 s}}{R}\right)}\left(\frac{p_{3}}{p_{2}}\right)\right]^{\frac{k^{*}-1}{k^{*}}}$

$\frac{T_{03}}{T_{c}}=\frac{T_{3}}{T_{c}}+\frac{k^{*}-1}{k^{*}}\left\{\frac{k_{01}^{*}}{2} \frac{T_{01}}{T_{c}}\left[\left(\frac{c_{3}}{c_{0}}\right)^{2}+\Delta \eta_{w}+\Delta \eta_{p a}\right] M_{0}^{2}-\left[\left(\frac{\Delta e_{d e p}}{R T_{c}}\right)_{03}-\left(\frac{\Delta e_{d e p}}{R T_{c}}\right)_{3}\right]\right\}$

$\frac{T_{1}}{T_{c}}=\frac{T_{01}}{T_{c}}\left(1-\frac{k^{*}-1}{k^{*}} \frac{k_{01}^{*}}{2}\left(\frac{c_{1}}{c_{0}}\right)^{2} M_{0}^{2}\right)+\frac{k^{*}-1}{k^{*}}\left[\left(\frac{\Delta e_{d e p}}{R T_{c}}\right)_{01}-\left(\frac{\Delta e_{d e p}}{R T_{c}}\right)_{1}\right]$

$\frac{p_{1}}{p_{01}}=e^{\left(\frac{\Delta s_{d e p, 1}-\frac{\Delta s_{d e p, 01}}{R}}{R}\right)}\left(\frac{T_{1}}{T_{01}}\right)^{\frac{k^{*}}{k^{*}-1}}$ 
É importante observar que será necessário um procedimento iterativo para as expressões (4.36) a (4.50), uma vez que as funções de desvio isotérmicas também são dependentes das variáveis de estado em processo de cálculo.

Uma vez determinados os pontos do diagrama entalpia-entropia do estágio axial, os números de Mach relevantes para o escoamento absoluto através do bocal e para o escoamento relativo através das palhetas rotativas serão dados pelas seguintes expressões:

$$
\begin{aligned}
& M_{0}=\sqrt{\frac{2}{k_{01}^{*}}\left[\frac{k^{*}}{k^{*}-1}\left(1-\frac{T_{3 s s}}{T_{01}}\right)+\frac{\left(\Delta e_{\text {dep }} / R T_{c}\right)_{01}-\left(\Delta e_{d e p} / R T_{c}\right)_{3 s s}}{T_{01} / T_{c}}\right]} \\
& M_{c 2}=M_{0} c_{2} / c_{0} \sqrt{\frac{k_{01}^{*} T_{01}}{Z_{2} k_{2} T_{2}}} \\
& M_{w 2}=M_{0} w_{2} / c_{0} \sqrt{\frac{k_{01}^{*} T_{01}}{Z_{2} k_{2} T_{2}}} \\
& M_{w 2, i s}=M_{0} \sqrt{(1-\rho) \frac{k_{01}^{*} T_{01}}{Z_{2 s} k_{2 s} T_{2 s}}} \\
& M_{w 3}=M_{0} w_{3} / c_{0} \sqrt{\frac{k_{01}^{*} T_{01}}{Z_{3} k_{3} T_{3}}} \\
& M_{w 3, i s}=M_{0} \sqrt{\left[\left(\frac{w_{2}}{c_{0}}\right)^{2}+f_{c} \rho\right] \frac{k_{01}^{*} T_{01}}{Z_{3 s} k_{3 s} T_{3 s}}}
\end{aligned}
$$

O coeficiente $f_{c}$ utilizado na equação (2.16) para corrigir o salto de entalpia disponível para expansão no rotor devido à divergência das linhas isobáricas no diagrama entalpia - entropia será dado por:

$$
f_{c}=\left[\frac{\left(\Delta e_{\text {dep }} / R T_{c}\right)_{2}-\left(\Delta e_{\text {dep }} / R T_{c}\right)_{3 s}+\frac{k^{*}}{k^{*}-1}\left(\frac{T_{2}}{T_{c}}-\frac{T_{3 s}}{T_{c}}\right)}{\frac{k^{*}}{2} \frac{k_{01}^{*}}{k^{*}} \frac{T_{01}}{T_{c}} \rho M_{0}{ }^{2}}\right]
$$




\subsubsection{Coeficiente de Perda da Grade}

Para determinação do coeficiente de perda total as equações (2.83) a (2.85), apresentadas por Stewart para escoamento na saída da grade, deverão ser reformuladas para contemplar simultaneamente os efeitos de compressibilidade e de não idealidade do gás, resultando no sistema a seguir:

$$
\begin{aligned}
& \left(k \frac{p}{p_{0}} \frac{M}{V_{s d}}\right)_{2 t e} \operatorname{sen} \lambda_{2 t e}\left(1-\delta_{3 D}^{\prime}-\frac{t_{e}}{t}\right)=\left(\frac{p_{02}}{p_{0}}\right)\left(k \frac{p}{p_{0}} \frac{M}{V_{s d}}\right)_{2} \operatorname{sen} \lambda_{2} \\
& \left(k \frac{p}{p_{0}} M^{2}\right)_{2 t e} \operatorname{sen} \lambda_{2 t e} \cos \lambda_{2 t e}\left(1-\delta_{3 D}^{\prime}-\frac{t_{e}}{t}-\vartheta_{3 D}^{\prime}\right)=\left(\frac{p_{02}}{p_{0}}\right)\left(k \frac{p}{p_{0}} M^{2}\right)_{2} \operatorname{sen} \lambda_{2} \cos \lambda_{2} \\
& \left(\frac{p}{p_{0}}\right)_{2 t e}\left[1+\left(k M^{2}\right)_{2 t e} \operatorname{sen}^{2} \lambda_{2 t e}\left(1-\delta_{3 D}^{\prime}-\frac{t_{e}}{t}-\vartheta_{3 D}^{\prime}\right)\right]=\left(\frac{p_{02}}{p_{0}}\right)\left(\frac{p}{p_{0}}\right)_{2}\left[1+\left(k M^{2}\right)_{2} \operatorname{sen}^{2} \lambda_{2}\right]
\end{aligned}
$$

A equação de conservação de massa entre as seções da garganta (thr) e da saída (2te) proposta por Stewart para considerar a condição de escoamento supersônico na saída da grade será modificada assumindo-se a ocorrência de uma perda por sobre-expansão no escoamento, conforme a expressão abaixo:

$$
\left(k \frac{p}{p_{0}} \frac{M}{V_{s d}}\right)_{2 t e} \operatorname{sen} \lambda_{2 t e}\left(1-\delta_{3 D}^{\prime}-\frac{t_{e}}{t}\right)=\left(k \frac{p}{p_{0}} \frac{M}{V_{s d}}\right)_{t h r} \operatorname{sen} \lambda_{2 b}\left(1-\delta_{3 D, t h r}^{\prime}-\frac{t_{e}}{t}\right)
$$

O algoritmo para solução das equações (4.58) a (4.60) requer que o valor arbitrado para $M_{2 t e}$ se aproxime do valor correto sempre por valores superiores, caso contrário não haverá convergência do cálculo. Por fim, o coeficiente de perda total de energia cinética no escoamento compressível de gás real será determinado a partir da razão de pressões totais $p_{02} / p_{0}$ conforme a seguinte expressão:

$$
\xi=1-\frac{\frac{k^{*}-1}{k^{*}}\left[\left(\frac{\Delta e_{d e p}}{R T_{c}}\right)_{02}-\left(\frac{\Delta e_{d e p}}{R T_{c}}\right)_{2}\right]+\frac{T_{02}}{T_{c}}\left\{1-\left[e^{\left(\frac{\Delta s_{d e p, 02}}{R}-\frac{\Delta s_{d e p, 2}}{R}\right)}\left(\frac{p}{p_{0}}\right)_{2}\right]^{\frac{k^{*}-1}{k^{*}}}\right\}}{\frac{k^{*}-1}{k^{*}}\left[\left(\frac{\Delta e_{d e p}}{R T_{c}}\right)_{0}-\left(\frac{\Delta e_{d e p}}{R T_{c}}\right)_{2 s}\right]+\frac{T_{0}}{T_{c}}\left\{1-\left[e^{\left(\frac{\left.\Delta s_{d e p, 0}-\frac{\Delta s_{d e p, 2 s}}{R}\right)}{R}\left(\frac{p_{02}}{p_{0}}\right)\left(\frac{p}{p_{0}}\right)_{2}\right]^{k^{*}-1}}\right\}\right.}
$$




\subsubsection{Considerações Sobre Bocais Supersônicos}

Na seção 4.2 será mostrado que uma eficiência maior para o expansor de estágio único e consequentemente uma produção maior de energia elétrica é obtida a partir da utilização de um bocal bidimensional com perfil convergentedivergente. Para aplicação em turbomáquinas é usual empregar um bocal com garganta em canto vivo conforme mostrado na figura 64 (a). Esta construção é capaz de produzir fluxo supersônico uniforme e paralelo com o menor comprimento possível para a corda [62]. Sua geometria é composta por três partes: uma seção convergente (subsônica), uma seção divergente (supersônica) e uma seção plana na superfície de sucção. A seção convergente é responsável por girar o escoamento e acelerar até a velocidade sônica. A seção divergente acelera o fluxo até o número de Mach especificado para a saída do bocal. A seção plana na superfície de sucção completa o perfil do bocal, sendo seu comprimento determinado pelo ângulo de saída da palheta.

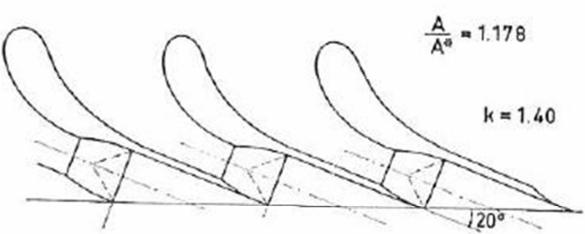

(a)

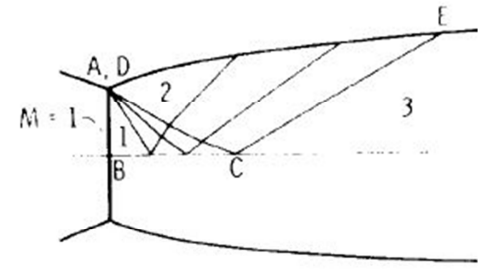

(b)

Figura 64 - (a) Bocal com seção supersônica simétrica mais curta possível capaz de produzir um escoamento uniforme, livre de choque e paralelo [62]. (b) Região de expansão (ABCD) e de retificação (DCED) em bocal com garganta em canto vivo [63].

Na seção divergente o fluxo expande ao redor do canto vivo produzindo ondas que são refletidas na linha de centro, conforme mostrado na figura 64 (b). A expansão do fluxo na verdade é produzida na região ABCDA aproximadamente em igual proporção através do escoamento ao redor da quina e através da reflexão das ondas na linha de centro. A superfície do perfil a jusante da garganta deverá ser construída de forma a cancelar a reflexão das ondas incidentes, produzindo 
assim um fluxo paralelo na saída do bocal (região DCED). Para isto a inclinação da superfície deverá estar alinhada com a direção do fluxo a jusante da onda. A seção divergente é tradicionalmente projetada conforme o método das características, utilizado para resolver a equação diferencial hiperbólica resultante do escoamento supersônico bidimensional de um gás perfeito [63].

O desafio atual no desenvolvimento do expansor de estágio único aplicado ao ciclo rankine orgânico é justamente o projeto de um bocal convergentedivergente de alto desempenho operando com gases densos [64]. A complexidade molecular do fluido é traduzida pela derivada fundamental $\Gamma$ [65], a qual determina o comportamento da dinâmica do gás, definida pela seguinte expressão:

$$
\Gamma=1-\frac{v}{V_{s d}}\left(\frac{\partial V_{s d}}{\partial v}\right)_{s}
$$

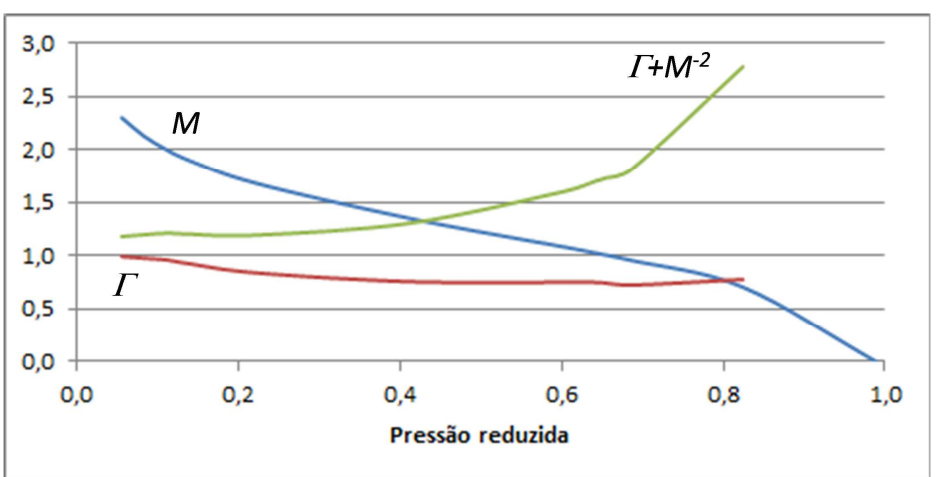

Figura 65 - Evolução dos parâmetros aerodinâmicos $M, \Gamma$ e $\Gamma+M^{-2}$ ao longo de uma expansão isentrópica do R245fa a partir das condições de estagnação $p_{0}=36$ bar e $T_{0}=433,2 \mathrm{~K}$.

Para um gás ideal a derivada fundamental da dinâmica do gás está diretamente relacionada com o expoente isentrópico por $\Gamma=(k+1) / 2$, sendo sempre maior que 1, o que significa que a velocidade do som será sempre decrescente ao longo de uma expansão isentrópica. Ondas de compressão num gás ideal tendem a coalescer e formar ondas de choque, enquanto que ondas de expansão não terão esta possibilidade. Em gases densos $\Gamma$ pode assumir valores menores que 1, o que significa que a velocidade do som diminui ao longo de uma compressão isentrópica e aumenta ao longo de uma expansão isentrópica. Este comportamento 
invertido é mais pronunciado quando $\Gamma+M^{-2}<1$, situação na qual as ondas de expansão podem teoricamente formar ondas de choque. Fluidos que apresentam este comportamento são denominados gases Beth-Zeldovich Thompson ou gases BZT. Não há evidências da ocorrência de tais efeitos para o R245fa na faixa operacional estudada no presente trabalho, conforme mostrado na figura 65 .

O método proposto por Wheeler e Ong [66] consiste em uma adaptação do método das características para utilização em gases reais, sendo fundamentado no fato de que a expansão do fluido de trabalho obedece a uma relação politrópica $p v^{k}=$ constante para um expoente $k$ também constante. Esta premissa é fundamentada pela observação de que as linhas isentrópicas em um diagrama logarítmico pressão-volume admitem um ajuste linear como boa aproximação para o pentano e o R245fa em uma faixa ampla de condições de estagnação. A partir desta premissa é mostrado que a velocidade do som é dada pela expressão seguinte, obtida sem nenhuma consideração de equação de estado além daquela formulada pela relação politrópica $p v^{k}=$ constante:

$$
V_{s d}^{2}=\frac{k p_{0} v_{0}}{\left(1+\frac{k-1}{2} M^{2}\right)}
$$

A função de Prantdl-Mayer é definida como o ângulo $v$ que o escoamento irá girar ao acelerar desde a velocidade sônica até um valor determinado para o número de Mach. A função de Prandtl-Mayer é modificada considerando o caso particular dos gases densos, onde $k<1$ :

$$
v=\sqrt{\frac{1+k}{1-k}} \tanh ^{-1}\left(\sqrt{\frac{1-k}{1+k}} \sqrt{M^{2}-1}\right)-\tan ^{-1}\left(\sqrt{M^{2}-1}\right)
$$

A partir do valor desejado para o número de Mach de saída, a utilização da equação (4.65) permite então a determinação geométrica do perfil divergente do bocal através do método das características adaptado para utilização em gases reais [66]. 


\subsection{Otimização Integrada do Ciclo Termodinâmico e o Expansor}

Para análise do ciclo termodinâmico de recuperação de calor as seguintes premissas serão adotadas:

- O regenerador não será utilizado, uma vez que este não contribui para aumentar a potência elétrica produzida pelo ciclo em aplicação de recuperação de calor [14];

- O superaquecimento do fluido orgânico é especificado de forma a evitar o risco de condensação no interior do expansor. Para uma temperatura do evaporador no intervalo de $80^{\circ} \mathrm{C}$ até $120^{\circ} \mathrm{C}$ o superaquecimento de $5^{\circ} \mathrm{C}$ é suficiente. Para a temperatura do evaporador entre $130^{\circ} \mathrm{C}$ a $150^{\circ} \mathrm{C}$, um superaquecimento de $10^{\circ} \mathrm{C}$ será adotado;

- Uma diferença de temperatura mínima entre o gás exausto e o óleo térmico de $40^{\circ} \mathrm{C}$ ("pinch point" PP1) e entre o óleo térmico e o fluido orgânico de $10^{\circ} \mathrm{C}$ (“pinch point" PP2) serão adotadas;

- A bomba tem uma eficiência de $75 \%$;

- A temperatura do condensador é $50^{\circ} \mathrm{C}$;

- Será utilizado um expansor tipo turbina axial de estágio único e admissão parcial, acionando diretamente um gerador elétrico síncrono de dois polos.

Para o óleo térmico será suposta uma relação do calor específico $(\mathrm{kJ} / \mathrm{kg})$ com a temperatura $\left({ }^{\circ} \mathrm{C}\right)$ de acordo com a seguinte expressão, obtida no catálogo do fluido térmico Dowtherm Q:

$$
C_{p}=1,9+0,003(T-100)
$$

Na tabela 17 estão mostradas as composições do gás natural padrão [67] e do gás exausto do motor EHR CAT G3520C - DM5854, esta última calculada considerando que há combustão total e que a razão ar-combustível é dada conforme os dados de projeto da tabela 1 . 
Tabela 17 - Composição típica do gás natural (à esquerda) e do gás exausto do motor EHR CAT G3520C - DM5854 (à direita).

\begin{tabular}{|c|c|}
\hline & $\%$ mol \\
\hline $\mathrm{CH}_{4}$ & 87,76 \\
\hline $\mathrm{C}_{2} \mathrm{H}_{6}$ & 7,62 \\
\hline $\mathrm{C}_{3} \mathrm{H}_{8}$ & 1,52 \\
\hline $\mathrm{C}_{4} \mathrm{H}_{10}$ & 0,16 \\
\hline $\mathrm{N}_{2}$ & 2,52 \\
\hline $\mathrm{CO}_{2}$ & 0,40 \\
\hline $\mathrm{He}$ & 0,02 \\
\hline total & 100,00 \\
\hline $\mathrm{He}$ & \begin{tabular}{|c|}
\hline \\
$\mathrm{N}_{2}$
\end{tabular} \\
\hline $\mathrm{CO}_{2}$ & 73,75 \\
\hline $\mathrm{He}$ & 5,93 \\
\hline $\mathrm{O}_{2}$ & 8,00 \\
\hline $\mathrm{Ar}$ & 0,88 \\
\hline $\mathrm{H}_{2} \mathrm{O}$ & 11,15 \\
\hline total & 100,00 \\
\hline
\end{tabular}

A partir da composição do gás exausto é estabelecida uma relação entalpia temperatura conforme a referência [68], mostrada graficamente na figura 66. A seguinte expressão se ajusta com erro inferior a $0,1 \%$ no intervalo de $100^{\circ} \mathrm{C}$ a $550^{\circ} \mathrm{C}$ :

$$
e=0,860872+1,043573 T+0,000132 T^{2}
$$

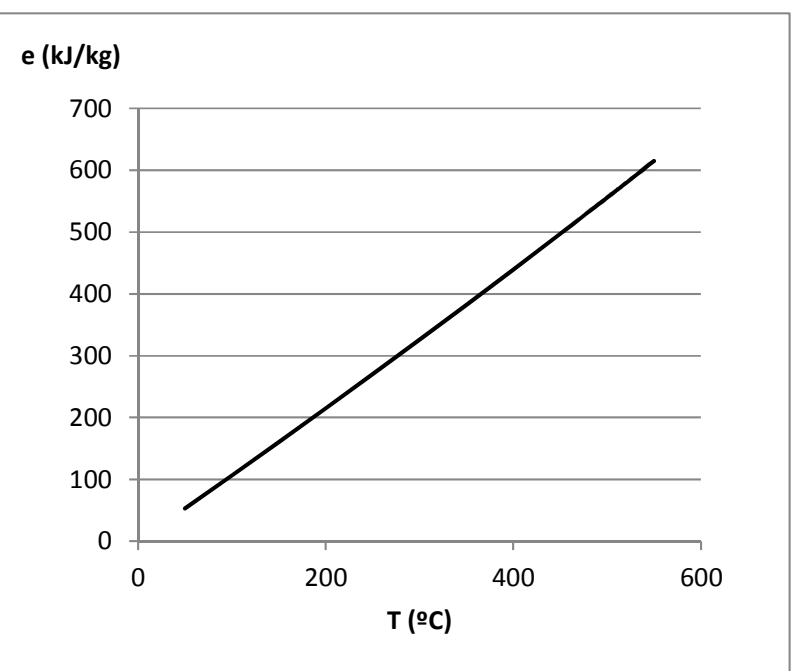

Figura 66 - Variação da entalpia do gás exausto do motor com a temperatura. 


\subsubsection{Operação do Sistema de Troca Térmica}

O sistema de troca térmico estará otimizado quando for transferida a maior quantidade possível de energia térmica disponível no gás exausto do motor. Este fato implica na minimização da temperatura de saída do gás exausto e também da temperatura de saída do óleo térmico, sendo nestas condições o "pinch point" PP1 localizado fisicamente na ponta fria do sistema. Estas condições serão adotadas apenas para o ciclo supercrítico, embora possam acarretar em uma área de troca térmica no sistema gás exausto-óleo térmico acima do razoável. Para o ciclo subcrítico o pinch-point PP2 é considerado como tradicionalmente no ponto de líquido saturado na entrada do evaporador. O "pinch point" PP2 será determinado pela igualdade das inclinações das curvas de evolução de temperatura do óleo térmico e do fluido orgânico versus calor transferido. Esta condição resulta na seguinte expressão:

$$
\left(\dot{m} C_{p}\right)_{\text {fluido_orgânico,PP2 }}=\left(\dot{m} C_{p}\right)_{\text {oleo_térmico,PP2 }}
$$

A partir destas premissas a evolução das temperaturas do exausto do motor, do óleo térmico e do fluido orgânico com o calor transferido é determinada a partir de balanço térmico, conforme mostrado nas figuras 67 e 68, para uma temperatura do evaporador de $80^{\circ} \mathrm{C}$ e $140^{\circ} \mathrm{C}$, respectivamente.

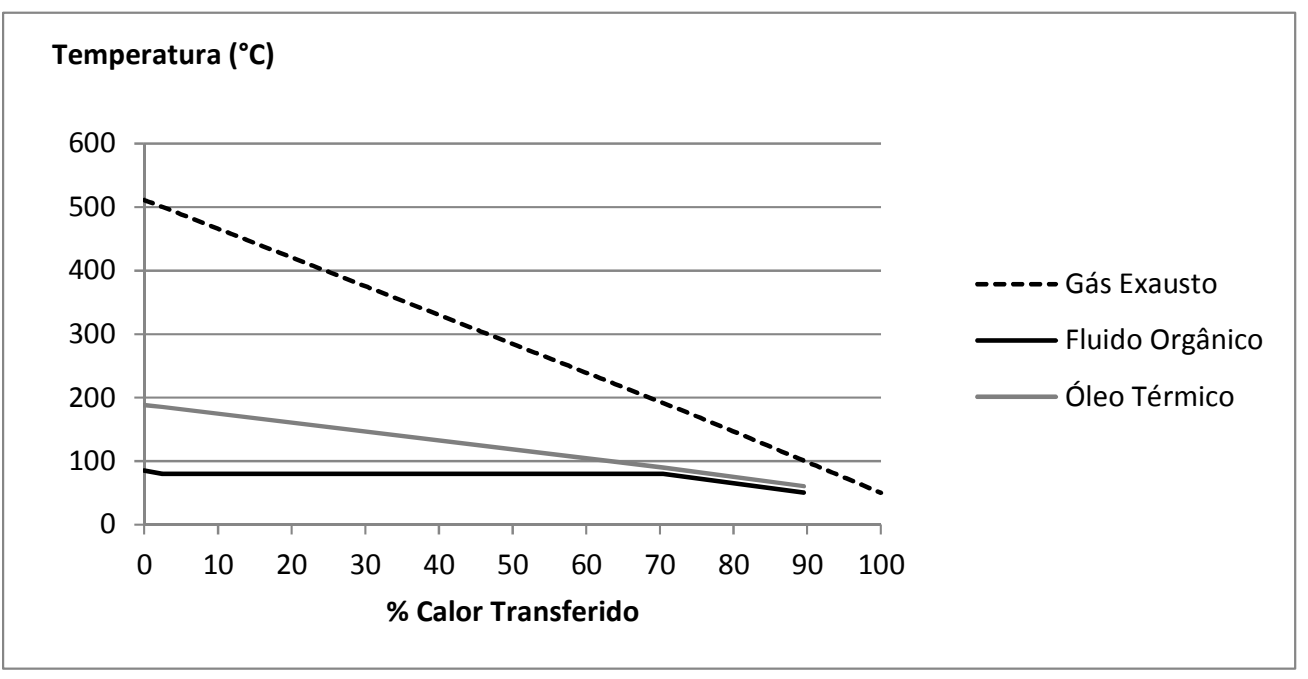

Figura 67 - Evolução das temperaturas no sistema de troca térmica com o calor transferido para o ciclo subcrítico (temperatura de evaporador $80^{\circ} \mathrm{C}$ ). 


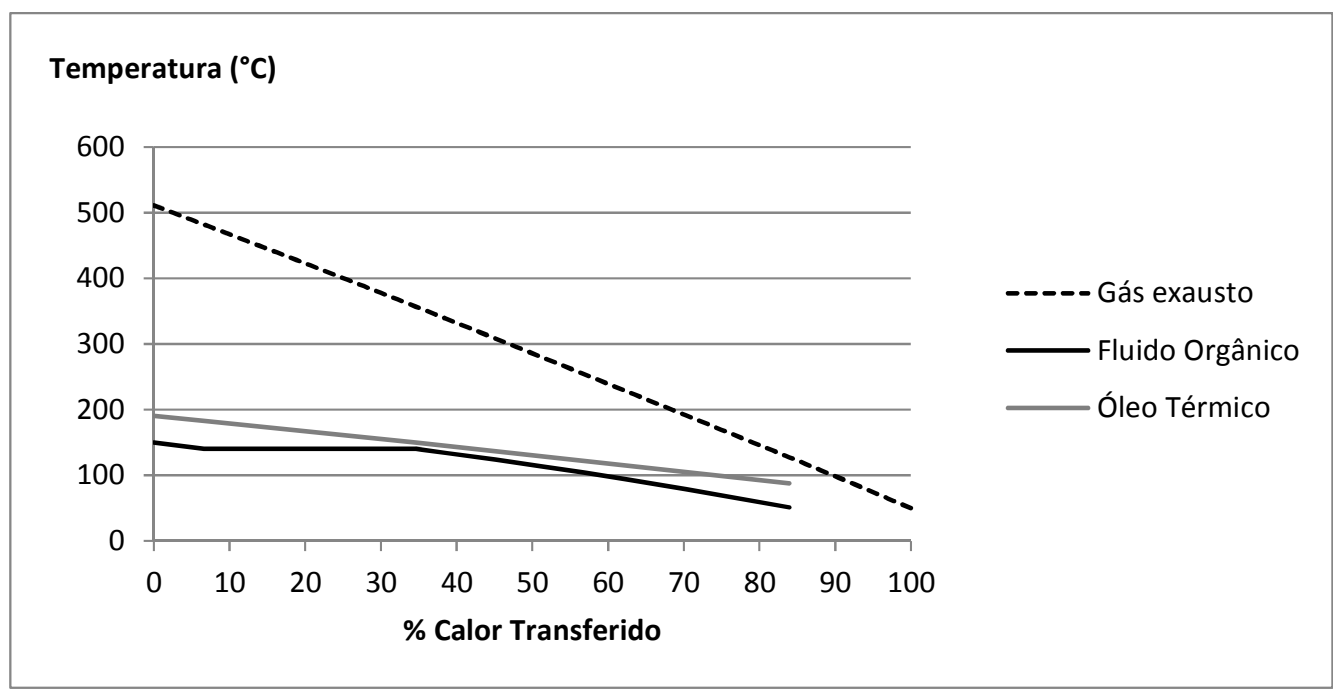

Figura 68 - Evolução das temperaturas no sistema de troca térmica com o calor transferido para o ciclo subcrítico (temperatura de evaporador $140^{\circ} \mathrm{C}$ ).

Os resultados da operação do sistema de troca térmica para o ciclo subcrítico, variando-se a temperatura do evaporador, estão mostrados na tabela 18. Estão relacionadas as temperaturas de entrada e saída e a vazão mássica do gás exausto do motor, do óleo térmico e do fluido orgânico, a taxa de calor transferido $\dot{q}$, bem como o salto entálpico $\Delta e_{i s}$ disponível para o expansor em condições isentrópicas. Pode ser observado que no ciclo subcrítico a elevação da temperatura do evaporador resulta na redução da quantidade de calor retirado do exausto do motor e na redução da vazão de fluido orgânico circulada. Por outro lado, a elevação da temperatura do evaporador resulta no aumento da energia específica disponível para o expansor.

Tabela 18 - Operação do sistema de troca térmica para o ciclo subcrítico com variação na temperatura do evaporador.

\begin{tabular}{|c|c|c|c|c|c|c|c|c|c|c|c|}
\hline \multicolumn{4}{|c|}{ Gás Exausto } & \multicolumn{3}{|c|}{ Óleo Térmico } & \multicolumn{5}{|c|}{ Fluido Orgânico } \\
\hline $\mathrm{T}_{\text {in }}\left({ }^{\circ} \mathrm{C}\right)$ & $\mathrm{T}_{\text {out }}\left({ }^{\circ} \mathrm{C}\right)$ & $\dot{\mathrm{m}}(\mathrm{kg} / \mathrm{s})$ & $\dot{q}(\mathrm{~kW})$ & $\mathrm{T}_{\text {in }}\left({ }^{\circ} \mathrm{C}\right)$ & $\mathrm{T}_{\text {out }}\left({ }^{\circ} \mathrm{C}\right)$ & $\dot{\mathrm{m}}(\mathrm{kg} / \mathrm{s})$ & $\mathrm{T}_{\text {ev ap }}\left({ }^{\circ} \mathrm{C}\right)$ & $\mathrm{T}_{\text {in }}\left({ }^{\circ} \mathrm{C}\right)$ & $\mathrm{T}_{\text {out }}\left({ }^{\circ} \mathrm{C}\right)$ & $\dot{\mathrm{m}}(\mathrm{kg} / \mathrm{s})$ & $\Delta \mathrm{e}_{\text {is }}(\mathrm{kJ} / \mathrm{kg})$ \\
\hline 511,0 & 100,7 & 3,496 & 1612,4 & 60,7 & 188,2 & 6,406 & 80,0 & 50,3 & 85,0 & 7,989 & 15,59 \\
\hline 511,0 & 101,4 & 3,496 & 1609,8 & 61,4 & 191,0 & 6,278 & 90,0 & 50,4 & 95,0 & 7,719 & 20,26 \\
\hline 511,0 & 102,5 & 3,496 & 1605,4 & 62,5 & 193,0 & 6,203 & 100,0 & 50,5 & 105,0 & 7,469 & 24,69 \\
\hline 511,0 & 104,6 & 3,496 & 1597,7 & 64,6 & 194,2 & 6,200 & 110,0 & 50,8 & 115,0 & 7,236 & 28,81 \\
\hline 511,0 & 108,1 & 3,496 & 1584,6 & 68,1 & 194,2 & 6,305 & 120,0 & 51,0 & 125,0 & 7,010 & 32,62 \\
\hline 511,0 & 114,5 & 3,496 & 1560,5 & 74,5 & 192,3 & 6,624 & 130,0 & 51,2 & 135,0 & 6,775 & 36,15 \\
\hline 511,0 & 119,8 & 3,496 & 1540,6 & 79,8 & 190,2 & 6,956 & 135,0 & 51,4 & 140,0 & 6,641 & 37,70 \\
\hline 511,0 & 127,6 & 3,496 & 1510,9 & 87,6 & 190,6 & 7,274 & 140,0 & 51,5 & 150,0 & 6,243 & 40,70 \\
\hline 511,0 & 140,3 & 3,496 & 1463,2 & 100,3 & 185,5 & 8,460 & 145,0 & 51,7 & 155,0 & 6,008 & 42,22 \\
\hline 511,0 & 162,7 & 3,496 & 1378,0 & 122,7 & 177,2 & 12,355 & 150,0 & 51,9 & 160,0 & 5,632 & 43,64 \\
\hline
\end{tabular}


Os resultados da operação do sistema de troca térmica para o ciclo supercrítico, variando-se a pressão do gerador de vapor, constam na tabela 19.

Tabela 19 - Operação do sistema de troca térmica para o ciclo supercrítico.

\begin{tabular}{|c|c|c|c|c|c|c|c|c|c|c|c|}
\hline \multicolumn{4}{|c|}{ Gás Exausto } & \multicolumn{3}{|c|}{ Óleo Térmico } & \multicolumn{5}{|c|}{ Fluido Orgânico } \\
\hline $\mathrm{T}_{\text {in }}\left({ }^{\circ} \mathrm{C}\right)$ & $\mathrm{T}_{\text {out }}\left({ }^{\circ} \mathrm{C}\right)$ & $\dot{\mathrm{m}}(\mathrm{kg} / \mathrm{s})$ & $\dot{q}(\mathrm{~kW})$ & $\mathrm{T}_{\text {in }}\left({ }^{\circ} \mathrm{C}\right)$ & $\mathrm{T}_{\text {out }}\left({ }^{\circ} \mathrm{C}\right)$ & $\dot{\mathrm{m}}(\mathrm{kg} / \mathrm{s})$ & $\mathrm{p}(\mathrm{MPa})$ & $\mathrm{T}_{\text {in }}\left({ }^{\circ} \mathrm{C}\right)$ & $\mathrm{T}_{\text {out }}\left({ }^{\circ} \mathrm{C}\right)$ & $\dot{\mathrm{m}}(\mathrm{kg} / \mathrm{s})$ & $\Delta \mathrm{e}_{\text {is }}(\mathrm{kJ} / \mathrm{kg})$ \\
\hline 511,0 & 102,0 & 3,496 & 1607,4 & 62,0 & 219,5 & 5,048 & 3,64 & 52,0 & 165,0 & 6,505 & 45,05 \\
\hline 511,0 & 102,1 & 3,496 & 1607,0 & 62,1 & 219,3 & 5,056 & 3,80 & 52,1 & 167,0 & 6,520 & 45,48 \\
\hline 511,0 & 102,2 & 3,496 & 1606,6 & 62,2 & 219,7 & 5,042 & 4,00 & 52,2 & 170,0 & 6,506 & 46,22 \\
\hline
\end{tabular}

A evolução das temperaturas do exausto do motor, do óleo térmico e do fluido orgânico com o calor transferido está mostrada na figura 69, para um ciclo supercrítico com pressão de 4,0 MPa.

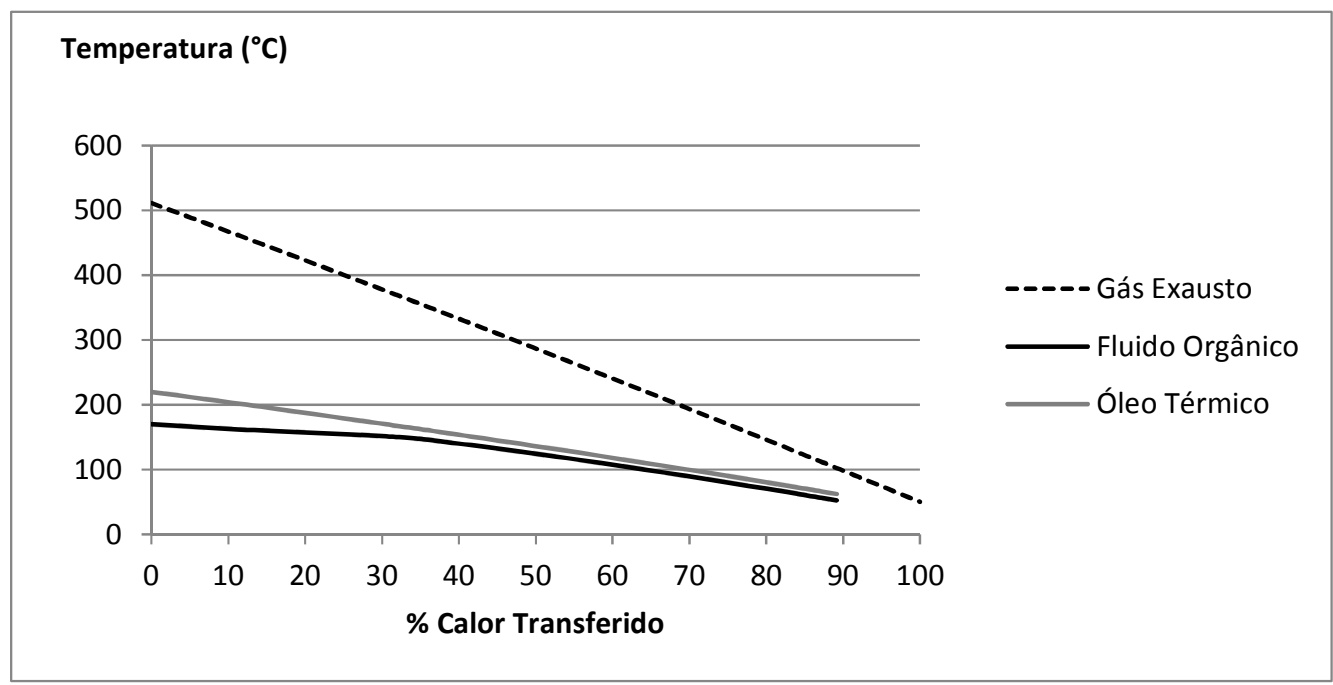

Figura 69 - Evolução das temperaturas no sistema de troca térmica com o calor transferido para o ciclo supercrítico (pressão 4,0 MPa).

Sob as premissas adotadas o ciclo supercrítico conta com uma maior recuperação de calor do exausto do motor, e portanto uma maior vazão de fluido orgânico circulada, além da sua maior energia disponível para o expansor quando comparado ao ciclo subcrítico. Pode ser observado que a variação da pressão supercrítica estudada (de 3,64 MPa para 4,00 MPa) foi bastante restrita em virtude da limitação de temperatura máxima admitida para o fluido orgânico. 


\subsubsection{Otimização do Expansor}

Em consulta à literatura algumas iniciativas foram dedicadas à otimização do projeto de estágios de turbinas axiais. Baljé [69] estabelece solução ótima para turbinas de admissão total e parcial operando em regime incompressível, dada como função da velocidade específica e do diâmetro específico. Restrições são impostas para limitar valores mínimos do número de Reynolds de modo a evitar a ocorrência de separação laminar nas palhetas, situação bastante relevante em turbinas de baixa pressão. Baljé mostra que a admissão parcial torna-se mais atrativa que a admissão total quando a velocidade específica é menor que 0,15 . Macchi e Perdichizzi [13] estudam o problema de otimização da turbina axial com admissão total operando com fluido não convencional, fazendo uso do modelo de perda de Craig \& Cox. A análise acrescenta de maneira relevante a questão da compressibilidade do meio, modelado como gás ideal com expoente $k^{*}=1,10$ constante, e as consequentes restrições sobre o projeto da turbina.

O projeto ótimo para o expansor será estabelecido a partir da determinação da geometria que resulta na máxima eficiência atingível, dadas as condições termodinâmicas do ciclo. O cálculo da eficiência do expansor tem como base o método de determinação do diagrama de velocidades e dos coeficientes de perda desenvolvido neste trabalho (capítulo 3). Examinando-se as equações de eficiência e as correlações generalizadas de perdas, torna-se evidente que uma otimização analítica não é possível, restando pesquisar uma técnica numérica para o problema em questão. Para tornar a solução mais fácil o número de variáveis independentes foi reduzido através do uso de parâmetros adimensionais, como a velocidade específica, o diâmetro específico o número de Reynolds e razões entre dimensões geométricas relevantes. A contribuição apresentada nesta seção é acrescentar a condição de gás real e de compressibilidade do meio ao problema da otimização da turbina axial sob condições de admissão parcial. A questão da utilização de fluidos não convencionais para o expansor é bastante relevante, uma vez que sua geometria e sua eficiência não podem ser antecipadas com base em experiência prévia. 
O problema de otimização será matematicamente formulado como:

Mínimo de $\left(1-\eta_{T-S}\right)$

Sujeito às seguintes restrições:

$$
\begin{aligned}
& M_{c 2} \leq 1,4 \\
& M_{w 2} \leq 0,8 \\
& M_{w 3} \leq 1,4 \\
& F L=\tan ^{-1}\left(\frac{h_{3}-h_{2}}{2 C_{x R}}\right) \leq 7^{\circ} \\
& \frac{R_{c, s}}{R_{c, p}}=\frac{2 \operatorname{asen} \lambda_{s} \operatorname{sen}\left(\lambda_{s}-\lambda_{2 b}\right)}{\sigma_{x}} \geq 0,5 \\
& o \geq o_{\min }
\end{aligned}
$$

O conjunto de variáveis relacionadas a seguir são denominadas variáveis de otimização, cujos valores deverão ser determinados de forma a se obter a melhor eficiência possível para o expansor:

Diâmetro Específico: $D_{s}$

Grau de reação: $\rho$

Relação altura diâmetro para as palhetas rotativas: $h / D$

Relação de alturas entre as palhetas rotativa e estacionária: $h_{3} / h_{2}$

Solidez axial das palhetas estacionárias: $\sigma_{x N}$

Número de palhetas estacionárias: $Z_{N}$

Solidez axial das palhetas rotativas: $\sigma_{x R}$

Número de palhetas rotativas: $Z_{R}$

A imposição das restrições expressas pelas equações (4.70) a (4.75) representam o vínculo necessário para garantir que a solução seja fisicamente correta e tecnicamente realizável. As restrições impostas pelas expressões (4.70) a (4.72) estão relacionadas ao efeito da compressibilidade do meio e à utilização de palhetas convergentes. A restrição (4.71), em particular, está relacionada ao número de Mach de incidência sobre o rotor. Abordando a questão do projeto de palhetas rotativas tridimensionais em turbinas axiais, Whitney et al. [70] e Stewart et al. [71] estabelecem limites para a denominada palheta transônica, onde o 
número de Mach de incidência no rotor é igual a 1 na base da palheta. Esta condição resulta num valor de $M_{w 2}$ da ordem de 0,8 no raio médio, para um estágio onde a relação de raios na base e no topo da palheta é de 0,7. Estes valores provavelmente motivaram a utilização do limite de 0,8 na restrição (4.71) por Macchi e Perdichizzi [13]. No presente trabalho o mesmo limite é adotado, embora até possa ser considerado conservativo para um estágio de baixa velocidade específica e baixa relação $h / D$. Será investigada também a alternativa de utilização de bocal convergente-divergente, sendo neste caso eliminada a restrição (4.70). Para a estimativa de perdas deste componente será adotada a mesma metodologia desenvolvida para as palhetas convergentes, da mesma forma que considerado por Macchi e Perdichizzi [13].

As restrições expressas pelas equações (4.73) a (4.75) estão relacionadas a limites geométricos impostos para assegurar um projeto eficiente e de fabricação viável. O limite máximo imposto ao ângulo de alargamento do jato $F L$ representa uma restrição ao projeto de palhetas com sobreposição, conforme a equação (4.73), de forma a assegurar que o jato incidente se difunda totalmente ao escoar através da palheta rotativa, ocupando completamente sua área de saída. A equação (4.74) estabelece indiretamente um valor mínimo para a solidez da palheta através da imposição de uma razão mínima entre os raios de curvatura das superfícies de sucção e pressão enquanto que a equação (4.75) estabelece um valor mínimo para a largura da garganta, sendo ambas aplicáveis às palhetas rotativas e estacionárias.

Um valor fixo será atribuído a algumas variáveis relacionadas a seguir, denominadas variáveis predeterminadas:

Ângulos de fluxo na entrada e saída dos bocais:

$$
\begin{aligned}
& \alpha_{1}=90^{\circ} \\
& \alpha_{2}=15^{\circ}
\end{aligned}
$$

Folgas adimensionalizadas da turbina:

$$
\frac{\Delta_{b}}{D}=0,001
$$




$$
\begin{aligned}
& \frac{\Delta_{s}}{D}=0,001 \\
& \frac{\Delta}{D}=0,02 \\
& \frac{\Delta_{r}}{h}=0,02
\end{aligned}
$$

Espessura do bordo de fuga:

$$
t_{b}=0,15 \mathrm{~mm}
$$

Rugosidade das superfícies:

$$
K_{s}=0,003 \mathrm{~mm}
$$

De uma maneira geral a eficiência é uma função monótona de cada das variáveis listadas acima, isto é, elas não otimizam o problema. Valores típicos para folgas e rugosidade foram adotados conforme Balje e Binsley [69]. Um aspecto importante é o pequeno valor atribuído para a espessura do bordo de fuga, tendo em vista a condição de escoamento supersônico na saída das palhetas [72]. Valores fixos são também atribuídos às variáveis relacionadas nas tabelas 20 e 21 que caracterizam as condições de serviço para o expansor operando em ciclo subcrítico ou supercrítico, respectivamente. A variável $S F$, denominada fator de tamanho, é um parâmetro dimensional introduzido por Macchi e Perdichizzi [13] para considerar a influência do porte da máquina no potencial de eficiência, conforme a seguinte expressão:

$$
S F=\frac{Q_{3}^{1 / 2}}{E_{i s}^{1 / 4}}
$$

Fixados os valores do diâmetro específico e da velocidade específica, uma máquina de menor porte terá um menor potencial de eficiência em virtude do menor número de Reynolds e da menor quantidade de palhetas que pode ser colocada na roda, considerando valores razoáveis para a largura da garganta. $\mathrm{O}$ parâmetro $S F$ tem a dimensão de comprimento de modo que:

$$
D_{s}=\frac{D}{S F}
$$


Tabela 20 - Condições de serviço para o expansor em ciclo subcrítico.

\begin{tabular}{|c|c|c|c|c|c|c|}
\hline pevap $_{\text {evPa }}$ & $\mathrm{T}_{\text {ev ap }}\left({ }^{\circ} \mathrm{C}\right)$ & $\mathrm{p}_{\text {red, }, 1}$ & $\mathrm{~T}_{\text {red, } 01}$ & $\mathrm{p}_{\text {red, } 3}$ & $\mathrm{SF}_{\text {is }}$ & $\mathrm{Ns}_{\text {is }}$ \\
\hline 0,789 & 80 & 0,217 & 0,838 & 0,095 & 0,0593 & 0,179 \\
\hline 1,004 & 90 & 0,276 & 0,862 & 0,095 & 0,0549 & 0,145 \\
\hline 1,261 & 100 & 0,347 & 0,885 & 0,095 & 0,0516 & 0,124 \\
\hline 1,565 & 110 & 0,430 & 0,908 & 0,095 & 0,0491 & 0,109 \\
\hline 1,921 & 120 & 0,528 & 0,932 & 0,095 & 0,0470 & 0,098 \\
\hline 2,335 & 130 & 0,642 & 0,955 & 0,095 & 0,0451 & 0,089 \\
\hline 2,567 & 135 & 0,705 & 0,967 & 0,095 & 0,0442 & 0,086 \\
\hline 2,817 & 140 & 0,774 & 0,990 & 0,095 & 0,0426 & 0,080 \\
\hline 3,087 & 145 & 0,848 & 1,002 & 0,095 & 0,0415 & 0,076 \\
\hline 3,380 & 150 & 0,929 & 1,014 & 0,095 & 0,0398 & 0,072 \\
\hline
\end{tabular}

Tabela 21 - Condições de serviço para o expansor em ciclo supercrítico.

\begin{tabular}{|c|c|c|c|c|c|}
\hline$p_{\text {ev ap }}(\mathrm{MPa})$ & $\mathrm{p}_{\text {red, } 01}$ & $\mathrm{~T}_{\text {red, } 01}$ & $\mathrm{p}_{\text {red, } 3}$ & $\mathrm{SF}_{\text {is }}$ & $\mathrm{Ns}_{\text {is }}$ \\
\hline 3,640 & 1,000 & 1,026 & 0,095 & 0,062 & 0,076 \\
\hline 3,800 & 1,044 & 1,030 & 0,095 & 0,063 & 0,075 \\
\hline 4,000 & 1,099 & 1,037 & 0,095 & 0,063 & 0,074 \\
\hline
\end{tabular}

Deve ser observado que os valores do fator de tamanho $S F_{i s}$ e da velocidade específica $N s_{i s}$ listados nas tabelas 20 e 21 são valores isentrópicos, com base na vazão $Q_{3}$ calculada para uma expansão isentrópica. Os valores reais não são conhecidos a priori, uma vez que dependem da eficiência a ser estimada para o expansor.

Para solução do problema de otimização proposto conforme as equações (4.69) a (4.75) foram utilizadas técnicas descritas em [73]. A solução do problema de otimização com restrições é obtida neste trabalho através do método da penalidade, que lança mão de uma sequência de soluções de otimização sem restrição. Isto é possível incorporando-se as restrições à função objetivo através das chamadas funções de penalidade, que atuam onerando a violação das restrições. A penalização é incrementada em sequência geométrica a cada ciclo de otimização com restrição, de modo que ao fim do processo a solução de fato atenda às restrições impostas pelo problema. $\mathrm{O}$ algoritmo de busca utilizado é o método de Powell, que se vale da denominada direção de movimento padrão, obtida a partir do deslocamento da solução após um ciclo de otimizações segundo as direções canônicas ou univariantes. Se o método prossegue descartando-se uma direção univariante que é substituída pela direção padrão previamente 
determinada, ao fim de $n$ ciclos nenhuma direção univariante deverá restar no conjunto de direções de busca. As direções geradas pelo método de Powell são direções conjugadas que resultam numa expectativa de convergência para o valor ótimo de uma função quadrática de $n$ variáveis após um número finito de passos dado por $(n+1)^{2}$.

Os algoritmos de otimização, de cálculo da perda através de grade axial em escoamento compressível, de cálculo do diagrama de velocidades e de cálculo das propriedades do gás real pela equação RKS foram implementados utilizando-se o Matlab R2011b. Para a aplicação em estudo, de uma maneira geral, foram necessárias 6 a 9 iterações de otimização com restrição para a convergência do processo, com a respectiva demanda de cerca de 15000 a 25000 cálculos de eficiência da turbina. 


\subsubsection{Resultados das Simulações}

O desempenho do expansor foi simulado nas condições de projeto e em regime permanente para as diversas condições do ciclo subcrítico e supercrítico mostradas respectivamente nas tabelas 20 e 21 . Simulações de desempenho do expansor fora da condição de projeto ou em regime transiente não foram abordadas no presente trabalho.

Dois conjuntos de simulações foram efetuados para a aplicação em questão. No primeiro deles foi utilizada a restrição $M_{c 2} \leq 1,4$ e foi adotado o valor de 3,0 mm para a largura mínima da garganta. Estas considerações correspondem a uma construção convencional utilizando perfil convergente para as palhetas estacionárias e rotativas. As simulações com a turbina de bocal de perfil convergente foram limitadas até uma temperatura máxima do evaporador de $140^{\circ} \mathrm{C}$. A partir deste valor esta concepção construtiva não é mais capaz de acomodar a expansão resultante de uma alta quantidade de energia disponível. No segundo conjunto de simulações não foi imposta nenhuma restrição sobre o número de Mach na saída dos bocais $M_{c 2}$ e foi adotado o mesmo valor de 3,0 mm para a largura mínima da garganta das palhetas rotativas. Estas considerações representam uma construção com perfil convergente-divergente para as palhetas estacionárias. As simulações com esta configuração iniciam a partir da temperatura do evaporador de $110^{\circ} \mathrm{C}$ e estendem-se até as condições supercríticas.

Devido ao elevado número de Reynolds e da admissão parcial, de uma maneira geral os cálculos de otimização convergem para soluções que apresentam largura da garganta mínima. Um valor reduzido para a largura da garganta resulta num maior número de palhetas rotativas, construção típica de uma turbina de impulso de admissão parcial. Esta opção é justificada pelo benefício do maior número de palhetas sobre a eficiência uma vez que a dimensão da corda é menor, o que resulta em redução das perdas por admissão parcial, conforme exposto na equação (2.122). A redução das perdas por admissão parcial sobrepuja um possível aumento das perdas viscosas decorrentes dos efeitos de um menor número de Reynolds local para o problema em questão. 
Os resultados da simulação para o expansor operando em ciclo subcrítico estão mostrados nas tabelas 22 a 25 e 26 a 29 , respectivamente para ambas as alternativas construtivas para as palhetas dos bocais: perfil convergente ou convergente-divergente. As tabelas 22 e 26 mostram os parâmetros de desempenho: a eficiência estimada para o expansor $\eta_{T-S}$, a velocidade específica $N_{s}$, o diâmetro específico $D_{s}$, o parâmetro de tamanho $S F$, o número de Reynolds da máquina $R e_{M}$ e o número de Laval da máquina $L a_{M}$, além da potência isentrópica e real desenvolvida pelo expansor.

Tabela 22 - Resultados para o expansor com bocal convergente operando em ciclo subcrítico - parâmetros de desempenho.

\begin{tabular}{|c|c|c|c|c|c|c|c|c|c|}
\hline Pevap $_{\text {evPa }}(\mathrm{MP})$ & $\mathrm{T}_{\text {ev ap }}\left({ }^{\circ} \mathrm{C}\right)$ & $\eta \mathrm{T}-\mathrm{S}(\%)$ & $\mathrm{N}_{\mathrm{s}}$ & $\mathrm{D}_{\mathrm{s}}$ & $\mathrm{SF}(\mathrm{m})$ & $\mathrm{Re}_{\mathrm{M}}$ & $\mathrm{La}_{\mathrm{M}}$ & $\mathrm{P}_{\text {is }}(\mathrm{kW})$ & $\mathrm{P}(\mathrm{kW})$ \\
\hline 0,789 & 80 & 80,81 & 0,180 & 8,12 & 0,060 & $6,90 \mathrm{E}+07$ & 0,666 & 124,5 & 100,6 \\
\hline 1,004 & 90 & 78,67 & 0,146 & 9,52 & 0,055 & $7,96 \mathrm{E}+07$ & 0,728 & 156,4 & 123,0 \\
\hline 1,261 & 100 & 76,73 & 0,125 & 11,05 & 0,052 & $9,31 \mathrm{E}+07$ & 0,803 & 184,4 & 141,5 \\
\hline 1,565 & 110 & 73,45 & 0,110 & 12,07 & 0,049 & $9,91 \mathrm{E}+07$ & 0,849 & 208,5 & 153,1 \\
\hline 1,921 & 120 & 69,90 & 0,099 & 13,48 & 0,047 & $1,12 \mathrm{E}+08$ & 0,928 & 228,7 & 159,8 \\
\hline 2,335 & 130 & 65,90 & 0,090 & 14,60 & 0,045 & $1,20 \mathrm{E}+08$ & 0,995 & 244,9 & 161,4 \\
\hline 2,567 & 135 & 63,63 & 0,087 & 15,19 & 0,045 & $1,25 \mathrm{E}+08$ & 1,035 & 250,4 & 159,3 \\
\hline 2,817 & 140 & 60,81 & 0,080 & 16,36 & 0,043 & $1,28 \mathrm{E}+08$ & 1,058 & 254,1 & 154,5 \\
\hline
\end{tabular}

As tabelas 23 e 27 mostram os parâmetros geométricos para o projeto otimizado do expansor: a relação altura da palheta-diâmetro $h / D$, a relação de sobreposição das palhetas $h_{3} / h_{2}$, a fração de admissão $\varepsilon$, o ângulo de alargamento do jato $F L$, a razão de aspecto $(h / C)_{R}$ e a solidez $\sigma_{R}$ da palheta rotativa. As tabelas 24 e 28 mostram os parâmetros aero-termodinâmicos resultantes da otimização da eficiência do estágio: $\mathrm{O}$ grau de reação $\rho$, a relação de volumes $V R=v_{3} / v_{01}$, o fator de aceleração axial $\underline{K}_{t}$ e os números de Mach do escoamento absoluto e relativo $M_{c 2}, M_{w 2}$ e $M_{w 3}$. As tabelas 25 e 29 mostram os parâmetros relevantes do diagrama de velocidades $u / c_{0}, c_{2} / c_{0}, w_{2} / c_{0}$ e $w_{3} / c_{0}$, além dos ângulos do escoamento relativo $\beta_{2}$ e $\beta_{3}$. 
Tabela 23 - Resultados para o expansor com bocal convergente operando em ciclo subcrítico - parâmetros geométricos.

\begin{tabular}{|c|c|c|c|c|c|c|c|}
\hline$p_{\text {evap }}(\mathrm{MPa})$ & $\mathrm{T}_{\text {ev ap }}\left({ }^{\circ} \mathrm{C}\right)$ & $\mathrm{h} / \mathrm{D}$ & $\mathrm{h}_{3} / \mathrm{h}_{2}$ & $\varepsilon$ & $\mathrm{FL}(\stackrel{\circ}{)})$ & $(\mathrm{h} / \mathrm{C})_{\mathrm{R}}$ & $\sigma_{\mathrm{R}}$ \\
\hline 0,789 & 80 & 0,050 & 1,156 & 0,325 & 7,0 & 1,82 & 1,82 \\
\hline 1,004 & 90 & 0,044 & 1,170 & 0,258 & 7,0 & 1,69 & 1,85 \\
\hline 1,261 & 100 & 0,038 & 1,170 & 0,216 & 7,0 & 1,69 & 1,81 \\
\hline 1,565 & 110 & 0,027 & 1,279 & 0,237 & 7,0 & 1,12 & 1,92 \\
\hline 1,921 & 120 & 0,022 & 1,318 & 0,207 & 7,0 & 1,01 & 1,86 \\
\hline 2,335 & 130 & 0,021 & 1,295 & 0,161 & 7,0 & 1,07 & 1,77 \\
\hline 2,567 & 135 & 0,021 & 1,340 & 0,147 & 7,0 & 0,96 & 1,92 \\
\hline 2,817 & 140 & 0,019 & 1,361 & 0,129 & 7,0 & 0,91 & 1,94 \\
\hline
\end{tabular}

Tabela 24 - Resultados para o expansor com bocal convergente operando em ciclo subcrítico - parâmetros aero-termodinâmicos.

\begin{tabular}{|c|c|c|c|c|c|c|c|}
\hline $\mathrm{P}_{\text {evap }}(\mathrm{MPa})$ & $\mathrm{T}_{\text {ev ap }}\left({ }^{\circ} \mathrm{C}\right)$ & $\rho$ & $\mathrm{VR}$ & $\mathrm{K}_{\mathrm{t}}$ & $\mathrm{M}_{\mathrm{c} 2}$ & $\mathrm{M}_{\mathrm{w} 2}$ & $\mathrm{M}_{\mathrm{w} 3}$ \\
\hline 0,789 & 80 & 0,054 & 2,34 & 0,907 & 1,201 & 0,618 & 0,631 \\
\hline 1,004 & 90 & 0,127 & 3,04 & 0,981 & 1,300 & 0,666 & 0,782 \\
\hline 1,261 & 100 & 0,147 & 3,92 & 1,035 & 1,400 & 0,709 & 0,871 \\
\hline 1,565 & 110 & 0,268 & 5,02 & 1,167 & 1,400 & 0,674 & 1,040 \\
\hline 1,921 & 120 & 0,358 & 6,41 & 1,389 & 1,400 & 0,622 & 1,170 \\
\hline 2,335 & 130 & 0,431 & 8,20 & 1,733 & 1,400 & 0,586 & 1,286 \\
\hline 2,567 & 135 & 0,461 & 9,30 & 1,848 & 1,400 & 0,567 & 1,333 \\
\hline 2,817 & 140 & 0,486 & 10,15 & 1,999 & 1,400 & 0,549 & 1,379 \\
\hline
\end{tabular}

Tabela 25- Resultados para o expansor com bocal convergente operando em ciclo subcrítico - diagramas de velocidades.

\begin{tabular}{|c|c|c|c|c|c|c|c|}
\hline$p_{\text {evap }}(\mathrm{MPa})$ & $\mathrm{T}_{\text {evap }}\left({ }^{\circ} \mathrm{C}\right)$ & $\beta_{2}$ & $\beta_{3}$ & $\mathrm{u} / \mathrm{c}_{0}$ & $\mathrm{c}_{2} / \mathrm{c}_{0}$ & $\mathrm{w}_{2} / \mathrm{c}_{0}$ & $\mathrm{w}_{3} / \mathrm{c}_{0}$ \\
\hline 0,789 & 80 & 30,2 & 25,6 & 0,4907 & 0,9417 & 0,4846 & 0,4959 \\
\hline 1,004 & 90 & 30,2 & 24,8 & 0,4700 & 0,8978 & 0,4602 & 0,5430 \\
\hline 1,261 & 100 & 30,8 & 25,3 & 0,4675 & 0,8805 & 0,4457 & 0,5514 \\
\hline 1,565 & 110 & 32,5 & 23,6 & 0,4550 & 0,8127 & 0,3914 & 0,6126 \\
\hline 1,921 & 120 & 35,7 & 24,8 & 0,4596 & 0,7594 & 0,3371 & 0,6500 \\
\hline 2,335 & 130 & 38,2 & 28,1 & 0,4552 & 0,7145 & 0,2990 & 0,6814 \\
\hline 2,567 & 135 & 39,7 & 28,7 & 0,4548 & 0,6948 & 0,2813 & 0,6922 \\
\hline 2,817 & 140 & 41,3 & 30,0 & 0,4553 & 0,6778 & 0,2655 & 0,7005 \\
\hline
\end{tabular}


Tabela 26 - Resultados para o expansor com bocal convergente-divergente operando em ciclo subcrítico - parâmetros de desempenho.

\begin{tabular}{|c|c|c|c|c|c|c|c|c|c|}
\hline $\mathrm{P}_{\text {ev ap }}(\mathrm{MPa})$ & $\mathrm{T}_{\text {evap }}\left({ }^{\circ} \mathrm{C}\right)$ & $\eta_{\mathrm{T}-\mathrm{S}}(\%)$ & $\mathrm{N}_{\mathrm{s}}$ & $\mathrm{D}_{\mathrm{s}}$ & $\mathrm{SF}(\mathrm{m})$ & $\mathrm{Re}_{\mathrm{M}}$ & $\mathrm{La}_{\mathrm{M}}$ & $\mathrm{P}_{\text {is }}(\mathrm{kW})$ & $\mathrm{P}(\mathrm{kW})$ \\
\hline 1,565 & 110 & 74,48 & 0,110 & 12,24 & 0,049 & $1,02 \mathrm{E}+08$ & 0,862 & 208,5 & 155,3 \\
\hline 1,921 & 120 & 73,05 & 0,099 & 13,81 & 0,047 & $1,17 \mathrm{E}+08$ & 0,953 & 228,7 & 167,0 \\
\hline 2,335 & 130 & 71,13 & 0,090 & 15,57 & 0,046 & $1,37 \mathrm{E}+08$ & 1,063 & 244,9 & 174,2 \\
\hline 2,567 & 135 & 70,33 & 0,087 & 16,33 & 0,045 & $1,44 \mathrm{E}+08$ & 1,115 & 250,4 & 176,1 \\
\hline 2,817 & 140 & 68,80 & 0,081 & 17,55 & 0,043 & $1,47 \mathrm{E}+08$ & 1,138 & 254,1 & 174,8 \\
\hline 3,087 & 145 & 67,95 & 0,077 & 18,33 & 0,042 & $1,51 \mathrm{E}+08$ & 1,180 & 253,7 & 172,4 \\
\hline 3,380 & 150 & 66,77 & 0,073 & 19,07 & 0,04 & $1,51 \mathrm{E}+08$ & 1,209 & 245,8 & 164,1 \\
\hline
\end{tabular}

Tabela 27 - Resultados para o expansor com bocal convergente-divergente operando em ciclo subcrítico - parâmetros geométricos.

\begin{tabular}{|c|c|c|c|c|c|c|c|}
\hline $\mathrm{P}_{\text {ev ap }}(\mathrm{MPa})$ & $\mathrm{T}_{\text {evap }}\left(^{\circ} \mathrm{C}\right)$ & $\mathrm{h} / \mathrm{D}$ & $\mathrm{h}_{3} / \mathrm{h}_{2}$ & $\varepsilon$ & $\mathrm{FL}\left({ }^{\circ}\right)$ & $(\mathrm{h} / \mathrm{C})_{\mathrm{R}}$ & $\sigma_{\mathrm{R}}$ \\
\hline 1,565 & 110 & 0,035 & 1,156 & 0,191 & 7,0 & 1,82 & 1,75 \\
\hline 1,921 & 120 & 0,030 & 1,208 & 0,180 & 7,0 & 1,43 & 1,98 \\
\hline 2,335 & 130 & 0,023 & 1,238 & 0,184 & 7,0 & 1,28 & 1,82 \\
\hline 2,567 & 135 & 0,023 & 1,242 & 0,170 & 7,0 & 1,26 & 1,84 \\
\hline 2,817 & 140 & 0,021 & 1,258 & 0,156 & 7,0 & 1,20 & 1,82 \\
\hline 3,087 & 145 & 0,020 & 1,247 & 0,137 & 7,0 & 1,24 & 1,83 \\
\hline 3,380 & 150 & 0,020 & 1,229 & 0,117 & 7,0 & 1,32 & 1,79 \\
\hline
\end{tabular}

Tabela 28 - Resultados das simulações para o expansor com bocal convergente-divergente operando em ciclo subcrítico - parâmetros aerotermodinâmicos.

\begin{tabular}{|c|c|c|c|c|c|c|c|}
\hline $\mathrm{P}_{\text {ev ap }}(\mathrm{MPa})$ & $\mathrm{T}_{\text {ev ap }}\left({ }^{\circ} \mathrm{C}\right)$ & $\rho$ & $\mathrm{VR}$ & $\mathrm{K}_{\mathrm{t}}$ & $\mathrm{M}_{\mathrm{c} 2}$ & $\mathrm{M}_{\text {w2 }}$ & $\mathrm{M}_{\text {w3 }}$ \\
\hline 1,565 & 110 & 0,078 & 5,04 & 0,974 & 1,535 & 0,800 & 0,858 \\
\hline 1,921 & 120 & 0,126 & 6,44 & 1,025 & 1,582 & 0,800 & 0,955 \\
\hline 2,335 & 130 & 0,160 & 8,24 & 1,087 & 1,622 & 0,800 & 1,026 \\
\hline 2,567 & 135 & 0,172 & 9,35 & 1,122 & 1,645 & 0,800 & 1,055 \\
\hline 2,817 & 140 & 0,198 & 10,20 & 1,187 & 1,654 & 0,800 & 1,107 \\
\hline 3,087 & 145 & 0,198 & 11,52 & 1,213 & 1,685 & 0,800 & 1,119 \\
\hline 3,380 & 150 & 0,205 & 13,02 & 1,267 & 1,707 & 0,800 & 1,141 \\
\hline
\end{tabular}


Tabela 29 - Resultados para o expansor com bocal convergente-divergente operando em ciclo subcrítico - diagrama de velocidades.

\begin{tabular}{|c|c|c|c|c|c|c|c|}
\hline Pevap $_{\text {eMPa) }}$ & $\mathrm{T}_{\text {ev ap }}\left({ }^{\circ} \mathrm{C}\right)$ & $\beta_{2}$ & $\beta_{3}$ & $\mathrm{u} / \mathrm{c}_{0}$ & $\mathrm{c}_{2} / \mathrm{c}_{0}$ & $\mathrm{w}_{2} / \mathrm{c}_{0}$ & $\mathrm{w}_{3} / \mathrm{c}_{0}$ \\
\hline 1,565 & 110 & 29,8 & 26,7 & 0,4631 & 0,9017 & 0,4699 & 0,5065 \\
\hline 1,921 & 120 & 30,8 & 25,9 & 0,4651 & 0,8749 & 0,4424 & 0,5320 \\
\hline 2,335 & 130 & 31,7 & 26,1 & 0,4662 & 0,8535 & 0,4209 & 0,5452 \\
\hline 2,567 & 135 & 32,2 & 26,6 & 0,4693 & 0,8469 & 0,4119 & 0,5495 \\
\hline 2,817 & 140 & 32,3 & 26,9 & 0,4636 & 0,8318 & 0,4024 & 0,5639 \\
\hline 3,087 & 145 & 33,0 & 27,8 & 0,4725 & 0,8321 & 0,3951 & 0,5599 \\
\hline 3,380 & 150 & 33,5 & 28,9 & 0,4767 & 0,8287 & 0,3883 & 0,5617 \\
\hline
\end{tabular}

Na figura 70 pode ser observada a eficiência estimada para o expansor axial de estágio único operando em ciclo subcrítico como função da temperatura do evaporador. Para ambas as alternativas construtivas analisadas a figura 71 mostra a potência produzida pelo expansor e a potência líquida produzida no ciclo de recuperação de calor, esta última obtida da subtração da potência do expansor pela potência da bomba. A potência do ciclo ideal também é mostrada para comparação.

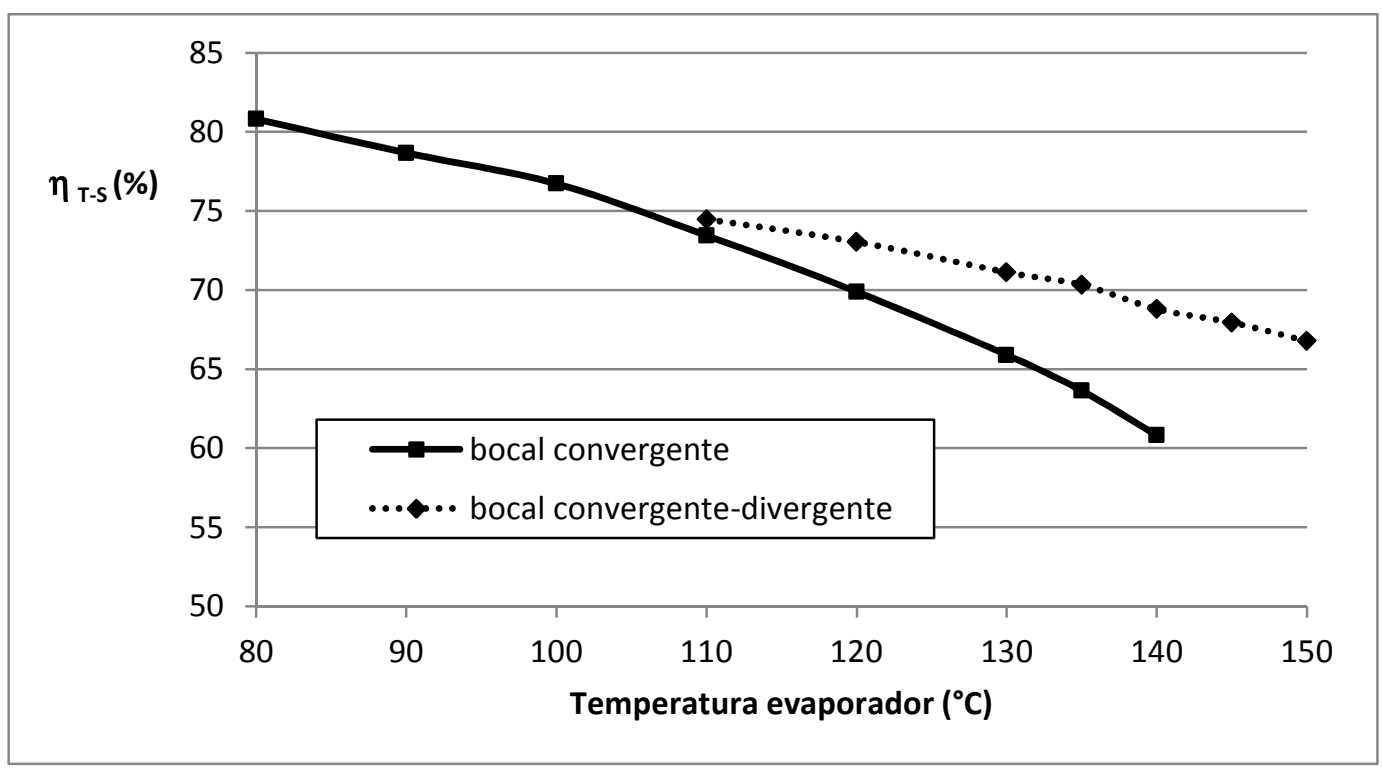

Figura 70 - Eficiência ótima do expansor de estágio único operando em ciclo subcrítico como função da temperatura do evaporador. 
Pode ser observado que para uma temperatura do evaporador acima de $110^{\circ} \mathrm{C}$ a utilização do bocal convergente-divergente torna-se atrativa, uma vez que resulta numa maior eficiência para o expansor. Isto decorre principalmente da possibilidade da utilização de um menor grau de reação para o estágio e a consequente redução na energia cinética residual no exausto.

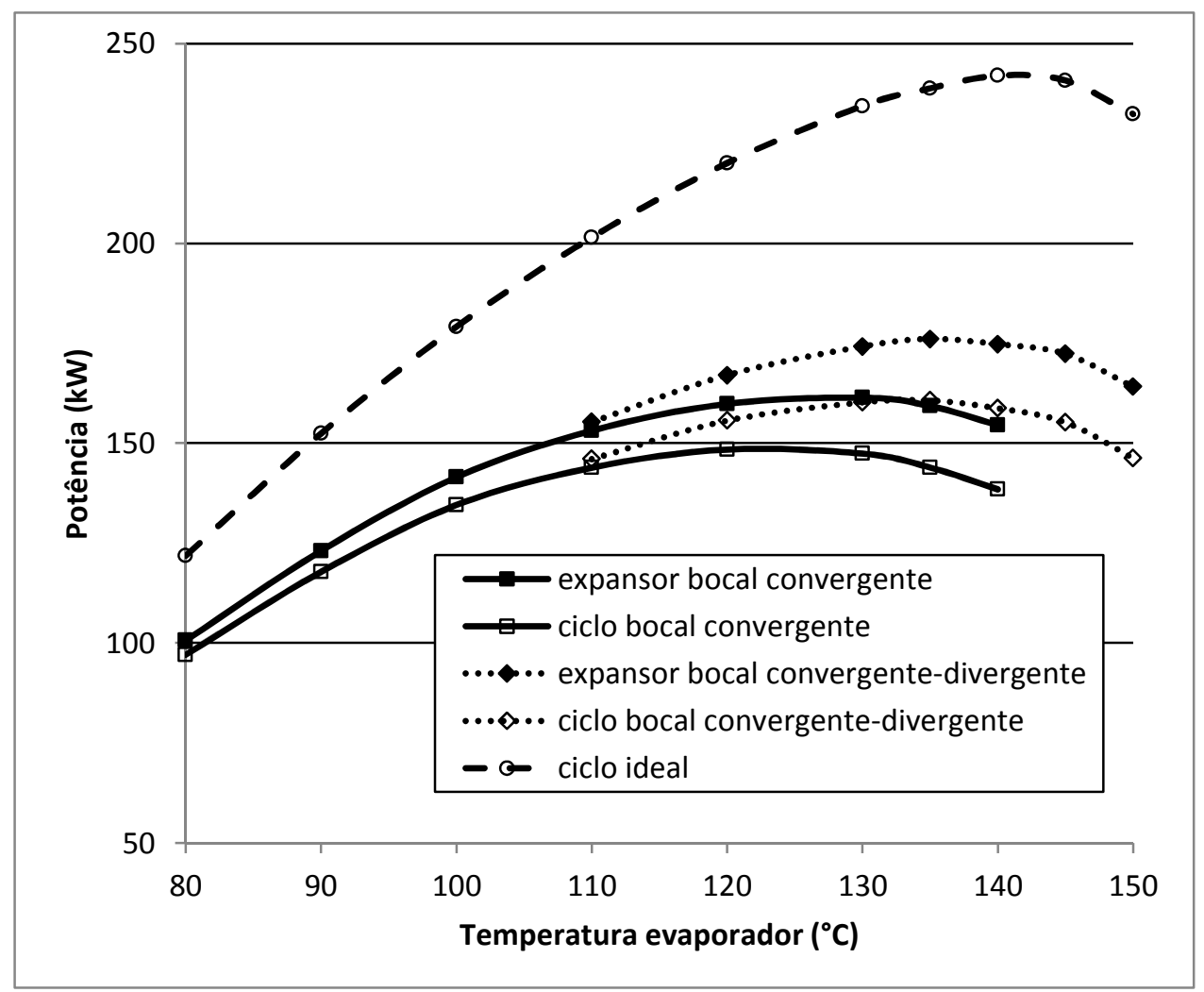

Figura 71 - Potência gerada pelo expansor e potência líquida gerada no ciclo subcrítico como função da temperatura do evaporador.

A figura 71 mostra que o valor da temperatura ótima do evaporador, sob a qual é produzida a maior potência líquida pelo ciclo de recuperação, será dependente da concepção construtiva adotada. No caso do expansor com bocal convergente a temperatura ótima é $120^{\circ} \mathrm{C}$ e a potência líquida produzida pelo ciclo de $148,4 \mathrm{~kW}$, enquanto que no caso do expansor com bocal convergentedivergente a temperatura ótima é $135^{\circ} \mathrm{C}$ e a potência $160,7 \mathrm{~kW}$. Considerando a hipótese de um ciclo ideal, onde o expansor e a bomba são máquinas isentrópicas, a temperatura ótima do evaporador é $140^{\circ} \mathrm{C}$, sendo produzido $242,0 \mathrm{~kW}$ de potência líquida nestas condições. 
De maneira similar os resultados da simulação do expansor operando em ciclo supercrítico estão mostrados nas tabelas 30 a 34, onde estão listados respectivamente os parâmetros de desempenho, geométricos e aerotermodinâmicos, além do diagrama de velocidades.

Tabela 30 - Resultados das simulações para o expansor com bocal convergente-divergente operando em ciclo supercrítico - parâmetros de desempenho.

\begin{tabular}{|c|c|c|c|c|c|c|c|c|}
\hline$p_{\text {ev ap }}(\mathrm{MPa})$ & $\eta_{\mathrm{T}-\mathrm{S}}(\%)$ & $\mathrm{N}_{\mathrm{S}}$ & $\mathrm{D}_{\mathrm{S}}$ & $\mathrm{SF}(\mathrm{m})$ & $\mathrm{Re}_{\mathrm{M}}$ & $\mathrm{La}_{\mathrm{M}}$ & $\mathrm{P}_{\text {is }}(\mathrm{kW})$ & $\mathrm{P}(\mathrm{kW})$ \\
\hline 3,640 & 67,03 & 0,076 & 18,10 & 0,043 & $1,54 \mathrm{E}+08$ & 1,240 & 293,1 & 196,4 \\
\hline 3,800 & 66,40 & 0,076 & 17,83 & 0,043 & $1,50 \mathrm{E}+08$ & 1,243 & 296,5 & 196,9 \\
\hline 4,000 & 66,02 & 0,075 & 18,29 & 0,043 & $1,56 \mathrm{E}+08$ & 1,287 & 300,7 & 198,5 \\
\hline
\end{tabular}

Tabela 31 - Resultados das simulações para o expansor com bocal convergente-divergente operando em ciclo supercrítico - parâmetros geométricos.

\begin{tabular}{|c|c|c|c|c|c|c|}
\hline$p_{\text {ev ap }}(\mathrm{MPa})$ & $\mathrm{h} / \mathrm{D}$ & $\mathrm{h}_{3} / \mathrm{h}_{2}$ & $\varepsilon$ & $\mathrm{FL}\left(\frac{\mathrm{o}}{)}\right.$ & $(\mathrm{h} / \mathrm{C})_{\mathrm{R}}$ & $\sigma_{\mathrm{R}}$ \\
\hline 3,640 & 0,021 & 1,202 & 0,118 & 7,0 & 1,46 & 1,75 \\
\hline 3,800 & 0,018 & 1,270 & 0,142 & 7,0 & 1,15 & 1,81 \\
\hline 4,000 & 0,018 & 1,276 & 0,138 & 7,0 & 1,13 & 1,86 \\
\hline
\end{tabular}

Tabela 32 - Resultados das simulações para o expansor com bocal convergente-divergente operando em ciclo supercrítico - parâmetros aerotermodinâmicos.

\begin{tabular}{|c|c|c|c|c|c|c|}
\hline$P_{\text {ev ap }}(\mathrm{MPa})$ & $\rho$ & $\mathrm{VR}$ & $\mathrm{K}_{\mathrm{t}}$ & $\mathrm{M}_{\mathrm{c} 2}$ & $\mathrm{M}_{\mathrm{w} 2}$ & $\mathrm{M}_{\mathrm{w} 3}$ \\
\hline 3,640 & 0,215 & 14,27 & 1,341 & 1,723 & 0,800 & 1,168 \\
\hline 3,800 & 0,229 & 15,22 & 1,320 & 1,714 & 0,800 & 1,191 \\
\hline 4,000 & 0,225 & 16,29 & 1,312 & 1,731 & 0,800 & 1,191 \\
\hline
\end{tabular}

Tabela 33 - Resultados das simulações para o expansor com bocal convergente-divergente operando em ciclo supercrítico - diagrama de velocidades.

\begin{tabular}{|c|c|c|c|c|c|c|}
\hline$p_{\text {ev ap }}(\mathrm{MPa})$ & $\beta_{2}$ & $\beta_{3}$ & $\mathrm{u} / \mathrm{c}_{0}$ & $\mathrm{C}_{2} / \mathrm{c}_{0}$ & $\mathrm{w}_{2} / \mathrm{c}_{0}$ & $\mathrm{w}_{3} / \mathrm{c}_{0}$ \\
\hline 3,640 & 33,9 & 30,3 & 0,4783 & 0,8241 & 0,3826 & 0,5673 \\
3,800 & 33,7 & 28,9 & 0,4696 & 0,8134 & 0,3798 & 0,5750 \\
4,000 & 34,1 & 29,0 & 0,4752 & 0,8151 & 0,3767 & 0,5704 \\
\hline
\end{tabular}


Os resultados da simulação da eficiência do expansor em ciclo supercrítico estão mostrados simultaneamente aos do ciclo subcrítico na figura 72 como função da pressão do gerador de vapor. A figura 73 mostra a eficiência térmica do ciclo de recuperação de calor para o expansor com bocal convergente, para o expansor com bocal convergente-divergente e para o ciclo ideal (máquinas isentrópicas). Para os valores ótimos da temperatura do evaporador mencionados para operação subcrítica, são obtidos os valores de 9,37\% e 10,43\% para a eficiência térmica de ciclo de recuperação com a utilização do expansor de bocais com perfil convergente e convergente-divergente, respectivamente.

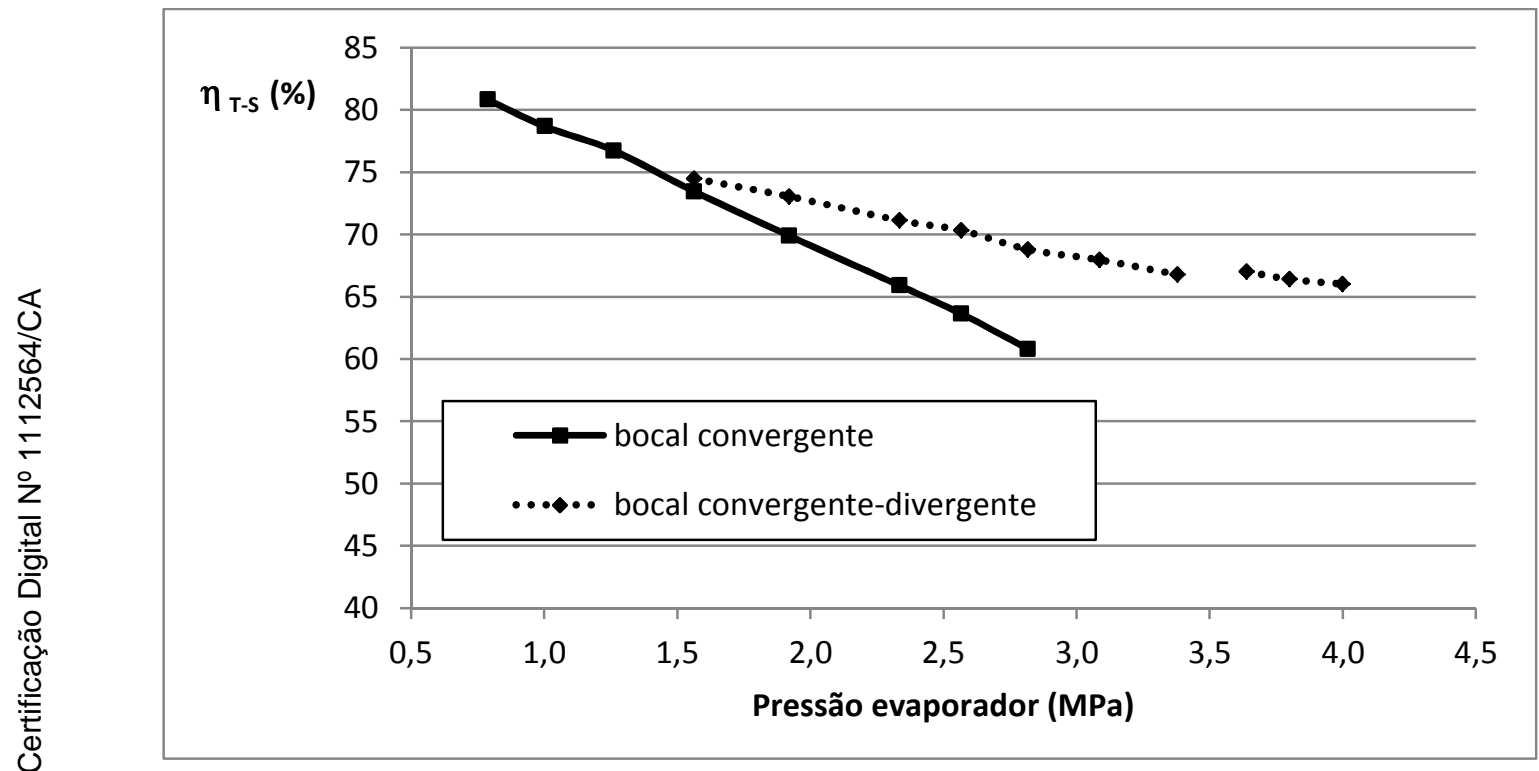

Figura 72 - Eficiência ótima do expansor de estágio único operando em ciclo subcrítico e supercrítico como função da pressão do gerador de vapor.

As figuras 74 e 75 mostram as velocidades adimensionalizadas do escoamento absoluto e relativo para o caso dos bocais com perfil convergente e com perfil convergente-divergente, respectivamente. 


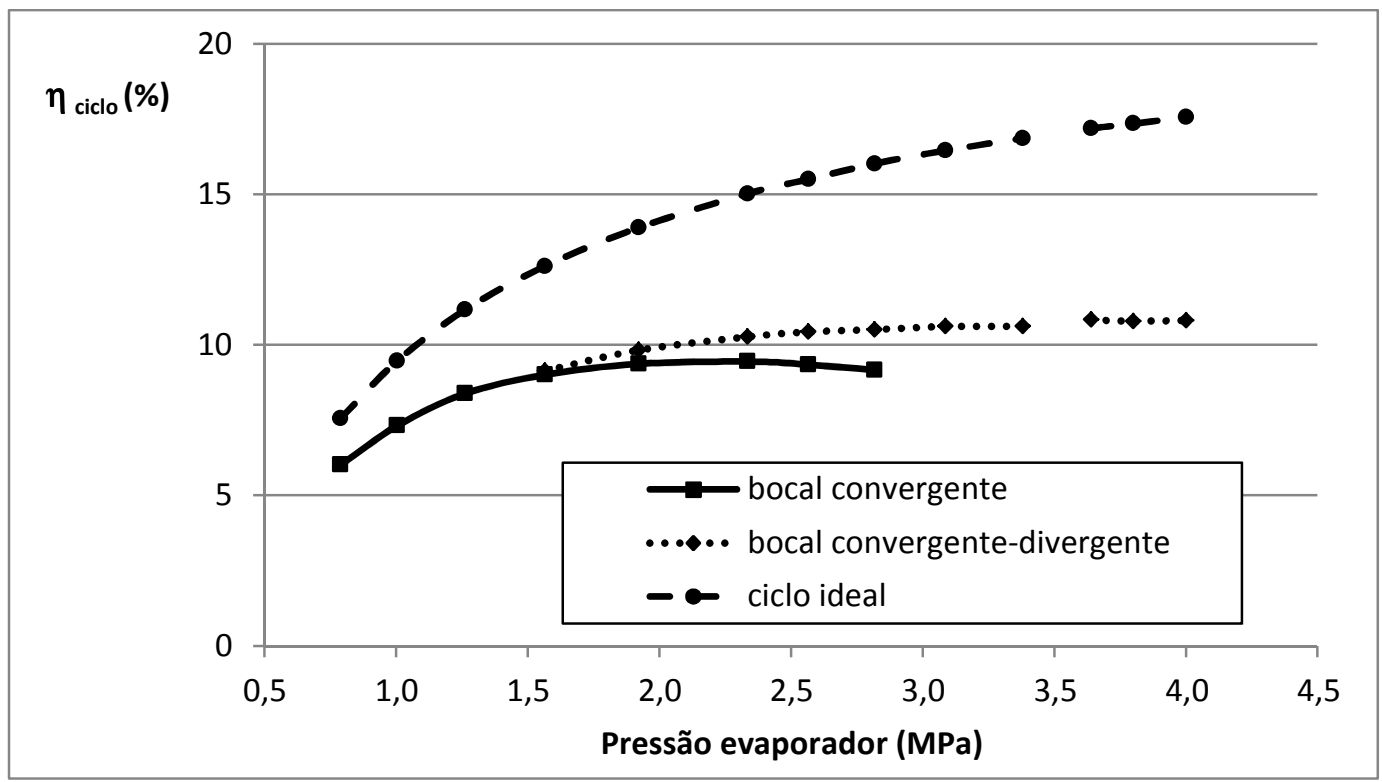

Figura 73 - Eficiência térmica do ciclo de recuperação de calor para o expansor de estágio único em função da pressão do gerador de vapor.

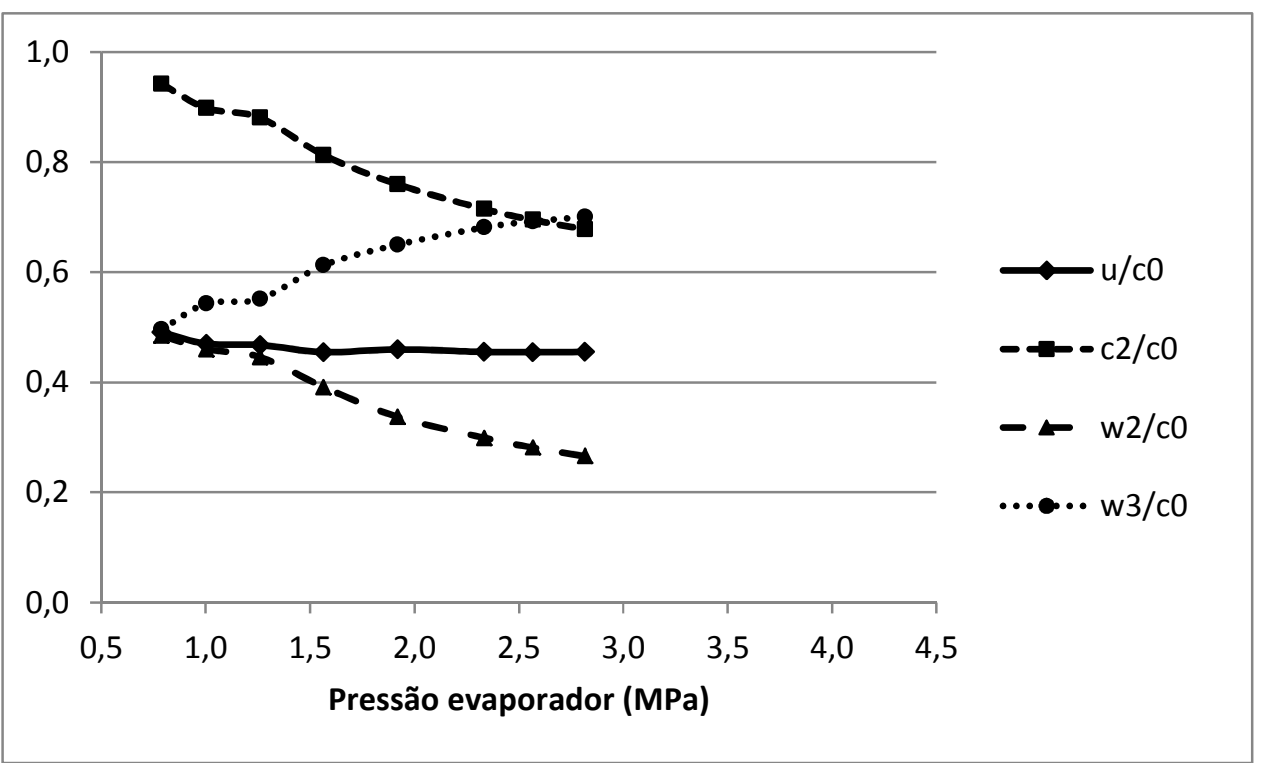

Figura 74 - Diagrama de velocidades adimensionalizado para o expansor com bocal convergente operando em ciclo subcrítico em função da pressão do evaporador.

As figuras 76 e 77 mostram o grau de reação do estágio e os números de Mach do escoamento absoluto e relativo para os bocais com perfil convergente e com perfil convergente-divergente, respectivamente. Para o caso dos bocais com perfil convergente pode ser observado que a condição limite do número de Mach 
de saída do bocal $M_{c 2}=1,4$ é atingida para a temperatura do evaporador de $100^{\circ} \mathrm{C}$. Para temperaturas maiores verifica-se que um grau de reação crescente é necessário para atender a esta restrição. Quando a temperatura do evaporador chega a $140^{\circ} \mathrm{C}$ verifica-se que o número de Mach de saída do rotor se aproxima do limite máximo $M_{w 3}=1,4$ atingindo-se então o limite de carga aerodinâmica do estágio. Nesta condição podem ser observados os efeitos de gás real, onde a velocidade do som cresce durante o processo de expansão, notando-se que $M_{c 2}=M_{w 3}=1,4$ enquanto $w_{3}>c_{2}$. Este efeito será discutido em maiores detalhes na seção 3.2 a seguir.

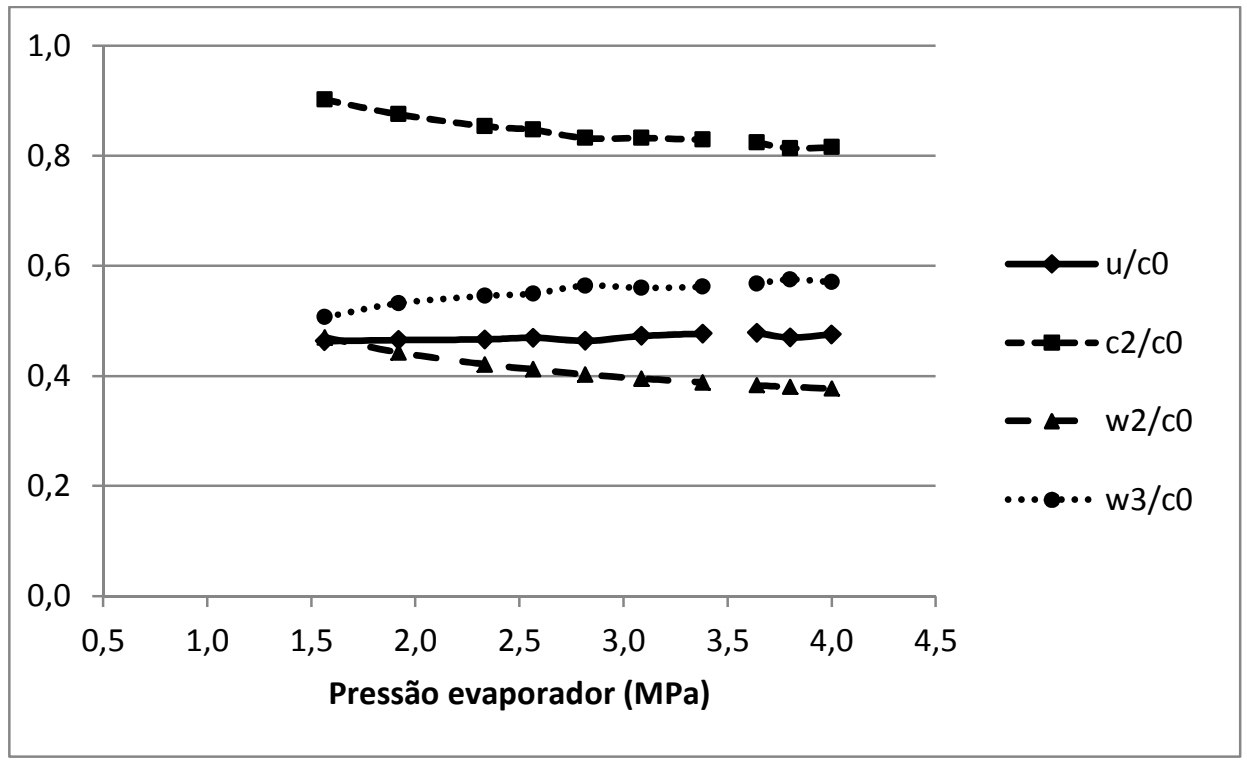

Figura 75 - Diagrama de velocidades adimensionalizado para o expansor com bocal convergente-divergente operando em ciclo subcrítico e supercrítico em função da pressão do gerador de vapor.

Para o caso dos bocais com perfil convergente-divergente pode ser observado que o estágio estará livre da restrição sobre $M_{c 2}$, porém estará sempre trabalhando sob a condição limite de entrada na palheta transônica dada por $M_{w 2}=0,8$. Nesta situação um grau de reação mais moderado será suficiente para otimizar a eficiência do expansor, entretanto um diâmetro específico maior será necessário para limitar o número de Mach relativo na entrada do rotor. 


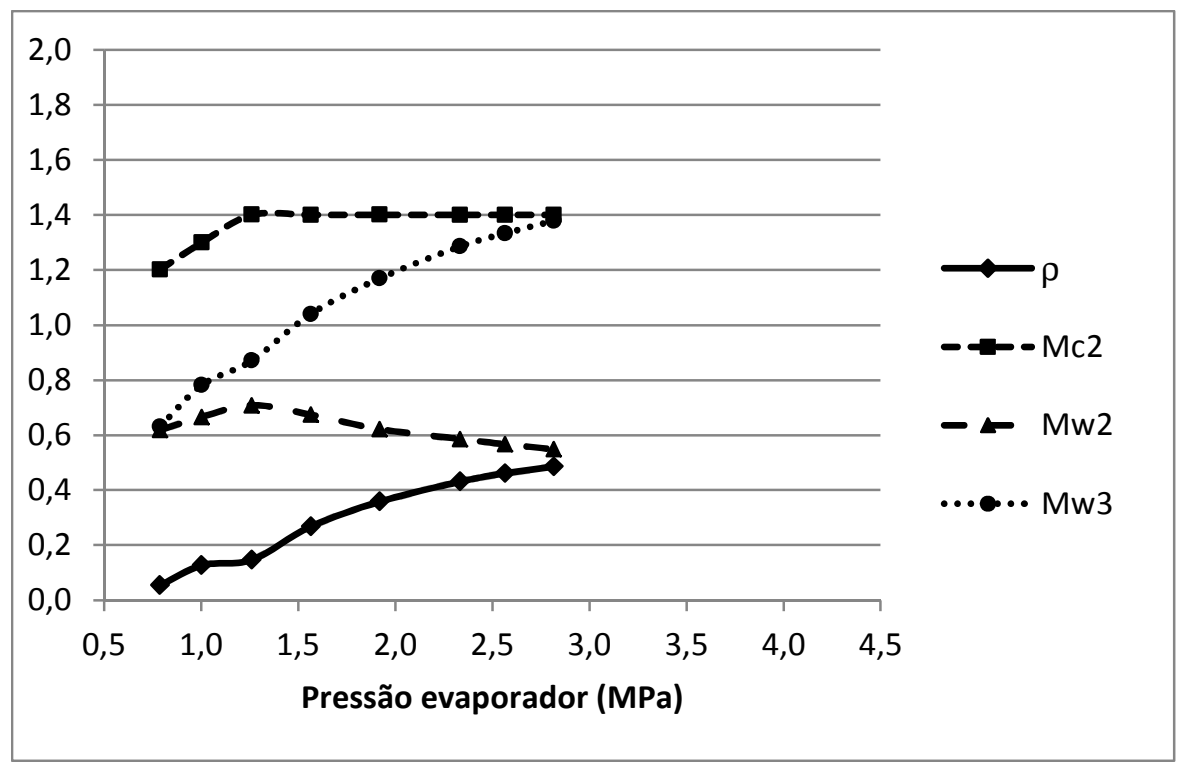

Figura 76 - Grau de reação e números de Mach do escoamento absoluto e relativo para o expansor com bocal convergente operando em ciclo subcrítico em função da pressão do evaporador.

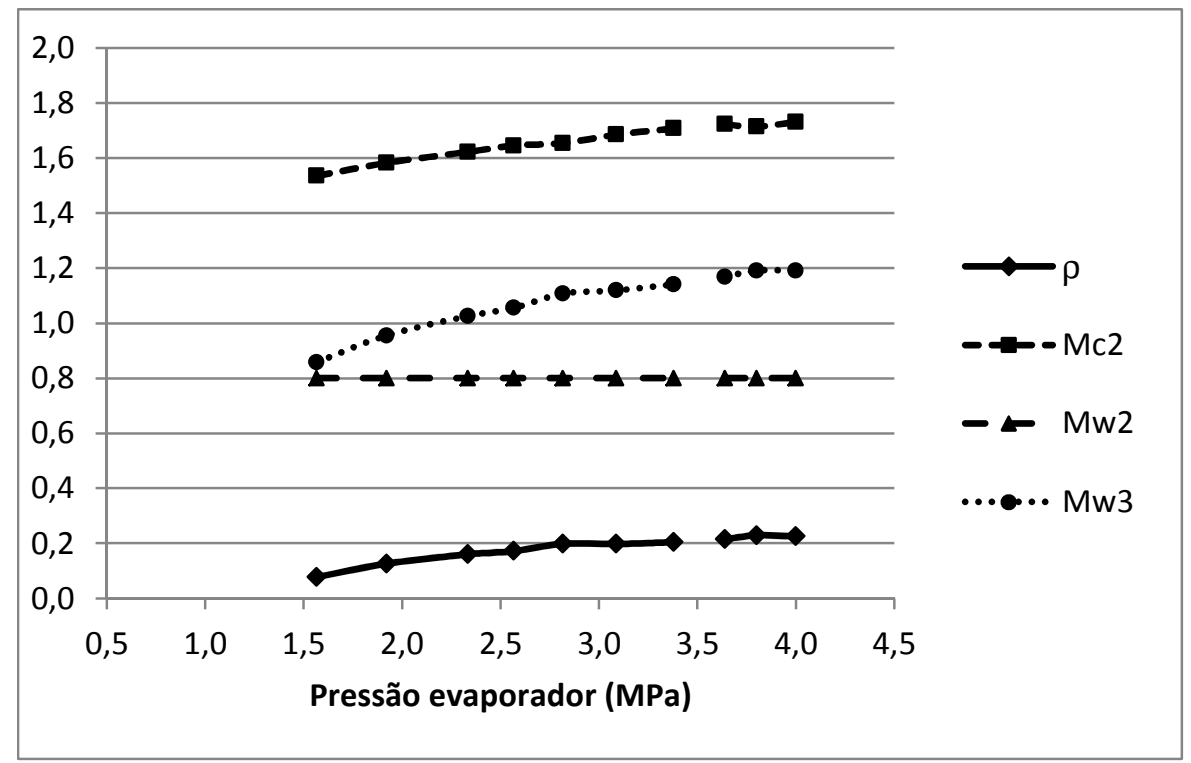

Figura 77 - Grau de reação e números de Mach para o expansor com bocal convergente-divergente operando em ciclo subcrítico e supercrítico em função da pressão do gerador de vapor.

A figura 78 mostra o efeito da compressibilidade do meio sobre a interrelação entre o diâmetro específico e a velocidade específica para o projeto ótimo do estágio com bocais de perfil convergente e de perfil convergente-divergente. 
Os maiores valores da velocidade específica correspondem às situações onde a temperatura do evaporador é baixa e as restrições dos números de Mach ainda não estão ativas. Os valores menores de velocidade específica, em contrapartida, indicam condições em que alguma das mencionadas restrições estão ativas, demandando por sua vez maiores valores para o diâmetro específico. Uma eficiência térmica de 10,81\% para ciclo de recuperação é obtida com a utilização do expansor de bocais com perfil convergente-divergente em operação supercrítica (pressão do evaporador de 4,0 MPa).

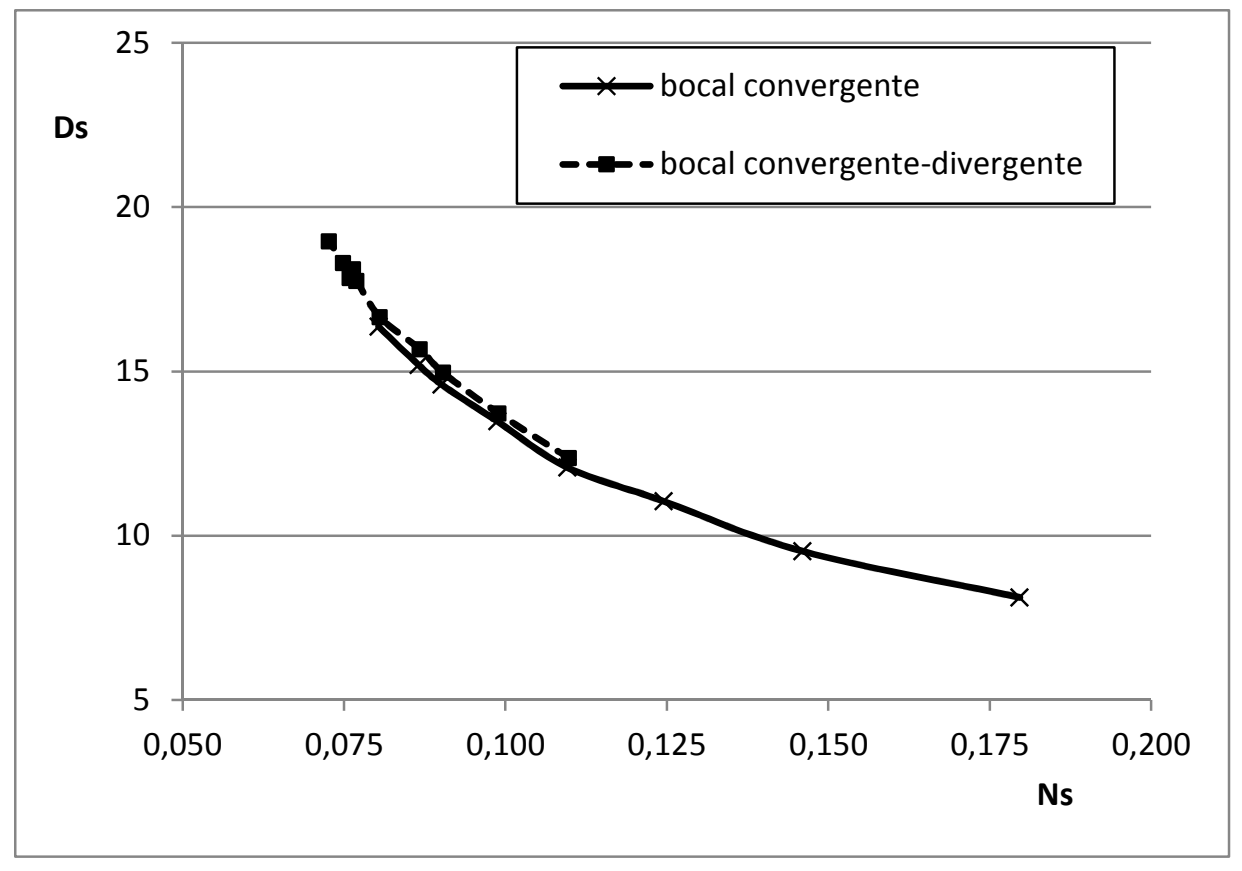

Figura 78 - Relação entre diâmetro específico e velocidade específica para o projeto otimizado do expansor em ciclo subcrítico e supercrítico.

As figuras 79 e 80 mostram os parâmetros geométricos básicos para os estágios com bocais de perfil convergente e de perfil convergente-divergente, respectivamente. São mostrados o grau de admissão $\mathcal{E}$, a razão de sobreposição $h_{3} / h_{2}$, além da razão de aspecto $(h / C)_{R}$ e a solidez $\sigma_{R}$ das palhetas rotativas versus a pressão do evaporador. Pode ser observado que para o estágio com bocal convergente em ciclo subcrítico a razão de sobreposição cresce e a razão de aspecto decresce com o aumento da pressão do evaporador, acompanhando a tendência de crescimento da relação de volumes e do grau de reação. Para o 
expansor com bocal convergente-divergente as dimensões geométricas experimentam variações menores, acompanhando a tendência do grau de reação.

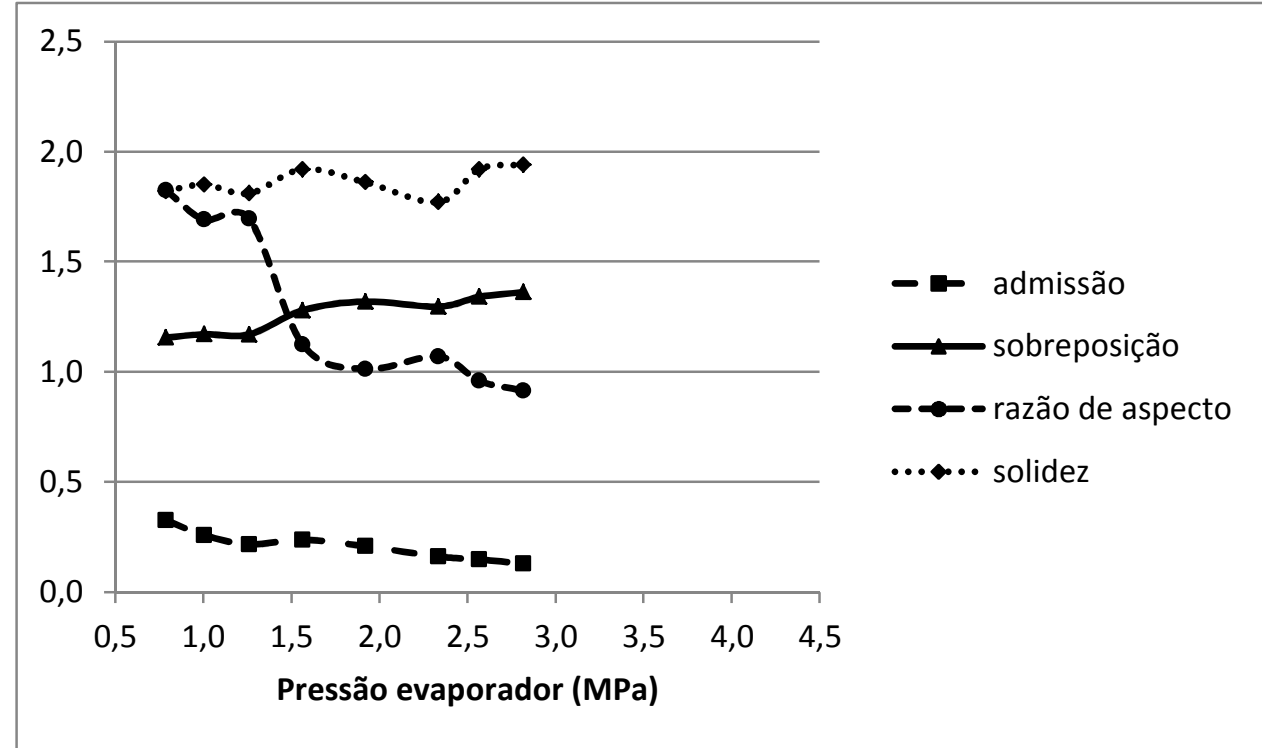

Figura 79 - Geometria do estágio com bocal convergente em ciclo subcrítico.

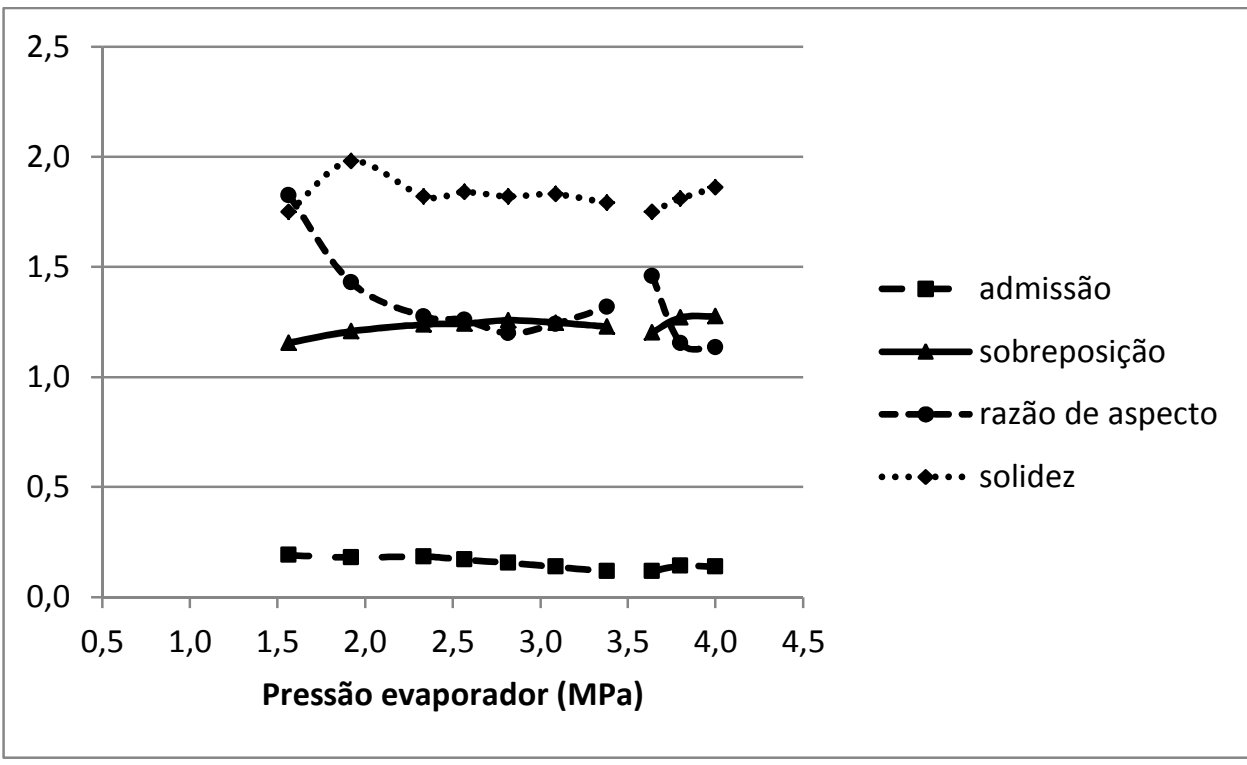

Figura 80 - Geometria do estágio com bocal convergente-divergente. 
A análise da aplicação do expansor axial é concluída com a discriminação das perdas para o estágio com bocal convergente e convergente-divergente, mostradas nas tabelas 34 e 35 , respectivamente. São consideradas as perdas viscosas nas palhetas rotativas e nas palhetas estacionárias, de vazamento para a região inativa, de admissão parcial, de atrito na roda e de energia cinética residual no exausto.

Tabela 34 - Discriminação de perdas para o estágio com bocal convergente operando em ciclo subcrítico.

\begin{tabular}{|c|c|c|c|c|c|c|}
\hline $\mathrm{P}_{\text {evap }}(\mathrm{MPa})$ & rotor & bocais & vazamento & adm. parcial & atrito disco & exausto \\
\hline 0,789 & $3,89 \%$ & $5,94 \%$ & $1,42 \%$ & $2,36 \%$ & $0,54 \%$ & $5,11 \%$ \\
\hline 1,004 & $3,89 \%$ & $6,69 \%$ & $2,21 \%$ & $2,73 \%$ & $0,68 \%$ & $5,24 \%$ \\
\hline 1,261 & $3,66 \%$ & $7,82 \%$ & $2,61 \%$ & $2,79 \%$ & $0,93 \%$ & $5,65 \%$ \\
\hline 1,565 & $4,05 \%$ & $7,15 \%$ & $4,31 \%$ & $2,83 \%$ & $1,24 \%$ & $7,15 \%$ \\
\hline 1,921 & $4,34 \%$ & $6,53 \%$ & $5,28 \%$ & $3,28 \%$ & $1,80 \%$ & $9,15 \%$ \\
\hline 2,335 & $4,77 \%$ & $5,81 \%$ & $5,10 \%$ & $3,98 \%$ & $2,31 \%$ & $12,41 \%$ \\
\hline 2,567 & $5,12 \%$ & $5,58 \%$ & $5,14 \%$ & $4,76 \%$ & $2,68 \%$ & $13,37 \%$ \\
\hline 2,817 & $5,47 \%$ & $5,39 \%$ & $5,28 \%$ & $5,42 \%$ & $3,35 \%$ & $14,58 \%$ \\
\hline
\end{tabular}

Tabela 35 - Discriminação de perdas para o estágio com bocal convergentedivergente operando em ciclo subcrítico e supercrítico.

\begin{tabular}{|c|c|c|c|c|c|c|}
\hline$p_{\text {evap }}(\mathrm{MPa})$ & rotor & bocais & vazamento & adm. parcial & atrito disco & exausto \\
\hline 1,565 & $3,70 \%$ & $10,93 \%$ & $2,16 \%$ & $2,56 \%$ & $1,06 \%$ & $5,18 \%$ \\
\hline 1,921 & $3,47 \%$ & $10,92 \%$ & $3,04 \%$ & $2,97 \%$ & $1,43 \%$ & $5,40 \%$ \\
\hline 2,335 & $3,65 \%$ & $11,13 \%$ & $4,00 \%$ & $2,68 \%$ & $1,82 \%$ & $5,82 \%$ \\
\hline 2,567 & $3,58 \%$ & $11,08 \%$ & $4,19 \%$ & $2,90 \%$ & $2,06 \%$ & $6,10 \%$ \\
\hline 2,817 & $3,81 \%$ & $10,95 \%$ & $4,61 \%$ & $3,07 \%$ & $2,36 \%$ & $6,68 \%$ \\
\hline 3,087 & $3,59 \%$ & $11,02 \%$ & $4,65 \%$ & $3,41 \%$ & $2,82 \%$ & $6,88 \%$ \\
\hline 3,380 & $3,49 \%$ & $10,92 \%$ & $4,63 \%$ & $3,85 \%$ & $3,31 \%$ & $7,40 \%$ \\
\hline 3,640 & $3,47 \%$ & $10,63 \%$ & $4,33 \%$ & $3,63 \%$ & $3,06 \%$ & $8,19 \%$ \\
\hline 3,800 & $3,89 \%$ & $10,95 \%$ & $5,05 \%$ & $3,26 \%$ & $2,97 \%$ & $7,83 \%$ \\
\hline 4,000 & $3,80 \%$ & $11,09 \%$ & $5,13 \%$ & $3,42 \%$ & $3,22 \%$ & $7,72 \%$ \\
\hline
\end{tabular}




\section{5 \\ Conclusões e Recomendações para Trabalhos Futuros}

No presente trabalho é desenvolvido um modelo de estimativa de perdas em grades de palhetas de turbinas axiais a partir dos trabalhos de Stewart [40] e Baljé [45]. O modelo é fundamentado na teoria da camada limite, no conceito do fator de difusão, nas equações de conservação para escoamento compressível e em resultados experimentais obtidos na literatura. A correlação para a velocidade máxima na superfície de sucção do perfil adotada por Balje [45], obtida a partir de experimentos em palhetas de compressores axiais, é modificada para aplicação em grades de turbinas utilizando-se um parâmetro de circulação mais adequado e um coeficiente angular determinado a partir de experimento em túnel de vento [41]. A sequência de cálculos do método compreende a determinação do fator de difusão, dos parâmetros da camada limite e da perda de pressão total, a partir da solução das equações de conservação, sendo obtido por fim o coeficiente de perda de energia cinética. Este novo modelo proposto foi validado através da comparação com demais métodos publicados na literatura ([36], [38], [45] e [47]), da utilização de resultados de trabalhos experimentais em grades e estágios de turbinas ([35], [43], [44], [52], [54], [55] e [56]) e também de resultados de testes de aceitação de turbinas a vapor realizados em bancada na fábrica [57]. A motivação é ter um método fundamentado em critérios de fluidodinâmica e voltado para a implementação computacional, em oposição aos métodos tradicionais, baseados no empirismo e voltados para o cálculo manual através de informações disponíveis em forma gráfica.

A etapa posterior consiste na investigação da aplicação do expansor axial de estágio único e admissão parcial acionando diretamente um gerador síncrono convencional em ciclo Rankine orgânico para recuperação de calor do exausto de um motor de combustão interna de 1992 kW de potência mecânica. A simulação do desempenho do estágio axial foi implementada com base no modelo de perdas proposto, nas equações do diagrama de velocidades e na consideração dos efeitos 
de gás real sobre as relações aero-termodinâmicas, através da equação RedlichKwong-Soave. A questão da utilização de fluidos não convencionais para o expansor é bastante relevante, uma vez que a geometria e o desempenho não podem ser antecipados com base em experiência prévia.

As condições de operação do expansor foram geradas considerando um sistema de troca térmica de modo a recuperar o calor disponível no exausto do motor. Neste sistema foram estabelecidos dois "pinch points", sendo um deles entre o fluido intermediário e o gás exausto do motor e o outro entre o fluido intermediário e o fluido orgânico. Em ciclo subcrítico este último "pinch point" é suposto estar localizado na entrada do evaporador, o que resulta em uma recuperação de calor decrescente com o aumento da temperatura do evaporador. A eficiência do ciclo de recuperação, por sua vez, mostra tendência crescente com o aumento da temperatura do evaporador. A influência simultânea destas duas condições resulta na existência de um valor ótimo para a temperatura do evaporador, sob o qual será produzida a maior potência elétrica possível pelo ciclo de recuperação.

A geometria e dimensões básicas para a máxima eficiência do expansor são determinadas para cada condição subcrítica e supercrítica do ciclo a partir de um algoritmo de otimização com restrições. Os resultados produzidos para a aplicação em estudo demonstram claramente a grande influência da compressibilidade do meio, expressa pelos valores dos números de Mach do escoamento absoluto na saída do bocal e do escoamento relativo na entrada e na saída das palhetas rotativas, cujas restrições a que estão sujeitos implicam na necessidade da adoção de valores não ótimos para o grau de reação e para o diâmetro específico do estágio na maior parte dos casos estudados. $\mathrm{O}$ expansor de bocais com perfil convergente é especialmente suscetível aos efeitos mencionados, sendo atingidos os limites para utilização de estágio único na condição de ciclo subcrítico. A utilização de bocais de perfil convergente divergente mostrou-se promissora para obtenção de uma maior eficiência no expansor, especialmente nas maiores temperaturas do evaporador e em condições supercríticas. O desafio atual do desenvolvimento do expansor de estágio único para o ciclo Rankine orgânico é justamente o projeto do perfil convergente-divergente de forma a atingir a 
expectativa de desempenho trabalhando sob a condição de gás denso. Uma adaptação proposta ao método das características [66] recentemente publicada na literatura vem ao encontro desta necessidade.

O presente trabalho parece ter produzido soluções tecnicamente viáveis para a construção de um expansor axial de estágio único e admissão parcial para a aplicação proposta. As variáveis geométricas como a razão de aspecto, solidez e razão de sobreposição apresentam valores alinhados com as melhores práticas de projetos de palhetas de turbinas. Embora de alguma forma haja uma penalização na eficiência do expansor, esta construção tem como motivação um custo mais baixo, a eliminação de uma caixa redutora, uma maior confiabilidade e a utilização de equipamentos de tecnologia disponível na indústria nacional.

$\mathrm{Na}$ temperatura ótima do evaporador de $120^{\circ} \mathrm{C}$, o projeto do expansor com bocal convergente mostrou ser capaz de gerar $159,8 \mathrm{~kW}$, com as seguintes dimensões: diâmetro da roda $633 \mathrm{~mm}$ e altura de palheta $14,2 \mathrm{~mm}$. Alternativamente o projeto com bocal convergente-divergente apresentou uma temperatura ótima do evaporador de $135^{\circ} \mathrm{C}$, produzindo $176,1 \mathrm{~kW}$ com as seguintes dimensões: diâmetro da roda $705 \mathrm{~mm}$ e altura de palheta $15,9 \mathrm{~mm}$. As dimensões citadas são compatíveis com a de equipamentos largamente utilizados na indústria para acionamento direto de geradores elétricos ou de bombas centrífugas.

O expansor axial de estágio único e bocal convergente é adequado para utilização em ciclo subcrítico até uma temperatura de $140^{\circ} \mathrm{C}$, devido ao elevado carregamento aerodinâmico envolvido acima desta condição. Para temperaturas maiores ou para aplicação em ciclo supercrítico será necessário utilizar um expansor com bocal convergente-divergente ou então um expansor com bocal convergente e dois estágios. O expansor de estágio único com bocal convergentedivergente é capaz de gerar 198,5 kW em ciclo supercrítico com pressão do evaporador de 4,00 MPa, sendo necessário um diâmetro da roda de $786 \mathrm{~mm}$.

Em função da estratégia desafiadora adotada para o limite aerodinâmico da grade rotativa, algumas das soluções geradas no presente trabalho podem ser 
consideradas arrojadas, principalmente no caso do expansor com bocais de perfil convergente em condições de alta temperatura do evaporador. Nestes casos as palhetas rotativas apresentam valores simultaneamente altos para o número de Mach e o ângulo de giro do escoamento, cuja configuração não possui referências na literatura [74] ou na indústria. Em virtude do elevado fator de difusão envolvido, o fluxo supersônico poderá estar vulnerável à ocorrência de ondas de choque não previstas no projeto preliminar. Uma solução para este impasse é determinar o desenho do perfil de forma a distribuir a difusão preferencialmente para a superfície de pressão em detrimento à superfície de sucção, conforme reportado nas referências [75] e [76]. A solidez da grade rotativa poderá ainda ser aumentada caso necessário através da redução do espaçamento entre as palhetas, tendo em vista o valor confortável adotado para a largura mínima da garganta. Em alguns casos o grau de reação também poderá ser reduzido para viabilizar a solução, com pequeno impacto na eficiência do expansor.

Para dar sequência ao presente trabalho é sugerido empreender a construção de um protótipo de uma planta de recuperação de calor através do ciclo Rankine orgânico equipada com um expansor axial, a partir das soluções indicadas pelo presente trabalho. É sugerido também ampliar as simulações de modo a incluir a operação fora do ponto de projeto, tendo em vista estimar o desempenho do expansor em situações de carga parcial. O projeto do expansor protótipo deve considerar a determinação detalhada dos perfis das palhetas, o projeto mecânico e o delineamento da fabricação do equipamento. Para o desenvolvimento dos perfis será interessante testar previamente modelos de grades de palhetas em túnel de vento para validação do projeto, principalmente no tocante ao comportamento em alta velocidade. Para a construção do protótipo é indicado adotar uma construção com o disco em balanço, mancais de rolamento e palhetas rotativas com sobreposição e cintadas. Será necessário incluir o projeto de um selo mecânico para contenção do fluido orgânico no interior do equipamento. Na construção deverá se ter o cuidado de atender as folgas radiais e axiais especificadas de forma a atingir o desempenho previsto para o expansor. O protótipo desenvolvido deve ser ensaiado com o objetivo de quantificar o desempenho dos componentes, em especial se utilizado o bocal com perfil convergente-divergente. 
6

\section{Referências Bibliográficas}

1 COLONNA, P.; LARJOLA, J.; ET AL. ORC Power Systems - The Early Days, Current Status and an Outlook on Research Topics and New Applications. Heat Powered Cycles Conference 2012 ECN, Netherlands, 10 to 12 September 2012.

2 LEE, J. H.; KIM, T. S. Analysis of Design and Part Load Performance of Micro Gas Turbine / Organic Rankine Cycle Combined Systems. J. of Mechanical Science and Technology, Vol. 20, no. 9, pp 1502-1513, 2006.

3 INVERNIZZI, C.; IORA, P.; SILVA, P. Bottoming Micro-Rankine Cycles for Micro-Gas Turbines. Applied Thermal Engineering 27 (2007) 100-110.

4 SCHUSTER, A.; ET AL. Efficiency Optimization Potential in Supercritical Organic Rankine Cycles. Energy 35 (2010), 1033-1039.

5 WANG, X. D.; ZHAO, L. Analysis of Zeotropic Mixtures Used in Low Temperature Solar Rankine Cycles for Power Generation. Solar Energy 83 (2009) 605-613.

6 DESAI, N. B.; BANDYOPADHYAY, S. Process Integration of Organic Rankine Cycle. Energy 34 (2009) 1674-1686.

7 LARJOLA, J. Electricity from Industrial Waste Heat Using High Speed Organic Rankine Cycle. Int. J. Production Economics 41 (1995) 227-235. 
8 MARCUCCILLI, F.; ZOUAGHI, S. Radial Inflow Turbines for Kalina and Organic Rankine Cycles. Proceedings European Geothermal Congress 2007 - Unterhaching, Germany, 30 May-1 June 2007.

9 SAITOH, T.; YAMADA, N. e WAKASHIMA S. Solar Rankine Cycle System Using Scroll Expander. J. of Environment and Engineering, Vol 2, No. 4, 2007.

10 PINI, M.; PERSICO, G.; CASATI, E.; DOSSENA, V. Preliminary Design of a Centrifugal Turbine for ORC Applications. First International Seminar on ORC Power Systems, TU Delft, The Netherlands, 22-23 September 2011.

11 LEMORT, V; QUOILIN, S. Advances in ORC Expander Design. INTERNATIONAL SYMPOSIUM ON ADVANCED WASTE HEAT VALORISATION TECHNOLOGIES - 13-14 September 2012, Kortrijk, Belgium.

12 UUSITALO, A.; HONKATUKIA, J.; TURUNEN-SAARESTI, T.; LARJOLA, J.; COLONNA, P. Suitability of Siloxanes for a Mini ORC Turbogenerator Based on High Speed Technology. Heat Powered Cycles Conference 2012 ECN Netherlands, 10 to 12 September 2012.

13 MACCHI, E.; PERDICHIZZI, A. Efficiency Prediction for Axial-Flow Turbines Operating with Nonconventional Fluids. Transactions of the ASME - Journal of Engineering for Power October 1981, Vol. 103/719.

14 QUOILIN, S.; LEMORT, V. Dynamic Modeling and Control Strategies for Organic Rankine Cycle Systems. International Symposium on Advanced Waste Heat Valorization Technologies, Kortrijk, September 13th 2012.

15 QUOILIN, S.; LEMORT V. Technological and Economical Survey of Organic Rankine Cycle Systems. $5^{\text {th }}$ European Conference "Economics and Management of Energy in Industry”, Portugal, April 2009. 
16 SPADACINI, C.; RIZZI, D.; SACCILOTTO, C.; SALGAROLlO, S.; CENTEMERI, L. The Radial Outflow Turbine Technology - Impact on the Cycle, Thermodynamics, Machinery Fluid and Rotor Dynamic Features. ASME ORC 2013 - $2^{\text {nd }}$ International Seminar on ORC Power Systems, October 2013, Netherlands.

17 HARINCK, J. Super and Transcritical Fluid Expansions for the NextGeneration Energy Conversion Systems. Doctoral Thesis Technische Universiteit Delft, Nederland - Jan. 2010.

18 DOMANSKY, P. Evolution of Refrigerant Application. International Congress on Refrigeration, May 1999, Milan, Italy.

19 CHAO, H.; CHAO, L.; HONG, G.; HUI, X.; YOURONG, L.; SHUANGYING, W.; JINLIANG, X. The Optimal Evaporation Temperature and Working Fluids for Subcritical Organic Rankine Cycle. Energy 38 (2012).

20 ANGELINO, G.; GAIA, M.; MACCHI, E. A Review of Italian Activity in the Field of Organic Rankine Cycles. VDI Berichte - Proceedings of the International VDI- Seminar ORC-HP Technology, vol 539, pages 465-482, Dusseldorf, September 1984 - VDI Verlag.

21 MEHER-HOMJ, C. B. The Historical Evolution of Turbomachinery. TAMU Turbomachinery Symposium 2000.

22 BALJÉ, O. E. A Study on Design Criteria and Matching of Turbomachines: Part A - Similarity Relations and Design Criteria of Turbines. Trans ASME Journal of Engineering for Power January 1962.

23 GLASSMAN, A. J. Turbine Design and Application. NASA SP-290, 1994.

24 SLIVKA, W. R.; SILVERN, D. H. Analytical Evaluation of Aerodynamic Characteristics of Turbines with Nontwisted Rotor Blades. NACA TN2365, 1951. 
25 ZHDANOV, I.; STAUDACHER, S.; FALALEEV, S. An Advanced Usage of Meanline Loss Systems for Axial Turbine Design Optimization. Proceedings of ASME Turbo Expo 2013: Turbine Technical Conference and Exposition. GT2013-94323.

26 FRIDH, J. Experimental Investigation of Performance, Flow Interactions and Rotor Forcing in Axial Partial Admission Turbines. Department of Energy Technology, Division of Heat and Power Technology, Royal Institute of Technology, Sweden - Doctoral Thesis, 2012.

27 BALJÉ, O. E.; BINSLEY, R. L. Axial Turbine Performance Evaluation. Part A: Loss-Geometry Relationships. Trans ASME - Journal of Engineering for Power October 1968.

28 SCHLICHTING, H. Boundary Layer Theory. McGraw-Hill Series in Mechanical Engineering, 1970.

29 LIEBLEIN, S.; SCHWENK, F. C.; BRODERICK, R. L. Diffusion Factor for Estimating Losses and Limiting Blade Loadings in Axial-FlowCompressor Blade Elements. NACA RM E53D01, 1953.

30 DIXON, S. L. Fluid Mechanics and Thermodynamics of Turbomachinery. Fourth Edition, 1998 - Butterworth-Heinemann.

31 HORLOCK, J. H.; LAKSHMINARAYANA, B. Secondary Flows and Losses in Cascades and Axial Flow Turbomachines. Int. J. Mech. Sci. 1963, vol. 5, pp. 287-307.

32 Silvern, D. H.; BAlJÉ, O. E. A Study of High Energy Level, Low Power Output Turbines. Department of the Navy Office of Naval Research April 1958. 
33 DAHLQUIST, A. N. Investigation of Losses Prediction Methods in 1D for Axial Gas Turbines. Division of Thermal Power Engineering, Department of Energy Sciences, Faculty of Engineering LTH, Lund University, Sweden Thesis for the Degree of Master of Science Nov 2008.

34 KOCHEndorfer, F. D.; MetTleE, J. G. An Analytical Method of Estimating Turbine Performance. NACA RM E8I16, 1948.

35 HAUSER, C. H.; PLOHR, H. W.; SONDER, G. Study of Flow Conditions and Deflection Angle at Exit of Two-Dimensional of Turbine Rotor Blades at Critical and Supercritical Pressure Ratios. NACA RM E9K25, 1950.

36 HORLOCK, J. H. Losses and Efficiency in Axial Flow Turbines. Int. J. Mech. Sci. 1960, vol. 2, pp. 48-75.

37 Ainley, D. G.; MAthieson, G. C. R. A Method of Performance Estimation for Axial-Flow Turbines. N.G.T.E. Report R. 111, May, 1952.

38 DUNHAM, J.; CAME, P. G. Improvements to the Ainley-Mathieson Method of Turbine Performance Prediction, ASME paper 70-GT-2, 1970.

39 KACKER, S. C.; OKAPUU, U. A Mean Line Prediction Method for Axial Flow Turbine Efficiency. Transactions of The ASME, Journal of Engr. for Power, 104:111-119, 1982.

40 STEWART, W. L. ; WHITNEY, W. J.; WONG, R. Y. A Study of Boundary Layer Characteristics of Turbomachine Blade Rows and their Relation to Overall Blade Losses. Transactions of The ASME - Journal of Basic Engineering, September 1960.

41 DUNAVANT, J. C.; ERWIN, J. R.: Investigation of a Related Series of Turbine-Blade Profiles in Cascade NACA TN 3802, 1956. 
42 STEWART, W. L. Analysis of Two-Dimensional Compressible Flow Loss Characteristics Downstream of a Turbomachine Blade Rows in Terms of Basic Boundary Layer Characteristics. NACA TN 3515, 1955.

43 WHITNEY, W. J.; STEWART, W. L.; MISER, J. W. Experimental Investigation of Turbine Stator Blade Outlet Boundary Layer Characteristics and a Comparison with Theoretical Results. NACA RM E55K24, 1956.

44 STEWART, W. L. ; WHITNEY, W. J.; WONG, R. Y. Use of Mean Section Boundary Layer Parameters in Predicting Three Dimensional Turbine Stator Losses. NACA RM E55L12A, 1956.

45 BALJÉ, O. E. - Axial Cascade Technology and Application to Flow Path Designs. Trans ASME, Journal of Engineering for Power October 1968.

46 BALJÉ, O. E. Turbo Machines, A Guide to Design, Selection and Theory. John Wiley \& Sons, 1981.

47 CRAIG, H. R. M.; COX, H. J. A. - Performance Estimation of Axial Flow Turbines. - Proc. Instn. Mech. Engrs., 1970-71.

48 WONG, R.; STEWART, W. L. Correlation of Turbine Blade Element Losses Based on Wake Momentum Thickness with Diffusion Parameter for a Series of Subsonic Turbine Blades in Two-Dimensional Cascade and Four Transonic Turbine Rotors. NACA RM E55B08, 1956.

49 DA LIO, L. Modello Monodimensionale per l'Ottimizzazione del Progetto di Espansori Assiali per Cicli Rankine a Fluido Organico. Tese di Laurea Magistrale in Ingegneria Energetica - Università Degli Studi di Padova, 2014.

50 MISER, J. W.; STEWART, W. L.; WHITNEY, W. Analysis of Turbomachine Viscous Losses affected by Changes in Blade Geometry. NACA RM E56F21, 1956. 
51 LOZZA, G. A Comparison Between the Craig \& Cox and the Kacker-Okapuu Methods of Turbine Performance Prediction. MECCANICA 17 (1982), 211221.

52 OHLSSON, G. O. Low Aspect Ratio Turbines. Transactions of the ASME, Journal of Engineering for Power, January 1964.

53 OHLSSON, G. O. Partial Admission, Low Aspect Ratios and Supersonic Speeds in Small Turbines. ScD thesis, Mechanical Engineering Department. Massachusetts Institute of Technology, January. 1956.

54 NING, W. Significance of Loss Models in Aerothermodynamic Simulation for Axial Turbines. Department of Energy Technology, Division of Heat and Power Technology, Royal Institute of Technology, Sweden - Doctoral Thesis, 2000 .

55 RIESS, W.; DALBERT, P.; GIESS, P. A.; HEINEMANN, H. J. Downstream Flow Angle Correlations for Turbine Cascades in Subsonic and Transonic Flow Conditions - Transonic and Supersonic Phenomena in Turbomachines: Proceedings of the Propulsion and Energetics (68th) (B) Specialists' Meeting, Munich, Germany, 10-12 September 1986.

$56 \mathrm{CHU}, \mathrm{T}$. L. Effects of Mach Number and Flow Incidence on Aerodynamic Losses of Steam Turbine Blades. Master of Science Thesis - Virginia Polytechnic Institute and State University, 1999.

57 MARTINS, G. L.; AFFONSO, L. O.; CAMPOS, R. S.; SIMÕES, M. R.; SILVA, M. V. S. Testes de Performance na Fábrica em Turbinas a Vapor. $8^{\circ}$ Fórum de Turbomáquinas Petrobras, 2011.

58 ASME PERFORMANCE TEST CODE 6 ON STEAM TURBINES (PTC 6-1996). 
59 LUJÁN, J. M.; SERRANO, J. R.; DOLZ, V.; SÁNCHEZ, J. Model of the Expansion Process for R245fa in an Organic Rankine Cycle (ORC). Journal of Applied Thermal Engeneering 40, 2012.

60 KOUREMENOS, D. A.; ANTONOPOUlOS, K. A. - Sound Velocity and Isentropic Exponents for Gases with Different Acentric Factors by Using the Redlich-Kwong-Soave Equation of State, Acta Mechanica 66 (1987) 177-189.

61 www.webbook.nist.gov/chemistry/.

62 OHLSSON, G. O. Supersonic Turbines. Transactions of the ASME Journal of Engineering for Power, January 1964.

63 VAnCO, M. R.; GOLDMAN L. J. Computer Program for Design of Two Dimensional Supersonic Nozzle with Sharp-Edged Throat. $\quad$ NASA TM X-1502, 1968.

64 GRÖNMAN, A. Numerical Modelling of Small Supersonic Axial Flow Turbines. Lappeenranta University of Technology - Doctoral Thesis 2010.

65 COLONNA, P.; NANNAN N. R.; GUARDONE A.; Van der STELT, T. P. Erratum to "On the Computation of the Fundamental Derivative of Gas Dynamics Using Equation of State". Fluid Phase Equilibr. 286 (1) (2009) 43-54.

66 WHEELER, A. P. S.; ONG, J. The Role of Dense Gas Dynamics on ORC Turbine Performance. Proceedings of the ASME Turbo Expo 2013: Turbine Technical Conference and Exposition - GT2013-95858.

67 SAPIRO, L. Performance Formulas for Centrifugal Compressors. Solar Turbines Inc., 1996. 
68 VDI HANDBUCH ENERGIETECHNIK - Thermodynamic Properties of Humid Air and Combustion Gases . VDI 4670 Part 1, Feb. 2003.

69 BALJÉ, O. E; BINSLEY, R. L. Axial Turbine Performance Evaluation. Part B: Optimization With and Without Constraints. Trans ASME, Journal of Engineering for Power, October 1968.

70 WHITNEY, W. J.; WONG, R. Y.; MONROE, D. E. Investigation of a Transonic Turbine Designed for a Maximum Rotor Blade Suction Surface Relative Mach Number of 1,57. NACA RM E54G27, 1954.

71 STEWART, W. L.; WONG, R. Y.; EVANS, D. G. Design and Experimental Investigation of Transonic Turbine with Slight Negative Reaction across Rotor Hub. NACA RM E53L29A, 1954.

72 GOLDMAN, L. J. Experimental investigation of a Low Reynolds Number Partial Admission Single Stage Supersonic Turbine. NASA TM X-2382, 1971.

73 VAZ, L. E.; PEREIRA, A.; MENEZES, I. F. M. Programação Matemática: Teoria, Algoritmos e Aplicações na Engenharia. PUC-Rio, Agosto 2012.

74 STEWART, L.; WHITNEY, W.; MISER, J. Use of Momentum Thickness in Describing Turbine Rotor-Blade Losses. NACA RM E56B29, 1956.

75 MISER, J.; STEWART, W.; MONROE, D. Effect of High Rotor Pressure Surface Diffusion on Performance of a Transonic Turbine. NACA RM E55H29a, 1955.

76 WONG, R.; MONROE, D.; WINTUCKY, W. Investigation of Effect of Increased Rotor-Blade Suction-Surface Velocity on Performance of Transonic Turbine. NACA RM E54F03, 1954. 